\title{
CITIES AND CULTURES
}

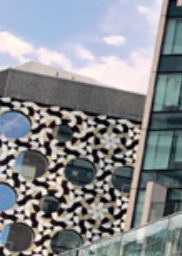

\section{$17=21$}
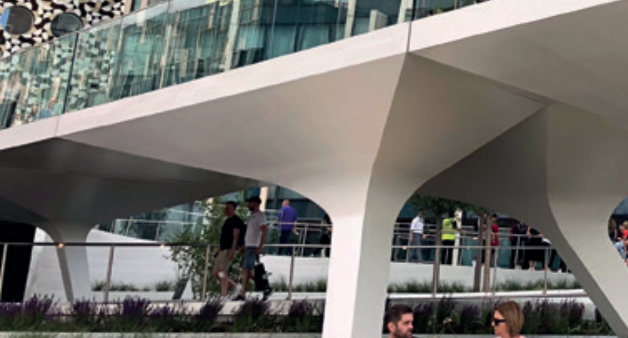

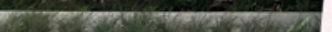

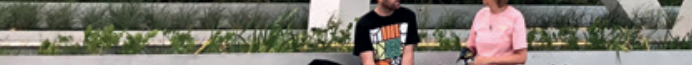

\section{Aesthetics of \\ Gentrification}

\section{Seductive Spaces and \\ Exclusive Communities in the Neoliberal City}


Aesthetics of Gentrification 


\section{Cities and Cultures}

Cities and Cultures is an interdisciplinary book series addressing the interrelations between cities and the cultures they produce. The series takes a special interest in the impact of globalization on urban space and cultural production, but remains concerned with all forms of cultural expression and transformation associated with modern and contemporary cities.

\section{Series Editor:}

Christoph Lindner, University College London

Advisory Board:

Ackbar Abbas, University of California, Irvine

Myria Georgiou, London School of Economics and Political Science

Derek Gregory, University of British Colombia

Mona Harb, American University of Beirut

Stephanie Hemelryk Donald, University of Lincoln

Shirley Jordan, Queen Mary, University of London

Nicole Kalms, Monash University

Geofffrey Kantaris, University of Cambrigde

Brandi Thompson Summers, University of California, Berkeley

Ginette Verstraete, VU University Amsterdam

Richard J. Williams, University of Edinburgh 


\section{Aesthetics of Gentrification}

Seductive Spaces and Exclusive Communities

in the Neoliberal City

Edited by

Christoph Lindner and

Gerard F. Sandoval 
Cover illustration: Oliver Wainwright

Cover design: Coördesign, Leiden

Lay-out: Crius Group, Hulshout

$\begin{array}{ll}\text { ISBN } & 9789463722032 \\ \text { e-ISBN } & 9789048551170 \\ \text { DOI } & 10.5117 / 978946372203^{2} \\ \text { NUR } & 75^{8}\end{array}$

\section{(c) $(1) \Theta \Theta$}

Creative Commons License CC BY NC ND

(http://creativecommons.org/licenses/by-nc-nd/3.o)

@ All authors / Amsterdam University Press B.V., Amsterdam 2021

Some rights reserved. Without limiting the rights under copyright reserved above, any part of this book may be reproduced, stored in or introduced into a retrieval system, or transmitted, in any form or by any means (electronic, mechanical, photocopying, recording or otherwise).

Every effort has been made to obtain permission to use all copyrighted illustrations reproduced in this book. Nonetheless, whosoever believes to have rights to this material is advised to contact the publisher. 


\section{Contents}

Acknowledgements

1. Introduction: Aesthetics of Gentrification

Christoph Lindner and Gerard F. Sandoval

\section{Part 1 Spaces of Global Consumption}

2. The Forces of Decline and Regeneration: A Discussion of Jane Jacobs and Gentrification

Samuel Zipp, Jennifer Hock, and Nathan Storring

3. Silicon Wafers and Office Park Dreams: Cross-Cultural

Designs, Aesthetics, and Art in and around California's Santa

Clara Valley

Jenny Lin

4. Selling Authenticity: The Aesthetics of Design Boutiques in Montreal

Guillaume Sirois

5. The Import of a Narrative: The Role of Aesthetics and Discursive Elements in Fabricating Change in the Centre of São Paulo

Beatriz Kalichman and Beatriz Rufino

\section{Part 2 Anxiety and Visibility}

6. Race, Authenticity, and the Gentrified Aesthetics of Belonging in Washington, D.C.

Brandi Thompson Summers

7. Art and the Aesthetics of Cultural Gentrification: The Cases of Boyle Heights and Little Tokyo in Los Angeles Jonathan Jae-an Crisman 
8. In Residence: Witnessing and Gentrification in Susan Silton's Los Angeles Susanna Newbury

9. Satellite Dishes, a Creative Incubator, and the Displacement of Aesthetics in Amsterdam

Daan Wesselman

\section{Part 3 Agency, Voices, and Activism}

10. Boulevard Transition, Hipster Aesthetics, and Anti-

Gentrification Struggles in Los Angeles Jan Lin

11. Speculative Spaces in Grand Paris: Reading JR in Clichy-sousBois and Montfermeil

Gillian Jein

12. On Empty Spaces, Silence, and the Pause

Rebecca Amato

13. The "Smart Safe City": Gendered Time, Violence, and

Displacement in India's Digital Urban Age

269

Ayona Datta

Index 


\section{Acknowledgements}

We are grateful to our home institutions, University College London and the University of Oregon, for supporting our transatlantic editorial collaboration and the broader academic network that this book brings together. For contributing their original work to this volume and for engaging in an extended group conversation about the limits, possibilities, and permutations of gentrification, we are greatly indebted to all of the authors in this book. We dedicate the book to Hannah and Joseph in London and Julio, Giovanni, and Liliana in Oregon.

Christoph Lindner and Gerard F. Sandoval 



\title{
1. Introduction: Aesthetics of Gentrification
}

\author{
Christoph Lindner and Gerard F. Sandoval
}

\begin{abstract}
This book examines the relationship between aesthetics and gentrification in contemporary cities from multiple, comparative, global, and transnational perspectives. In the introductory chapter, we argue that the aesthetics of gentrification produce sites of spectacular excess where the political economic forces driving urban redevelopment are empowered to remake space according to the needs of global capital. Through an analysis of the development of London's Greenwich Peninsula, we suggest that these forms of neoliberal, consumer-oriented aesthetics create seductive spaces and instil the desires needed to accelerate exclusionary urban transformations. The introductory chapter also considers the ways in which the aesthetics of gentrification now constitute a globalized, transnational phenomenon involving struggles for power in neoliberal urban contexts. We conclude that aesthetics increasingly function as a battleground where these urban spatial power struggles are played out through displacement, exclusion, and division.
\end{abstract}

Keywords: gentrification, aesthetics, neoliberal consumption, activism, urban renewal, race

\section{Seductive Spaces and Exclusive Communities}

The image featured on the book's cover (and reproduced below) was taken in 2019 at Greenwich Peninsula in southeast London shortly after the opening of a new linear park named The Tide (Figure 1.1). In the foreground, we see the end of The Tide's elevated walkway jutting out above a carefully manicured urban landscape. Various people are lounging around the park, some looking

Lindner, C. and G.F. Sandoval (eds), Aesthetics of Gentrification: Seductive Spaces and Exclusive Communities in the Neoliberal City. Amsterdam: Amsterdam University Press, 2021 DOI 10.5117/9789463722032_CHO1 


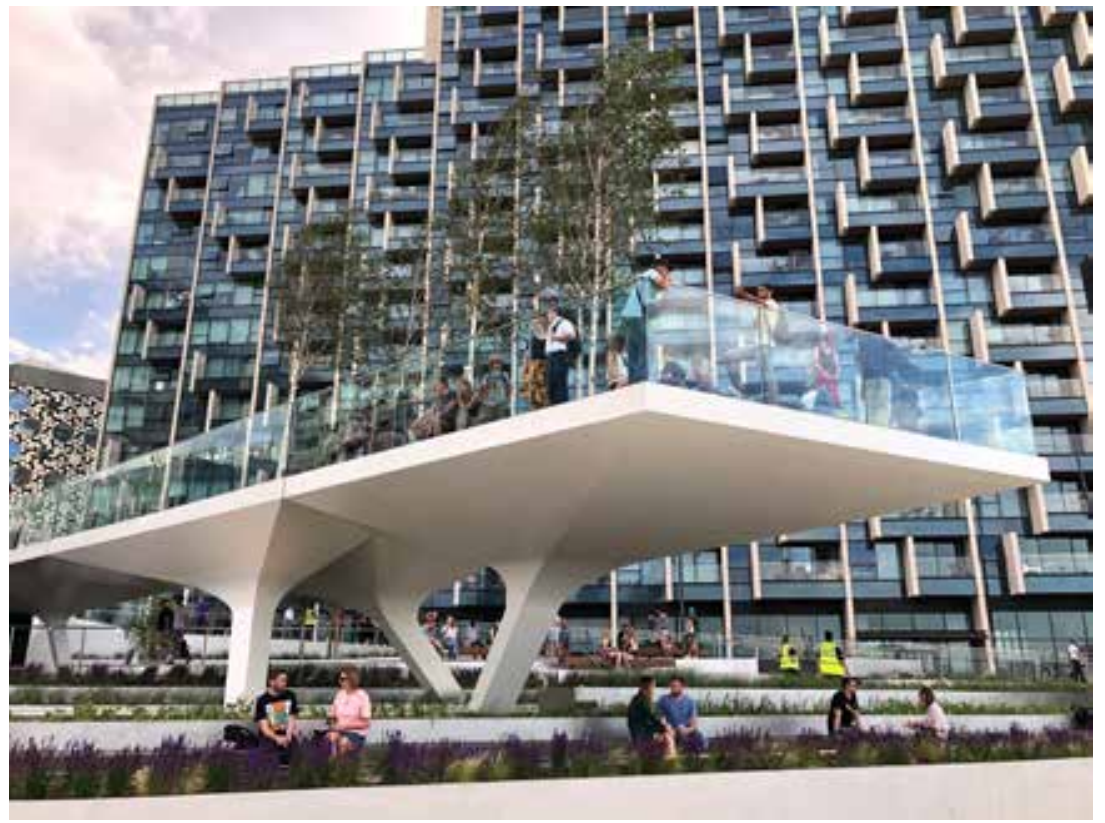

Figure 1.1: The Tide at Greenwich Peninsula. Photograph by Oliver Wainwright.

out at the riverside view from the elevated structure, others sitting in pairs beneath the structure immersed in conversation. In the background looms the glossy façade of a high-rise luxury apartment complex dominated by a geometric arrangement of mini balconies overlooking the scene of sociality and leisure staged below. We chose this image as it evokes the topic of this book: the aesthetics of gentrification and the ways in which those aesthetics are employed in neoliberal urban renewal strategies to create seductive spaces and exclusive communities. A closer look at Greenwich Peninsula and The Tide helps to bring these concerns into focus.

Completed in the summer of 2019 and designed by architects Diller Scofidio + Renfro, who famously co-designed the High Line elevated park in New York, The Tide marks the culmination of a decades-long effort to transform a stagnant site of postindustrial neglect into a vibrant, chic, and design-driven neighbourhood. The vision driving Greenwich Peninsula's transformation is articulated by the site's property developer, global placemakers Knight Dragon:

On Greenwich Peninsula London is transforming. Here is a new place inventing itself as the capital's most boldly modern landscape. An urban community with design and creativity embedded in its fabric. With 15,000 
new homes, 13,000 new jobs and 48 acres of open public space emerging over the coming years. Here a community of thousands of pioneers live in new riverside homes, work in a cutting-edge Design District and enjoy a new linear park The Tide - all wrapped by the river Thames. This is new London: a new destination for modern urban living. (Knight Dragon 2020)

Setting aside the promotional exuberance of this corporate sales pitch, the vision statement is revealing in the way it makes the case for the distinctiveness and novelty of the redevelopment project. Residents become "pioneers" joined together in a bold urban experiment aimed at forming a new community revolving around creativity (Smith 1982).

Not only does this vision replay Richard Florida's (2002) now tired argument about the regenerative power of the creative class, it also activates a rhetoric of settler colonialism by positing residents as homesteading adventurers - a trend long associated with gentrification and frequently tied to dynamics of race (Addie and Fraser 2019; Sandoval 2018; Lubitow et al. 2016; Osman 2011; Butler 2003). In short, despite all its claims to newness and invention, Greenwich Peninsula follows a well-established pattern of postindustrial revitalization supported by transnational global real-estate investments. The result is a neighbourhood ironically lacking in identity and originality - a site marked by flashy architecture, an abundance of pseudo-public space, predictable public art, corporate shopping and dining chains, superficial greenwashing, restricted mobility, and a general aura of affluence and placelessness.

As the area's symbolic centrepiece (Figure 1.2), The Tide exemplifies many of these qualities. Notably, the design of the park is conspicuously derivative (courtesy of the same architects involved in the High Line) and represents a fairly cynical example of a developer seeking to replicate the "High Line effect," whereby the creation of an elevated park sparks widespread public interest and unlocks rapid gentrification in the surrounding area (Lindner and Rosa 2017). Unsurprisingly, like most spin-off projects of this sort, The Tide falls flat in reproducing the success of the High Line. The prevalent view among architecture critics is that, unlike the High Line which adapts an abandoned freight railway for new public use, this park suffers from a lack of purpose, history, and meaning. City Lab's review, for instance, describes The Tide as an "exercise in pretty-but-functionless urbanism"; a "gangplank to nowhere"; an "expensive, heavily monitored add-on to a meretricious corporate development, possessing little in the way of either function or charm"; and an "infrastructural gewgaw to drum up a little attention for the blah condominium cluster that surrounds it" 


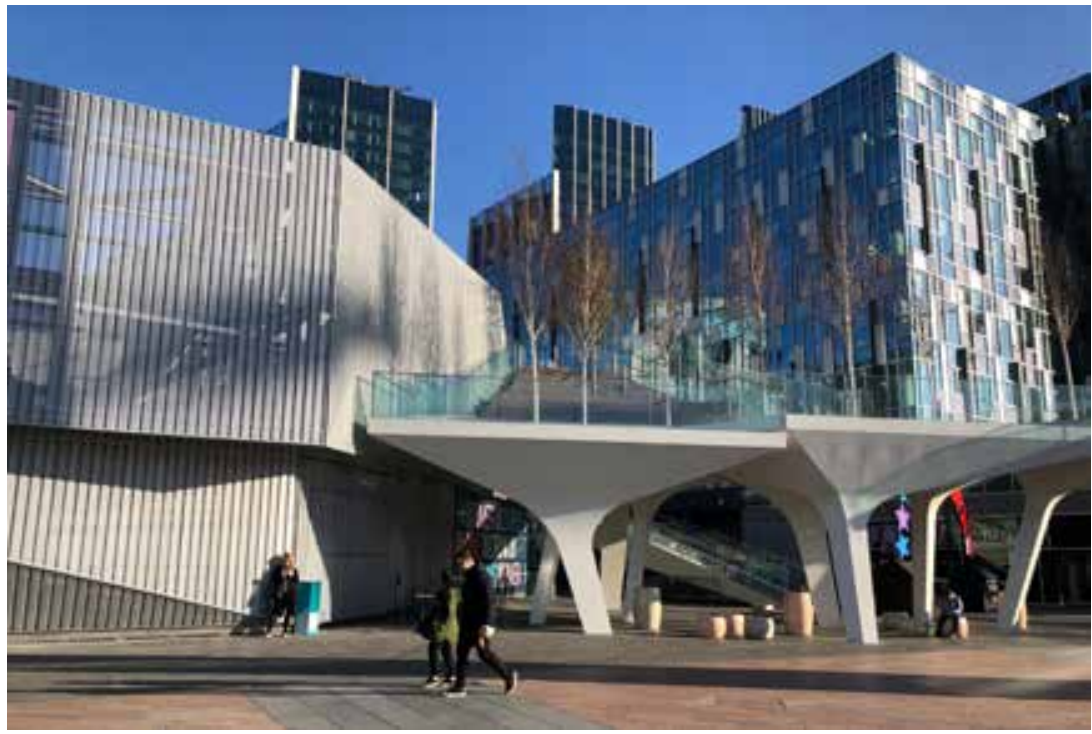

Figure 1.2: View from Peninsula Square. Photograph by Gerard Sandoval.

(O'Sullivan 2019). Similarly, Oliver Wainwright (who took the book's cover photograph) writes in his Guardian review that "when you're standing on the elevated deck, looking out over a jumbled vista of vents and service hatches, it's difficult to work out quite how anyone thought this was a good idea," adding that the walkway "has no purpose whatsoever, apart from providing a slightly different perspective on the surrounding carnage" (Wainwright 2019). He extends the critique to the entire area, which he characterizes as a "souped-up graveyard of novelty trinkets" and "junkyard of half-baked ideas and botched plans" (Wainwright 2019).

Among those ideas and plans is the Emirates Air Line cable car, a publicprivate partnership infrastructure project that transports tourists (and, theoretically, a very select subset of commuters) between Greenwich Peninsula and the Royal Docks business district across the River Thames (Figure 1.3). Built well before the residential redevelopment of North Greenwich during the 2012 London Olympic Games construction boom, this ostentatious caricature of a transportation project is not a functional piece of the city's everyday transportation system and attracts only a very small percentage of its passenger capacity (Saul 2013; Transport for London 2020). Rather, as suggested by the corporate partnership with Emirates, the cable car forms part of London's broader efforts to seduce global capital investment while boosting tourist appeal. The resulting spectacle of aerial-urban mobility has consequently attracted criticism for the way it contributes to London's 


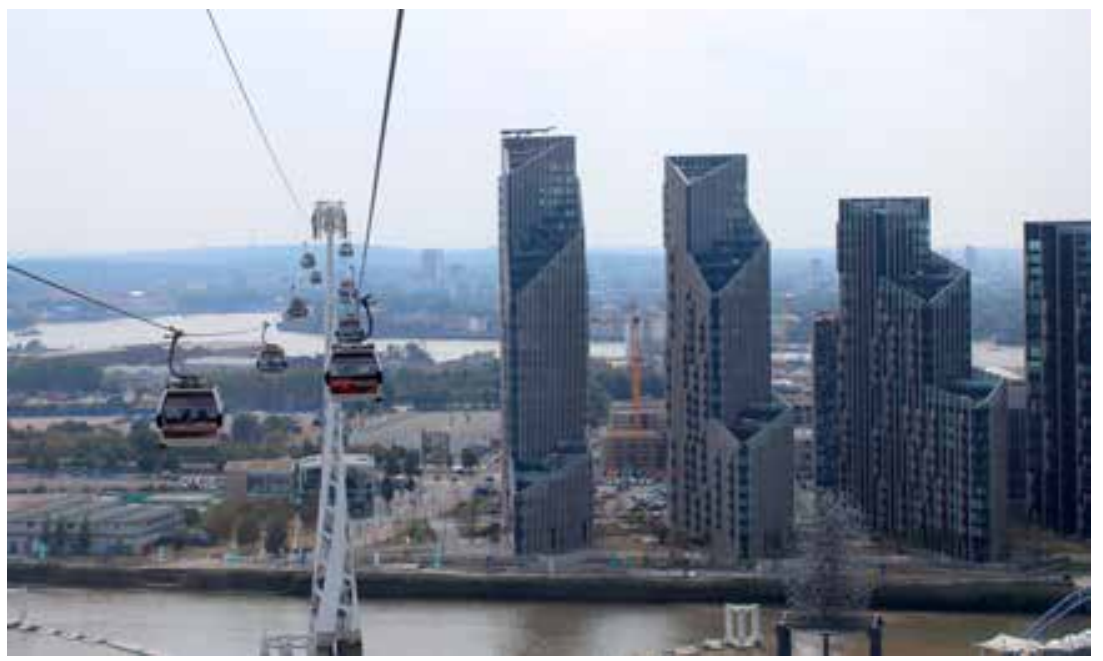

Figure 1.3: Emirates Air Line cable car, looking towards Greenwich Peninsula. Photograph by Hannah Lindner.

disneyfication. The cable car looks and functions like an amusement park ride, offering a carefully crafted experience of leisure, voyeurism, excitement, and distraction.

Interestingly, the interior of the gondolas is one of the only places where the Peninsula's history is explicitly told. As passengers cross above the river, a corporate promotional documentary is played on a screen inside, presenting a history of the area's redevelopment from one of London's principal ports through to its contemporary transformation into a chic, aesthetically polished neighbourhood. When crossing from Greenwich into East London, the history tour ends with a detailed description of The Crystal, a large events venue located adjacent to the Royal Docks cable car station that is marketed as "one of the world's most sustainable buildings." The Crystal building is an example of investment in East London's real estate transformation and a case study in greenwashing in commercial redevelopment. As such, the Emirates Air Line can be seen as a literal and symbolic line connecting two postindustrial sites sharing the same neoliberal approach to urban revitalization.

As an example of gentrification, Greenwich Peninsula is perhaps not among the most obvious in London. Hipsterized neighbourhoods such as Shoreditch, Hackney, and Peckham, to name a few, conform more closely to the conventional model of local residents being displaced by a more socio-economically privileged population. Because Greenwich Peninsula was built on disused industrial land, the development is less a site of direct displacement 
and more an aestheticized space of exclusive living and consumption that precludes alternative and more inclusive ways of creating, inhabiting, or experiencing the neighbourhood. Even so, Greenwich Peninsula contributes to, and is symptomatic of, a wider process of gentrification unfolding across the city, a trend marked by the proliferation of unaffordable housing and an accompanying decrease in mixed-income populations. In many ways, Greenwich Peninsula epitomizes the ultimate end of the neoliberal city - a site of spectacular excess where the forces of development have been empowered to remake space according to the needs of global capital. The role of aesthetics in creating such exclusive and seductive transformations is the focus of this book's engagement with gentrification.

\section{Gentrification, Globalization, Aesthetics}

Gentrification is widely studied across disciplines in the social sciences, humanities, and art and design fields. Within existing scholarship, the topic is predominantly approached from economic, geographic, planning, sociological, and related social-scientific perspectives (Freeman 2005; Lees et al. 2010; Zukin 1987; Zuk et al. 2017). These perspectives are vital to understanding the forces, conditions, and effects of gentrification on cities and communities, and over the last several decades - but particularly in the present era of neoliberal globalization and accelerated urbanization - they have yielded key insights into dynamics of urban displacement and exclusion in locations around the world. Indeed, the rise of "planetary gentrification," to use the term developed by Loretta Lees, Hyun Bang Shin, and Ernesto López-Morales (2016), has seen not only a global proliferation of neoliberal urban redevelopment, but also increasing transnational synchronization of the processes involved. The effect is that, as Lees (2019) argues, "gentrification is no-longer, if it ever was, a small scale process of urban transformation," but "globally is more often than not practiced as large scale urban redevelopment" and "is now predominantly state-led or state-induced" (7). Gentrification, in short, has gone global and is now part of what Saskia Sassen (2014) describes as "the new logics of expulsion" (1) driving the global economy.

In this book, we aim to expand on these analytical perspectives by additionally examining the roles that exclusion and seduction play within the aesthetics of gentrification. We argue that aesthetics are integral to the global story of gentrification, particularly in the way aesthetics are increasingly being used - via neoliberal consumerism (Castro 2015) - to produce the seductive conditions and instil the desires needed for creating exclusionary 
urban transformations predicated on displacing and disempowering vulnerable populations. Although the authors in this book approach aesthetics from a range of theoretical perspectives, it is fair to say that the volume as a whole does cohere around a broad understanding of aesthetics as a visual regime in the sense that Jacques Rancière gives to the concept: aesthetics as politics and comprising "forms of visibility that disclose artistic practices, the place they occupy, what they 'do' and 'make' from the standpoint of what is common to the community" (Rancière 2004: 13). At stake therefore in our various analyses of the aesthetics of gentrification is not only greater understanding of the social-spatial politics of cities but also new insight into the subjects and operations of urban power (Foucault 1982).

Although they examine a geographically and culturally diverse range of case studies, the chapters in this book have certain themes in common. First, we understand the aesthetics of gentrification as an increasingly transnational phenomenon involving struggles for power in neoliberal urban contexts. Second, we are alert to how urban redevelopment actively produces spaces of desire and seduction that deliberately look and feel constructed in order to create gentrification effects that encourage mobility and exploit displacement of low-income populations. Third, we see aesthetics as increasingly being one of the battlegrounds where these urban spatial power struggles are played out through displacement, exclusion, and division. And finally, we are sensitive to the ways in which people become complicit - both consciously and inadvertently - with gentrification processes and their seductive elements. To pursue these concerns, we have organized the book's chapters into three interconnecting thematic groupings: spaces of global consumption; anxiety and visibility; and agency, voices, and activism.

\section{Spaces of Global Consumption}

Part 1, "Spaces of Global Consumption," focuses on how gentrification encompasses processes of neoliberal consumption involving housing, cultural entertainment, retail experience, and the aesthetics of placemaking. Together, the chapters in Part 1 demonstrate how the aesthetics of gentrification are manifested in spaces of consumerism and circulate globally. The emphasis in Part 1 is on visual culture, architecture and design, and the importance of local narratives in supporting global market conditions.

In the opening chapter of Part 1 , "The Forces of Decline and Regeneration," Samuel Zipp, Jennifer Hock, and Nate Storring revisit Jane Jacobs' legacy in light of twenty-first-century urban dynamics. In particular, they draw 
on Jacobs' three concepts of the "sidewalk ballet," "organized complexity," and the "self-destruction of diversity" to help situate her work in relation to contemporary aesthetics of gentrification. One crucial issue that emerges in their discussion is Jacobs' understanding and writing on issues of race, which is an area of her work that has been underexamined by scholars. Zipp, Hock, and Storring's analysis of Jane Jacobs is an important starting point for the book's overall consideration of how the aesthetics of gentrification are reshaping cities. Key concerns, for example, include how Jacobs' thinking relates to neighbourhood aesthetics, neighbourhood building types, residents' access to a diverse range of mobility options, and locally-based commercial retail, which all contribute to the uniqueness of neighbourhoods yet have also become foundational building blocks for gentrification.

In "Silicon Wafers and Office Park Dreams," Jenny Lin critiques the visual culture of California's Silicon Valley and the intellectual milieu of the information age. Her historical analysis traces the morphing of global software design giants, such as Apple and Google, into visually monolithic buildings expressing a corporate structure based on collaboration, experimentation, and a horizontally-based management structure. Lin argues that Silicon Valley's circulatory global corporate aesthetics contribute to a context of placelessness, economic inequality, and displacement. Here, the aesthetics of gentrification emerge from an unlikely space - one of intellectual collaboration operating within a local context concerned with reclaiming multiculturalism and resisting gentrification.

Guillaume Sirois considers the aesthetics of gentrification produced in and around boutiques in Montreal's Mile End District. In his chapter on "Selling Authenticity," he maps the interconnections between the global flows of neoliberal consumption and the commodification of local culture. Sirois demonstrates how the aesthetics of gentrification in this boutique district manifest through the constructed values of authenticity, materiality, and hospitality. As he reveals, locally-designed products often signify to buyers a break with the global market economy, when in fact those products ultimately complement and reinforce larger dynamics of neoliberal globalization.

The final chapter of Part 1 traces the revitalization of a neighbourhood in República, a district in the central area of the Brazilian city of São Paulo. In "The Import of a Narrative," Beatriz Kalichman and Beatriz Rufıno analyze the aesthetics and discursive elements in the neighbourhood's transformation from quitinetes (worker housing built in the 1950s and 6os) toward more affluent studio apartments. Kalichman and Rufino argue that the aesthetics of gentrification in República hinge on emulating the postindustrial 
transformation of SoHo in New York City in the 1970s. Their case study points to the links between aesthetics and planetary gentrification as cities in the global south seek to replicate visual and spatial patterns of neoliberal urban renewal via a circularity of global capital in real estate development.

\section{Anxiety and Visibility}

Part 2, "Anxiety and Visibility," traces the shadow side of gentrification in a sequence of chapters that reveal the often discriminatory nature of urban redevelopment. Through a diverse set of case studies, the authors address issues of racialized gentrification, xenophobia, and "othering" present in gentrification processes and their accompanying aesthetics. The broader idea developed in Part 2 is that gentrification is not limited to the cultural-spatial change seen in a transforming neighbourhood, but can involve a deeper shift in that neighbourhood's milieu of belonging reflective of racial and ethnic composition.

In her chapter on Washington D.C., Brandi Thompson Summers analyzes a mainly Black neighbourhood experiencing rapid gentrification. She problematizes ideas of "diversity" by demonstrating how a convergence of hipster aesthetics within a Black cultural space has resulted in the displacement of many Black low-income residents. As her analysis reveals, the gentrification process in this Black cultural space exploits a concept of authenticity in which people attach meaning to things (instead of the experiences of people), leading in turn to racialized gentrification as young, upper-income whites settle into the neighbourhood.

In "Art and the Aesthetics of Cultural Gentrification," Jonathan Jaean Crisman follows up with two Los Angeles-based case studies: Boyle Heights and Little Tokyo. Crisman assesses the role art is playing in cultural gentrification within these two diverse contexts. The chapter traces how an arts-based aesthetics of engagement opens up opportunities for these communities to shape the gentrification process. Crisman argues that these forms of aesthetics link ethics, collective interaction, and participatory community development. He ends on an optimistic note, stressing that these cultural places can open up new potentials in combating the atomizing effects of gentrification.

Maintaining the focus on Los Angeles, Susanna Newbury's chapter examines the art performance of Susan Silton who locates her work in a gentrifying neighbourhood in the city. Silton's work relates to aesthetics as representation as it is based on a performance practice of ethical imperative within reparative witnessing, which helps individuals see and account 
for their roles in historic forms of crisis (such as the roles played within gentrification). Newbury argues that Silton's LA-based performances make a connection between the crises brought about through global neoliberal consumerism and its grounding within gentrifying neighbourhoods.

In "Satellite Dishes, a Creative Incubator, and the Displacement of Aesthetics in Amsterdam," Daan Wesselman provides examples of how the aesthetics of gentrification contribute towards reifying "otherness" within Amsterdam's Bos en Lommer neighbourhood. He details the different treatment of immigrant tenements as they become defined in aesthetic terms through xenophobic expressions. Wesselman distinguishes the aesthetic value given to the non-white part of a neighbourhood with satellite dishes attached to social housing and compares that to the aesthetic value given to the part of the same neighbourhood without immigrants. This analysis directly demonstrates the xenophobia enacted through the aesthetics of gentrification and the active role that art, fashion, and consumption play in the neighbourhood's division. Wesselman argues that the newly-inserted globalized aesthetics of gentrification - following the typical creative incubator formula - displace the political battle over otherness occurring across the street.

\section{Agency, Voices, and Activism}

Part 3, "Agency, Voices, and Activism," foregrounds the emergence of representational politics in certain forms of anti-gentrification movements. These anti-gentrification struggles push back in diverse ways as activists respond to new or growing inequalities created through neoliberal urban redevelopment. A particular concern in Part 3 is the relationship between gentrification and racialized spaces, including the displacement of marginalized populations as a consequence of emerging hipster consumerist spaces. These urban conflicts have, in turn, activated agency and voice for anti-gentrification political movements.

In "Boulevard Transition, Hipster Aesthetics, and Anti-Gentrification Struggles in Los Angeles," Jan Lin provides an insightful study of Boyle Heights' rapid gentrification and the community resistance against that transformation. As Lin explains, residents in Boyle Heights, a historically Latinx neighbourhood, have fought back against arts-based gentrification. In particular, they have experienced the co-optation of the neighbourhood's Latinx ethnic identity by hipster entrepreneurs seeking to profit not only from new public infrastructure investments in the area, but also from the neighbourhood's edgy diversity. In response, Latinx grassroots activist 
organizations have engaged in a neighbourhood-based anti-gentrification movement as they view the new art galleries and hipster aesthetics as threats to their community. Moreover, Lin argues, the activist organizations have struggled to gain ground and lay claim to their space despite deploying an anti-gentrification toolkit encompassing community-based art and theatre.

Gillian Jein considers the aesthetics of gentrification through analysis of street art and spatial politics in the Parisian banlieues. In "Speculative Spaces in Grand Paris," she highlights the ways in which long-standing political and racial tensions between the centre and peripheries of the city are accentuated, critiqued, and destabilized by artists working against the backdrop of state-led urban redevelopment. Focusing on the work of JR, a street artist who combines large-format photography with the provocative ethos of graffiti, Jein shows how public art installations can bring gentrification into view by expressing the tensions involved in neighbourhood change.

Rebecca Amato argues in "On Empty Spaces, Silence, and the Pause" that the production of empty spaces in New York City is a crucial component of gentrification. Amato demonstrates that techniques such as filtering, investing in the aesthetic potential of ageing neighbourhoods, and declaring vacancy, have all helped to fuel gentrification. As she discusses, New York City encourages the development of underutilized land parcels for high-rises, green sustainable construction, and increased density. Amato contrasts these trends against the activist efforts to provide alternative, more inclusive models of urban redevelopment based on cooperative centres and community gardens.

The book's final chapter examines confluences between mobility, technology, and gender in the urban peripheries of Delhi. In "The 'Smart Safe City" Ayona Datta extends existing thinking on gentrification by considering the ways in which new forms of "technocratic gentrification" have emerged in the global south as a result of the rise of smart cities and postcolonial urbanism's dependence on acceleration and speed. In particular, she presents findings from an innovative research project that uses mobile technology and social media to support young women negotiating precarious lives in Delhi's digital and urban margins. Datta argues that their everyday mobility across the city highlights the ambiguities and paradoxes of their lives, including tensions between belonging and exclusion.

\section{Investigating Gentrification}

The aesthetics of gentrification are rapidly transforming cities. These changes are both cultural and material. Culturally, the aesthetics of gentrification 
transform the milieu of a place by adding to the displacement of low-income populations, racially marginalized ethnic groups, and other vulnerable populations priced out of their neighbourhood. Materially, the transformations are physical via investments in infrastructure, the redesigning of public spaces, and the building or rehabilitating of housing. Whether culturally or materially, these rapidly transforming spaces are ones of seduction and exclusion.

In the following chapters, we explore how seduction has played an essential role in attracting both people and capital to neighbourhoods labelled as "edgy," "ethnically diverse," "cool," "hipster." We also explore what happens when conditions of seduction collide with the political environment of local activists trying to stop or reroute gentrification. In terms of exclusion, the aesthetics of gentrification create spaces that are unavailable, inaccessible, or unaffordable for either existing residents or incoming populations. There may not be walls around these new developments, but as the Greenwich Peninsula example shows, the combination of flamboyant architecture, restricted mobility, and ambiguity over whether open space is public or private all contribute to forming an aesthetic of exclusion.

Our goal for this book is to encourage new dialogue on the aesthetics of gentrification, both within and beyond social science studies of gentrification. In our thinking, the chapters published here elicit crucial questions that should be further analyzed, theorized, and debated. First, who are the financiers of transnational gentrification projects? What proportion of the capital is being supplied transnationally via multinational corporations? Second, what other forms and methods of seduction and exclusion exist that have not been surfaced in this book? Third, how are the emerging antigentrification transnational social movements affecting the redevelopment and consequent transformation of neighbourhoods? Furthermore, to what extent can vulnerable populations increase their agency to secure benefits from the aesthetics of gentrification? Is this even possible? And, lastly, what role does racialization continue to play in the aesthetics of gentrification within a global Black Lives Matter movement?

This last question on racialization is critical to answer and, alongside the other questions raised above, we examine the role of racism in gentrification throughout several chapters. Summers' study directly focuses on this issue through her discussion of the transformation of a Black community in Washington D.C. into a higher income multiracial neighbourhood where Blackness is accepted but represents a generic form of diversity that becomes commodified. In addition, Zipp, Hock, and Storring discuss how Jane Jacobs approached issues of race, which represents a fresh perspective on Jacob's work. Jein follows the racialized making (and unmaking) of the Parisian 
banlieues as dangerous and deviant no-go zones. And Wesselman analyzes xenophobic processes tied to the aesthetics of satellite dishes in Amsterdam. These authors make the clear connection between racism in the aesthetics of gentrification and the "othering" of places.

Another important theme running through many of the chapters is the emergence and value of activism and transnational social movements. This is evident, for example, in Lin's analysis of the community activism in Boyle Heights, Crisman's discussion of anti-arts protest, and Newbury's focus on artist-led critiques and resistance. Social activism against gentrification or tenant right protests, or even efforts to maintain the ethnic symbolism of neighbourhoods, are on the rise globally. The book's examples span the United States, Britain, Brazil, Canada, India, The Netherlands, and France, and demonstrate the pivotal role social movements and "the revolt of the excluded" (Dikec 2017) can play in both resisting and reinforcing the aesthetics of gentrification.

These anti-gentrification movements constitute rebellious communities whose activist efforts to halt gentrification can make those spaces appear - at least superficially - more exciting, edgy, and attractive. Ironically, this frequently ends up contributing to gentrification because the atmosphere of resistance tends to increase the seductive capacity and cultural value of the neighbourhood, leading to the dispossession of original residents through rising rents and increased property taxes (Harvey 2012: 77-8). The implication is that the appeal of counterculture and the allure of "authentic local places" (Zukin 2009) are drivers of gentrification - hence our use of the phrase "seductive spaces and exclusive communities" in the book's title. For example, Sirois points out a contradiction he observes in Montreal's small boutiques. As he discusses in his chapter, these boutiques in a rapidly gentrifying neighbourhood cater to customers seeking unique local products as an alternative to the global economy, but the boutiques are actually plugged into and directly support the global consumer market. As this suggests, the aesthetics of gentrification can play a subtle yet influential role in maintaining contradictions that ultimately benefit neoliberal urban redevelopment.

Gentrification itself is now a structural condition of transition within cities across the world. It relies on a neoliberal, consumer-based population that is rapidly transforming neighbourhoods. As detailed throughout the book, gentrification commodifies local culture, creates inauthentic local narratives, and leads inexorably to displacement and expulsion. Three key elements are implicated in these processes: transnational neoliberal consumerism, global capital financing of the real estate market, and local 
anti-gentrification social movements trying to resist these forces. All of these entangling elements combine to create eruptions of accelerated urban change. These urban transformations threaten to create neighbourhoods lacking uniqueness, an established history, or a sense of purpose and meaning. They lead to new forms of urban placelessness that impede belonging, reinforce exclusion, and further embed structural mechanisms of global inequality.

\section{Works Cited}

Addie, Jean-Paul D. and James C. Fraser (2019) "After Gentrification: Social Mix, Settler Colonialism, and Cruel Optimism in the Transformation of Neighbourhood Space." Antipode 51.5: 1369-1394.

Butler, Tim (2003) "Living in the Bubble: Gentrification and its 'Others' in North London." Urban Studies 40.12: 2469-2486.

Castro, J.C.L. (2015) “The Consumer as Agent of Neoliberalism." Matrizes, São Paulo 9.2: $273-288$.

Dikec, Mustafa (2017) Urban Rage: The Revolt of the Excuded. New Haven: Yale University Press.

Florida, Richard (2002) The Rise of the Creative Class. New York: Basic Books.

Foucault, Michel (1982) “The Subject of Power." Critical Inquiry 8.4: 777-795.

Harvey, David (2012) Rebel Cities: From the Right to the City to the Urban Revolution. London: Verso.

Knight Dragon (2020) “Vision.” Greenwich Peninsula. Retrieved from: https://www. greenwichpeninsula.co.uk/about/vision (accessed 16 April 2020).

Freeman, Lance (2005) "Displacement or Succession? Residential Mobility in Gentrifying Neighborhoods.” Urban Affairs Review 40.4: 463-491.

Lees, Loretta (2019) "Planetary Gentrification and Urban (Re)Development." Urban Development Issues 61: 5-13.

Lees, Loretta, Tom Slater and Elvin K. Wyly (eds) (2010) The Gentrification Reader. London: Routledge.

Lees, Loretta, Hyun Bang Shin and Ernesto López-Morales (2016) Planetary Gentrification. Cambridge: Polity Press.

Lindner, Christoph and Brian Rosa (eds) (2017) Deconstructing the High Line: Postindustrial Urbanism and the Rise of the Elevated Park. New Brunswick: Rutgers University Press.

Lubitow, Amy, Bryan Zinschlag and Nathan Rochester (2016). "Plans for Pavement or for People? The Politics of Bike Lanes on the 'Paseo Boricua' in Chicago, Illinois." Urban Studies 53.12: 2637-2653. 
Miriam Zuk, Ariel H. Bierbaum, Karen Chapple, Karolina Gorska and Anastasia Loukaitou-Sideris (2017) "Gentrification, Displacement, and the Role of Public Investment." Journal of Planning Literature 33.1: 31-44.

O’Sullivan, Feargus (2019) “That Sinking Feeling: London's 'Tide' Disappoints.” City Lab, 11 July 2019. Retrieved from: https:/www.citylab.com/design/2019/07/ london-tide-park-diller-scofidio-renfro-landscape-design/593620 (accessed 16 April 2020).

Osman, Suleiman (2011) The Invention of Brownstone Brooklyn: Gentrification and the Search for Authenticity in Postwar New York. Oxford: Oxford University Press.

Rancière, Jacques (2004) The Politics of Aesthetics: The Distribution of the Sensible, trans. G. Rockhill. London: Continuum.

Sandoval, Gerardo (2018) "Planning the Barrio: Ethnic Identity and Struggles over Transit-Oriented, Development-Induced Gentrification." Journal of Planning Research and Education. https://doi.org/10.1177/0739456X18793714

Sassen, Saskia (2014) Expulsions: Brutality and Complexity in the Global Economy. Cambridge, MA: Harvard University Press.

Smith, Neil (1982) “Gentrification and Uneven Development." Economic Geography. 58: 139-155.

Saul, Heather (2013) “Boris Johnson’s £6om Cable Cars Used Regularly by Just Four Commuters.” The Independent, 22 November. Retrieved from: https://www. independent.co.uk/news/uk/politics/boris-johnsons-6om-cable-cars-usedregularly-by-just-four-commuters-8954646.html (accessed 16 April 2020)

Transport for London (2020) “Emirates Air Line Passenger Journeys.” Retrieved from: https://tfl.gov.uk/corporate/publications-and-reports/emirates-air-linepassenger-journeys (accessed 16 April 2020).

Wainwright, Oliver (2019) “London's Answer to New York's High Line? You Must be Joking." The Guardian, 10 July. Retrieved from: https://www.theguardian. com/artanddesign/2019/jul/10/tide-elevated-walkway-greenwich-peninsulalondon-new-york-high-line (accessed 16 April 2020).

Zuk, Mariam, Ariel Bierbaum, Karen Chapple, Karolina Gorska and Anastasia Loukaitou-Sideris (2017) "Gentrification, Displacement, and the Role of Public Investment." Journal of Planning Literature. 33.1: 31-44.

Zukin, Sharon (1987) "Gentrification: Culture and Capital in the Urban Core." Annual Review of Sociology 13.1: 129-47.

Zukin, Sharon (2009) Naked City: The Death and Life of Authentic Urban Places. New York: Oxford University Press. 
About the Authors

Christoph Lindner is Professor of Urban Studies and Dean of The Bartlett Faculty of the Built Environment at University College London, where he writes about cities, globalization, and social-spatial inequality.

Gerard F. Sandoval is an Associate Professor in the School of Planning, Public Policy and Management at the University of Oregon. His research focuses on the roles of immigrants in community regeneration, the urban planning interventions of governments in low-income immigrant communities, and the transnational relationships that exist within immigrant neighbourhoods. 


\section{Part 1}

Spaces of Global Consumption 



\title{
2. The Forces of Decline and Regeneration: A Discussion of Jane Jacobs and Gentrification
}

\author{
Samuel Zipp, Jennifer Hock, and Nathan Storring
}

\begin{abstract}
This chapter takes the form of a discussion about the urbanist Jane Jacobs and the legacy of her work in the era of gentrification. Zipp introduces, Storring surveys Jacobs' contributions to our thinking about gentrification, and Hock analyzes Jacobs' "reticence" on the problem of racism in urban history. Then all three discuss the ways that Jacobs' signature ideas - the "sidewalk ballet," organized complexity, the "self-destruction of diversity," and others - appear now, in a time when cities are beset by problems she predicted but only glancingly addressed.
\end{abstract}

Keywords: Jane Jacobs, gentrification, race, social capital, rent gap, post-war

People or uses with more money at their command, or greater respectability (in a credit society the two often go together), can fairly easily supplant those less prosperous or of less status, and commonly do so in city neighborhoods that achieve popularity. The reverse seldom happens. — Jane Jacobs, The Death and Life of Great American Cities, 98

\section{Samuel Zipp / Introduction: The Jacobs Impasse}

The Jane Jacobs we know, the patron saint of Hudson Street, is trapped in amber now. Those who revere her still think of her as essentially timeless - an evergreen font of wisdom about urban life, the hero of all the morality tales

Lindner, C. and G.F. Sandoval (eds), Aesthetics of Gentrification: Seductive Spaces and Exclusive Communities in the Neoliberal City. Amsterdam: Amsterdam University Press, 2021 DOI 10.5117/9789463722032_CHO2 
city lovers tell themselves. But if she remains "Saint Jane" to many, she is less revered by others, appearing now as a thinker mired in the past at best, and an object of mild suspicion at worst. Her ideas are a relic of New York's Greenwich Village in another era, these folks say, a toolkit of small-scale ideas rendered more or less useless in a time of huge-scale urban and global problems.

It's tempting to agree with the skeptics. Jacobs, it may seem, has become a historical figure. Between the 1960 and the 1980 s, in an age of suburbanization, she was the thinker around which so many of our urban stories revolved, her vision of restoring vitality to cities crucial to turning back the devastation unleashed by several generations of modernizing dreams seemingly come to ruin. Now, however, she has become something else. Not quite the villain of a newer, emergent generation of city stories, her familiar lessons about the virtue of neighbourhoods, "eyes on the street," and mixed uses nevertheless seem quite beside the point to those fixated on the quandaries of precarity, inequality, racialized dispossession, the financialization of housing, and climate catastrophe. "Much of the power of her work," the urbanist Owen Hatherley writes, "comes from the accuracy with which she described the homogenising effect of the public-private meat axe on America's great cities. Transferred elsewhere, many of her ideas have the quality of a cargo cult" (Hatherley 2017: 18).

One of the reasons for this impasse is, of course, gentrification. Whatever Jacobs may have had to say about the problem - and as we will discuss, she had a number of ideas about it and what to do about it - it has become something of a working assumption amongst Jacobs skeptics that her ideas are the original source of the "aesthetics of gentrification" that bedevil cities today. For some, the basic ideas Jacobs recommended in The Death of Life of Great American Cities have themselves become the building blocks of upscale urbanism. Since the 1980 s and gos, the ideals that became codified in her name - an urbanism of the streets, stoops, and small-scale neighbourhood - have lost their power to lead the way out of urban crisis. Adopted as the ideal vision of a middle class "back to the city" movement in the 1970s, they are now simply mobilized as lifestyle amenities for real estate boosterism, instruments of accumulation in the quivers of urban developers (Tochterman 2012; Moskowitz 2016).

As we will discuss, this is in part because of a larger problem: Jacobs herself would not let herself see cities as primal scenes of exclusion. She recognized the fact of inequalities - of class, and particularly of race - but was less concerned with confronting the way they had a constitutive role in making, not just ruining city life. She tended to see them as forces that could 
undo the natural virtues of urban density and diversity - not fundamental properties of the ways that American cities had been built and arranged for more than a century before her mid-twentieth century moment.

For her, cities were about freedom and creativity. They were dynamic organisms, self-organizing systems of interdependencies - seedbeds for "organized complexity" that were predisposed to create vibrant social worlds if the planners and bulldozers could be turned back and people's innate interest in creating "new work" unleashed. The contemporary crisis of cities that goes by the name of gentrification, the process Jacobs first called the "self-destruction of diversity," was for her an unfortunate part of the larger churning - the death and life - that city economies unleashed. Vibrant city economies, she argued, drive overall prosperity. They might still be harnessed to transform the stagnant "plantation age" economies of modernity into new, human-centred, democratic worlds.

Jacobs' innate belief in the generative power of cities, her sheer faith in their innate capacity to produce new ideas and collaborative innovation from their diversity of uses and peoples, may seem outmoded to many today. It might even seem naïve - but that faith gave her the conviction that cities were places where problems gathered not to fester but to be solved. More than a tribune of the ideal neighbourhood, Jacobs was perhaps our greatest champion of the city as a decentralized, dynamic, always unpredictable human system. The city, she believed, could never be a modern machine for living erected by the wise and all-knowing. It existed because people themselves created lives from its chaotic, improvisational economies.

Can we recover some of her faith in the problem-solving powers of city life? Or have the self-generating powers of her city economies run out of steam? Were they ever anything more than fables, fantasies about small-scale democracy ready to be captured by the forces of neoliberalism? I suspect that we should not settle for either the myth of Saint Jane or the urge to toss her into the dustbin of history. Either impulse leaves her caught, failed by partial appreciation for the full range of her thinking, held in the hardened suspension of hasty assumptions.

\section{Nathan Storring / Cataclysmic Re-entry: Jane Jacobs, Before and After Gentrification}

Three years before sociologist Ruth Glass coined the term gentrification in 1964, Jane Jacobs' The Death and Life of Great American Cities attempted to describe a similar set of symptoms in different terms. While many of her 
peers operated under the belief that "urban blight" spreads like a contagion, Jacobs argued that the opposite was the case: those with money and clout do the displacing. Yet scholars of gentrification have largely ignored that much of Jacobs' breakout book, together with some of her subsequent writings, provide a robust, imperfect, and challenging theoretical framework for understanding neighbourhood disinvestment and reinvestment, migration and displacement in American cities.

In Death and Life, Jacobs foreshadows Neil Smith's later "rent gap" theory of gentrification (Smith 1979: 545) by observing that concerted disinvestment is a crucial precursor to reaping profits from undervalued urban land. She was also one of the first to blow the whistle on the practice later known as "redlining" - which she calls "credit blacklisting," since the common term had not yet been coined - whereby conventional credit was withdrawn from communities deemed unsafe investments by banks and government agencies (Jacobs 1961: 11, 127, 295, 314, 326, 332). As both Jacobs and Smith observe, this practice helped create a gap between the actual and potential value of land. Urban redevelopment authorities helped further widen this gap by displacing residents and clearing the land, taking on these costs on behalf of private developers. In this way, the urban renewal regime paved the way for the "cataclysmic re-entry of conventional money," as Jacobs put it, with often devastating results for the people who once lived and worked in these areas (Jacobs 1961: 303). Of course, by the time Death and Life was released in 1961 a handful of brownstoners were already proving that slum clearance was an unnecessary and expensive step of the gentrification process.

While much of this "cataclysmic money" was being put into governmentled urban renewal, Jacobs observed that far more was already going into a market-led process that she called "the self-destruction of diversity." In Death and Life, Jacobs famously argues that the foundation for successful urbanism is a dense, complex diversity of uses. Less well known, though, is her argument that the market tends to both create and destroy these very mixtures. Like other market-oriented theorists of the city, Jacobs believed that the high costs of urban land encourage denser, more efficient uses of that land. Density, in turn, further increases the value of land. However, more controversially, Jacobs believed that this apparently beneficent feedback loop has a tipping point. Like the growth mechanisms of a cell that has gone cancerous, the same processes that drive urban diversification also eventually lead to homogenization and a collapse in values. As costs continue to rise in neighbourhoods facing fierce competition for space, eventually only the most profitable uses can afford to compete. Unlike in urban renewal, Jacobs says, "[t]he cataclysmic effects in such cases arise, not from vast 
wholesaling of credit at all, but from the aggregate of many individual transactions which happen to be heavily concentrated in one locality in one period of time" (Jacobs 1961: 313). Over the course of a generation or more, Jacobs believed that these homogeneous places would be abandoned by anyone with the choice to do so, and become low-cost and low-income enclaves once more, until the diversification process begins again.

Unlike in the early literature of gentrification, Jacobs never cordons off housing as a special case in this market process. Upscale homogenization applies across retail, commercial, industrial, and residential uses. In fact, Jacobs found early American examples of these monocultures in older downtowns as they shifted from diverse commercial cores to "theatre districts" or "financial districts," and the centre of gravity moved elsewhere. In some sense, then, gentrification could be understood as a subset of Jacobs' self-destruction of diversity. In the cases where the district in question began as a working-class residential area, and the market converges upon middle-class or luxury housing as the homogeneous "highest and best use," self-destruction leads to what we conventionally call gentrification.

Throughout Death and Life, Jacobs also makes a strong case for the importance of population stability in neighbourhoods. At the heart of her argument is the idea of "social capital" (a term that had not yet been popularized by sociologists, but which had already been sputtering into life in its current definition for over half a century). For Jacobs, social capital refers to the network of relationships in a neighbourhood that residents regularly draw upon for public safety, political effectiveness, social mobility, and resilience. She writes,

To be sure, a good city neighborhood can absorb newcomers into itself, both newcomers by choice and immigrants settling by expediency, and it can protect a reasonable amount of transient population too. But these increments or displacements have to be gradual. If self-government in the place is to work, underlying any float of population must be a continuity of people who have forged neighborhood networks. (Jacobs 1961:137-138)

Slum clearance killed neighbourhood networks, but "displacements" had market-driven causes as well. On the one hand, Jacobs found that constant out-migration in so-called slums had deleterious effects similar to slum clearance. In particular, if every resident who makes a gain in education or employment immediately chooses to leave the neighbourhood, their strongest relationships will likely survive, but many more casual ones may not. Those left behind lose access to the migrant's resources, knowledge, 
and inspiration. For Jacobs, this brain drain is part of the vicious cycle of persistently low-income neighbourhoods. On the other hand, Jacobs felt that an influx of newcomers could similarly disrupt the social capital of a neighbourhood - but only if that population remains transient and churning. Prefiguring recent studies by Columbia University researcher Lance Freeman (Freeman 2006), Jacobs argues that the incumbent residents who manage to remain in a gentrifying neighbourhood may actually benefit from the additional assets and clout that gentrifiers bring. But unlike Freeman, Jacobs emphasizes that any shared benefits require newcomers to assimilate into the existing community over time.

Jacobs herself was not oblivious to the power dynamics of her presence in gentrifying Greenwich Village. She saw herself in this role: as a newcomer with choice who had assimilated into the community and used her assets and clout accordingly. In Death and Life, for example, Jacobs notes that the Village was only saved from an urban renewal scheme in the early $1950 \mathrm{os}$ when officials were confronted with evidence that the area had attracted "newcomers with money," like herself. She notes, however, that this "was possibly the least significant of the constructive changes that had occurred unnoticed" (Jacobs 1961: 272).

What were these other "constructive changes"? Jacobs argued that gentrification was not the only path to neighbourhood change, speaking at length instead about "unslumming," a process of economic regeneration that occurs when existing residents find some form of social mobility yet choose to stay in their old neighbourhood. "It hinges," says Jacobs, "on whether a considerable number of the residents and businessmen of a slum find it both desirable and practical to make and carry out their own plans right there, or whether they must virtually all move elsewhere" (Jacobs 1961: 272). If allowed, these many little plans gradually upgrade a neighbourhood physically, and more importantly, the social capital of these newfound "people with choice" gives others in the neighbourhood slightly more access to their growing resources. In Death and Life, Jacobs presents unslumming and mild gentrification as often happening in parallel, with a small yet steady stream of newcomers mingling with striving long-time residents, both adding to the economic diversity and resources of the neighbourhood as a whole. However, even in 1961, Jacobs recognized that this combination of endogenous and exogenous growth and investment is a delicate balance. "An unslumming slum is peculiarly vulnerable in still another respect," she writes. "Nobody is making a fortune out of it" (Jacobs 1961: 287-288).

Jacobs rarely returned to the specific subject of gentrification in her writings until the early aughts, when she began revisiting many of her 
earlier ideas, including these questions of disinvestment and reinvestment, in-migration and out-migration in city life. In "Time and Change as Neighborhood Allies," from 2000, she describes once again the "self-destruction of diversity" - however, in this case, she replaces her former terminology with the word "gentrification," affirming the affinity between the two processes. She also further differentiates between the early stages of the process described in Death and Life, a "golden age of gentrification" that adds diversity and provides new resources to existing inhabitants and the advanced stages of the process, wherein gentrification "explodes into a feeding frenzy of real-estate speculation and evictions," ultimately leading to a homogenization of uses (Jacobs 2016: 358). She notes that this "golden age" has become vanishingly short, suggesting the need for both a greater supply of "gentrifiable" neighbourhoods, and support for new approaches to retaining affordable housing, retail, and work spaces.

The unslumming process also makes a reappearance in this speech, though with a significant clarification. In Death and Life, Jacobs presents unslumming as a relatively generalized urban process that can take place in any neighbourhood; in "Time and Change," Jacobs presents it as a process unique to immigrant neighbourhoods. This new, narrower interpretation arguably tempers her previous optimism on the subject of race, suggesting that the processes of resident-driven neighbourhood change Jacobs celebrates in Death and Life are not available to intergenerationally poor, non-immigrant communities in American cities - including many African American neighbourhoods today.

Jane Jacobs' final published book, Dark Age Ahead, continued the retrospective tone of her final years, returning to urban planning issues, like housing and traffic engineering, alongside her more recent interests in institutions and ethics. Her treatment of gentrification in the book follows suit, and although it only makes a brief appearance, it provides a telling personal disclosure. As Jacobs details the various failed government responses to our ongoing urban housing shortage, she writes:

Sometimes the "slums" were inherently such desirable areas with such attractive community life that gentrifiers in possession of savings and do-it-yourself resourcefulness achieved renovations that public policy and financial redlining denied them. Frequently they needed to fight interlocked establishments of developers; philanthropists; planners; architects; federal, state, and local bureaucrats; and elected officials to save their spontaneously rejuvenating areas from destruction. Usually they lost these battles (Jacobs 2004: 144). 
While this portrait of "gentrifiers" is surely a composite, some of it seems undeniably autobiographical. In 1948, Jacobs and her husband moved into a rat-infested building in New York's West Village with a bullet hole in the front door. They renovated their home over the course of two decades, and famously faced down numerous slum clearance threats to their neighbourhood. It is notable, then, that Jacobs identifies herself here as a gentrifier. Perhaps she still saw herself as part of a "golden age" of gentrification in the Village, as a gentrifier who integrated into the community and gave back, but even so, it is perhaps also a recognition that her presence contributed to both the "unslumming" and the gentrification of her beloved neighbourhood.

Jane Jacobs belongs in the canon of gentrification literature. Before a significant discourse on the subject even existed, she had already identified the rent gap as a driver of cataclysmic reinvestment, and observed the negative and positive impacts of well-off newcomers to a neighbourhood on incumbent residents. Long before discussions of "commercial gentrification" emerged, Jacobs contextualized the gentrification process within broader "forces of decline and regeneration." While most gentrification narratives, even today, focus exclusively on acts of resistance as the primary mode of agency on the part of incumbent residents, Jacobs provides an alternative model of resident-driven neighbourhood change. Of course, Jacobs also had her signifcant oversights, particularly regarding the relationship between her theories and racism. However, given her unique contributions to the gentrification discourse and her continued popular influence, Jacobs' work deserves to be contextualized historically and scrutinized seriously - not dismissed outright, nor accepted passively, as is so often the case today.

\section{Jennifer Hock / Reading Between the Lines: Jane Jacobs' Reticence on Race and Racism}

If, as Nathan argues, Jacobs still has much to teach us about the phenomena of economic decline and revival, we need to start wrestling with one aspect of her thought that seems puzzling today: her apparent reluctance to address issues of race and racism, crucial aspects of the conversation on gentrification. At first glance, her writings seem colour-blind in the contemporary, neoliberal sense of the word: dismissive of both the injuries of racism and the importance of racial and ethnic communities and identities. Her best-known work, The Death and Life of Great American Cities, does not portray deepening racial segregation during the mid-century years as a crisis, and people of colour appear to be peripheral to her narrative. As Herbert Gans, Marshall 
Berman, and others have pointed out, Jacobs' city initially seems to be a world of white working-class neighbourhoods, ranging from "solid working-class whites at the bottom to professional middle-class whites at the top" (Berman 1988: 324). Indeed, in the absence of explicit discussion of racial conflict even as she celebrates other types of diversity, Jacobs' writings, particularly her well-known celebratory passages on the small-scale urbanism of the stoop and the street, run the risk of becoming building blocks in a white spatial imaginary that emphasizes nostalgia for the old, ethnic neighbourhood in the face of today's sprawling multiracial and multi-ethnic city (Lipsitz 2011). Yet a closer reading of her work shows that Jacobs' reticence on the issue of race - her refusal to consider race a fundamental characteristic of urban neighbourhoods - was a distinct social and political position in the late 1950 and early 1960 s, one that needs consideration before we can understand her larger arguments about the importance of social and physical diversity in the "unslumming" neighbourhood.

In 1954, as Jacobs was establishing her reputation as a critic of public housing and the urban renewal program, Gordon Allport published a book called The Nature of Prejudice, a work of social psychology and one of the most influential texts on racial bias published in the post-war years. Writing in response to the scientific racism of the previous generation, which purported to be based on documented and identifiable group differences, Allport characterized prejudice as a kind of irrational social contagion and focused on the processes by which it was formed and transmitted from person to person and from one generation to another. At the social scale, it manifested itself in shared beliefs about racial superiority and overt discrimination, behaviours intended to subordinate individuals and groups.

Like many contemporaries writing in the shadow of the Holocaust in the post-war years, Allport emphasized the fundamental similarities among groups and individuals. Even "where visibility does exist," he wrote, speaking specifically of visible racial difference, "it is almost always thought to be linked with deeper-lying traits than is in fact the case" (Allport 1954: 132). Prejudice was learned, and through self-awareness could be unlearned. Structured, cooperative contact among members of different groups was essential to this self-awareness, a key means to dispel irrational beliefs and reduce discriminatory behaviour. In Allport's words, "Prejudice may be reduced by equal status contact between majority and minority groups in the pursuit of common goals" (Allport 1954: 281). The resulting theorization of intergroup tension and conflict, known as the "contact hypothesis," held that isolation of groups from one another worked to confirm irrational beliefs 
about out-groups; conversely, social contact was essential to reducing fear, misunderstanding, and the resulting discriminatory behaviour.

Allport's explanation of the dynamics of racial conflict help us understand the way white liberals, particularly housers and planners, approached race relations in the post-war North. If group differences were fundamentally irrelevant and prejudice irrational, liberals could work to diffuse tensions and reduce discrimination by creating situations and physical spaces in which that irrationality could be identified and exposed and commonalities explored. Public housing, which liberals hoped would transform the dynamics of the nation's housing market, quickly became the key site where this debate was played out. "We have two alternatives as we enter a period of rapid expansion in public housing and as we prepare to destroy our slums," Morton Deutsch and Mary Evan Collins wrote in the widely read Interracial Housing in 1951. "We can either house people according to their needs without regard to their race, religion, or national origin, or we can create, much as we have done in the past, segregated communities..." (Deutsch and Collins 1951: 4). In their studies of both racially segregated and racially integrated housing projects in New York and Newark, Deutsch and Collins found that prejudice was widespread; the majority of white housewives entering integrated public housing did not like the idea of living with black families. But they also found public housing created precisely those "equal status" situations that helped dispel irrational prejudice, and that "neighbourly contact" with black families reduced hostility among whites - indeed, the more fine-grained the spatial integration, the more positive whites were about other races. As Deutsch and Collins wrote, "We are, in effect, rejecting the notion that has characterized much sociological thinking in the field of race relations: the notion [...] that 'stateways cannot change folkways.' The evidence of our study is that official policy, executed without equivocation, can result in large changes in belief and feelings despite initial resistance to the policy" (Deutsch and Collins 1951: 127).

It is hard to conceive of Jacobs as a racial liberal like Deutsch and Collins in part because of her sympathy to "folkways" and her objections to "stateways" - particularly those stateways imposed by postwar housers and planners. It is also hard to conceive of her as a racial liberal because in so many other ways she is allied with the rising generation of 1960 s radicals and community advocates, many of whom were fifteen, twenty, or even twentyfive years younger than she was. She was anti-establishment. She advocated for the grassroots in the face of a technocratic planning establishment. She became a vocal opponent of the Vietnam War. Christopher Klemek has cleverly characterized her radical, community-centred approach as "New 
Left Urbanism" and the term so accurately describes her thinking that we often forget that she was 45 years old when Death and Life was published. Much of her intellectual formation took place in the very different climate of the 1930s, 1940s and 1950s (Klemek 2009).

On issues of race and racism, the Jacobs of Death and Life has more in common with the older generation of racial liberals, who were primarily concerned with ending discrimination and facilitating cultural assimilation and individual opportunity, than with the radicals who would think more systemically and identify and condemn "institutional racism." Like many racial liberals, she believed that racial prejudice was the result of ignorance and habit and would diminish over time, and so discussion of racism remains coded in her writings, appearing only occasionally in comments opposing racial segregation or outright discrimination. She actively works to downplay cultural differences that critics found stigmatizing - insisting, for instance, that East Harlem's Puerto Ricans, whose working class street life many planners found to be a blighting influence on the neighbourhood, "are essentially the same as the people of the mixed, Americanized street on which I live, and essentially the same as the people who live in high-income apartments or fine townhouses, too" (Jacobs 1961: 59). East Harlem's problems, she argues, are due to the ravages of multiple redevelopment projects. Like racial liberals like Charles Abrams or Robert Weaver, she refers to people of colour not as "Negroes" or as "Puerto Ricans" but as "discriminated against" populations, and she dismisses the presence of communities of colour as a meaningful factor in neighbourhood change at all (Jacobs 1961: 103). In the case of one neighbourhood, she counters prevailing narratives of blight and decline quite explicitly: its "basic troubles are not owing to a criminal or a discriminated against or a poverty stricken population," she says about a Boston neighbourhood in the process of becoming a black ghetto; "its troubles stem from the fact that it is physically quite unable to function safely and with related vitality as a city district" (Jacobs 1961: 34).

The key difference between Jacobs and other racial liberals of the era, of course, was her distrust of top-down physical planning solutions as a meaningful way of addressing segregation, prejudice, and discrimination. She was not colour-blind in the contemporary, neoliberal sense; she took her integrationist beliefs to the streets in a demonstration in 1963, when a proposed shift in school district boundaries threatened to leave her daughter's racially mixed public school nearly all-white (Goodman, "If School Is De-Integrated," 1963). But where Weaver, Abrams, and others saw the expansion of the federal government into the housing market as an 
opportunity to create modern residential environments in which integration might take place, Jacobs believed that newcomers - in her world, the African Americans and Puerto Ricans who were moving into the nation's great cities during the Second Great Migration - would be integrated into existing neighbourhoods and urban economies. Complex diversity at the local level - older buildings, varied housing types and land uses, localized economies, and street-level social interdependencies - could do what the monoculture of housing projects could not: provide the social and physical context in which this integration could happen.

Like many in the early 1960 s, Jacobs hoped and expected that prejudice and discrimination would gradually be eliminated in the post-war world. She saw residential integration and neighbourhood revitalization proceeding apace with broader cultural change: "The effective breaking down of discrimination outside a slum, and the less dramatic self-diversification within an unslumming slum, proceed concurrently," she wrote. "If America has now, in the case of Negroes, reached an effective halt in this process ... - a thought that I find both highly improbable and quite intolerable - then it may be that Negro slums cannot effectively unslum ... In this case, the damage to our cities might be the least of our worries; unslumming is a by-product of other kinds of vigor and other forms of economic and social change" (Jacobs 1961: 284).

Highly improbable and quite intolerable: Jacobs is optimistic in ways we might not recognize today. Allied in other ways with members of the younger generation, she lacked their concern about the apparent durability of racism, perpetuated by nominally race-neutral customs and policies. Both her insistence on integration as the desired goal for black and Puerto Rican urban newcomers and her relative lack of interest in the role of racism as an enduring, structuring element in urban development mark her as the product of an earlier era, rather than the harbinger of our own.

The challenge Jacobs offers a contemporary audience on the issue of racism and gentrification, then, is not the one we expected at first. A closer reading, acknowledging the widespread mid-century belief that the very presence of communities of colour caused neighbourhood decline and the racial liberal response that emphasized equal status and opportunity, reveals the complexities of Jacobs' position and the historical distance that separates her understanding of racism from ours. Instead, she challenges us to think seriously about the mix of land uses, variety of buildings types, social interdependencies, and fine-grained, complex local economies that - she believed - might one day operate to make communities of colour at home in the city. 


\section{Discussion}

Zipp: Your essays suggest a divided legacy for Jacobs. On the one hand she should be seen as an analyst of gentrification, not simply a harbinger of its ill effects. But she also treats with kid gloves the social phenomenon that has made gentrification such an urgent topic today: race. Of course, gentrification can and has happened in places where race is of little, or at least reduced significance. Does her "reticence" on race make Jacobs' work less useful today? Or can we pry her loose from the primal scene of the "sidewalk ballet" - Greenwich Village in the 1950s and 6os where the classic "aesthetics of gentrification" was founded - and find in her work any other clues as to what might be done about gentrification?

Storring: Jacobs may not provide much insight into the social and cultural forces behind gentrification in American cities today, however she does offer plenty more of use regarding the economic forces. For one thing, Jacobs has always been a strong advocate for new models of affordable housing. While she critiqued the "projects" built under the American urban renewal regime for their anti-urban design, Jacobs led the effort to build the more granular West Village Houses in New York City, 420 affordable apartment units planned by the neighbourhood and subsidized by New York City and New York State. After moving to Toronto in 1969, Jacobs also became a booster of her adopted city's emerging public housing program, which created affordable housing by buying up and converting older houses and by building new infill development in empty lots and even in backyards.

On the other hand, Jacobs also prefigured many of the market-oriented arguments about affordability that are popular today. In her final book Dark Age Ahead, for example, she argues that North American cities have fallen behind on new housing construction, leading to rising prices and homelessness rates. And Jacobs had been calling for the liberalization of land-use zoning for over three decades before that. In this same vein, she believed that promoting broad-based ownership and other forms of secure tenure was particularly important to battling gentrification, for businesses as well as homes. In the speech I mention in my opening essay, she even speculates that long-term mortgages, low-interest rates, and government guarantees to lenders could help improve workspace ownership rates, just like they had for housing (Jacobs 2016: 362).

Hock: I'm convinced that Jacobs remains relevant as much because of the quality and accessibility of her writing as the value of her ideas and 
observations. She may be able to help specialists formulate policy, certainly, but she also teaches the average reader how to understand and appreciate aspects of the city they hadn't been able to articulate before, and street life - even that hackneyed "sidewalk ballet" - remains chief among them.

When it comes to issues of race, racism, and gentrification, we need to bring Jacobs into the twenty-first century by placing her in dialogue with writers who have thought deeply about the ways in which racism is implicated in the "sidewalk ballet." For instance, the political theorist Iris Marion Young, who builds on Jacobs' ideas in her characterization of city life as "an openness to unassimilated otherness," even as she admits that this view remains an unrealized ideal in contemporary cities characterized by segregation, marginalization, and exclusion (Young 1990: 251). Also relevant here is Elijah Anderson, who characterizes American cities as patchworks of racially exclusive and homogenous neighbourhoods but who also sees rare instances of mixing and encounter under "cosmopolitan canopies where people of different racial and cultural types not only share space but seek out each other's presence" (Anderson 2011: 30). Too often we either take Jacobs' descriptions of street life at face value or we dismiss them as nostalgic, where in fact many have continued to study the conditions under which various types of cooperation and conflict emerge in urban public places.

Zipp:Jacobs is remembered primarily as an advocate for a proper kind of urban space - the streets and stoops of the piecemeal city over the modern city of towers and plazas. Have we too closely associated her with debates over physical urban space and ideal forms of urban public life? How might this have shaped the way that Jacobs has taught people to understand gentrification?

Hock: Forty or fifty years after the publication of Death and Life, Jacobs' reputation as a defender of older neighbourhoods and her vivid writings on urban public life combine to offer a kind of alibi for the gentrifier - an alibi that might be consonant with her ideas in some ways and quite far removed from them in others. It's quite easy today to read her defence of the streets and the stoops, her disdain for redevelopment, and her description of the virtues of older buildings through the eyes of the young, predominantly white professionals who have flooded into city centres since the 1990s, valorizing brownstones and rowhouses, walkability, and street life. To this growing demographic, accustomed to racially and economically homogeneous landscapes and uncertain of its place in the city, her idealized descriptions of urban public life might seem to describe the benefits of various kinds of 
diversity. After all, Jacobs' West Village streets have room for the working class as well as the middle class, for public figures as well as strangers, for reciprocity and interdependence as well as privatism. For an affluent newcomer to an urban neighbourhood, Jacobs might seem to suggest that social differences are part of the larger sidewalk ballet.

Watching the speed at which many neighbourhoods gentrify today, Jacobs might describe them not as "unslumming" but as undergoing the self-destruction of diversity. (What she called "cataclysmic money" today comes from the private sector as well as the state.) But her emphasis on consensus and interdependence also masks conflict and allows gentrifiers to understand their role in neighbourhood change in the best possible light.

Storring: At its core, Jacobs' vision of the city was not an aesthetic one. And as Jennifer observes, reducing her ideas to the "ballet of the sidewalk" and its set pieces of stoops, sidewalks, and storefronts may simply provide an alibi for gentrifiers. However, Jacobs had deep concern for the self-determination of people and communities. Again and again, in her writing on city planning and economics, Jacobs comes back to the idea that the greatest urban good is to enable as many people as possible to pursue their own plans for life and livelihood. The most beautiful American city, to her, is one that allows and even enables the countless plans of countless people, and celebrates that hodgepodge visually. Hudson Street may have become the prototype for Jacobsian urbanism in popular culture, but she chose this street in Greenwich Village because she found it utterly ordinary - not an extraordinary exemplar of beauty or urban order. The evolving aesthetic of people's plans, ever increasing in complexity, can happen in a tower block or a suburb, too - if we allow it and invest in it.

Zipp: One of the keywords in discussions of gentrification is "displacement." A catch-all for the various ways that people are forced out by neighbourhood change, it suggests that gentrification is of a piece with the expulsions of slum clearance Jacobs herself campaigned against. It is also invoked to capture the more ephemeral results of gentrification - the subtle shifts in neighbourhood commerce, atmosphere, and aesthetics that reveal that one group - or "community" has been "displaced" by another.

Thinking about this issue, it strikes me that there's an irony at the heart of common thinking about Jacobs. On the one hand she is seen as the great tribune of urban community - the kinds of places we often imagine as stable and rooted, where people make neighbourhood networks - their "social capital" - and resist the displacement brought on by slum clearance 
and gentrification alike. On the other hand, she is the foremost chronicler of urban process, of the flux, inventiveness, and change that propels city life. What role does this tension play in her ability to come to grips with gentrification?

Storring: In the spirit of Jane Jacobs' later book, The Nature of Economies, one might say that a neighbourhood is stable in the same way an ecosystem is stable. Individual elements are constantly coming and going, beginning and ending, but the overall system has a kind of equilibrium, an emergent character, that evolves on a longer time scale. Likewise, Jacobs recognizes that "urban community" isn't a stable term. Old-timers move on or pass away, and newcomers arrive, and either connect or don't. "Social capital," for Jacobs, represents the continuity of relationships throughout this churn. If the churn becomes so fast or violent that the fund of relationships is diminished and no new ones have time to grow in their place, it leaves a neighbourhood politically helpless and unresilient. For Jacobs, the violent displacement and transient newcomers that accompany gentrification threaten the equilibrium of social capital, but the alternative for her isn't stasis. As she would conclude later in her life, if change is inevitable, all we can do is recruit time and change as allies instead of failing to fight them as foes.

Hock: I think the real tension may lie between the activist and normative aspects of Jacobs' thought. As an activist, she knew very well how to foster a sense of stable community in the face of unwanted change; it's an effective way to fight the bulldozer. As a writer, she was a systems-builder who often emphasized ideal or normative scenarios in which cities worked effectively - a way of thinking that runs counter to our sense that our most pressing urban problems are fundamentally problems of disequilibrium. This may be one of the reasons her later thinking on urban economies is less popular than her earlier critiques of urban renewal. It seems difficult, even immoral, to use the language of balance, interdependence, and complexity to describe gentrification.

Zipp: Not sure about "immoral," but it seems true that one of the reasons gentrification is so hard to turn back once it gets going is that, even though it can appear as a problem of "disequilibrium," of "tipping points" and so forth, it is actually a complex, interrelated problem of both everyday neighbourhood change and government policy, of what, Jennifer, you called "folkways" and "stateways." Jacobs was a well-known champion of "folkways" over "stateways." But as Nathan has suggested, there's more to Jacobs than 
meets the eye. How has she imagined the role of government beyond its role as wielder of the "meat axe?" So much of metropolitan development depends on how public subsidies are conceived and in whose hands they land. Can we envision a more proactive role for government in turning back the "self-destruction of diversity"?

Storring: Jacobs is most remembered for her skewering of the failures of government intervention in the city. She fought against the Vietnam War and the urban renewal regime. Later, in Canada, she advocated for breaking up government monopolies in energy, mail service, and transportation. Yet this is only a partial picture. As Jacobs told an interviewer in 2002, "I never said that government was messing around too much in our lives. I said it was doing stupid things. That's not the same thing at all. It may be doing too little in our lives and still be doing stupid things" (Jacobs, 2002).

Jacobs believed that government has a strong role to play, both in responding to housing affordability and in addressing the underlying precarity that makes a neighbourhood so susceptible to gentrification in the first place. As I noted before, Jacobs argued that governments should invest in affordable housing, particularly in a tactical way that adds and protects housing in the very places where displacement is expected to happen. She also argued that government should actively intervene in the market on behalf of young businesses - not the tech entrepreneur class that has become so powerful today, but the many ordinary business people who have little political or economic power in the face of large, established corporations (Storring and Zipp 2016). As early as Death and Life, it's clear that Jacobs saw everyday entrepreneurship as an important means for people who face racism and other forms of discrimination to seek economic opportunity on their own terms and to provide resources and inspiration to others in their community. As she argues in a 1994 speech to a society of women entrepreneurs, despite wishing and legislation and criticism, the glass ceiling for many groups has not dissolved until members of that marginalized group bypassed entrenched systems themselves by becoming successful proprietors of their own businesses (Jacobs 2016: 329). If these entrepreneurs remain in or return to their old neighbourhoods, Jacobs believed their success can become part of the virtuous cycle of "unslumming" by offering others access to their growing resources, clout, knowledge, and life experience. Recently, community members in the Boyle Heights neighbourhood of L.A. have coined the term "gentefication" to capture both the upsides and downsides of this process, as educated Latinos and Latinas return to their old Latino neighbourhood (Delgadillo 2016). 
Jacobs believed government could act as a "third force," actively protecting these emerging economic interests from monopolization, regulatory capture, and even outright attacks from established players. In general, she admired interventions that either removed regulations or subsidies that actively favour big business or set new performance standards that left room for people to meet those standards creatively, whether through market dynamics or direct community involvement. For example, Jacobs ironically admired the effectiveness of the Federal Housing Administration and the Veterans Administration at spurring suburban housing construction after World War II, even if she felt the urban form it created was unequal and environmentally and economically unsustainable. Therefore, when it comes to gentrification, if we want to take inspiration from Jacobs, I would argue for government intervention that protects and cultivates the plans of incumbent residents, rather than ones that try to freeze the economic, social, or physical status quo.

Hock: We tend to remember her critiques of heavy-handed government intervention and her emphasis on small-scale decision making, but Jacobs' broader interest in urban economies and urban organization meant she had creative ideas about the multiple scales at which urban residents exert their political power and the way in which we decentralize various services. City districts that are small enough to be responsive to constituents but large enough to wield actual political power might be a good idea, she said, given the fact that so much of the gentrification debate falls at a scale that's not addressed well by either pro-development city councils or often reflexively slow-growth neighbourhood advisory groups.

Zipp: For me, thinking with Jacobs remains useful because of her faith in people acting together to solve problems. In a time in which so much seems broken or corrupt, Jacobs sees the city as the place where people are thrown together to create something greater than themselves and where the self-organizing capacities to work out the knottiest troubles will naturally arise. Of course, her colour-blind liberalism and her democratic faith - in self-organizing systems, in the essential sameness and capacity of all people - led her away from a full confrontation with the forces of exclusion and domination that had already done so much to shape cities.

One might argue that "unslumming" becomes "the self-destruction of diversity" precisely because not everybody is given a free and fair playing field for their energies and interests. Some people - the white, male, and propertied, historically - have had less fettered access to capital, while others have had to struggle to win equal access to urban space, and to the 
subsidies that allow entry to the same property market that has been such a fecund source of wealth creation. The state-managed flux of urban life that Jacobs celebrated has served some more than others, and narrowed and winnowed away the very diversity that urban life promises to deliver, and that Jacobs also championed.

Urbanists on the right long ran a rudimentary version of the basic Jacobs software: let the self-organizing properties of the market do their work and all will sort itself out. That brand of common sense long reigned supreme, lodging itself in the neoliberal urban development policy that underwrites an actually existing unfree market by continuing to steer public subsidy to highly concentrated sources of private capital. In recent years, however, things have started to change. Where once discussion of redlining, zoning, housing segregation, and gentrification had little purchase beyond a narrow swath of academics and organizers it now routinely surfaces online and in national magazines and newspapers. In fact, much city writing on the left these days amounts to pointing out, again and again, how the power of race, class, gender and other forms of social division shape our unequal cities. We don't know yet what effect this will have, but can thinking with Jacobs offer a path beyond this face-off to a place where we might actually realize the democratic cities she envisioned? Can we modify the standard Jacobs playbook to find a way to truly harness everyone's creative capacities and make equal cities and economies?

Storring: Perhaps the debate is already changing. The recent fault lines emerging around affordability in U.S. cities seem to have fractured the traditional divisions of right and left. When it comes to electoral politics, the Yes in my Backyard (YIMBY) activists, who have been gaining ground, run the gamut from progressive to conservative. They fight for the liberalization of housing markets in order to improve affordability, but the legacies of redlining and segregation play a substantial part in their argument, and many of them support public housing, too. Meanwhile, the pejoratively named Not in my Backyard (NIMBY) activists they oppose focus more on gentrification and the local effects of new development, a traditionally progressive cause, yet they often find themselves in the position of defending an unfair and deteriorating status quo. The interesting part to me is that both sides carry distinct strands of Jane Jacobs DNA.

Hock: Moments when hardened political fault lines fracture are opportunities for new types of thinking about cities, as Jacobs herself discovered in the 196os. My hope is that an increased awareness of the pervasiveness of 
racialized inequality in our cities will lead to a more sophisticated vocabulary for discussing it and for understanding its role in structuring urban phenomena like gentrification. Jacobs may not help us there. But gentrification, so often discussed at the neighbourhood level, is ultimately a problem of the part's relationship with the whole, and on that issue she had much to say. As the climate change crisis deepens, our understanding of social, racial, economic, and environmental justice may intersect more often, and her ideas about cities as complex ecologies, emphasizing interdependence and complexity, may prove helpful once again.

\section{Works Cited}

Allport, Gordon (1954) The Nature of Prejudice. Boston: Addison Wesley, 1954. Anderson, Elijah (2011) The Cosmopolitan Canopy: Race and Civility in Everyday Life. New York: Norton.

Berman, Marshall (1988) All That Is Solid Melts Into Air. New York, NY: Penguin.

Delgadillo, Natalie (2016) "Defining 'Gentrification' in Latino Neighborhoods," CityLab, August 15.

Deutsch, Morton and Mary Evan Collins (1951) Interracial Housing. Minneapolis: University of Minnesota Press.

Freeman, Lance (2006) There Goes the 'Hood:Views of Gentrification from the Ground $U p$. Philadelphia: Temple University Press.

Goodman, Susan (1963) "If School Is De-Integrated, Villagers Will Picket," Village Voice, July 4.

Hatherley, Owen (2017) “Where Are All the People?" London Review of Books 39.15: 13-18.

Jacobs, Jane (1961) The Death and Life of Great American Cities. New York, NY: Random House.

Jacobs, Jane (2002) "Cities and Web Economies," interview with Blake Harris, The New Colonist.

Jacobs, Jane (2004) Dark Age Ahead. New York, NY: Random House.

Jacobs, Jane (2016) "Time and Change as Neighborhood Allies," in Samuel Zipp and Nathan Storring (eds) Vital Little Plans: The Short Works ofJane Jacobs. New York, NY: Random House.

Jacobs, Jane (2016) "Women as Natural Entrepreneurs," in Samuel Zipp and Nathan Storring (eds) Vital Little Plans: The Short Works ofJane Jacobs. New York, NY: Random House.

Klemek, Christopher (2009) "The Rise and Fall of New Left Urbanism," Daedalus, Spring: $73-82$. 
Lipsitz, George (2011) How Racism Takes Place. Philadelphia: Temple University Press. Moskowitz, Peter (2016) "Bulldoze Jane Jacobs," Slate, May 24.

Smith, Neil (1979) "Toward a Theory of Gentrification: A Back to the City Movement by Capital, Not People," Journal of the American Planning Association 45.4: $538-548$.

Storring, Nathan and Samuel Zipp (2016) "Remembering and Understanding Jane Jacobs, Beyond Left and Right," The Globe \& Mail, May 16.

Tochterman, Brian (2012) "Theorizing Neoliberal Urban Development: A Genealogy from Richard Florida to Jane Jacobs," Radical History Review 112 (Winter): 65-87. Young, Iris Marion (1990) Justice and the Politics of Difference. Princeton, NJ: Princeton University Press.

\section{About the Authors}

Samuel Zipp is a cultural and urban historian who teaches American Studies and Urban Studies at Brown University. He is the co-editor, with Nathan Storring, of Vital Little Plans: The Short Works ofJane Jacobs (Random House, 2016), and the author of The Idealist: Wendell Willkie's Wartime Quest to Build One World (Belknap, 2020) and Manhattan Projects: The Rise and Fall of Urban Renewal in Cold War New York (Oxford, 2010).

Jennifer Hock is a historian of modern architecture and urban design. Her work on twentieth-century cities focuses on issues of race and racism, migration and citizenship, and social change as they intersect with the built environment. Her current book project, Freedom Here, charts the impact of the civil rights movement on design and planning in Boston in the postwar years. She teaches at the Maryland Institute College of Art.

Nate Storring is a writer, researcher, and nonprofit communications professional with a focus on connecting the public to urban design, planning, and policy. With Samuel Zipp, he is the co-editor of Vital Little Plans: The Short Works ofJane Jacobs. He currently serves as Co-Executive Director, Communications at Project for Public Spaces. 



\title{
3. Silicon Wafers and Office Park Dreams: Cross-Cultural Designs, Aesthetics, and Art in and around California's Santa Clara Valley
}

\author{
Jenny Lin
}

\begin{abstract}
This chapter examines the visual culture of Silicon Valley. I look to Silicon Valley's "golden years," exemplified by the establishment of Xerox PARC in the 1970s, and analyse how PARC's researchers' embrace of open exchange and experimentation manifested in university campus-like office design. I subsequently consider the morphing of PARC's design into the monumental corporate architecture of Apple Park, and the work/ play environments of Google and Airbnb. I argue that these late capitalist corporations aestheticize Silicon Valley's foundational values, transforming the promotion of cross-cultural sharing into empty visual signs that mask economic inequality and displacement. Finally, the chapter discusses collaborations between artists and community groups, facilitated by the San José Museum of Art, which aim to reclaim multiculturalism and resist the area's unsustainable gentrification.
\end{abstract}

Keywords: Silicon Valley, Office Parks, Corporate Design, High-Tech Culture, San José Museum of Art

\section{Far from Boring}

Like many kids who grew up in California's suburbs, I spent my sixteenth birthday at the nearest Department of Motor Vehicles - in Los Gatos, a sleepy town in the southern San Francisco Bay Area. With my driver's license and used Ford Taurus, I cruised the quiet streets with friends and sat listening

Lindner, C. and G.F. Sandoval (eds), Aesthetics of Gentrification: Seductive Spaces and Exclusive Communities in the Neoliberal City. Amsterdam: Amsterdam University Press, 2021 DOI 10.5117/9789463722032_CHO3 
to mix tapes in empty parking lots and cul-de-sacs. On weekends, I drove north to San Francisco, the enviable other (which everyone in the Bay Area calls the city) suddenly within blessed reach. I went thrift store shopping on Haight Street, attended singalong movies at the Castro theatre, browsed street style magazines in Japan Town, and explored graffitied alleys in the Mission District. San Francisco felt exhilarating - full of hippies, drag queens, punks, and tourists - connected through a labyrinth of hilly streets densely lined in Victorian homes and public transport sorely lacking in the suburbs. By contrast, nearby San Jose seemed, as the artist Lawrence Weiner once described it to me, like "the most boring place on earth" (2008, personal communication). But with hindsight and the sparkle of nostalgia (floppy discs are my Proustian madeleines), I now realize the incredible feats achieved in the terrain of my youth. Santa Clara County today comprises over a dozen cities and thousands of companies including San Jose (home to Adobe and Cisco), Santa Clara (home to Intel), Palo Alto (home to Hewlett-Packard), Mountain View (home to Google), and Cupertino (home to Apple), to name some prominent examples. These companies have transformed the way we communicate, conduct transactions, and exist in the world. After training as an art historian, I have also come to appreciate Silicon Valley's unique culture, which, while plagued by unaffordability and economic disparity, urgently appears far from boring.

This chapter examines the culture of Silicon Valley (and by extension, that of San Francisco) vis-à-vis representative spaces, sites, and visual markers. I begin by ruminating on what art history can contribute to our understanding of Silicon Valley, and why a study of the region belongs in the histories of art and design. Then, with a historical lens, I look to Silicon Valley's so-called golden years beginning in the 1970s, exemplified by the establishment of Xerox PARC (Palo Alto Research Center, hereafter PARC). I analyze the values and utopian dreams of PARC's early high-tech researchers, and how their embrace of university campuses as models, open exchange of ideas, and contemplative autonomy manifested in an office environment exuding a particular strand of what Louise Mozingo terms "pastoral capitalism" (2011). First appearing in East Coast suburbs in the United States, pastoral capitalism marks a style of corporate architecture integrating bucolic, landscaped surroundings that resemble the countryside. The pastoral capitalism developed at PARC, which fashioned the high-tech office as a quasi-monastic campus and wildly experimental laboratory, was particularly well-suited to Northern California's sunshine, moderate climate, and hippie-influenced resistance to strict corporate hierarchies. I subsequently consider the morphing of PARC's pastoral capitalism into the 
monumental corporate architecture of Apple Park (built 2017) - a behemoth loop of pervasive glass and open interior plans masking increased privatization and diminished employee independence. I further explore the work/play environments and superficial promotion of diversity prevalent at Google and Airbnb in light of signifiers of inequality and economic disparity, seen in the protest signs of striking workers and tent encampments erected at the doorsteps of vibrantly designed, leisure-filled offices. I argue that these late capitalist corporations aestheticize Silicon Valley's foundational values, transforming the promotion of cross-cultural sharing into empty visual signs that mask economic inequality and displacement. Finally, I discuss collaborations between artists and community groups, facilitated by the San José Museum of Art, which aim to reclaim multiculturalism and resist the area's unsustainable gentrification.

So far, very little has been written by art or design historians about the visual culture of Silicon Valley - a massive oversight as the region revolutionized image culture. In a rare example, architectural historian Simon Sadler contrasts the "architecture" of Steve Jobs with that of Rem Koolhaas, considering the challenges Apple's ubiquitous designs and Jobs' legacy and "ruthless command of markets" pose to the discipline of art and architectural history:

One day the Bay Region will make for a particularly intriguing study in New Deal, systems-driven and neoliberal art history, the Golden Gate Bridge an analog of Brunelleschi's Dome, a place awash with new money, fusing science, technology, engineering and learning, humans and gods, an outpost of godly and economic universalism at the center of a trade network. (Sadler 2003)

We have not yet come close to any such study of Silicon Valley. The lack of art historical scholarship is particularly surprising given that the area's programmers expanded pictorial reproduction, what Walter Benjamin (1936) famously theorized as initiating a fundamental shift in the nature of art and our socio-political and cultural relations, to allow for the nearly instant, world-wide dissemination of pixelated images.

\section{Looking Past Key Players}

Much ink has been spilled, or, more appropriately, keys pressed, over the rise of Silicon Valley. Thus far, scholars have tended to focus on primary players 
associated with the area's spectacular development. Margaret O'Mara's captivating and comprehensive tome, The Code: Silicon Valley and the Remaking of America (2019), details the careers of seminal figures from William Shockley, inventor of the transistor, to Facebook founder Mark Zuckerberg, while also acknowledging the "non-technologists," such as government and venture capitalists who played key roles in Silicon Valley's development. A great deal can be learned from such scholarship, as well as from biographies of individuals like the oft-mythologized Jobs, who got ousted from Apple before returning as the company's "savior" (Isaacson 2017; Schlender and Tetzeli 2015). Other writers have focused on instrumental groups including the PARC employees, credited with inventing the first personal computer, graphical interface, and major precursors to the Internet and Instant Messaging, as animated through Michael Hiltzik's Dealers of Lightning:Xerox Parc and the Dawn of the Computer Age (2000).

In contrast, scholars have less to say about Silicon Valley's visual culture, with some notable exceptions. O'Mara describes the international reproduction and spread of "the low-rise, lushly landscaped world of Silicon Valley" (2011: 75). Langdon Winner analyzes San Jose's Winchester Mystery House - a labyrinthine Victorian home that owner Sarah Winchester had perpetually constructed from 1886 to 1922 to elude ghosts after the death of her husband (the inventor of the Winchester rifle) - as analogous to the seemingly never-ending suburban sprawl of Silicon Valley's high-tech industry (1992). Winner writes:

As one drives from San Jose to Santa Clara, Sunnyvale, Mountain View, and Palo Alto, there is little indication where one town stops and another begins. Shopping malls, industrial parks, fast-food restaurants, and housing tracts blend together into a motley tapestry without clear edges or form. (1992: 33)

Such contributions from historians and political and urban theorists provide valuable accounts of Silicon Valley's rise and keen observations of some of the region's characteristic features (e.g., low-rise landscaping, sprawl), but they tend to be limited by positing visual culture as backdrop or metaphor, rather than as major factor within the area's socio-economic dynamics. Exceptionally, scholar of information theory AnnaLee Saxenian has shown how Silicon Valley's clustered layouts and networks between university campuses and companies fundamentally contributed to the region's success (1994). Design historian John Harwood's research on International Business Machines (IBM) and the company's corporate design overseen by Eliot 
Noyes, while not primarily located in Silicon Valley, further demonstrates why high-tech aesthetics matter; IBM's corporate design, the first and most sophisticated of its kind, stood not as an addendum but as fundamental to the company's pervasive power (Harwood 2011).

Like most present-day studies of Silicon Valley, stories of individual creative "geniuses" have traditionally dominated my field of art history. But since the 1960 , art historians, inspired by feminist, post-colonial, and post-modern theories, have questioned the prevalence of biography. Instead of celebrating great artists and great art, critical art historians consider the ideologies promoted by images and examine power structures that cultivate "geniuses," while excluding others (e.g., women, ethnic minorities, LGBTQ artists/designers). Feminist art historian Linda Nochlin's canon-exploding question "Why Have There Been No Great Women Artists?" posed in her essay of the same title in 1971, feels fresh when adapted to today's maledominated world of high tech. Why do there appear to be practically no great women computer programmers (despite the fact that a woman, Ada Lovelace, is credited as the first programmer, and amidst the existence of notable women in computer science such as Grace Hopper, who invented the COBOL programming language)? Nochlin would likely respond that the answer does not lie in biology, as some still publicly contend, such as former Google employee James Damore, who released a memo arguing that biological differences explain engineering's gender gap (Tiku 2019: 83), but rather in the patriarchal support systems (e.g., education, mentorship) that enable some while prohibiting others from becoming "great" (Nochlin 1971). In the following sections, I acknowledge marginalized figures including research interns and minority programmers who have played important but overlooked roles in the history of high tech. To shed further light on unequal power structures, I consider some of Silicon Valley's key spatial layouts, interior designs, and technological forms that organize, discipline, include and/or exclude the region's denizens.

The dearth of art and design scholarship on Silicon Valley likely stems from the general perception of the area's culture as lacklustre, or even non-existent. San Jose's cultural production has long been overshadowed by the art, architecture, and performing arts of its neighbour to the north, San Francisco, and also to California's most populated city to the south, Los Angeles, with the latter's Hollywood glamour, mid-century flair, and booming contemporary art scene. Yet San Jose and Silicon Valley teem with an undeniably influential visual culture, fascinating paradoxically because of its seeming banality. Overall, Silicon Valley's visual culture can be characterized by horizontality, playfulness, multiculturality, and startling juxtapositions. 
Horizontality crystallizes in sprawling office parks, cubical layouts, ranch homes (epitomized by Joseph Eichler's post-World War II tract housing), wide freeways and boulevards. In the shadows of corporate offices, safe carparks and homeless tent encampments also unfold in sprawling horizontality. Playfulness, meanwhile, appears in the funky designs of companies like Google that blur boundaries between work and leisure. Frequently overlooked but for me amply instructive, multiculturality presents itself in the area's ubiquitous immigrant-owned restaurants, markets, tea shops, salons and other small businesses, varied ethnic festivals at community centres and places of worship, and prolific community-oriented cultural output: Bollywood dance classes at the Cupertino YMCA; Chinese calligraphy shows in local galleries and libraries; Latinx murals in downtown San Jose. Silicon Valley's visual culture signals the area's gentrification (division, disparity, and displacement through extreme juxtapositions), as well as the cross-cultural pollinations that shaped the technological revolution.

\section{Golden Years}

In 1971, journalist Don Hoefler popularized the term Silicon Valley to describe Santa Clara County, which had until then been known by the moniker "Valley of Heart's Delight," so called for its hundred thousand acres of verdant fruit tree orchards. In the latter half of the twentieth-century, orchards gave way to suburban garages-turned-startups and research parks next to Stanford University, dedicated to integrating higher learning and industry. These sites spawned myriad technological innovations, including semiconductors, microchip processors, personal computers, and the Internet. As Saxenian argues, friendly cooperation between students and employees at university campuses and companies, even competing ones, was crucial to the region's success:

Silicon Valley's decentralized industrial system was integrated in part by a variety of informal and formal cooperative practices ... Many of these cooperative practices were simply attempts to be neighborly ... in the early days of the industry it was not uncommon for production engineers to call their friends at nearby competing firms for assistance. (1994: 44)

One of the most generative nodes in Silicon Valley's early networks was PARC. In 1970, Xerox Corporation, then a Rochester-based company known for its office copier machines, set up its PARC subsidiary in Palo Alto, intentionally 
located within biking-distance of Stanford University. PARC brought together a group of "geniuses, prodigies, owners of doctorates from the leading halls of learning" (Hiltzik 2000:4), and tasked them, rather ambiguously, with creating "architecture of information" and "the office of the future." The PARC researchers succeeded on many fronts, inventing revolutionary machines including the laser printer and the first personal computer (which Jobs famously saw before releasing Apple's own version, Lisa). PARC swiftly became known for its cutting-edge research and educational ambiance. David Thornburg, a former PARC researcher recalls, "We saw ourselves as a university environment where we didn't have to teach courses" (Perry and Wallich 1985: 72).

PARC aligned itself with top research universities, such as the Massachusetts Institute of Technology (MIT), running "co-op" programmes that allowed well-paid graduate student interns to fluidly integrate their research and work experience. Fred Tou, a Chinese-American alumnus of MIT who interned at PARC from 1979-1982, remembers chatting with classmates back in Cambridge, Massachusetts over a chat programme on the Arpanet, experimenting with precursors to today's Instant Messaging and Internet (2019, personal communication). Tou and his fellow interns were also among the first people to utilize PARC's machines, including the Alto computer and Dover laser printer, to type and print their theses and dissertations. (In those days, graduate students would usually hire typists to transcribe their hand-written work). PARC was divided into three main laboratories: the Computer Science Lab; Systems Science Lab; and Optical (Imaging) Science Lab, each of which employed full-time researchers and research interns, who embarked on independent projects, but also gathered regularly to share discoveries. Tou describes the Systems Science Lab, and especially its "Smalltalk" group (originally led by Alan Kay and later by Adele Goldberg), as especially mellow and inviting; researchers hosted parties at their homes, encouraging conversations between full-time employees and summer interns in relaxed atmospheres (2019, personal communication).

Similar to neighbours Varian Medical Systems and Hewlett-Packard today located in Stanford's own research park (established in 1951), PARC maintained a simple low-slung office building as its headquarters at 3333 Coyote Hill Road (opened in 1975). Surrounded by and set into the rolling hills off Interstate 280, which connects San Jose and San Francisco, PARC's minimal design, marked by alternating bands of windows and concrete, signified the subsidiary's values: opposition to the opulent status symbols and hierarchies of traditional corporations and embrace of collegiate models of youthful experimentation. The ranch house-style horizontality and university-like hallways linking offices and laboratories, as well as the 


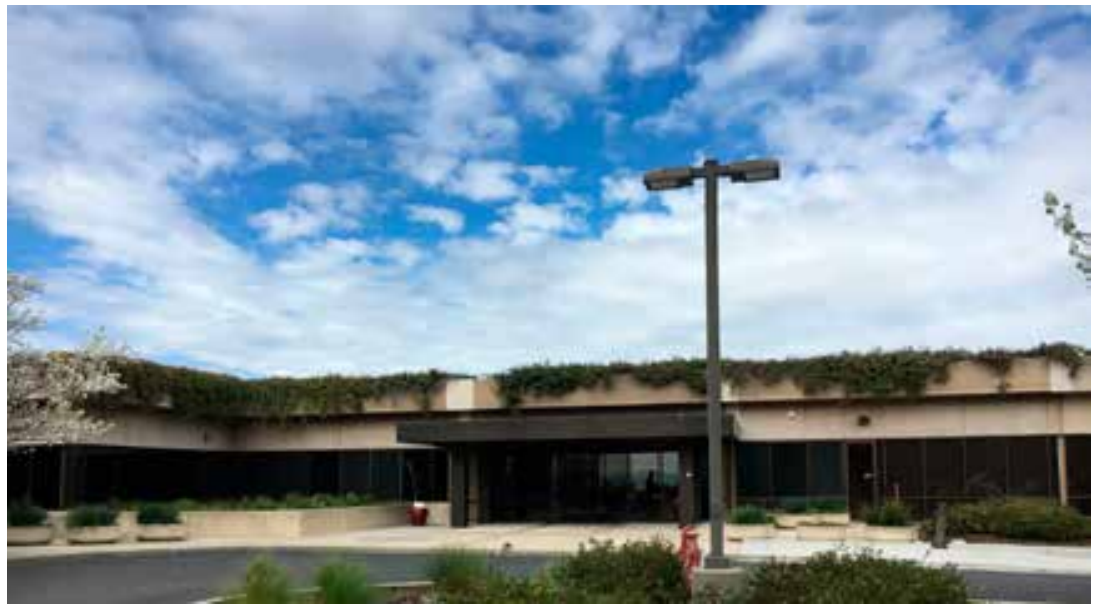

Figure 3.1: Xerox PARC (established 1970), exterior of headquarters at 3333 Coyote Hill Road, Palo Alto (opened 1975). Photograph by the author.

use of inexpensive materials and lack of ornamentation expressed the easy-going Californian lifestyle and declaredly non-hierarchical ethos of the burgeoning tech industry. This relaxed style was echoed in PARC employees' casual attire, which would become standard fashion in Silicon Valley, emblematized in Jobs' black turtleneck and jeans. As Doug Fairbairn, a former engineer recalls, 'I figured if Kay [famed leader of PARC's 'Smalltalk' group that created overlapping windows and a subsequent fellow at Apple] works there, I bet I don't have to wear a tie" (Perry and Wallich 1985: 65).

A feature of site-specificity, the PARC building consists of separable modules, so that in case of a massive earthquake, each module can neatly separate from the other and safely slide down the hill. As Giordano Beretta, a senior research at PARC from 1984-199o recalls, "The building...consists of a row of pods that can move independently in an earthquake (it did not help in Loma Prieta because the epicenter was south instead of west)" (2019). Beretta also notes that the architects who designed the building (George Hellmuth, George Kassabaum, and Gyo Obata) reported having been inspired by a Carthusian monastery: "each pod has a central commons area around which are the private offices. Between pods there are atriums like in an ancient Roman house" (Beretta 2019). These practical features and monastic aspirations, along with the building's clean lines, rectangular geometries, and basic modern materials, expressed the ethos of a contemplative scientific laboratory primed for experimentation. Tony Tessier, a Xerox employee who visited PARC several times in the 1970s, reiterates: "The general atmosphere was that of a university campus" (2019). 
PARC researchers were widely considered, especially by outsiders including Xerox's corporate executives on the East Coast, to be experimental free thinkers, exploring wacky ideas like artificial intelligence, and developing oddball inventions such as personal computers, the mouse, computing networks, and email in a convivial atmosphere that fostered collaboration and freedom from the group's corporate parent company. As Alvy Smith, a former PARC employee who went on to co-found Lucasfilms' Computer Division and Pixar, remarks: "PARC had this aura of being a very far-out place. It was corporate, but it was very unusual for anything corporate to have the apparent foresight to bring some of the best people in the world together and let them do anything they wanted" (Perry and Wallich 1985: $65)$. PARC researchers could come and go at whatever hours they pleased; "Some, like Alan Kay, did their best work from 4:00 AM to 8:00 AM" (Perry and Wallich 1985: 66). Non-PARC employees, such as students working in Stanford's artificial intelligence lab, frequently hung around the offices, attending talks and meetings.

PARC's common spaces helped cultivate the spirit of freedom, openness, and collaboration. Researchers would meet regularly in the now iconic "bean bag room" to give talks to one another in a physically relaxing, but highly mentally challenging environment. As Adele Goldberg recalls in an interview conducted by the Computer History Museum, one of the ideas behind having people sit in bean bags was that no one could easily jump up to attack the person giving a talk. Laughing, the computer scientist adds, "I went to PARC pregnant with my first daughter, and so those bean bags were not as attractive to me as they were to other people" (Goldberg 2011). She also remembers her parents' reaction when visiting PARC, "This isn't a workplace," they said, disapprovingly, "this is a playground," to which she responds, "it was, and that's a good thing" (Goldberg 2011). In addition to the bean bag room, PARC also had its own research library, and a larger room with views of the surrounding hills where guest speakers delivered public talks. Researchers recall moving industrial designer Bill Bowman's "Wheel," a portable office station comprised of a teak desk-top and keyboard, two adjustable monitors and a Volvo seat, outside the offices into the surrounding pasture (Perry and Wallich 1985: 74). A secretary made a call from the "Wheel," "with the horses eating grass around it," an amusing action predicting present-day telecommuting. While all PARC's full-time researchers had their own offices, they easily encountered each other's work. As Smith, who helped develop "Superpaint" at PARC in 1973, explains, "The color graphics lab was a long narrow room with seven doors into it. You had to go through it to get to a lot of other places. Most people, 
when they walked through, would look at the screen and stop. Even the most trite stuff had never been seen before" (Perry and Wallich 1985: 68). Other office design features encouraged employees to generate ideas in communal spaces. The hallways, for example, were covered in whiteboards, so that impromptu conversations could turn into brainstorming sessions illustrated by spontaneous equations and drawings. Ironically, the systems invented at PARC, which laid the groundwork for today's personal computers and the Internet, oft criticized for dehumanizing communications, sprang from designs dedicated to facilitating face-to-face conversations.

Simultaneously, PARC respected individual employees' workplace autonomy, as demonstrated in the provision of private offices. Lawrence Stewart remarks:

When I was at PARC between 1977 and 1984 pretty much everyone had a private office, including student interns like me ... It is kind of a sad reflection on corporate cost-benefit analysis that we have open offices now. You get a lot more done when you can shut the door and have people respect that and not bother you. (2019)

PARC's informal atmosphere and respect for employee independence was echoed at companies throughout Silicon Valley. A former employee of IBM's San Jose office explains:

There was a time when we were free to come and go as we pleased. The researchers, some of them Nobel prize winners, would take long lunch breaks and walk around the park surrounding our office building. A lot of great ideas were generated that way, through walking and conversation. Later, IBM changed its policies so lunch breaks could only last fortytwo minutes; that seemed to reduce productivity." (Chu 2019, personal communication)

As Saxenian argues, Silicon Valley companies gained a competitive edge in the 1970s through this casual corporate culture, intentionally distinguished from East Coast counterparts (1994).

In those early years, many Silicon Valley companies also invested greatly in their employees. I spoke with retired engineers and product managers who worked at IBM in San Jose for twenty or thirty years. IBM paid them to complete PhD programmes, forging partnerships with Stanford and other universities to educate students to excel in the burgeoning fields of informatics and programming, what would later become computer science. 
When I tell these retirees about the many contract workers I know in Silicon Valley today, who receive no benefits, stock options, or job security, they shake their heads: "We were lucky. Ours were the golden years" (Ting and $\mathrm{Wu}$ 2019, personal communication).

\section{Contemporary Corporate Culture}

As Silicon Valley has grown, corporations have become bigger and more powerful, now flexing global clout in grand office campuses that create their own insular worlds. A primary example, Apple Park, Cupertino's Apple headquarters opened in 2017, comprises a 2.8 million square foot, four-story, ring-shaped building on a 175-acre campus designed by Norman Foster \& Partners. Recently assessed at $\$ 3.6$ billion ( $\$ 4.17$ billion including computers, furniture, and maintenance equipment) by Santa Clara Country, Apple Park currently provides workspace for 12,000 employees. Construction on the headquarters began before Jobs' death, and many consider the looped, spaceship-like structure as the late Apple chairman and CEO's would-be magnum opus. The building integrates a restrained mid-century modern style paired with the materials and colour schemes of its laptops and phones to create a space that feels serious and semi-transparent. The glass-clad, curved corridors circling the entire building contain Eero Saarinen's mid-century modern "Womb chairs," intended, in the spirit of PARC's impromptu hallway conversations, to encourage employees to sit and chat while taking in the views (Compton 2017). The surrounding green space, undulating and filled with trees, both encompasses and is encompassed by the massive building. A guide at the Apple Park Visitor Center tells guests the trees are expected to soon grow so tall as to overtake the entire view. "This might create cabin fever," the guide jokes (2019, personal communication).

An Apple employee I spoke with describes the new headquarters as "very impressive, but not very pleasant" (2019, personal communication). The offices on higher floors, which would offer the best views, all have frosted glass windows, epitomizing the secrecy for which Apple is known. The main building also has no openable windows; Jobs famously hated the idea of windows that could open and contaminate. There are only small vents, a few inches wide, at the tops of windows to let in air. The building is mostly cooled naturally, utilizing currents from the Santa Cruz mountains, except during the hot summer months. As made abundantly clear at the Visitor Center, an extended Apple Store, products are designed here. But it 


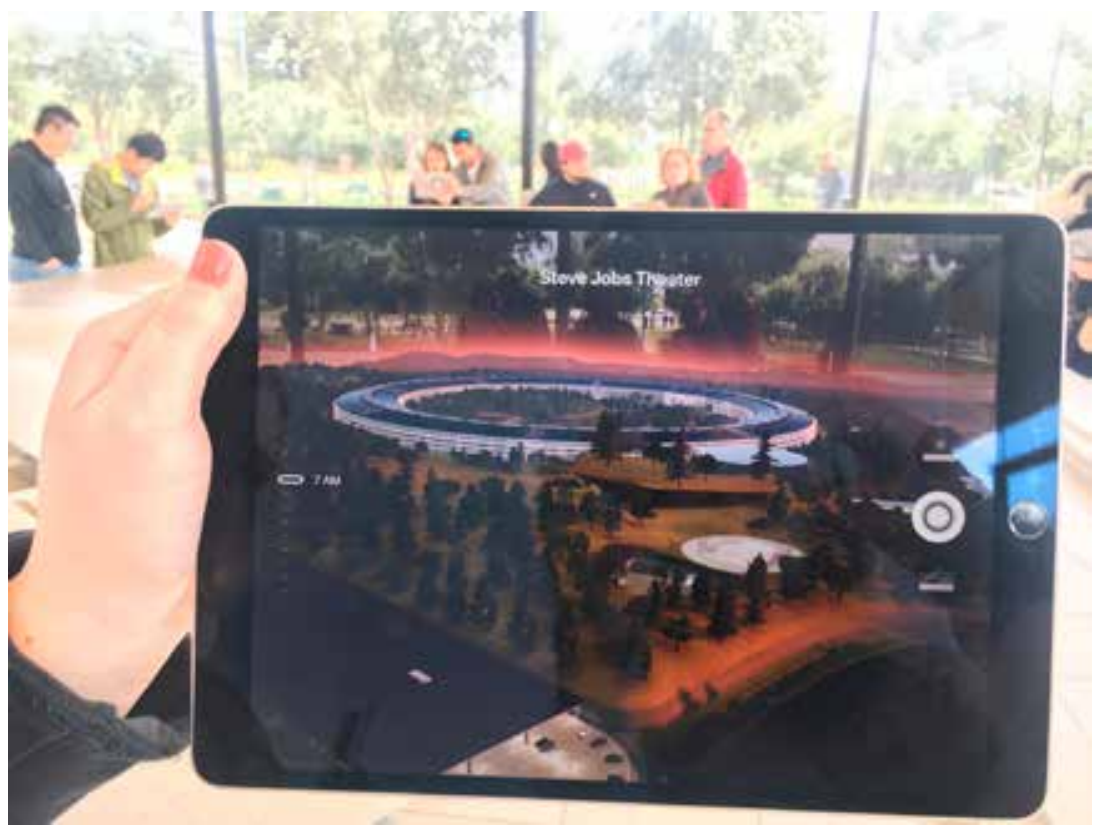

Figure 3.2: Apple Park modelled in virtual reality on iPad, Apple Park Visitors Center, Cupertino (2019). Photograph by the author.

seems that Apple Park's architects have given little thought to the people designing the products. Many engineers accustomed to private offices or cubicles detest the floor plan, which centres around large open workspaces and shared tables, referred to as pods, divided by full-height glass doors and walls. Numerous employees have reportedly injured themselves by walking into the omnipresent glass. Engineers affix Post-it Notes to the glass to avoid injury, but every night maintenance workers remove all the notes.

On a recent visit to Apple Park, a few hours after a gaggle of celebrities, including Oprah Winfrey, Reese Witherspoon, and Steven Spielberg (an alumnus of nearby Saratoga High School), had been on site to promote Apple's new entertainment streaming network, I noticed a group of protestors at the campus's outskirts. "We work for a carpentry union and built most of what's in there," a protestor tells me, "Then Apple suddenly let us go and hired non-union workers to finish our jobs so they didn't have to pay fair wages or benefits" (2019, personal communication). The protestors picketed at the western end of Apple Park, handing out fliers with an image of the Grim Reaper floating above a sprawl of cubicles. Across from the protestors loomed The Hamptons, an expensive apartment complex that advertises “Luxury Living Next to Apple Park.” Many people, including 
construction workers, teachers, policemen, and medical professionals who work in Cupertino and adjacent cities, spend as long as two hours commuting from south San Jose, Gilroy, or other surrounding towns where housing is relatively more affordable, though still expensive by national standards. Not far from Apple Park, a Cupertino church offers safe overnight parking for people, employed but unable to afford the area's exorbitant housing, forced to sleep in their cars.

In stark contrast, Sir Jonathan Ive, Apple's former chief designer, chose to live in San Francisco and be chauffeured in his Bentley Mulsanne to Apple Park, which he played a large role in designing (Parker 2015). Who, aside from Ive who elected not to, can afford to live in Silicon Valley? In 2017, Silicon Valley's median income was over \$100,000 per year (almost twice the national median), and the starting salary for an engineer in a high-tech company is usually roughly that. Most of the area's homes are occupied by highly skilled high-tech workers, many of whom are immigrants from all over the world (with especially high populations from China and India). There are also numerous retirees who still live in Silicon Valley's suburbs and who remember a different time, when you could get anywhere in fifteen-minutes, and when the housing was affordable for single-income households, non-high-tech professionals, and graduate student research interns, including those at PARC.

The convivial environments fostered by Silicon Valley's early high-tech campuses like PARC, and their researchers' discovery that computers could be used for personal enjoyment as well as work, stand as prototypes for contemporary companies such as Google, which creates fun-filled offices aimed at keeping employees well-fed and entertained. The Googleplex in Mountain View, currently the global headquarters of Google and its parent company Alphabet, boasts outdoor spaces with oversized lounge chairs and primary-coloured bicycles that employees ride to and fro. Google offers daily buffets with an array of tasty dishes and employees are encouraged to invite friends and families to join them for meals at the office. Pool tables, exercise classes, and massages offer enjoyable work-time diversions. Bean bags, like those at PARC but in the red, blue, yellow, and green hues of the Google logo, abound.

For critics like Dave Eggers, who satirizes an unmistakably Google-like company in his dystopian novel The Circle (2013), such satisfying perks and pleasurable environments create a smokescreen, masking the erosion of public spaces while keeping people ensconced in a corporatized system. Illusions of freedom and public goodwill (signalled by the company's motto "Don't Be Evil") extend to Google's Internet search engine, which falsely 
appears like a public platform. Ramesh Srinivasan, in his book Whose Global Village? Rethinking How Technology Shapes our World, observes:

The new technology ... is primarily produced and shaped by powerful corporations and institutions ... Yet we treat commercial platforms such as Facebook, Twitter, or Google today as if they were public spaces and systems, ignoring that they must remain primarily accountable to their shareholders. (2017:1)

Within Google, intracompany tensions over lack of equity and outrage over the mishandling of sexual harassment cases recently erupted with an internationally coordinated company walk-out, staged on November 1, 2018. Beginning at 11 AM local time, Google employees in offices around the world walked-out in protest of discriminatory and sexist practices, prompted by a New York Times report of Google's \$9o million exit payment to Android co-founder Andrew Rubin, who was "accused of coercing a female employee to perform oral sex" (Tiku 2019: 83). Congregating outside Google's New York office, employees held signs with printed phrases such as "WORKER'S RIGHTS ARE WOMEN'S RIGHTS" and "TIME'S UP TECH." In addition to insisting on more transparency in the handling of sexual misconduct, protestors demanded "a commitment to end pay and opportunity inequity, for example making sure there are women of color at all levels of the organization, and accountability for not meeting this commitment" (Stapleton et al. 2018). Despite the San Francisco Bay Area's reputation as a diverse melting pot, Google, the first big Silicon Valley company to release data on its demographics, showed its technical workforce to be astonishingly non-diverse in terms of sex and race; in 2017, after hiring 20,00o new full-time employees, Google's technical workforce was $80 \%$ male, $56 \%$ white, and $41 \%$ Asian (Tiku 2019: 85 ).

Some non-Google employees have also expressed anger, at times violently, toward the tech giant that dictates so much of our online lives. Recent news stories tell of people being assaulted for wearing Google glasses in San Francisco bars, and of attacks on Google buses shuttling employees between the company's Mountain View campus and San Francisco's Mission District, where longstanding immigrant communities, non-profit organizations and artists have faced multiple waves of displacement. In response, Silicon Valley's corporate buses now tend to be unlabelled with tinted windows. In a reversal of mid-twentieth century "white flight," in which white middle-class families fled from cities to suburbs, many affluent high-tech employees today choose to live in San Francisco and commute to their offices in Silicon Valley. 


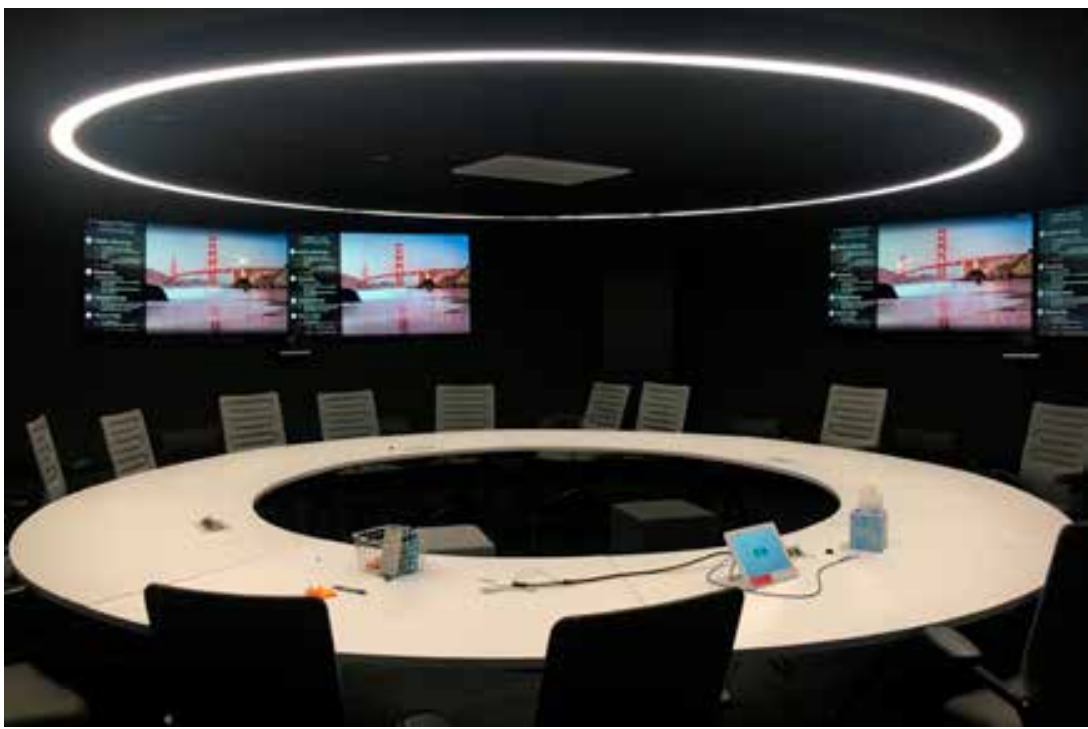

Figure 3.3: Airbnb conference room, interior of headquarters at 888 Brannan Street, San Francisco (2018). Photograph by the author.

Some newer tech companies, such as Airbnb, bypass Silicon Valley, headquartering themselves instead in San Francisco. Airbnb applies a post-modernist style of pop-culture- and transcontinental travel-inspired kitsch to their workplaces. A poster hanging at the top of the open atrium of one of Airbnb's SoMa (South of Market) buildings heralds the slogan: "Open Your Heart and Home." At Airbnb's headquarters, individual offices are foregone in lieu of communal workstations, themed conference rooms, and semi-private nooks. The conference rooms, mostly modelled after prime Airbnb properties and experiences around the world, include replicas of the first Airbnb listing, founders Brian Chesky and Joe Gebbia's San Francisco apartment on Rausch Street; a minimalist apartment in downtown Copenhagen; a beach shack in Bali; a dance club in Havana; and a ramen bar in Tokyo; as well as a donut-themed room; a colourful ball pit; and a lookalike of the war room in Dr. Strangelove.

The luxurious, playground-like interiors of this so-called sharing economy company, complete with sleek furniture, a gourmet cafeteria and wall of alcohol on tap, stand in striking juxtaposition to the increasing numbers of homeless people camped outside the office doors. The grandiose Airbnb offices also differ tremendously from the housing of many of the company's contract workers, who can barely (if at all) afford tiny studios in San Francisco. Like many gig economy companies, Airbnb has depended largely 
on part-time contract workers, who do not receive the same benefits as full-time employees, save for the perks of their playful offices. While the aesthetics of Airbnb's headquarters align with the promotion of opening oneself up to new experiences in different stimulating environments, the lack of individuated office space also hauntingly parallels the company's negative impacts on local economies and real-estate markets. Critics argue that Airbnb contributes to the housing crisis in San Francisco and elsewhere by raising rents and removing scarce housing from the market.

Gentrification in San Francisco appears most visibly in the Mission District, where throngs of long-term residents in the historically predominantly Latinx community, including families, artists, non-profit organizations, and small business owners, have been pushed out as the neighbourhood becomes increasingly trendy and desirable for highly paid tech employees. David Campos, a former city supervisor who represented the majority of San Francisco's Mission District, states: "The Mission is ground zero for the fight for the future of San Francisco. People think San Francisco is an island of progressive thinking [but San Francisco] has the fastest-growing income inequality of any city in the nation" (2015). Campos blames Airbnb, at least in part, for the Mission's gentrification. He requested the city conduct a related study, which, as reported by The New York Times, "found that 29 percent of potential rental units in the Mission were listed on Airbnb" (Pogash 2015). Moreover, the experiences offered through Airbnb's platform - such as "Mission Murals and Latino Food" - seem to parody an imagined ethnic authenticity, while actual diversity has been drastically diminished due to gentrification and the overwhelming displacement of working-class people and people of colour from San Francisco. Campos notes: "People who come here say 'I love the murals' [but] you cannot have the art without the artists. We are losing this neighborhood" (Campos 2015).

The 2019 film, The Last Black Man in San Francisco, written by Joe Talbot and Rob Richert, addresses the recent widespread displacement of African Americans from San Francisco. In a poignant concluding scene, the film's protagonist, a Black man who grew up in the city, overhears two young, white, high-tech workers talking to each other on the bus: "This city blows ... I've been saying for months, let's just move to east LA [another site of heated debates over gentrification]." The protagonist, who has been struggling to reoccupy his grandfather's former home that the family was priced out of, interjects: "Excuse me ... You don't get to hate San Francisco ... You don't get to hate it unless you love it” (Talbot 2019). The Last Black Man in San Francisco reveals the human and cultural costs of gentrification. 
A related New York Times article, "The Loneliness of Being Black in San Francisco," reports:

San Francisco was once a national beacon of African-American culture, home to a thriving jazz scene that had so many clubs it was known as the Harlem of the West. But these days, blacks say they take notice when they see another African-American in affluent and middle-class neighborhoods ... The decline has been steady and noticeable. One of seven residents was black in 1970 . Today, it is nearly one of 20 , with most of the city's 46,00o blacks living in public housing. (Fuller 2016)

As housing prices soar, communities of colour, which long defined San Francisco and the surrounding Bay Area, face eviction and often have no choice but to move out of the area. People of colour and their beloved cultural contributions are then replaced by simulacra (to employ Jean Baudrillard's term): superficial images and faux experiences of Latinx, African American and Asian "street cultures" curated by corporations and accessible only to particularly privileged patrons. Amidst gentrification, actual multicultural pluralism diminishes, while racial, ethnic, and socio-economic diversity becomes aestheticized (transformed into empty signs).

\section{Multicultural Representations and Collaborations}

While high-tech companies increasingly aestheticize diversity and crosscultural communication, local artists and art institutions struggle to achieve actual multicultural representation. In recent years, the San José Museum of Art (SJMA) has expanded its efforts to exhibit challenging contemporary artworks from internationally active artists. Many of these artists are people of colour and immigrants, like so many of the people who shape the region's culture, but who have frequently been left out of Silicon Valley's origin stories and art historical canons. Curator Rory Padeken explains that the SJMA also actively forges collaborations with local community groups and works to draw in more diverse audiences (personal communication, 2019). For the 2016 exhibition, "Border Cantos," which presented Richard Misrach's photographs and Guillermo Galindo's musical instruments built from discarded objects (e.g., jugs, flashlights, toys) found along the U.S./Mexico border, SJMA partnered with thirty-nine community organizations, including MACLA (Movimiento de Arte y Cultura Latino Americano), to present related programming addressing immigration and diasporic identities. 
SJMA's employees strive to overcome problematic discrepancies in San Jose's diverse demographics and attendance at the museum, a civic institution that should serve the city's residents. For instance, the Vietnamese American community, which accounts for $11 \%$ of San Jose's population, has typically accounted for less than $1 \%$ of museum attendees. As a cautionary tale, Padeken points to the controversy surrounding "An Ocean Apart: Contemporary Vietnamese Art from the United States and Vietnam," a travelling exhibition that came to SJMA in 1995 (personal communication, 2019). The exhibition offended many members of San Jose's Vietnamese American community, because they felt it supported communist Vietnam, while inadequately representing the perspectives of those Vietnamese refugees who had fled to the United States. In response, Padeken and other employees at SJMA now make concerted efforts to engage with local Vietnamese Americans and other immigrant and minority communities. They translate exhibition materials into Vietnamese, as well as Spanish, and partner with the Vietnamese-American Community Center, organizing public arts activities for the annual Tết Festival celebrating Lunar New Year. Padeken recently curated the 2018-2019 exhibition, "Dinh Q. Lê: True Journey is Return," which featured, as described on the museum's website: "major video and photography installations entwining rarely heard narratives of war and migration from people in North Vietnam, the Vietnamese diaspora, and refugees who, like Lê, have returned to live in their home country" (San José Museum of Art, 2019). The curator assembled a board of advisors, including members of San Jose's Vietnamese American community, ensuring they participated in the curatorial process.

In another example, The Propeller Group, led by currently Ho Chi Minh City-based Vietnamese American artist Tuan Andrew Nguyen, exhibited at the SJMA from 2017-2018. Like Lê, The Propeller Group makes work about the Vietnamese diaspora, while collectively crafting projects centred on memories of war, recovery, hope, and acceptance of diverse identities. In conjunction with the exhibition and in collaboration with San Jose-based street artist El Mac and immigration rights activist Sophie Cruz, The Propeller Group contributed a mural, Sophie Holding the World Together, to the museum's recently established "SJMA without borders" programme: A Mural of Hope: Sophie Holding the World Together (San José Museum of Art, 2018). The permanent mural, painted by El Mac outside the Children's Discovery Museum in downtown San Jose, employs pixel-like graphics to depict then seven-year-old Cruz, who has become a face of the US immigration reform movement. Born in Los Angeles to undocumented immigrants from Oaxaca, Mexico, Cruz first made 


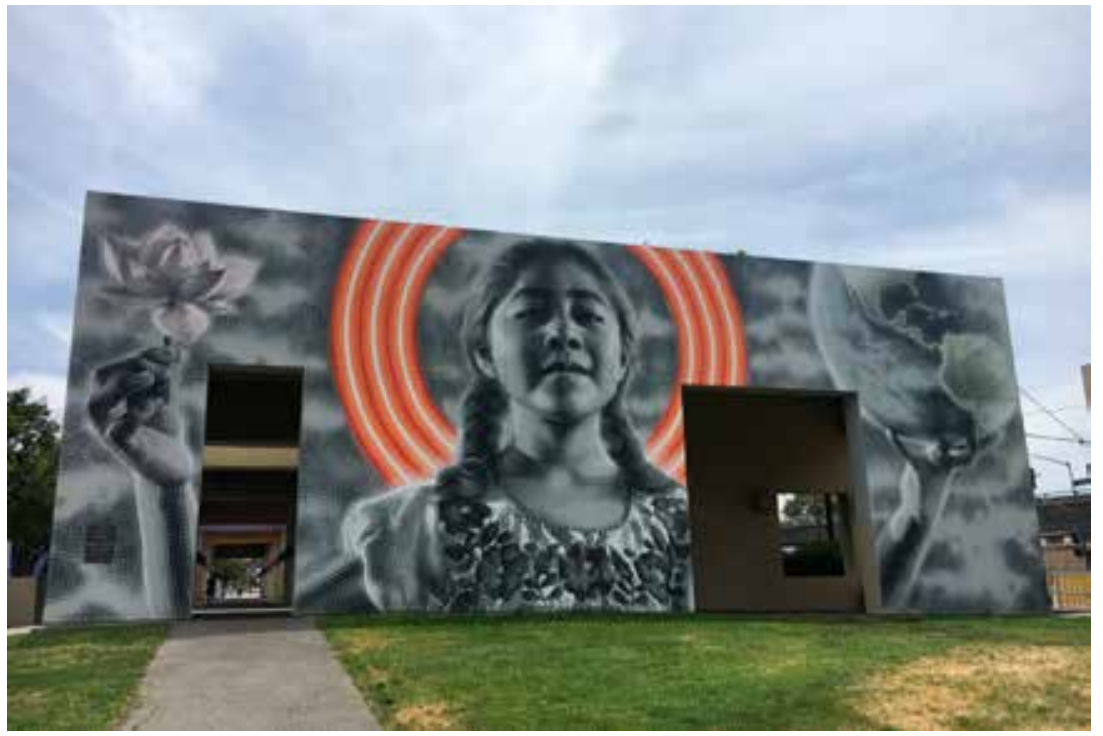

Figure 3.4: The Propeller Group, El Mac, and Sophie Cruz, Sophie Holding the World Together, San José Museum of Art without Borders (2017). Photograph by the author.

headlines in 2015 when she crossed a police barrier in Washington D.C. to hand Pope Francis a letter asking him to help all immigrant children, writing: "My friends and I love each other without caring about the color of our skin." Cruz, who decided how she wanted to be presented in the mural, holds a globe in one hand and a flower in the other. You have to walk up to the mural and look closely to see an accompanying plaque bearing a fragment of a poem by Italian-Uruguayan poet Mario Benedetti, translated into Spanish, Vietnamese, and English: "No Te Rindas/Đừng bỏ cuộc/Don't Give Up ... This is the Hour and the Best Moment." Sophie Holding the World Together represents the typically underrepresented, voices a call to action through poetic inscription, and demonstrates how, as in early high-tech experimentation, collaborations and dreams of improving human communication can yield something for the public that enriches cross-cultural understanding.

\section{Reflecting on the Past to Imagine a Different Future}

This chapter has shown how the initial transformation of the Valley of Heart's Delight into Silicon Valley sprang from a dedication to diverse communities and the open exchange of ideas, as crystallized in sites such 
as PARC. In more recent years, powerful high-tech companies that produce hugely popular products (Internet search engines, personal computers, house-sharing apps) have increasingly aestheticized values of community and multicultural diversity. Today, playfully designed offices and gleaming gigantic corporate headquarters tower over exploited workers. We see the advertising of essentializing images of/touristic experiences with ethnic identity that obscure the mass displacement of working-class people and people of colour from the Bay Area.

Of course, Silicon Valley's "golden years" were far from hippie-influenced perfection. Prior to the 1970s, the burgeoning tech economy in Santa Clara Valley was almost exclusively tied to the military-industrial complex as the United States government doled out large contracts to the most successful companies. Saxenian observes "Military demand dramatically improved the fortunes of Northern California firms," while also noting that governmental support "dropped to only 12 percent in 1972 [as] ... Silicon Valley managed to achieve a gradual transition to commercial production" (1994: 26). The social and health problems associated with today's widespread use of personal computers - a phenomenon Silicon Valley's early researchers spawned - are just beginning to be investigated. And certainly, not all Silicon Valley employees have benefitted equally from the high-tech boom. The area's invaluable construction workers, custodial staff, service workers, teachers, and public servants have long struggled to earn fair compensation. Nonetheless, given our present circumstances, wherein the existence of homeless encampments and workers protesting outside magnificently designed corporate headquarters that cost billions of dollars have become the norm, we must ask: what can we learn from a time, and perhaps from the very foundations of Silicon Valley, when conditions at least appeared fairer and more sustainable?

One common origin story of Silicon Valley begins not in California, but in New Jersey, once home to Bell Telephone Laboratories (Bell Labs), an exploratory research centre comprised of many of the world's brightest scientists. The Bell Labs research and development complex in Holmdel Township, designed by Saarinen, includes a boxy modernist building with a mirrored exterior and a space-age-looking water tower modelled after the design of an early transistor, invented in 1947 by three Bell Labs researchers: John Bardeen, Walter Brattain, and William Shockley. These researchers won the Noble Prize in physics in 1956, the same year Shockley moved from New Jersey to Mountain View, California, to be near his ailing mother in his hometown, Palo Alto, and to start Shockley Semiconductor Laboratory. Notoriously difficult (those who knew him 
remember that he only got along with his subordinate students, and that he could not keep a secretary; his wife had to serve the role), Shockley, who would later become a professor at Stanford and conduct racist eugenicsrelated studies, bred a hostile workplace. One year after the founding of Shockley Semiconductor, eight employees left to start their own enterprise: Fairchild Semiconductor. The "traitorous eight" included two men who would go on to co-found Intel: Robert Noyce and Gordon Moore. The latter famously hypothesized in 1965 that the number of transistors on an integrated circuit would nearly double each year; "Moore's law" has stayed true to this day. This oft-recounted origin story, when looked at carefully, tells not only of single geniuses, but of collaborations, resistance to inequities, and revolt, which collectively led to great hypotheses and design innovations.

The Intel Museum, in addition to recounting some of this origin story, features a display explaining silicon wafer production. On the periodic table of elements, silicon sits below carbon and above germanium. Engineers who worked in Silicon Valley since the 196os tell me that germanium was almost used in microchips instead; Silicon Valley could have been Germanium Valley. Like germanium, silicon, in its pure state, is a natural insulator, only becoming a conductor through a "doping" process that entails introducing impurities (hence the name, semiconductor). The high-tech treatment of silicon, which is extracted from sand and then transformed into a powerful conductor through the introduction of foreign bodies, stands as an apt metaphor for Silicon Valley - a place transformed from orchards into a productive hub, prospering because of diverse peoples and ideas from all walks of life and all over the world. Many of the most forward-thinking scientists began congregating in the San Francisco Bay Area in the 196os, and despite the personal prejudices of figures like Shockley still echoed today, they came from a wide array of racial, ethnic, religious, and national backgrounds.

Today - amidst mounting economic disparity and divisions between corporate executives, employees, and contract workers - artists, non-profit organizations, and immigrants' rights activists offer models for moving beyond aesthetics of gentrification and towards actual cross-cultural collaborations and inclusionary efforts. I hope more art will be made and more research conducted to illuminate and protect the Bay Area's deeply rooted multicultural diversity. Like the Valley's namesake, silicon - a semiconductor requiring the introduction of foreign bodies to achieve an "impure" state capable of successfully conducting energy - our society's well-being relies on integration and sharing across cultures. 


\section{Works Cited}

Baudrillard, Jean (1981) Simulacra and Simulation. Trans. Glaser, S. Ann Arbor, MI: University of Michigan Press.

Benjamin, Walter (1936) “The Work of Art In the Age of Mechanical Reproduction.” In Zohn, H. (trans.), Illuminations: Essays and Reflections. New York: Shocken, 217-251.

Beretta, Giordano, Tony Tessier, and Lawrence Stewart (2019). Answers to "Did Xerox PARC Have Open Offices?" Retrieved from Lawrence: https://www.quora. com/Did-Xerox-PARC-have-open-offices (accessed 5 March 2020).

Compton, Nick (2017) “In the Loop:Jony Ive on Apple's New HQ and the Disappearing iPhone." Wallpaper, November. Retrieved from: https://www.wallpaper.com/ design/jony-ive-apple-park (accessed 5 March 2020).

Eggers, Dave (2013) The Circle. New York: Vintage Books.

Fuller, Thomas (2016) "The Loneliness of Being Black in San Francisco." The New York Times. Retrieved from: https://www.nytimes.com/2016/07/21/us/blackexodus-from-san-francisco.html (accessed 5 March 2020).

Goldberg, Adele (2011) Adele Goldberg: Bean Bags and PARC Culture. Mountain View: Computer History Museum.

Harwood, John (2011) The Interface: IBM and the Transformation of Corporate Design 1945-1976. Minneapolis: University of Minnesota Press.

Hiltzik, Michael (1999) Dealers of Lightning: Xerox PARC and the Dawn of the Computer Age. New York: Harper.

Hoefler, Don (1971) “Silicon Valley USA." Electronic News, 1, January 11.

Isaacson, Walter. (2011) Steve Jobs. New York: Simon \& Schuster.

Mozingo, Louise (2011) Pastoral Capitalism: A History of Suburban Corporate Landscapes. Cambridge, MA: MIT Press.

Nochlin, Linda (1971) “Why Have There Been No Great Women Artists?” In Gornick, Vivian and Barbara Moran (eds) Woman in Sexist Society: Studies in Power and Powerlessness. New York: Basic Books, 344-366.

O'Mara, Margaret (2019) The Code: Silicon Valley and the Remaking of America. New York: Penguin.

O'Mara, Margaret (2011) “Silicon Valleys: Here, There, and Everywhere." Boom: A Journal of California, 1.2: 75-81.

Parker, Ian (2015) "|The Shape of Things to Come: How an Industrial Designer Became Apple's Greatest Product." The New Yorker, February 16. Retrieved from: https://www.newyorker.com/magazine/2015/o2/23/shape-things-come (accessed 5 March 2020).

Perry, Tekla and Paul Wallich (1985) "Inside the PARC: The 'Information Architects."” IEEE Spectrum, October, 62-75. 
Pogash, Carol and David Campos (2015) "Gentrification Spreads an Upheaval in San Francisco's Mission District.” The New York Times. Retrieved from: https:// www.nytimes.com/2015/05/23/us/high-rents-elbow-latinos-from-san-franciscosmission-district.html (accessed 5 March 2020).

Sadler, Simon (2013) "Steve Jobs: Architect." Places, March. Retrieved from: https:// placesjournal.org/article/steve-jobs-architect/?cn-reloaded=1 (accessed 5 March 2020).

San José Museum of Art (2019) “Dinh Q. Lê: True Journey is Return.” Retrieved from: San José Museum of Art website, https://sjmusart.org/exhibition/dinhq-le-true-journey-return (accessed 5 March 2020).

San José Museum of Art (2018) “A Mural of Hope.” Retrieved from: San José Museum of Art website, https://sjmusart.org/mural-hope.

Saxenian, AnnaLee (1994) Regional Advantage: Culture and Competition in Silicon Valley and Route 128. Cambridge, MA: Harvard University Press.

Schlender, Brent and Rick Tetzeli (2015) Becoming Steve Jobs: The Evolution of a Reckless Upstart into a Visionary Leader. New York: Crown Business.

Srinivasan, Ramesh. (2017) Whose Global Village? Rethinking How Technology Shapes our World. New York: New York University Press.

Stapleton, Claire, Tanuja Gupta, Meredith Whittaker, Celie O'Neil-Hart, Stephanie Parker, Erica Anderson, and Amr Gaber (2018) "We're the Organizers of the Google Walkout. Here Are Our Demands.” The Cut, November 1. Retrieved from: https://www.thecut.com/2018/11/google-walkout-organizers-explain-demands. html (accessed 5 March 2020).

Talbot, Joe (2019) The Last Black Man in San Francisco. Los Angeles: Plan B Entertainment.

Tiku, Nitasha (2019) "Three Years of Misery Inside Silicon Valley's Happiest Company." Wired, September, 80-95.

Winner, Langdon. (1992) “Silicon Valley Mystery House.” In Michael Sorkin (ed.), A Theme Park: The New American City and the End of Public Space. New York: Hill and Wang, 31-6o.

\section{About the Author}

Jenny Lin is an art historian, writer, and associate professor of critical studies in the University of Southern California's Roski School of Art and Design. She is author of the book Above sea: Contemporary art, urban culture, and the fashioning ofglobal Shanghai (Manchester University Press, 2019) and multiple essays on varied topics including transnational fashions; cultural revolution; urban imaginaries; architectural lighting; and queer feminist video art. 



\title{
4. Selling Authenticity: The Aesthetics of Design Boutiques in Montreal
}

\author{
Guillaume Sirois
}

\begin{abstract}
This chapter considers how the practice of design takes place in a city like Montreal, where it has been widely promoted in the last decade. It focuses on designers who create everyday-life objects and, more specifically, on the visual environment that characterises the design boutiques in Montreal's Mile End district. It shows that the aesthetics of these spaces are developed around a set of values, namely authenticity, materiality and hospitality. These aesthetics are crucial to distinguish design products and signal to potential clients that these products belong to an alternative version of the market economy. Yet, the aesthetics of these boutiques contribute to an aesthetics of gentrification, which raise questions about the local culture, the history of the neighbourhood, and its population.
\end{abstract}

Keywords: Designer; Boutique; Visual Culture; Montreal; Creative City

In Montreal, the practice of design has been actively supported by city officials in the last decade. Indeed, in 2006, the city obtained the international designation of UNESCO City of Design, and, at the same occasion, inaugurated a new office charged with the mandate of promoting the various practices of design in the city. If the designation came as a surprise for many observers of cultural development in the city, it must be acknowledged, more than ten years later, that this creative activity has progressed significantly in the city. Among the various practices of design that have flourished in Montreal since, this chapter focuses specifically on the practice of designers who create objects (furniture, fashion accessories, household linen, toys, lamps, home decor, etc.). This specific practice of design has been widely promoted by the City of Montreal's Design Office in relation to tourism and 
economic development in an effort to make Montreal a design destination. More specifically, I consider here the stores specialized in local design that propose these objects to visitors and local clientele. Through visual methods, I have investigated the visual environment developed in the design boutiques in the Mile End district in Montreal, a neighbourhood that went through significant waves of gentrification over the last decades. My analysis shows that the aesthetics developed in these boutiques are centred around a set of values, namely authenticity, materiality, and hospitality. These visual environments are meant to distinguish design products from more banal commodities that can be found in any shop and thus signal to lovers of design that they will find in these boutiques products that correspond to their values and lifestyle.

The first section of the chapter gives contextual details by briefly examining how design has become a key area of cultural policy intervention in Montreal, as it was perceived as a strategic industry that is capable of giving a public face to the re-imagined creative identity of the city. The second section turns to object designers themselves to consider how their practice takes place in the city. Finally, the third section provides a visual analysis of a series of boutiques visited during this investigation. It looks closely at their visual environment to show how it is aligned with the taste of the community of "creative" people who have recently nested in the neighbourhood.

\section{Showcasing Montreal's Creativity}

In the last two decades, the cultural landscape in Montreal has been significantly transformed by two interrelated policy streams: the first one aims at transforming the city into "a cultural metropolis of the twentyfirst century" (Brunet and Kadri 2014), whereas the second one seeks to have Montreal internationally recognized as a "city of design." The policy conversation on these topics dates back to 2002, when Gérald Tremblay, the newly-elected mayor of Montreal, invited leaders from various sectors to convene in the "Sommet de Montréal" to reimagine the development of their city. This is around the same period that a group of cultural leaders created the advocacy organization Culture Montréal, a group dedicated to the promotion of a new place for arts and culture in the developing city. This group of cultural leaders enthusiastically embraced the paradigm of the new cultural economy that was emerging at the time around the world (Hewison 2014), in which arts and culture are conceived as key development tools 
to reinvigorate city centres affected by successive waves of the relocation of manufacturing facilities overseas. Fuelled by a popular and academic discourse on notions such as "creative economy" (Throsby 2010), the model of the "creative city" was largely perceived as an easy-to-import model of development. Following this model adopted by cities around the world, like Barcelona (Degen and Garcia 2012), which always served as a strong example in Montreal (Cohendet, Grandadam and Simon 2011), the city started to count on culture and creativity as a key sector to spearhead its economic and urban redeployment.

The work of Richard Florida was particularly influential in the development of such a vision in Montreal (Tremblay and Tremblay 2010). Even if Florida's work has been seriously criticized from an academic perspective (Peck 2005), his views were highly regarded by city officials. Indeed, the American scholar was invited to the city by Culture Montréal to study its potential for creativity growth. His analysis (Stolarick, Florida, and Musante 2005) concluded that the city has significant assets that can be used to attract creative people, which are said to be an essential element of economic and urban development. The campaign led by Culture Montréal was rapidly successful and convinced city officials to adopt, in 2005, a first cultural policy bearing the title "Montreal, Cultural Metropolis." Yet, ambitions associated with this vision were beyond the capacity of the municipal administration, and Culture Montréal's advocacy efforts also targeted the two other levels of government (provincial and federal) as well as the business sector. These efforts led to another summit dedicated specifically to the cultural metropolis project, which saw all partners agreeing on a ten-year action plan to transform such a vision into reality. Overseen by a steering committee of high officials, the plan has had several versions over the years. Among the things that remain constant in these policy documents is the insistence on positioning the city on the international stage. Here, the influence of Florida is patent as several documents insist on the necessity to compete with the "world's major cities" or compare Montreal with major cultural capitals like Paris, New York, or Berlin.

Since the adoption of the first policy, it was clear for the proponents of the cultural metropolis vision that such a project must be translated into physical changes in the city. In this perspective, the practice of design appeared as the perfect creative discipline by which these changes could be brought about, since this practice is multi-faceted and manifests itself in various forms in the city. Indeed, in its definition of design, the city of Montreal adopts a very broad perspective: "For the City of Montreal, design is an activity of ideation, creation, planning, production and management 
that influences the quality of its living environment, makes its economy more competitive, participates in its cultural expression and strengthens its identity and that of its businesses" (Ville de Montréal 2006). With such a definition, the city of Montreal has promoted various practices of design in the last decades, from the conception of new public spaces to the presentation of ephemeral installations throughout the city or the promotion of objects designed in Montreal. The declared ambition of municipal authorities is to turn the city into a "world-class design centre," so that all citizens and visitors of the city will understand, at first glance, that they are in a creative environment.

Among the many initiatives put in place by the City of Montreal's Design Office to promote local design, there is the CODE souvenir catalogue, a promotional tool targeting private and public corporate buyers, as well as the general public. The catalogue, produced annually, presents a selection of the best products created by local designers that can serve as corporate presents or souvenirs from Montreal. With this initiative, the city hopes to link business development and the advancement of the creative identity of Montreal by increasing local purchases. Thus, the City of Montreal transforms commercial transactions into a culturally significant activity. Today, shopping is a ritualistic activity (Miller 1998) that has important significance in contemporary societies. Indeed, Sharon Zukin (2004) argues that shopping is no longer merely a necessary activity by which we acquire the things that we need, but also a mode of expression in public. Therefore, she maintains that shopping is a creative activity, especially when it comes to fashion and lifestyle, since it bears the promise of an improved self and reveals our aspirations about ourselves and our society. However, this is also one of our most controlled activities, since all our purchasing patterns are carefully scrutinized by marketers, stores, and advertisers in the hope of managing it in a more refined way.

\section{Designers in the City}

Contemporary designers are caught in a strange paradox. On the one hand, their discipline has been historically understood as a form of resistance to the industrialization and standardization of life that comes with a capitalist economy. A Victorian creator like William Morris, who is often regarded as a founding figure of modern design, conceived his work as a way to value human craftmanship in contrast to the limited possibilities offered 
by industrial production (Midal 2009). According to this vision, the role of the designer is to make beauty accessible to people through the objects and environment that surrounds us every day. This initial vision is carried forward by social designers who consider that their main task is to improve life in society not only by bringing beauty, but also innovative solutions, to social, environmental, and technological problems (Tromp and Hekkert 2019). On the other hand, design has always been deeply embedded in a capitalist economy as designers create goods intended to be produced and distributed on the market. They conceive beautiful objects that are purposely created to arouse our desire and increase consumption.

In this perspective, designers are now key players in what Gilles Lipovetsky and Jean Serroy (2013) call the "aesthetization of the world." With this term, the two authors do not mean that we now live in a world of absolute beauty, but rather that we have entered a new state of the capitalist economy - that they call "artistic capitalism" - in which aesthetics have become a structural factor. If questions related to aesthtetics were generally minor or peripheral in the market economy, it is now a key strategy by which entrepreneurs distinguish their products from the competition. Instead of competiting on the price of their commodities as is traditionally the case in the market economy, entrepreneurs pay greater attention to the stylization of their products and the environment in which they are presented. This way, their products acquire, through aesthetic means, a certain signification and are associated with a specific way of life that correspond to the desire of their customers. In this perspective, the design sector nowadays takes place in a "cool capitalism" (McGuigan 2009) that tends to absorb any kind of criticism towards capitalism and turns it into a competitive asset.

In a first phase of research, I conducted a series of ten interviews with Montreal designers who conceive various kinds of objects to understand how contemporary practitioners situate themselves vis-à-vis this tension. The statements collected during this series of interviews are used here only as an illustration of local designers' discourse, as a fully-developed analysis of this discourse has been presented elsewhere (Sirois 2020). In fact, Montreal designers see themselves and their production as an incarnation of an alternative capitalist economy. Indeed, the respondents were unanimously comfortable with conducting their professional activity within the capitalist economy: they are generally at ease with calling themselves entrepreneurs, and many of them embrace this designation with enthusiasm. Several of the respondents even fully assume that their production takes place in the luxury industry and that 
their merchandise is accessible only to economically-privileged people. However, they also insist on a series of alternative values guiding the development of their practice, which they specifically oppose to the current state of manufacturing production in the globalized capitalist economy. Creativity is, of course, one of the first values that is praised by designers, as their productions display originality by contrast to the repetitiveness of mass production. Similarly, many designers insist on the sustainability of their production, since their objects are made to last, which is contrary to the "fast fashion" movement that produces goods made to be consumed and discarded rapidly. Finally, their mode of production is also an area where they distinguish themselves from mass production: many of them make a point of producing locally, slowly, and in an inspiring environment, away from the stressful and dehumanized production of big industries.

In such a context, the question becomes how is this production distinguished from more banal commodities when it is presented to the public? How is this specific production marketed to signal its difference? The city of Montreal has deployed significant efforts over the last decade to promote these objects that embody or express the creative identity of the City. Does it become clear to strollers who walk its streets? As it has been suggested (Remaury 2006), recognizing a production as "being design" is a marker of taste that singles out these objects as belonging to a certain aesthetic category. So, what are the specific markers that distinguish these objects?

To study these questions, I established a database of designers working in Montreal, based on the repertoire of designers assembled by the city's Design Office. The database concentrated solely on designers who conceive objects (furniture, accessories, objects for domestic and professional spaces, etc.), excluding those who specialize in designing environments, experiences, events, or creations that are not for sale in design shops. For each of the designers included in the database, I also tracked the main points of purchase where their products are available. Thus, I obtained a list of boutiques and shops where local design is offered in the city. All these points of purchase were put on a map and categorized by the number of local designers represented at the location.

The greatest concentration of boutiques specialized in local design is found in the Mile End, a neighbourhood comprised in the borough of Plateau-Mont-Royal, just North-East of Downtown. From a small village of artisans and workers that it was in the $19^{\text {th }}$ century, the area quickly evolved to become an important industrial sector in the city. At the beginning of the 
twentieth century, the city actively courted major companies in the garment industry, which resulted in building the new John W. Peck manufacturing plant at the corner of Saint-Laurent boulevard and Saint-Viateur street. From 1920 to 1990, Montreal was the country's capital of the garment industry (Desjardins 2017) and a great concentration of these factories were situated in the east part of the neighbourhood, surrounded by modest habitations for the workers. In addition, the neighbourhood has traditionally been home to several migrant communities that occupy a special place in the city's identity, notably the long-established Jewish, Portuguese, and Greek communities.

However, with the decline of the manufacturing production in the sector, the neighbourhood has undergone significant transformations in recent decades. The Peck manufacturing plant is now occupied by the French videogame multinational Ubisoft, and the neighbourhood is among the most expansive sectors in terms of real estate. Following a typical narrative involving creative activity in the gentrification process (Vivant and Charmes 2008), the neighbourhood has been transformed by new creative activities that have taken the place of former factories, which were emptied out by delocalization movements. In addition to the videogame industry that has florished in the sector, attracted by generous tax benefits offered by the state, the Mile End is today well-known for its independent music scene (Straw 2018) that attracts young musicians from across the country and beyond. Non-profit organizations and artists' collectives have also settled in former industrial buildings, and some of them are now engaged in a social struggle to preserve the authenticity and affordability of the neighbourhood (Douay 2012). As it is common in this type of transformation (Maltais 2016), the commercial landscape in the neighbourhood has adapted to the new population that now lives and works in the neighbourhood: new restaurants, bars, and shops now operate next to shops that have been in this neighbourhood for decades.

Among these new ventures that now populate the main shopping streets are the design boutiques. I have identified a total 22 different points of purchase that offer the products of local designers in this neighbourhood. The concentration of boutiques is particularly notable along the SaintLaurent boulevard, which occupies a distinctive place in Montreal. The street that Montrealers call the Main officially divides the city between the East and the West and, unofficially, between the francophone and anglophone communities (Germain and Rose 2000). It is along this street, which functions as a symbol of the city's diversity and heterogeneity (Poulot 2017), that many design boutiques were established, adding a new layer of 
cultural signification to the boulevard. Indeed, the physical presence of these boutiques along the street can be construed as the symbolic inscription of a new taste regime in the city landscape.

To better understand this phenomenon, all the boutiques in this neighbourhood were visited and 18 of them were systematically photographed following a pre-established shooting script (Suchar 1997). For each of them, a series of eight to ten photos was produced, including street view, shop windows, display furniture, and the merchandize itself. The following section presents the results of a content analysis (Rose 2016) that was carried out on the set of images.

\section{Visual Analysis: Displaying Design}

The first element that is striking when analyzing this visual material is the relative banality of these boutiques in the urban landscape. Indeed, at first glance, nothing seems to differentiate them from other restaurants and shops that populate the street. They generally occupy the first floor of a two- or three-storey building made of bricks or grey stone that is very typical in this sector. No visual element signals to visitors that they enter a district dedicated to design or fashion, as is the case in other cities. If some boutiques put a bench or a trestle in front of their shop windows, there is not much there to catch the attention of the average passer-by who is not looking out for design. This observation may seem surprising at first, but it is in fact the first marker of an aesthetic that is built around authenticity. As explained by Sarah Banet-Weiser, our contemporary society is now eager for anything that "feels authentic" as "we lament more and more that it is a world of inauthenticity, that we are governed by superficiality" (Banet-Weiser 2012:3). She argues that some of the cultural spaces that were once the territory of authenticity, notably self-identity and creativity, have been increasingly dominated by brand culture. In this perspective, the design boutiques are conceived as a space of resistance to the superficiality of the brand culture that is so prevalent in the design sector and retailing activity. By standing in opposition to global brands, local design boutiques strive to incarnate a form of authenticity that is made explicit in the visual aspect of the space. Such a preoccupation with authenticity leads to a great level of attention to the materiality of objects presented and the relation to customers, thanks to spaces that embody hospitality. 


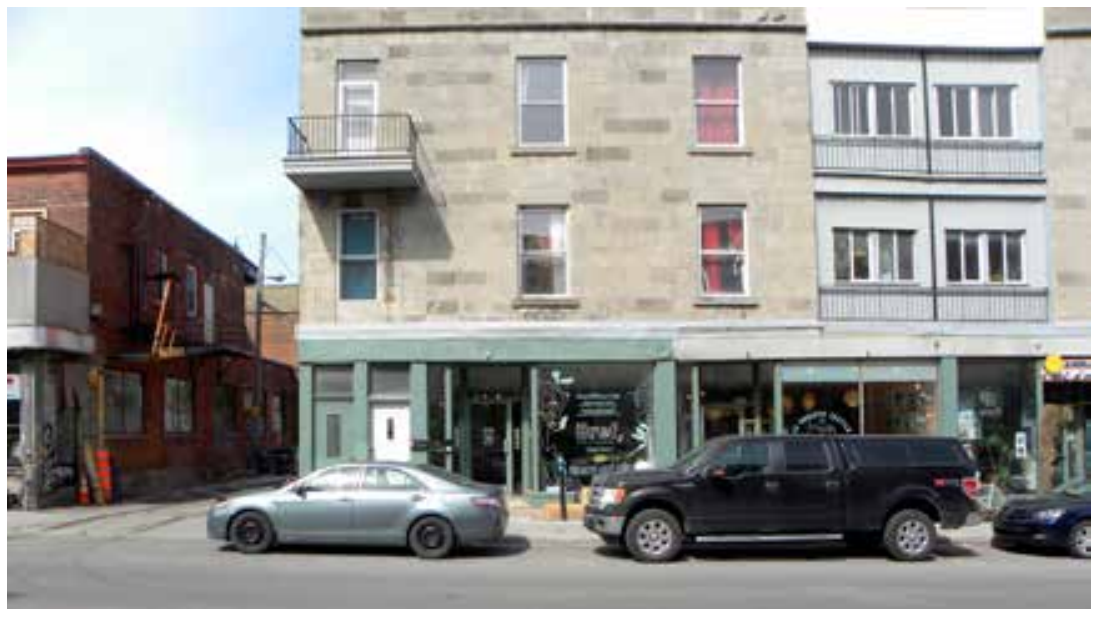

Figure 4.1: Bref, Montreal. Photograph by Pablo Saavedra-Renaud.

\section{Authenticity}

The notion of authenticity is ubiquitous in the discourse about local design, whether it is in the promotional discourse put forward by the City of Montreal or in the words of practitioners. Indeed, authenticity is conceived as a key value of this community as it differentiates their products from industrialization and mass production, artificial and composite materials, and the phenomena of delocalization of production. One of the first added-values of design is specifically to propose authentic goods, at least locally-conceived and preferably locally-produced, which demonstrate the creativity and originality of Montreal designers. This is, for example, what an experienced designer states when she is asked what would be her best advice to young designers: "You need to be authentic. This is the basis. To have your own universe, your own creativity. [...] It is unbelievable the number of young creators that come up with a product and it is only inspired by Pinterest, only copies. It is trendy. In order to last in this business, you need to find your own creation and it doesn't take only two months to find your style, your line." Such a value also has a strong presence in the commercialization of the objects produced by local designers. One of the boutiques studied here even has it in its logo. The boutique is called YUL Design in reference to the Montreal airport acronym, and the store's logo, which evokes a stamp, even states under the name of the boutique "certified authentic."

The preoccupation with authenticity is often conveyed by references to the past that populate the decor of these shops. It is suggested notably in a series of old objects put side by side with design products on the shelves of the boutiques. These objects may be a simple evocation of a somewhat idealized 


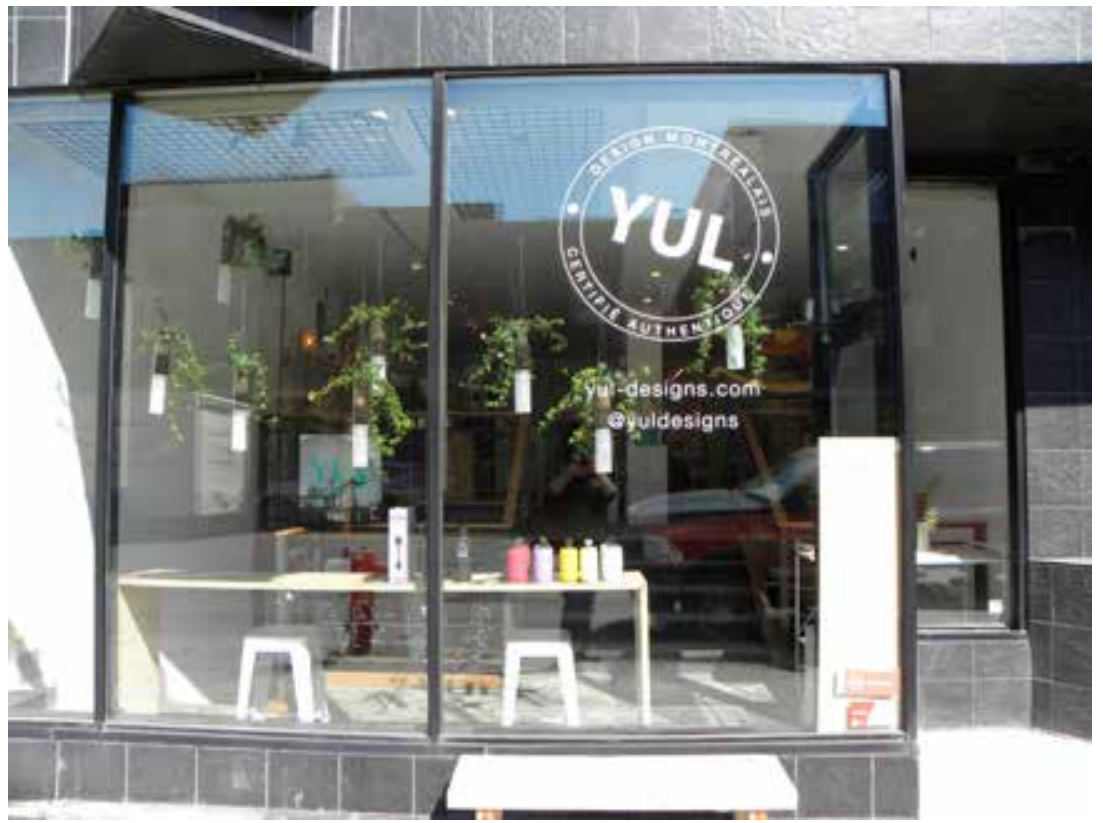

Figure 4.2: YUL Design, Montreal. Photograph by Pablo Saavedra-Renaud.

past, like the set of old objects (old encyclopedia, earth globe, and snowshoes) that is displayed in one boutique visited, or objects that are more closely related to craft culture, like the old sewing machine exhibited in other boutiques specialized in clothes or objects that evoke the local culinary culture, including a maple syrup cane, in the window of another boutique selling kitchen tools.

This evocation of the past also occurs in elements of furniture, like an old retail counter or antique display cases used to present the merchandise in other shops. The same designer who advises her young colleagues to value authenticity in their creative process also insists that such an authenticity should become obvious to customers who enter her boutique. She maintains that customers should immediately recognize that the environment is not cluttered with generic pieces of furniture but, rather, is carefully curated. The pervasive presence of the past in the design boutiques creates a link with the traditional commercial activity and allows the designer community to situate their production in line with an imagined glorious past predating globalization and the neoliberal economy. Even though the modest population that used to live in the neighbourhood would probably not have been able to afford these products, these boutiques are an attempt to recreate a romanticized urban life in which the city was inhabited by small artisans making durable goods and selling them to the local community. 


\section{Materiality}

The desire to show authenticity is also carried in the great emphasis that is put on the materiality of the objects presented. Although there are rare exceptions, the display of the merchandise in these boutiques is generally characterized by a certain minimalism so that the customer can appreciate the physical quality of the object. Accent is put on the pairing of colours, on the contrast between different materials, or on the singular shape or texture of an object. For designers who consider that all of these elements are integral parts of their creations, this aspect is paramount. For instance, one designer specializing in ceramics comments: "It is the material that informs me about its potential and it is with this information that I can make a good design." And this relation to the material extends beyond the creation of the object itself to its marketization. She adds: "When I am looking at an object, when I am drawing, creating, conceptualizing, I am thinking about the packaging. I have not done anything yet, and I am already thinking about the packaging. It is a whole."

To highlight this key dimension in the design process, most of the boutiques studied here do not balk at using, in their own visual environment, rich materials associated with quality and durability. Wood, leather, cork, fabrics like linen and felt, or marble are common materials found in these shops. This attention to materiality is even visible in labelling, posters, and display panels that populate the decor of these boutiques, which are themselves made of wood, rich papers, and blackboards, often with a touch of originality. This is another way to affirm the importance of materiality and craft culture and therefore signal to customers the values promoted in these commercial settings.

More than just for vanity, these aesthetic choices reflect a vision of craftmanship and excellence. Indeed, the quality of the material and the mastery of execution in the fabrication of an object are commonly presented as one of the central justifications for the high price of these commodities. One designer specialized in high-quality furniture explained how he presents his products to his clients: "It is made in Montreal. It is a product that is made to last. We can guarantee the product. All that has a value." For him, "it is an education that needs to be done towards the clientele to make them understand that they invest in something, that this is not only a short-term purchase." Such a statement is representative of an often-repeated discourse in the designer community according to which customers get value for their money when they buy design products because they acquire goods that are made to last, as they are fabricated with rich materials and made locally by 


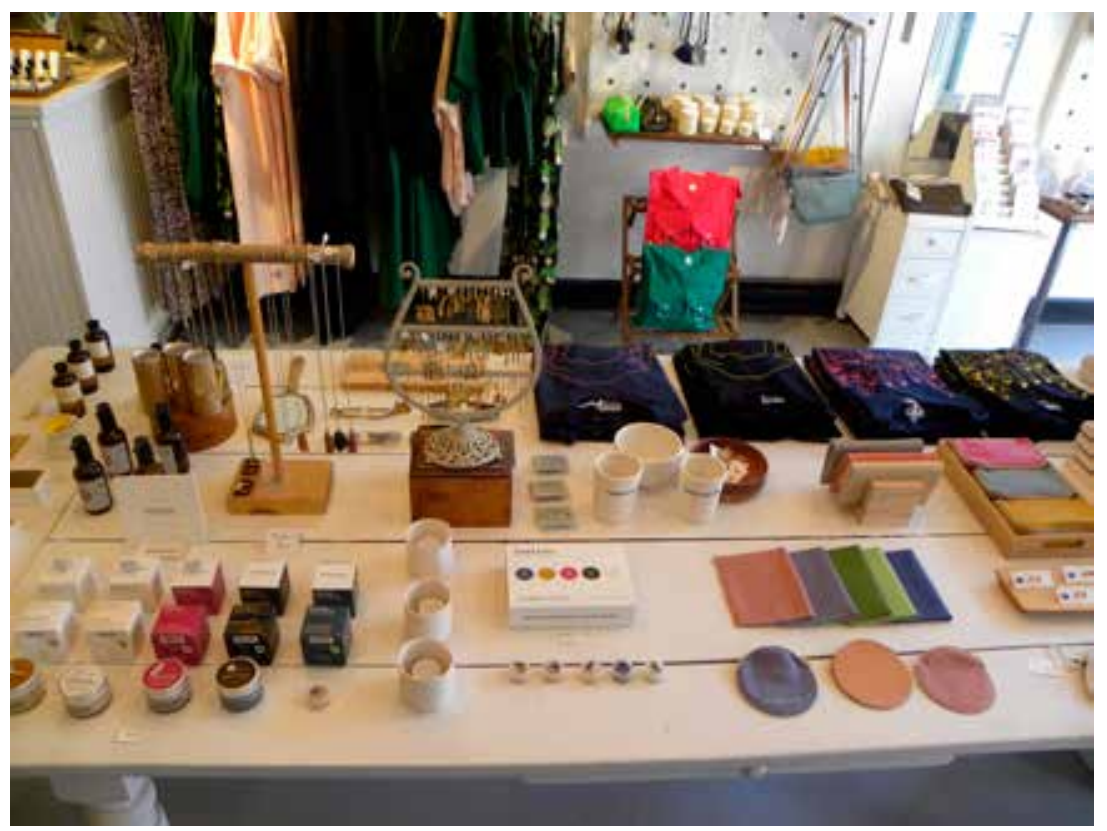

Figure 4.3: General 54, Montreal. Photograph by Pablo Saavedra-Renaud.

artisans who have developed an advanced expertise in this material and the process of fabricating high-quality goods. Moreover, such a discourse holds that this mode of production is more ethical as it is not based on the overexploitation of workers, and more sustainable as it opposes the overconsumption entailed by low-quality production.

\section{Hospitality}

Finally, a last point to note about these commercial spaces are the efforts deployed to make them welcoming and warm. For example, one of the boutiques specialized in kitchen tools includes in its space a couch, so that the clientele can take a moment during their shopping to think about the choice they have to make or simply sit down and relax to enjoy the good smell coming out of the kitchen situated at the back of the shop. Along the same lines, two other boutiques studied here are actually hybrid spaces, as they integrate both a coffee shop and a boutique, where the customer can sit down for a coffee or a drink while looking at, and eventually buying, objects designed by local creators. These strategies can be construed as an effort to transform these commercial spaces into living spaces that would 


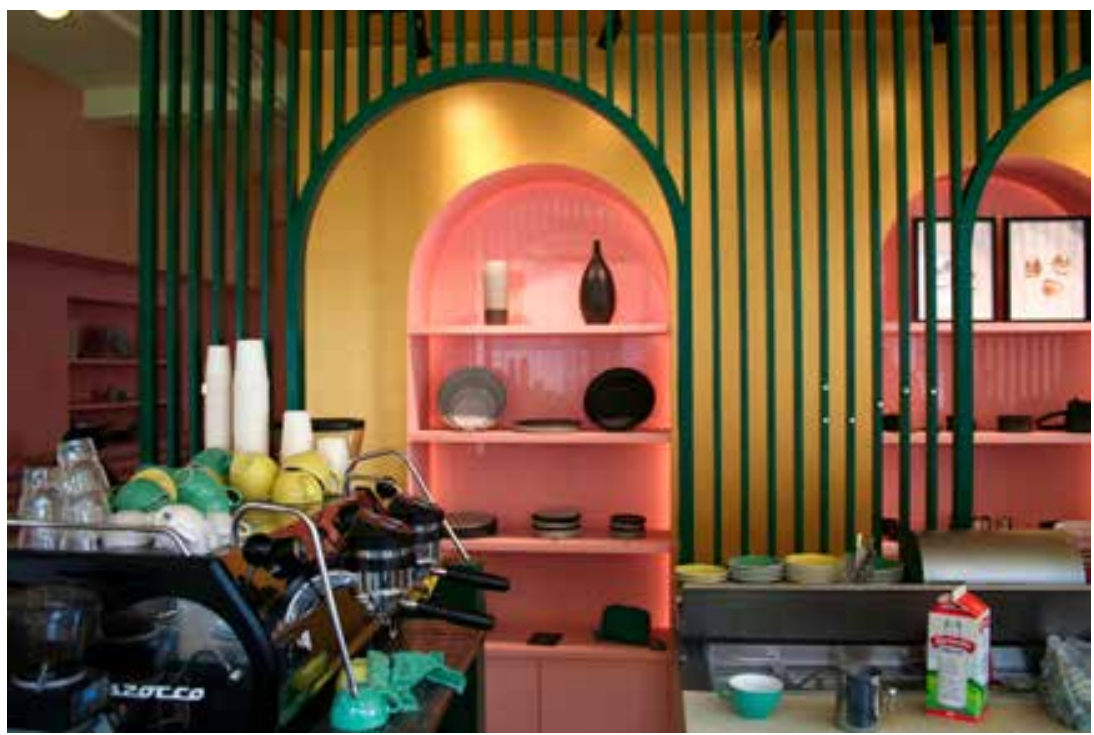

Figure 4.4: Pastel Rital, Montreal. Photograph by Pablo Saavedra-Renaud.

be friendlier to customers. In a more discreet way, this is the same strategy that is used by many shop owners who add plants, elements of furniture, and images on the wall that are not for sale but rather aimed at creating a "homey" atmosphere. One of the designers clearly explained to me that the guiding principle in the design of his boutique was to make it look like an apartment. A comparable strategy is to organize cultural events in the boutiques on the occasion of the launch of a new collection or simply to highlight the work of a creator. Like a gallery opening or book launch, these events transform the boutique into a social space in which the well-informed public gathers, creating visibility for the boutique.

All these hospitality strategies certainly have a commercial dimension. There is no doubt that setting up a convivial space and trying to expand the time spent by potential clients on location has always been one of the techniques of the good merchant. Yet, in the case of design boutiques, they seem to go one step further by trying to establish a long-term relationship with their clients and even to create a community around their commercial activity. This is especially important in the case of small businesses in which the promotional budget is very limited or even non-existent, and in a sector where most of the reputation is built on word-of-mouth referrals. This is where the work of the object designer meets that of the experience designer, as shopping for design is not only looking for the right object that answers one's needs, but also immersing oneself in a creative milieu. 
In this perspective, the preoccupation with conviviality is aligned with the discourse of several designers who insist on the importance of social relationships in the development of their work. Hence, they care for the experience of the customer and aim toward creating a space favouring authentic conversations and exchanges, away from the coldness and superficiality so prevalent in contemporary relationships, and especially in commercial relationships.

\section{Conclusion: In Search of Locality}

The City of Montreal has decided to invest in the promotion of its local designers because this creative industry was perceived as having the potential to show the uniqueness of the city. Such a belief is rooted in the discourse of this community of creators who claim to embody a form of authenticity, contrasting with the homogenization of lifestyle generated by the neoliberal economy. As noted by Sharon Zukin (2010), authenticity is nowadays an instrument of power, since the claim of being authentic in one's own taste generally corresponds to a claim of superiority. However, it remains very difficult to agree on what constitutes authenticity and it generally requires a step back to be able to see it. With Zukin, it can be argued that authenticity is made of various layers of cultural significance, which have settled in one place or one practice, whereas new people, new practices, or new venues only complicate such cultural significations. Thus, authenticity seems inseparable from the question of place, since it is always in relation to a certain local reality that authenticity can be recognized: this is the way things are in a specific place, not reproducing or importing cultural practices that are coming from elsewhere. Therefore, the authenticity of the Mile End district resides in its traditional working-class population and its industrial past that have so strongly coloured the development of the neighbourhood. However, the new population of creative people who live and work in the area has added a new layer of cultural signification that is now an integral part of the neighbourhood's identity.

One can ask what is typical of Montreal, or the Mile End, in these design boutiques that claim to represent the city's authentic creativity? There are, here and there, a few visual elements that evoke the local context, like a well-known photo of Montreal's airport in one boutique or an old advert that mentions the name of the city in another shop. However, these elements seem almost anecdotal; they are pieces in a general background but they are not particularly significant. Another element that might be 
more relevant is the presence of small advertisements disseminated in the decor of these boutiques that highlight local designers. However, this remains a minor practice as the local designer community prefers to stay away from brands, logos, and trademarks that are symbolically the opposite of the values - such as quality and durability - they want their product to represent. The designer community prefers to let the product speak for itself and the decor in which it is presented is there specifically to emphasize the qualities that an experienced customer will have no trouble recognizing.

The aesthetics that are developed in these boutiques have limited links to Montreal or to the neighbourhood in which they are established. The choices made with regards to the physical aspect of these commercial spaces emphasize a craft culture, of which one can undoubtedly find roots in the Mile End district. Yet, the revival of the craft culture is not unique to Montreal; it has surfaced in various forms in several cities throughout the world, including, for example, in New York, where it has been studied by Richard Ocejo (2017). As a consequence, the designer boutiques in Montreal look like many other shops in trendy neighbourhoods of other cities. Yet, the aesthetics of these boutiques, centred on authenticity, materiality, and hospitality, are important for local designers as those aesthetics signal to locals and tourists that the products they sell belong to the international movement that revisits the old savoir-faire of craft culture. These aesthetic choices are particularly important for a culture that rejects the usual marketing tools by which a product is distinguished from the competition. It is through these visual environments that they signify to potential clients that they will find on location products that are aligned with their values, which reflect their beliefs and lifestyle.

In their study of the "maker culture" in Portland, Oregon, Steve Marotta and Charles Heying (2018) show that the "local" is often conceived as a "defensive position" against globalization, which allows a community of practitioners to unite around a set of values, which includes authenticity, sustainability, and locality. Like in Portland, the community of local designers in Montreal share a set of values that is purposely opposed to the logic of neoliberal capitalism and globalization. The aesthetics they develop in the boutiques where they present their objects are not defined by a local cultural flavour, per se, or by a specific material that would be characteristic of Montreal or even a distinctive style, but rather are guided by this set of values. However, the inscription of such a version of locality in the urban landscape is certainly not neutral. In fact, the visual environment of these boutiques contributes to the elaboration of a specific aesthetics of gentrification that probably suits the lifestyle of the new creative population 
now living in the neighbourhood. Yet, the same visual enivronment also contributes to the structuring of the city around preferences in taste. In this context, one may wonder where that leaves many members of Montreal's community of local designers hoping that creating beautiful objects is also a way to enrich the lives of all their fellow citizens.

\section{Note}

All quotations from interviews are my own translation from the original in French.

\section{Works Cited}

Banet-Weiser, Sarah (2012) Authentic TM: The Politics of Ambivalence in Brand Culture. New York: New York University Press.

Brunet, Valérie and Boualem Kadri (2014) "La métropole culturelle: un nouveau visage de la triade mondialisation-métropolisation-mise en tourisme? Les cas de Marseille et de Montréal." In B. Kadri (ed.), Dynamiques métropolitaines et développement touristique. Montréal: Presses de l'Université du Québec, 37-6o.

Cohendet, Patrick, David Grandadam, and Laurent Simon (2011) "Rethinking Urban Creativity: Lessons from Barcelona and Montreal." City, Culture and Society 2.3: 151-158.

Degen, Monica and Marisol Garcia (2012) "The Transformation of the "Barcelona Model': An Analysis of Culture, Urban Regeneration and Governance." International Journal of Urban and Regional Research 36.5: 1022-1038.

Desjardins, Yves (2017) Histoire du Mile End. Québec: Septentrion.

Douay, Nicolas (2012) "Lactivisme urbain à Montréal: des luttes urbaines à la revendication d'une ville artistique, durable et collaborative." L'information géographique 76.3: 83-96.

Germain, Annick and Damaris Rose (2000) Montréal: the Quest for a Metropolis. New York: Wiley \& Sons.

Hewison, Robert (2014) Cultural Capital: The Rise and Fall of Creative Britain. London: Verso.

Lipovetsky, Gilles and Jean Serroy (2013) L'esthétisation du monde : Vivre à l'âge du capitalisme artiste. Paris: Gallimard.

Maltais, Alexandre (2016) "Anciens et nouveaux petits commerçants face à la transformation socioéconomique de deux anciens quartiers populaires montréalais.” Territoires urbains et mixité sociale 77: 148-165. 
Marotta, Steve and Charles Heying (2018) "Interrogating Localism: What does 'Made in Portland' Really Mean?" In Susan Luckman and Nicola Thomas (eds), Craft Economies. London: Bloomsbury, 141-149.

McGuigan, Jim (2009) Cool Capitalism. London: Pluto Press.

Midal, Alexandra (2009) Design: introduction à l'histoire d'une discipline. Paris: Pocket.

Miller, Daniel (1998) A Theory of Shopping. Ithaca: Cornell University Press.

Ocejo, Richard E. (2017) Masters of Craft: Old Jobs in the New Urban Economy. Princeton: Princeton University Press.

Peck, Jamie (2005) "Struggling with the Creative Class." International Journal of Urban and Regional Research 29.4: 740-770.

Poulot, Marie-Laure (2017) Le long de la Main cosmopolite : Promouvoir, vivre et marcher le boulevard Saint-Laurent à Montréal. Québec: Presses de l'Université du Québec.

Remaury, Bruno (2006) "Les usages culturels du mot design." In Brigitte Flamand (ed.), Le design : Essais sur des théories et des pratiques. Paris: Institut français de la mode; Éditions Regard.

Rose, Gillian (2016) Visual Methodologies: an Introduction to Researching with Visual Materials. London: Sage.

Sirois, Guillaume (2020) "Artisan or Designer: Montreal Craft Workers and the Global Discourse on Creativity." In Annette Naudin \& Karen Patel (eds), Craft Entrepreneurship. London: Rowman \& Littlefield, 89-106.

Stolarick, Kevin, Richard Florida, and Louis Musante (2005) Montréal, ville de convergences créatives: Perspective et possibilités. Montréal: Catalytix.

Straw, Will (2018) "Visibility and Conviviality in Music Scenes." In Andy Bennett and Paula Guerra (eds), DIY Cultures and Underground Music Scenes. New York: Routledge, 21-30.

Suchar, Charles S. (1997) “Grounding Visual Sociology Research in Shooting Scripts.” Qualitative Sociology, 20.1: 33-55.

Throsby, David (2010) The Economics of Cultural Policy. Cambridge: Cambridge University Press.

Tremblay, Rémy and Diane-Gabirlle Tremblay (2010) La classe créative selon Richard Florida: un paradigme urbain plausible? Québec: Presses de l'Université du Québec.

Tromp, Nynke and Paul Hekkert (2019) Designing for Society: Products and Services for a Better World. London: Bloomsbury Visual Arts.

Ville de Montréal (2006) Montréal, ville UNESCO de design (dossier de candidature). Ville de Montréal.

Vivant, Elsa and Éric Charmes (2008) "La gentrification et ses pionniers : le rôle des artistes off en question." Métropoles 3: 29-66 
Zukin, Sharon (2004) Point of Purchase: How Shopping Changed American Culture. New York: Routledge.

Zukin, Sharon (2010) Naked City: The Death and Life of Authentic Urban Places. Oxford: Oxford University Press.

\section{About the Author}

Guillaume Sirois is an assistant professor in the Department of Sociology, Université de Montréal. His current research focuses on contemporary art and other visual practices, including design, architecture, and fashion. His research interests also include cultural policy, creativity, and globalization. 


\title{
5. The Import of a Narrative: The Role of Aesthetics and Discursive Elements in Fabricating Change in the Centre of São Paulo
}

\author{
Beatriz Kalichman and Beatriz Rufino
}

\begin{abstract}
This chapter examines the use of aesthetic and discursive elements in the production of a narrative about República, a district in the central area of São Paulo (Brazil) that has been transformed through a real estate boom in the past ten years. We focus on newly built studio apartments, and on the efforts to differentiate them from the quitinetes, apartments with similar features built in the 1950s and 1960s that have been heavily stigmatized. We situate our analysis of this purposeful urban transformation within a context intertwined with urban marketing, publicity, and image making. Our research shows the strong presence of an industrial aesthetic in the area, which we understand as being a deliberate echo of the gentrification process that took place in SoHo in New York City in the 1970s.
\end{abstract}

Keywords: São Paulo, quitinete, studio, República, SoHo effect, gentrification in Latin America

\section{Introduction}

In recent years the district of República, São Paulo (Brazil), has transformed significantly. The area, formerly known as a derelict part of the city centre, is now being celebrated in the media as being "revitalized," and since 2012 has seen an accentuated rise in real estate activities. What is particularly interesting in this process is that a good portion of what has been produced by the recent real estate boom in the area are new small open floor apartments

Lindner, C. and G.F. Sandoval (eds), Aesthetics of Gentrification: Seductive Spaces and Exclusive Communities in the Neoliberal City. Amsterdam: Amsterdam University Press, 2021 DOI 10.5117/9789463722032_CHO5 
marketed and sold as high-end studios. This is significant because the district has long been known for its quitinetes, apartments with the same features built in the 1940s and 1950s that have been widely stigmatized and linked to the centre's supposed decay. While the quitinetes had their prices heavily depreciated in the last decades of the twentieth century, the newly built studio apartments have an expensive square meterage that represents a rise in property value in the area. The old quitinetes are also finding their prices appreciating in this process.

In this chapter we will discuss the importance of aesthetics and discursive elements in the process of change currently taking place in the district, and how this process seems to reference a narrative about the transformation of central areas that originated in New York in the 1970s, with the conversion of lofts to residential use. Loft living has spread globally since then, making the trend, and the neighbourhood of SoHo in particular, into a paradigmatic case study. We argue that an effort led by developers and local government is appreciating property values in República. This development effort is designed to replicate the transformations that took place in New York, including the heavy use of industrial aesthetics in residential and commercial development and an optimistic discourse of art-led urban renewal. We demonstrate that this imported narrative serves not only as a common interpretation of the transformations taking place in República, especially within advertising and the media, but also as a way of fostering the transformation itself. This discursive creation serves as a mask that conceals many of the socioeconomic tensions present in República's everyday reality.

The visual continuity in the area studied - with both recently opened businesses and the studio's display units relying on industrial elements (such as burnt cement and exposed brick) - emphasizes a particular aesthetics of gentrification encompassing a new role of art and culture in urban renewal, an idea that has permeated the imagination of both the media and the public in São Paulo, as elsewhere. This specific discursive construction was reinforced and exploited by the studio developers in order to raise the prices of their products by distancing them from the quitinetes and tailoring them and their publicity to fit a broader fabricated narrative of transformation.

It is important to emphasize the role of industrial aesthetics, as discussed by Zukin (1982), in the creation and import of this narrative, not only by developers but also by the State. The area is changing due to an attempt to create a price appreciation process by fostering the perception that there is one. This is the same type of gentrification aesthetics that previously marked the famous price appreciation experience in New York. Such a use of industrial aesthetics is not merely visual. Those aesthetics are also being 
used to reference the transformation process that gave rise to them in the first place, as well as the role of art and artists in urban renewal. To discuss these aspects and to better understand how the cultural elements of urban interventions can be instrumentalized by both State and private agents, we use the idea of urban-cultural interventions, defined by Kara-José (2007) as urban transformation projects that put culture in a prominent place within a context intertwined with urban marketing, publicity, and image making.

In this chapter, the centre of São Paulo will be discussed taking three scales into account. The first one is the city as a whole, so we can situate the transformations in the studied area within a broader context. The second one is the central area, that includes 10 districts, totalling 32.6 square kilometres, and when we refer to the centre we will be referring to this area. The city centre is quite heterogeneous, and although we will not be able to detail all of this diversity, it is important to mention that, as shown in the map in Figure 5.1, the districts located in the southwest part of the centre concentrate a population of higher income while the districts to the east concentrate a lower income population (Nakano, Malta and Rolnik 2004). In addition, it is also important to note that, since the centre of São Paulo is a very heterogeneous area, the different uses that can be made of the idea of living in the centre, returning to the centre, etc., can refer to different areas that benefit from, or are undermined by, the rhetorical associations. Since we will mainly be discussing perceptions, and how they can be changed, using the idea of the centre, as one space, can help us understand how the perception of the area is fixed in the urban imaginary, and how the ideas about the central areas of other cities can be mobilized and transposed to São Paulo's context.

The district of República, within the South-Western area of the city, borders the wealthier districts of the centre, and borders Santa Cecília and Consolação, two districts of a higher income. We concentrated our field work in this area, using a research methodology informed by direct observation that included visits to the buildings and their display units, as well as visits to cultural centres and businesses in the area. Our research also included a historical study and an analysis of the area's representation in the media. This research approach, combined with a literature review, helped to situate the neighbourhood's transformation within academic discourses on gentrification.

It is also important to note that although this chapter will not be analyzing the metropolitan scale, that scale informs the city dynamic as a whole. A key reason is that the restrictions for accessing a more centrally-located dwelling are closely linked to the peripheralization phenomenon in São 


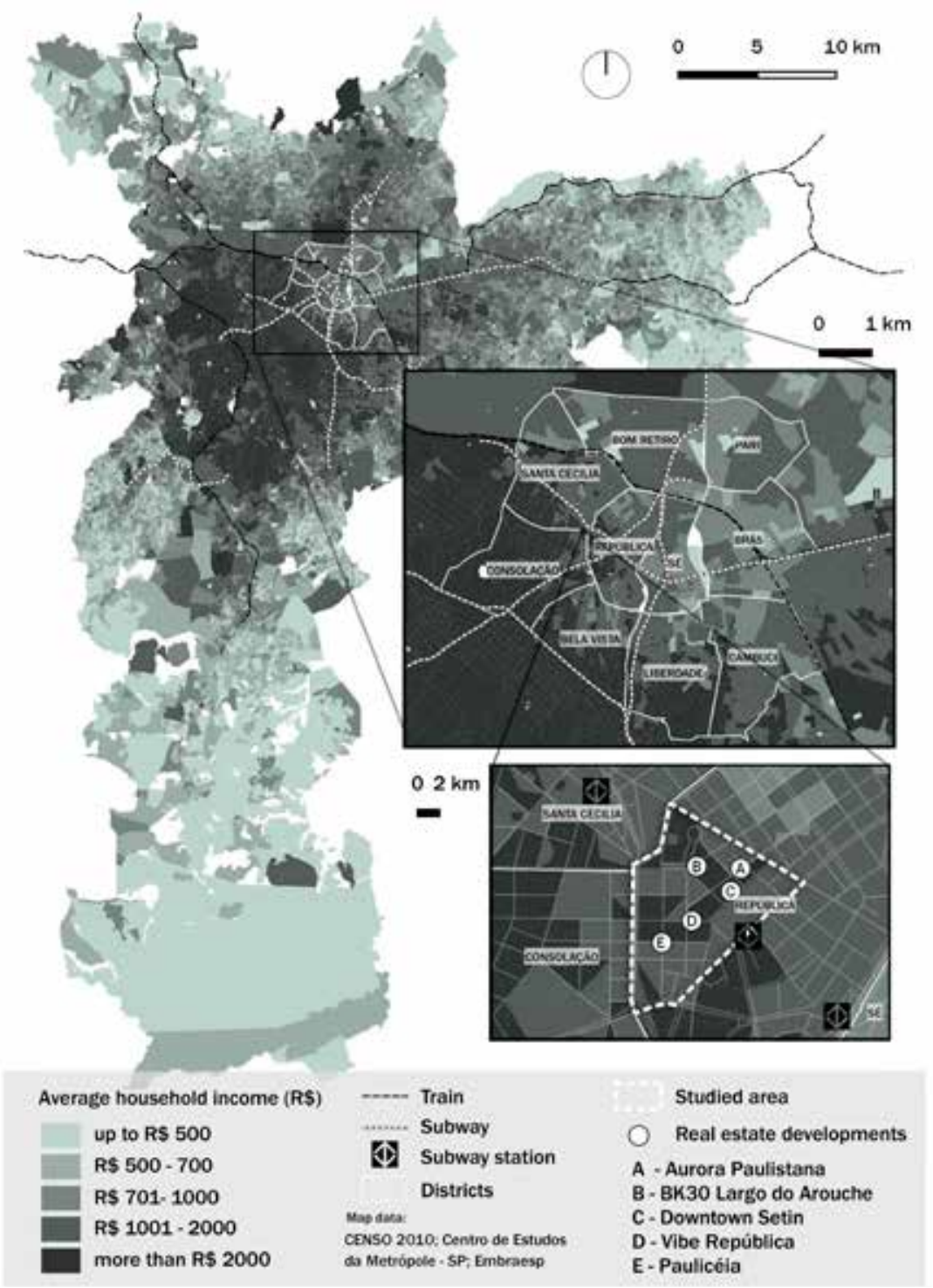

Figure 5.1: Household income map of São Paulo, with the central districts and studied area highlighted. Source: authors.

Paulo. This situation is especially dramatic in Brazil, where an unfair pattern of urbanization has left a great deal of peripheral areas with very limited public investment in basic infrastructure, perpetuating inequalities. For this reason, understanding the forces that shape the occupation of the centre is important if we want to understand how urban inequalities are perpetuated. 
To develop this argument, the chapter divides into five parts, starting with introducing these transformations and followed by a short presentation of our theoretical framework. We continue by historically contextualizing the changes in São Paulo's city centre and its quitinete apartments, including the forces that led to their supposed decay. In the fourth part we concentrate on analyzing the transformations that are taking place in the district of República, mapping both their visual and discursive convergences, and how they fit into a larger narrative that borrows from international examples of urban transformation. Finally, the chapter concludes by focusing on how the narrative import serves as a way to mask the specific reality of the neighbourhood while simultaneously transforming it.

\section{Making Urban Interventions Cultural Interventions}

In the 1970s, when the middle and upper classes left the city centre and the area was labelled derelict and blighted by São Paulo's government, at both state and city levels, many different approaches were developed to solve what was considered to be a problem, with solutions varying according to how the issue was framed. We believe, like Weber (2002), that choosing to frame the changes through terms such as obsolescence or blight, like the authorities often did, is a way of building discursive practices that tend to benefit private capital. This occurs not only because it depreciates the value of an area by maximizing a possible rent gap and justifying the transformation projects that those discursive practices themselves tend to produce. The denial of the value of the current uses that are in place takes a back seat to the promotion of ideas that those uses should be replaced by other uses considered more legitimate (Weber 2002).

Since this discourse is biased, it is impossible to dissociate the redevelopment discourse it produces from that same bias. What that mixture usually produces is an investment, often public, that aims to substitute an existing population for another with a higher income (Weber 2002) - a process that is commonly understood as gentrification. This is why, when we refer to a redevelopment plan or a revitalization plan in this chapter, we will be understanding it as a state or private project that has gentrification as its goal, as many such plans were designed to revitalize the centre of São Paulo since the 1970s (Kara-José 2007).

São Paulo's urbanists have been borrowing ideas from their counterparts in the Global North since the beginning of its urbanization, trying to mirror first European, then North American cities, following a trend that could be 
traced back to the country's historical situation, first as a colony then as a dependent economy (Maricato 2000). In the 1970s and 1980s the Bologna Plan was very influential in the way Brazilian urbanists and governments thought about city centres, or at least the part of it that focused on historic heritage preservation, with the idea of maintaining the existing population being mostly left out. The idea of urban revitalization as a strategy of economic development, in partnership with the private sector, became influential in the 1980 s and was mainly borrowed from US examples, such as the Quincy Market and Baltimore Inner Harbour transformations, that emphasized real estate opportunities (Kara-José 2007).

Otília Arantes (2015), while writing about an international trend to locate cultural facilities at the centre of revitalization plans in the nineties, highlights their supposed role in distinguishing spaces and attracting a target audience to an area to promote a gentrification process. The idea of cultural centre revitalization spread internationally, reaching local administrations in many countries and becoming the new vogue. When the trend reached São Paulo, the presence of a cultural elements in revitalization plans for the city centre was so ubiquitous that Kara-José (2007) coined the term "urban-cultural interventions" to describe the dynamic. In those projects both the investment in culture and culture itself are presented as apolitical and beneficial to society as a whole, generally hiding any disputes around urban policy, their beneficiaries, and those who are hurt by them.

The thinking was that urban-cultural interventions would serve as a way to attract the "right audience," filtering the public through their interest or possibility to access the new cultural spaces created, and would justify steps such as forced residential relocations through the legitimacy of art and culture and the perception of their universal benefit. The rise of urbancultural interventions is linked with the fact that, in a context of increased competition for the attraction of international capital and people, creating a culturally-active neighbourhood is a key aspect of urban and institutional marketing for local administrations (Kara-José 2007). It is further worth pointing out that, although there are similarities between the Brazilian phenomenon and its forerunners in the Global North, the dynamics of state intervention and the possibility of property value appreciation are quite different in Latin America as a whole (Betancur 2014; Contreras and Venegas 2017).

Arantes (2015) locates the roots of culture's centrality in urban planning in the movements that rejected the modernist tendency to a totalizing planification. According to her, those movements gradually altered their contents from their embodied, critical potential to a fragmentary model of 
planning that favours certain spaces within the city. These spaces tended to transform urban space into a picturesque set for target audiences. The lack of continuity between those progressive and the social practices that would give their shape substance were combined with their appropriation in the marketing of local administrations. As result, "the resistance ideal of those dissidents was transformed, with no violence, into platitudes" (Arantes 2015: 98).

One interesting example of this fragmentation in São Paulo are the $O p$ erações Urbanas (Urban Operations) that allow the municipality to design special urban regulations and financing mechanisms for a circumscribed area to attract private investment. The Operação Urbana Centro (Central Urban Operation), established in 1997, had an important role in the changes in our studied area. In the city, the fragmentary nature of some intervention initiatives, which were part of an urban planning model that allowed the government to pick a given space and transform it in an atomized manner (Arantes 2015), was combined with a tendency to aestheticize urban life. This was enacted in requalified urban spaces that try to combine culture and publicity (Kara-José 2007) in a process in which the city is at the same time the display and the commodity to be sold. In Arantes' (2015) words:

the publicity apotheosis of the commodity form, finally universalized, resulted in the reduction of the city's architecture to an imagetic simulation, composed of shifting sings that contain in themselves contradictory information, overlapping, contaminations, etc [...] (98)

In the cases studied by Kara-José (2007) the focus was on the way those scenarios were built by the state, which financed the construction and restoration of historic buildings and cultural facilities and created scenic spaces that were differentiated from their surroundings. What our research in República shows is a coordination of private agents that do something similar, with the use of an industrial aesthetic in the new cafés and restaurants in the area. The same aesthetic is also present in the studios' display units, creating a visual continuity between them with a comparable scenic effect. But this is not merely a visual strategy. Rather, the situation involves appropriating the ideas that permeated the rise of the industrial aesthetic.

The industrial aesthetic rose to prominence in the 197os. It first appeared in old manufacturing spaces in New York which were converted to residential use and work spaces, mainly by artists, who transformed them into live-in studios. But, as Sharon Zukin puts it "around 1970, as the bare, polished wood floors, exposed red brick walls, and cast iron facades of this 'artists' quarters' 
gained increased public notice, the economic and aesthetic virtues of loft living' were transformed into bourgeois chic" (Zukin 1982:2). Loft living soon became a trend, expanding across national borders and reaching cities that did not necessarily have those same manufacturing spaces to convert. The rise of live-in lofts was linked to the loss of space that the manufacturing and industrial activities experienced in some cities, so it is important to understand this process as part of an economic shift.

It is also important to remember that the prestige artists and their studios were acquiring, helped increase the value of their lofts and their neighbourhoods. Some gained by being close to those spaces, or living in them, as they increased in attraction to a greater number of people. Despite being a common narrative, the idea that this was a spontaneous change driven by artists who were then followed by the market might be naïve and may have cemented the perception of artists as main agents of urban renewal. Here it is important to note that the success of the loft conversions was linked to both an urban renewal strategy devised by the State and investments made by developers in those areas. The discourse that the presence of artists drove the renewal masked the forces shaping the change (Zukin 1982).

Still, the loft conversions in New York circulated widely as a model, along with the perception of the artists' transformative role in the renewal process. As lofts in different neighbourhoods in cities around the world were converted, one particular neighbourhood seems to have been entrenched in people's imagination: SoHo. In the case of São Paulo, this particular neighbourhood serves as a reference in plans for urban transformation for both government and private agents.

\section{From the Heart of the Metropolis to the Abandonment of the Centre}

The city of São Paulo has an estimated population of 12 million people distributed over an area of $1.521,11 \mathrm{~km}^{2}$. It is the most populous city in Brazil and has an annual budget larger than that of most states in the country (IBGE, n.d.). Founded in 1554, the city began its most intense cycle of development after World War II, due to the combination of industrialization, population growth, and territorial expansion, and it was at that time that the core of the city began expanding southwest (Rossetto 2002).

The same combination that produced intense development also created the need for housing that, due to strong inequalities and legal constraints in the renting market, implemented in 1942, had to be met via home ownership. For the growing population of lower income people that the city both 
attracted and produced, this mostly meant building their own houses in distant peripheries without basic services such as running water or sanitation. For the wealthier part of the population, it meant either buying one of the newly-built apartments in República or a plot of land on which to build a house. And for the new in-between class that the economic grow th had produced, this created the quitinete.

In the 1940s and 1950s, a time with no housing finance mechanism and in which the possibility of renting was hindered, the quitinete was a way to create an affordable option for a growing middle class to whom the city centre meant easy access not only to their jobs, but also to a host of goods and services that would become part of a new way of life. The intensive use of the plots of land by the quitinete developments made living in the area more affordable, due to the division of land costs by a greater number of homeowners, and the size of the apartment itself made it possible for some homeowners to pay for them even though there was no financing systems set up for the housing market (Rosetto 2002).

The quitinete consisted of a small open floor apartment, having only the bathroom as a separated space, and got its name from the kitchen appliance that was common in those space-limited dwellings. Living in such small spaces was only possible due to the great number of new services around them, with many buildings having restaurants, cafes, and laundries on their ground floors (Rossetto 2002). Those apartments, however, carried a certain stigma, and were considered a place unsuitable for families and linked to what was then considered inappropriate behaviours, ranging from prostitution to the cohabitation of unmarried couples (Ferreira 2016). But although the apartments themselves carried that stigma, the district of República, where most of them were located, concentrated a great number of office jobs and a large part of the new leisure activities that were increasingly popular.

At that time the city centre exerted a symbolic appeal so intense over the population that it led Richard Morse to say, in 1954, that the people of São Paulo were "under the hypnotic spell of the heart of the metropolis, with its excitement, lights, and grandeur" (Morse 1970: 375). An advertisement for Copan, an apartment complex in República that included many quitinetes, published in May 25 of 1952, also builds on a similar idea by promising to "give the people of São Paulo the central dwelling they haven't even imagined in their dreams, and yet it's here, magnificent, full of comfort, not a step away from everything, but itself the heart of a centre with its own life" (BNI 1952). The heart of the metropolis, however, was not a fixed point, and it had been moving southwest from Sé, where the urbanization had started, 
to República. The same advertising elaborates this idea in an interesting way in the section dedicated to store owners who might be interested in renting the shops on the ground floor, saying: "Reserve your store now, in the place that will soon be the fine centre of the metropolis, that once more will move, like what happened in 1934, when the city crossed the Chá overpass" (BNI 1952).

This moving heart kept moving southwest until the new fine centre overlapped with Copan, but it did not stop there, and government investments in new areas moved it further along in the 1960 s and 1970 . The rise of the new centralities away from the city centre coincided with changes in urban infrastructure that deteriorated conditions of walkability, as the city's heavy investment in a car-centred model transformed the centre with new flyovers and parking spaces. At a time in which automobiles emerged as the focus of both the urban agenda and the middle and upper class way of life, the city centre had become more of a node in the city's road layout than a place to go for this part of the population. Having this radial model also meant that those who used public transport usually had to go through the centre before reaching their destination, which made the area a suitable location for commerce that catered to the same population as the public transport, and helped to consolidate its new profile in the 1970s.

While the middle classes left the centre and its quitinetes in the $1970 \mathrm{~s}$ and 1980 os a new population moved in. Although it is clear there was a net population loss overall in the centre, we can also say there was a population substitution. Part of the idea, so popular in the media at the time, that the area was empty and needed to be revitalized had to do with the perception of the newcomers. By that time the quitinetes were already prohibited from being built, since they were incompatible with a law passed in 1957 that fixed the intensity of use of land plots, but the old ones were still there, and their small size, combined with the depreciation of prices in the centre, made them a viable option for the poor population of São Paul that wanted a centrally-located dwelling (Kalichman 2019).

Weber argues, while discussing the origins of the idea of blight and its racist undertones, that "the scientific basis for blight drew attention to the physical bodies inhabiting the city, as well as the unhygienic sanitary conditions those bodies 'created'" (Weber 2007:526). This also seems to be true for the idea that drove São Paulo's revitalization plans since the 1970s, and makes particular sense when we consider the perceptions surrounding the quitinetes - apartments that were inhabited mostly by the poor after the centre's supposed decay. 


\section{Building Downtown}

With 24 storeys and 310 apartments, the development of Downtown República represented a big shift in the urban landscape of the district following its completion in 2018. Its blue glass exterior towers above República Square, where a metro station and busy bus stops share space with street prostitution, just across the avenue from a new rooftop restaurant. The development is one of seven buildings of Setin Developments' "Downtown" segment, which focuses on high-density buildings, consisting mainly of studio apartments with shared facilities such as laundry rooms and entertaining areas.

The idea of a "downtown" does not make geographical sense when thinking about São Paulo and the term is not commonly used, with the wording in English itself already indicating an imported idea. Still, all buildings from the Downtown segment seem to be integrated into a broader network in the area that is constructed both visually and through discourse, and that includes businesses and new residential developments in a cohesive narrative, with each one of those similar spaces being a node in a network that is strengthened with each addition. As this mesh develops, the idea of República as some kind of "downtown" is further consolidated, with the overlapping of this import weaving itself into the area's perception and materiality.

The district of República came first in the ranking of new residential units launched in 2014 and 2015 (Secovi 2016), which was a result of the ebb of a Brazilian real estate boom that had been happening between 2007 and 2013 (Rufino 2017). República served as a last frontier of this expansion, only being explored after other districts showed signs of saturation. During this process the price per square metre of the apartments in the area increased significantly, reaching prices equivalent to those in São Paulo's richer neighbourhoods (Carmagnani 2019).

Antonio Setin, developer and owner of the company that bears his name and launched the Downtown segment, attributes the recent change in the area to the shortage of possibilities in other parts of the city:

The centre's recovery happened in spite of the developers, politicians, and the market. It was the lack of outorga onerosa available for purchase in most neighbourhoods of São Paulo that brought the developers back. It helped me to make a decision. (Setin 2017)

Outorga onerosa is a form of building permit that allows its buyer to go above the set floor area ratio, with the municipal government selling a 
limited stock of them per area in the city. Setin states that the lack of it is what drove investments back into the area in spite of governmental efforts, but it is important to note that the reason why the centre still has outorga onerosas is Operação Urbana Centro. The fact that it took the operation twenty years to attract its target audience, however, might be explained by the lack of outorga onerosa in the rest of the city that drove developers there.

Setin's statement above, given to a website focused on the centre of São Paulo, sounds quite different to what he declared to Folha de São Paulo, a newspaper controlled by a family who historically owned land in the centre, which may explain why the paper is frequently publishing articles about the area's supposed revitalization. In an article about how "compact and versatile apartments" were in demand in São Paulo the developer declared: "I don't sell apartments, I sell the best sandwich in town, the best nightclubs and the Mario de Andrade Library" (Setin 2016). His statement enumerates different attractions of the city centre to promote his developments, which reinforces the idea, present in the quitinete era, that the area around the apartments is what makes them a good option. When talking to the general public, Setin's message seems to be that he sells location and experience rather than apartments. But Setin is not the only developer to invest in the area, with a number of companies, big and small, building in República.

In this chapter we concentrated on the information collected on five large real estate developments launched between 2014 and 2018, all of them consisting mainly of studio apartments and located in the western side of República, where a lot of the real estate activity is concentrated. However, it is important to note that there are other developments being built in the area and its surroundings. What is particularly interesting is that although these developments are built by different companies their appearance is quite uniform, drawing heavily from the industrial aesthetic when it comes to their decoration.

In 2018 Brazilian Home Vogue said that "it seems that the industrial style won't go away this season, not if it depends on São Paulo's restaurants and cafés" (Jacob 2018). Although the magazine was referring to a wider trend in the city, the observation is particularly true for the studied area, where both the new businesses and residential developments frequently resort to a style that, according to another Home Vogue article "fits very well into integrated dining rooms and gives any home a modern look" (Vogue 2018). The fact that the industrial aesthetic is being heavily used in a district that has been mostly residential and commercial can be explained by the 
magazine, which states that in spite of its historical origins in the conversion of lofts "today the style can be applied in brand new environments" (Vogue 2018). This perception has already been incorporated by the market, which has made a host of mock industrial materials available, such as fake burnt cement and exposed brick finishes.

Many of those materials were present in the developments we visited and in their display units. The most common features we observed were exposed piping, exposed lamp bulbs, and the use of finishes that resembled burnt cement. Interesting bike imagery appeared in decorations, and bicycles were also present in the display units as part of the depiction of the projected lifestyle of the prospective owner. One of the developments even had a bicycle in the lobby that was fully painted in yellow and stripped of its gears, highlighting its purely decorative function.

The resemblance between the developments was so strong that two of them, from different developers, had the same poster that said "WE NOT ME." The use of the poster, one of them in a display apartment and the other in a promotional rendering, is one example of the use of English language in the decoration and of the emphasis on an idea of togetherness and sharing that, as we will see, is quite common in the narrative about the centre. The incorporation of graffiti was also quite common, matching a wider trend in the area, and the way developers absorbed an expression that had transgressive roots reminds of Arantes' (2015) quote about the absorption of transgressive ideas in urban planning by governmental publicity.

If the visual elements present at the studios already suggested a connection to the lofts of SoHo through the use of an industrial aesthetic, this becomes fully explicit in a publicity e-book made by Setin Developments to introduce their studios to the market. The guide, which highlights the benefits of buying a studio and tries to differentiate them from the quitinetes, says: "You should understand that the concept of the studio is developed based on the north American lofts, that convert industrial or commercial spaces to residential ones" (Setin Developments 2018).

The advertisement of this supposedly new product in the centre requires the advertisement of the accompanying lifestyle, with two different developers producing web video series to do so. One of the web series, fully sponsored by one company, has episodes dealing with themes such as street art and its importance within city activist movements; the benefits of sharing culture, in which a tourist rents an apartment that seems to belong to the developers through a sharing platform; and street parties, that are shown as a part of the solution to prejudice and segregation in the city (Gafisa n.d.). The other 


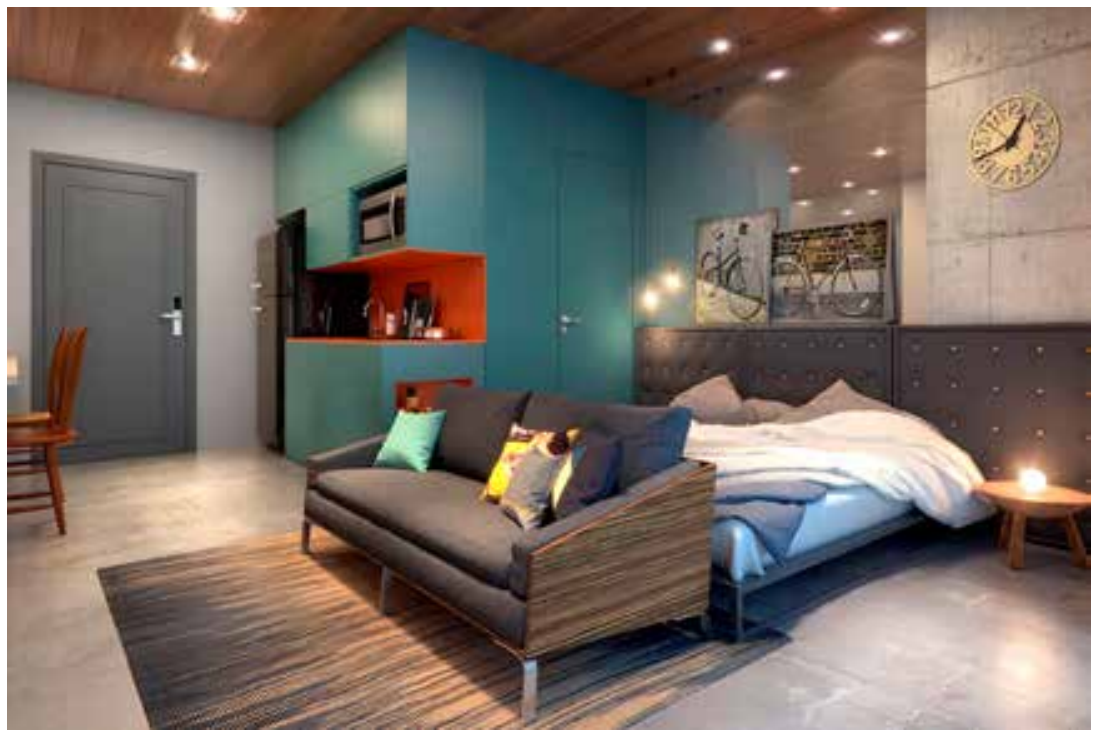

Figure 5.2: Rendering of a bedroom in BK30. Source: developer's website.

web series is produced by a consulting group that specializes in the centre, with different sponsors dictating different themes for each episode. One episode is sponsored by a developer focused on the part of República where it had its most recent property launch, presenting the place as interesting and diverse (A Vida no Centro, n.d.).

Both series present a seemingly progressive view of the city and its transformation, but offer very atomized solutions, such as fighting prejudice with street parties. It is worth pointing out that those web series are incorporating elements of urban activism into a less traditional form of publicity, blurring the lines between them while doing so and assimilating - and possibly neutralizing - their subversive potential in the process. The line between content creation, publicity, and urban activism is often blurred when it comes to the conversation about urban transformations. This is an important point to highlight in the context of the centre's fabricated narrative of renewal. In Arantes' (2015) words "the tale of the 'rediscovered city' seems to mobilize a very up to date conceptual apparatus, barely hiding in its alleged subversion an aestheticizing coexistence with the most extreme forms of contemporaneous alienation" (2015: 97).

The documentary ARTE | TERRRITÓRIO(Art Territory), with the subtitle 'Back to the Centre of São Paulo', produced by RedBull Station, a cultural centre owned by the brand, employs a similar strategy, while focusing on 
the role of art, and artists, in a back-to-the-city movement. It starts with a voiceover of Felipe Morozini, a visual artist, saying:

What we see today in São Paulo, and anywhere in the world, is art occupying the city centre, specially the streets. I can clearly see the amount of spaces inaugurated in the last few, 10, 15 years: galleries, art spaces, cultural centres, and completely different from one another. (Redbull Station 2016)

Morosini's statement, which reflects the documentary's overall view, portrays the back-to-the-city movement led by artists as an echo of international events that reverberate in different forms according to the way they are understood locally. Here, the people interviewed interpret the transformation in São Paulo as a spontaneous movement made by a group of artists that appreciate the centre's "cosmopolitan and rich city experience" (Redbull Station 2016) as Fernanda Brenner, interviewed by the documentary, puts it.

Another example of the use of this narrative was made by Heineken. In 2018, the brand released Heineken Block, which according to an interview given by the brand's marketing director is part of the Cities platform, a global marketing strategy "by the beer company that aims to inspire the consumers to unlock the secrets of their cities and transform urban space in a positive way" (Castellón 2018). The Brazilian website for the campaign shows a video with no dialogue that is used in all countries in which the brand advertises the campaign. Although it has the mandatory "drink in moderation" warning in Portuguese, the video clearly takes place in New York, as established by many visual cues. The video shows three friends leaving a closing bar in an empty industrial street and finding a garage for rent, that they then turn into a bar. Two similar open shots are shown in the beginning and the end of the advertisement, with the first showing how the area was empty and the second how "alive" it became after the bar opening. What is more, this new bar features many of the decorative elements that we see in the Western part of República, such as string lights and neon signs.

The New York narrative of renewal is present here again, although this time the reference is more specifically to Brooklyn. The text below the video, preceded by the title in English "the city is your canvas," states:

Heineken believes that simple ideas can transform a city. NY, London, and Berlin with its Block Parties are proof of that, showing that the people are responsible for change anywhere. Inspired by the transformative vibes Heineken brings in Heineken Block to SP [São Paulo], a party that 
will unblock a surreal place in the greatest capital in Brazil and foster through music, art, and gastronomy a collaborative experience, in which you'll take to the streets and show that São Paulo is yours, is mine, is everyone's. (Heineken n.d.)

The idea of the city as a canvas - the artist's tabula rasa - obscures the political and economic contents that come from issues that go beyond the reach of the creative power of these transformative vibes, and in the same way that the urban-cultural interventions those market strategies disguise trends themselves as transformations that would be beneficial to everyone.

Interestingly Heineken's global strategy is carefully linked to each city in which it invests, framing the city as both platform and product. This incorporates São Paulo into a common narrative about urban transformation that is created with the Global North as the reference point. Two things are worth noticing here. First, the new global scale of marketing and cultural production (Harvey 1992) that allows Heineken to use the same advertisement in many different countries is precisely one of the elements that enables the target audience in São Paulo to recognize the imported meaning and reference of the industrial aesthetic in República. Second, the inclusion of São Paulo in a common global narrative about urban change obscures the city's specificities by importing assumptions that are not rooted in its reality.

The way New York is used as an example is part of a larger trend. The transformations in SoHo in particular are so entrenched in the popular imagination as a success story about how art and culture can revitalize a neighbourhood that they were explicitly cited as a goal by one state official interviewed by Kara-José (2007) about Monumenta Luz, an urbancultural intervention sponsored by the Inter-American Development Bank that started in 1999, in an area of República much more precarious than the one analyzed in this chapter. The interviewee, who represented the state-level government in the elaboration of the plan, suggested that the housing within the project perimeter should be "aimed towards a public that consumes culture, that has the purchasing power to do so, that can appreciate living near it" (Kara-José 2007: 250). According to her, this public would be comprised of "cultural producers, people connected with cultural activities, designers and artists, a sort of SoHo, thinking out loud, in the longer term and having solved the safety issue" (Kara-José 2007: 250). A point to highlight is that "pensando alto," the original phrasing, can be translated both as thinking out loud or as aiming higher. One translation posits SoHo as an example, while the other sees Soho as an ambitious goal. 
In both translations, however, SoHo emerges as paradigmatic and is used to think about and plan state interventions.

An interesting example of this was the seminar "SoHo Effect - Experience exchange and public policies as an antidote to gentrification" that took place at an event organized by Brazil's Ministry of Culture in 2018. According to the event's website 'SoHo Effect' is the term used to refer to artist-led gentrification, since the neighbourhood was the most famous example of this phenomenon" (MinC 2018). The use of SoHo's image in this case is particularly interesting because it is being used in an event about the exchange of ideas in public policy, organized by the government at the national level. This reveals the full extent to which the gentrification of SoHo has colonized imaginaries of urban transformation.

It is further worth noting how the event website describes artists, stating that they are "placemakers by instinct: when artists group together in an area they inject energy, build social networks, business networks and contribute to the neighbourhood's vibrance and distinction" (MinC 2018). Significantly, the English word "placemakers" was used in the original text, and we frequently found English being used throughout the examples studied in our research, whether in publicity material, state projects, or home decoration. The transposition of ideas without translation mirrors a broader tendency in the import of those ideas to Brazil, and sheds light on the limitations of a strategy that tries to merge two urban contexts as different as São Paulo and New York.

The idea of new bars and restaurants helping to "revitalize" the city, as shown in the Heineken's publicity, is also prevalent in São Paulo's media, with features titled "The guide to the restaurants and bars of Santa Cecília's new scene," that helps the reader navigate the new places that supposedly drove the change in the neighbourhood that borders República. Another example is "Gastronomic attractions revitalize the centre in the region between República square and Amaral Gurgel Terminal," which is precisely the area we are focused on. This last example represents the use of media to highlight the new businesses that are supposedly changing the area and ran in Folha de São Paulo, the newspaper that printed the Setin interview.

What is interesting is how those bars and restaurants resemble both the studios and accompanying publicity explored here, with elements borrowed from industrial aesthetics such as burnt cement and exposed brick and other details, such as string lights, chalkboard signs with elaborate lettering and posters in English, so one can feel a certain continuity between those spaces. This continuity, that helps to establish a network of spaces referencing an urban transformation that took place elsewhere, creates a sort of simulation 


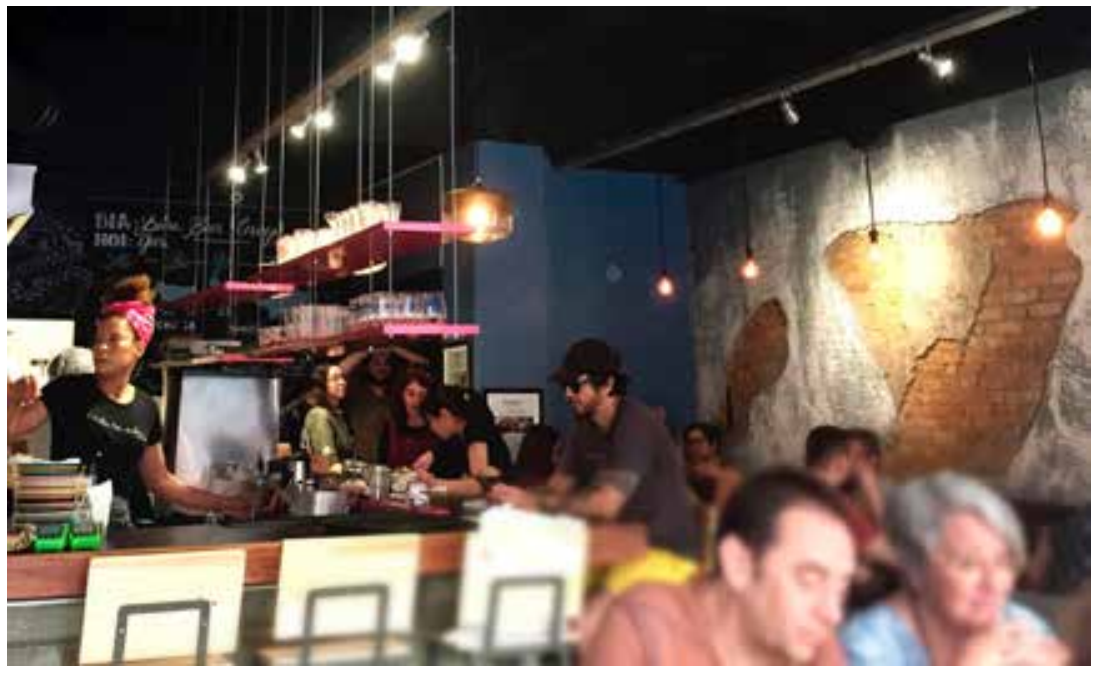

Figure 5.3: Bia Hoi Restaurant, one of many businesses within República featuring an industrial décor. Source: the authors.

of the original place, but is unable to generate the same process in São Paulo. The most famous gentrification processes that originated the term took place in the Global North and were closely linked to particular political, economic, and social dynamics specific to those countries (Betancur 2014). Those dynamics are completely different in Brazil and Latin America (Betancur 2014; Contreras and Venegas 2017), yet there is an underlining similarity in their aesthetics.

Furthermore it is important to point out how the current narrative about the urban change taking place in República is in great part a fabrication, produced by a host of agents that, through the import of a narrative, try to promote their products. More than that, we want to stress how fragile this construction is, given the current situation in República. First, even though São Paulo occupies a privileged position as a financial centre in Latin America (Betancur 2014; Santos 2011) this does not mean that the city has the social structure that would allow for a traditional gentrification process to occur (Betancur 2014). Second, the level of precariousness in city centres in Latin America is far higher than in the cities of the Global North which originated the theory and narratives about gentrification in general, including those of SoHo (Contreras and Venegas 2017). In the specific case of República, the high levels of homelessness and tenements concentrated in the area (Otero, Harkot, and Santoro 2019) need to be considered, keeping in mind that these vulnerabilities are deepened by the economic crisis that widens from 2015 . 


\section{Conclusion}

Whereas the middle and upper classes, along with private investments, moved progressively Southwest after the 1970s and 1980s, today there is a flowback to the area, if not by this part of the population at least from private investment. That is not to say that a gentrification process will necessarily take place in República, and a careful analysis taking into account the area's specificities will need to be conducted in a few years to measure the change. What our research showed is the strong presence of the industrial aesthetic in the area which we understood as being an echo of the gentrification process that took place in SoHo. This is not to say, of course, that all of those who mobilize those industrial elements do so with an explicit reference to SoHo or are trying to leverage a transformation like the one that neighbourhood went through. However, what our research shows is that the images that have spread in São Paulo carry with them traces of SoHo's context and origins, even if superimposed with other layers of meaning. Their instrumentalization is intentional, and is part of an attempt to increase real estate prices in the area through an emulation of gentrification that tries to foster the very process it imitates.

\section{Note}

All translations from Portuguese to English in this chapter were made by the authors.

\section{Works Cited}

A Vida no Centro (n.d.) "A Vida no Centro." Retrieved from: https://www.youtube. com/channel/UCxh2PIOJJBCiCsRQ9UI5iww/featured (accessed 2 June 2020). Arantes, Otília Beatriz Fiori (2015) O "cultural turn" no discurso sobre a cidade. Campinas, São Paulo: RUA, 5: 89-99.

Arantes, Pedro (2007) Interesse público, poderes privados e práticas discursivas na política de renovação do Centro de São Paulo. São Paulo: Instituto Polis.

Betancur, John (2014) "Gentrification in Latin America: Overview and Critical Analysis." Urban Studies Research 2014: 14.

BNI (1952) "Um monumento a grandeza paulistana e ao conforto de sua gente." Folha de São Paulo, 25 May, 12-13. 
Carmagnani, Maria (2019) Retornando ao centro: a nova produção imobiliária no distrito da República. Master's dissertation. São Paulo: Faculdade de Arquitetura e Urbanismo, Universidade de São Paulo

Castellón, Lena (2018) “Heineken Block Projeto de verão da Heineken abre com atrações como Emicida." Clube de Criação, 2 February.

Contreras, Yasna and Vladimir Venegas (2016) Perspectiva teórica del concepto de "gentrificación" y su abordaje en Latinoamérica. Em: Cambios socioespaciales en las ciudades latinoamericanas: ¿procesos de gentrificación? Universidad Externado de Colombia, 19-34.

Ferreira, Luiza Sassi Afffonso (2016) A rua "renovada" transformações urbanas, habitação e cotidiano na rua Paim. Master's dissertation. São Paulo: Faculdade de Arquitetura e Urbanismo, Universidade de São Paulo

Gafisa (n.d.) "Cidade-se.” Retrieved from: https://www.youtube.com/watch?v=IByyC_ tjX48\&list=PLbmRrbONCXCw6PoWSLu7k76ygEaFK939F (accessed 2 June 2020).

Harvey, David (1992) A condição pós-moderna, trans. by Adail Sobral e Maria Gonçalves. São Paulo: Loyola.

Heineken (n.d.) “HEINEKEN BLOCK \#SHAPEYOURCITY.” Retrieved from: https:// www.heineken.com/br/block (accessed 15June 2020).

IBGE (n.d.) “Panorama do município de São Paulo.” Retrieved from: https://cidades. ibge.gov.br/brasil/sp/sao-paulo/panorama (accessed 2 June 2020).

Jacob, Paulo (2018) “1o cozinhas com pias pretas," Casa Vogue, 8 July. Retrieved from: https://casavogue.globo.com/Interiores/Ambientes/noticia/2018/o7/10cozinhas-com-pias-pretas.html (accessed 5 June 2020).

Kalichman, Beatriz (2019) Vendendo studios no centro das quitinetes: o caso da República pensado a partir da gentrifijicação e a gentrifijicação pensada a partir do caso da República. Master's dissertation. Rio de Janeiro: Instituto de Planejamento Urbano e Regional, Universidade Federal do Rio de Janeiro

Kara-José, Beatriz (2007) Políticas culturais enegócios urbanos: a instrumentalização da cultura na revalorização do centro de São Paulo (1975-200o). São Paulo: Annablume.

Maricato, Ermínia (200o) “As ideias fora do lugar, e o lugar fora das ideias." In Arantes, Otília Beatriz Fiori, Vainer, Carlos and Maricato, Ermínia, A cidade do pensamento único. Desmanchando consensos. Petrópolis, Vozes: Coleção Zero à esquerda.

MinC (2018) “Mercado das Indústrias Criativas no Brasil." Retrieved from: http:// micbr.cultura.gov.br/evento/SoHo-effect-intercambio-de-experiencias-epoliticas-publicas-como-antidotos-a-gentrificacao (accessed 2 June 2020).

Morse, Richard (1970) Formação histórica de São Paulo. São Paulo: Difel.

Nakano, Kazuo, Candido M. Campos, and Raquel Rolnik (2003) "Dinâmicas dos sub-espaços da área central de São Paulo." In Caminhos para o centro: Estratégias de desenvolvimento para a área central do município de São Paulo. São Paulo: Emurb/Cebrap/CEM. 
Redbull Station (2016) “ARTE | TERRRITÓRIO.” Retrieved from: https://www.redbull. com/br-pt/arte-territ\% $\mathrm{C}_{3} \% \mathrm{~B}_{3}$ rio-artistas-ocupam-o-centro-de-s\% $\mathrm{C}_{3} \% \mathrm{~A}_{3} \mathrm{O}$ (accessed 2 June 2020).

Rossetto, Rossella (2002) Produção imobiliária e tipologias residenciais modernas: São Paulo - 1945/1964. São Paulo: Tese de doutorado, FAUUSP.

Rufino, Beatriz (2017) "Financeirização do Imobiliário e transformações na produção do espaço: especificidades da reprodução do capital e expansão recente na metrópole paulistana." In Álvaro Ferreira, João Rua, and Regina Célia de Mattos, Metropolização do espaço, cotidiano e ação. Rio de Janeiro: Consequência, 213-240.

Santos, Milton (2011) “São Paulo, metrópole global do terceiro mundo." Revista do Departamento de Geografia, São Paulo 7: 7-24.

Secovi SP - Sindicato das Empresas de Compra, Venda, Locação, e Administração de Imóveis e dos Condomínios Residências e Comerciais de São Paulo (2016) Balanço do Mercado Imobiliário 2015. São Paulo.

Setin Developments (n.d.) Tamanho é documento! Retrieved from: https://blog. setin.com.br/download-checklist-8-principais-razoes-para-optar-pela-comprade-um-studio (accessed 15 June 2020).

Setin, Antonio (2016) "Compactos versáteis estão entre os imóveis mais procurados." Folha de São Paulo, 28 August, 6.

Setin, Antonio (2017) "Antonio Setin: o centro melhorou, mas ainda falta uma revolução." Interview with Denise Bococcina, A Vida no Centro. São Paulo, 21 August.

Vogue (2018) "10 salas de jantar com decoração industrial." Vogue, 11 January. Retrieved from: https://casavogue.globo.com/Interiores/Ambientes/ noticia/2018/o1/10-salas-de-jantar-com-decoracao-industrial.html (accessed 5 June 2020).

Weber, Rachel (2002) "Extracting Value from the City: Neoliberalism and Urban Redevelopment." Antipode 34: 519-540.

Zukin, Sharon (1982) Loft living: cultural and capital in urban change. New Brunswick: Rutgers University Press.

\section{About the Authors}

Beatriz Kalichman is an associate researcher at Observatório das Metrópoles (Metropolitan Observatory) in São Paulo. She has a BA in Public Policy Management and a Master's Degree in Urban and Regional Planning. Her research interests centre on the circulation of ideas in public policy, focusing on the power dynamics that orient this process. 
Beatriz Rufino is a lecturer at the Department of Urban Planning at University of São Paulo. Her research concentrates on housing policies, urban planning and policies, and real-estate dynamics. Within debates about financialization and neoliberalism, she is interested in understanding the transformations of metropolitan spaces in Brazil and Latin America. 


\section{Part 2}

Anxiety and Visibility 



\title{
6. Race, Authenticity, and the Gentrified Aesthetics of Belonging in Washington, D.C.
}

\author{
Brandi Thompson Summers
}

\begin{abstract}
This chapter tracks the contemporary convergence of hipster aesthetics with a Black cultural space that results in the aesthetic re-coding of a popular gentrified Washington, D.C. commercial corridor as a diverse neighbourhood. I examine representations of blackness and diversity and analyze how they are deployed in the pursuit of authenticity in the gentrified city. Authenticity has become an instrument through which people attach meaning to things and experiences rather than people. I argue that the tension between the polar class/race lifestyles spur attraction from young, upper-income white residents and tourists to the area. Ultimately, blackness in the marketplace must be that which sells, and that which can be easily transacted by proprietors of capital.
\end{abstract}

Keywords: Washington, D.C., blackness, diversity, gentrification

In 2013, anticipating its forthcoming store on H Street, in northeast Washington, D.C., Whole Foods Market's Mid-Atlantic regional president, Scott Allshouse, spoke of the synergies between the Whole Foods brand and the rapidly gentrifying commercial corridor. He specifically highlighted H Street's demographics as representing what Whole Foods values: "That neighborhood reflects a lot of what Whole Foods is about - diversity, passion for food, history. Things like that. That's what we are too. We are so in tune with that. That sense of community and pride" (O'Connell 2013). A press release from the same year announcing the new store also references the corridor's diversity as an attribute and implies that diverse communities 
with diverse, cultural opportunities can benefit both old and new residents, thus establishing diversity as a desirable commodity and aesthetic. The press release states:

The H Street Corridor is a thriving hub of diversity and cultural richnessa perfect match for Whole Foods Market's goal to support each and every community we're in...Whether you're a long-time resident or new to this neighborhood, we are proud to have the opportunity to join you and help write the next page of history. Being among the flourishing food scene, culture offerings of the arts district and the exciting mix of residents will make Whole Foods Market a great partner to those in the community.

Whole Foods uses "diversity" presumably to signal a multicultural, multi-racial neighbourhood, as a way to accrue value for both the Whole Foods brand and the H Street corridor's brand. The irony of the Whole Foods claim on diversity, culture, community, and history is its leadership by proclaimed libertarian CEO, John Mackey. While the Whole Foods brand is often associated with progressive politics and "socially minded commerce" due to its adoption of spiritual, sustainable, and countercultural practices, Mackey has spoken openly about his commitment to advance individual freedom without regard for social equality (Davis 2017). It is this kind of "diversity" in appearance that actually encourages neoliberal exploitation. As Shannon Winnubst explains, neoliberal social rationalities spawned language of multiculturalism, and "its even more aestheticized child, diversity, in the late 199os as the new, preferred vocabulary for social difference" (Winnubst 2015: 3). "Diversity" and "development" are buzzwords that allay fears about displacement and inequality. Yet, while the diversity project was aligned with social justice, the two ideas are sometimes presented as synonymous, if not interchangeable.

Changes to the commercial landscape of $\mathrm{H}$ Street resemble other contemporary "revitalized" urban spaces that can be paradoxically described by the concurrent celebration of diversity and the increasing separation and isolation of different social groups. This shift can be explained, in part, by the infiltration of diversity discourses and by practices of aestheticization that work to naturalize lifestyle and landscape tastes as well as concretize neighbourhood forms and cultural difference. The H Street commercial corridor was known for many years as a Black-business downtown district that provided numerous retail options and public spaces for Black residents that were central to economic and social life. The area is now seen and aesthetically valued by local and national media, and local politicians, as a diverse space for corporate interests. 
Recognized as one of three Black commercial districts devastated by the April 1968 uprisings that erupted largely in response to the assassination of Reverend Dr. Martin Luther King, Jr., the H Street NE corridor was named USA Today's top "up and coming" neighbourhood as well as one of Forbes magazine's "Hippest Hipster" destinations in 2011. In 2014, the New York Times describes the H Street, NE corridor as "increasingly mixed, racially and economically, as row houses within a block or two of the corridor undergo upscale renovations, property values rise and ethnic restaurants and fashionable pubs proliferate" (Meyer 2014). Yet in the not too recent past it was a predominantly low-income, Black neighbourhood. Linked to these designations has been a gradual demographic shift in the area's population. According to the US Census, the Black population in the $\mathrm{H}$ Street neighbourhood has been falling since 1990, when African Americans made up nearly 77 percent of the population. Black residents dropped from 73 percent in 2000 to 45.2 percent in 2010 , while the white population has jumped from 22.4 percent in 2000 to 47.7 percent in 2010. Now, the location of the $\mathrm{H}$ Street corridor is recognized as a particularly attractive space for commercial and residential development because of its proximity to Union Station and because it is within commuting distance from Penn Quarter, Downtown, and other popular neighbourhoods.

The history of $\mathrm{H}$ Street tells the story of a Black space that underwent significant challenges to achieve the political and economic infrastructure that enabled it to thrive. The area did not suffer from lack of attention or a commitment of funds, but a lack of sustainable options, due to racialized systems of dispossession, to support the people who lived, worked, and shopped there. In the years following the 1968 uprisings, the H Street NE corridor went through a significant period of disinvestment and neglect by the state that was a continuation of the economic decline precipitated by urban renewal and white flight. As a result, the area was deemed a blighted, unwelcoming ghetto, teeming with transient people who did not care about their own condition or the conditions of their environment. Although the downfall of the H Street corridor was due to several factors, negative renderings of blackness in the media prevented the restoration of $\mathrm{H}$ Street as a renewed Black retail space.

In recent years, community organizations and government agencies have put significant effort into the rebuilding and rebranding of $\mathrm{H}$ Street as diverse. Now divided into three districts: Urban Living, Central Retail, and Arts and Entertainment Districts, $\mathrm{H}$ Street is sprinkled with restaurants selling the trappings of a global village: Belgian mussels, Taiwanese ramen noodles, Lebanese falafels, German ales, Ethiopian injera, plus countless 
hipster bars, coffee shops, and bakeries. Patrons strolling along the street are also met by large, graphic signposts detailing a distinctly multicultural history of the corridor. On H Street you can partake in the pleasures of visible and edible ethnicity as a form of aestheticized difference - a politics that are provisional, variable, and a distinct move away from the homogeneous and monolithic. This popular Washington, D.C. neighbourhood is among several others that have undergone significant social, cultural, and economic changes that privilege newer, affluent, white residents and tourists coming to the region in droves, thus contributing to Washington's designation as the most intensely gentrified city in the United States, as more than 20,000 residents were displaced from the city between $2000-2013$ as a result of a meteoric rise in home values, increased investment, and new amenities added to lower-income, traditionally Black communities (Richardson, Mitchell, and Franco 2019).

Revitalization efforts in Washington have led to the introduction of urban amenities and cultural alcoves that attract a different class of customers and tourists; those interested in improvements to lifestyle (bike lanes, farmer's markets) as opposed to equitable social and economic opportunities. This distinction between presumed Black and white interests also highlights struggles over entitlement between the new crop of residents, who have considerable education and access to resources and have invested their time and energy into the remodelling of the area, versus the old guard, who experienced the neighbourhood's most challenging periods when they lacked adequate financial support from the government and other entities.

In what follows, I examine representations of blackness and diversity and analyze how they are deployed in the pursuit of authenticity in the gentrified city. A vital component of understanding how blackness figures into the "revitalization" of the H Street corridor is how culture and authenticity work as instruments of urban development. Given the prominence of culture as a key resource for post-industrial cities to attract tourists and residents, several have implemented strategies to promote urban branding. Racialized expressions are more marketable in the emerging "creative city" that emphasizes cultural consumption and creative, aesthetic practices. Creating authenticity is an integral process to the socio-spatial organization of gentrifying cities. Several scholars have addressed the role authenticity plays in the making of spaces, especially the role of power in integrating exclusionary practices (Jackson, 2005; Pattillo, 2007; Zukin, 2008; BrownSaracino, 2009). Authenticity inherently involves value and how people value a particular place. Furthermore, authenticity structures a sense of 
belonging by producing, protecting, and celebrating spatial narratives. Mobility is a privilege that is attached to whiteness, so it is those that possess whiteness who are more likely to call a neighbourhood authentic or boast its "authentic" qualities as desirable.

Authenticity has become an instrument through which people attach meaning to things and experiences rather than people - hence the proliferation of boutiques, craft breweries, and cafés alongside the practice of branding neighbourhoods in terms of distinctive cultural identities. While displacement, through a loss of access to affordable goods and services, is certainly taking place on $\mathrm{H}$ Street, I argue that it is this exact encounter between the polar class/race lifestyles between long-time Black residents and new white newcomers that spur attraction from young, upper-income white residents and tourists to the area. At the same time, one can be stern or exhibit anger over the changes (as aesthetic, not critique), as long as the fundamental power relations of society, founded on broad appeal to white buyers remain intact. In other words, new residents can express their discontent over aesthetic shifts in the built environment as a matter of taste, rather than acknowledging the violence experienced by marginalized populations as a result of the changes. Therefore, blackness in the marketplace must be that which sells, and that which can be easily transacted by proprietors of capital. Ultimately, I track the contemporary convergence of hipster aesthetics with a Black cultural space that results in the aesthetic re-coding of the neighbourhood as a diverse commercial corridor.

\section{Representing the Real: Black Aesthetic Emplacement}

Over time, "diversity" has developed incredible linguistic power. This is especially relevant within the context of Whole Foods Market expanding and opening a store on $\mathrm{H}$ Street, and as mentioned above, evoking the language of diversity. The term "diversity," Gabriella Modan points out, "has maintained its veneer of concern for social justice, but picked up new meanings associated with hipness, as it's used in new contexts that have nothing to do with inclusion, power sharing, or social justice" (Modan 2012: 190). This façade of interest in social justice, and the depoliticization of diversity, has become a popular rallying cry and organizing principle for emerging businesses that cater to customers who are interested in lifestyle amenities like yoga studios, organic foods, fair-trade coffee, etc., buttressed by a commodified ethical mode of consumption. These businesses, which appear in some of the most contested spaces where the poor and marginalized lived for years 
without access to basic services, purport to support global initiatives that improve the lives of the most vulnerable populations.

Whole Foods Market was founded in 1980 and grew from being a small, natural foods store based in Austin, Texas to become the country's largest organic food store and seventh-largest grocery store chain (Davis 2017). Colloquially known as "whole paycheck" for their high prices and reputation for catering to a young, upper-middle class population, Whole Foods thrives on being more than just a grocery store, but a mission-driven, lifestyle chain that emphasizes its "responsibility to co-create a world where each of us, our communities and our planet can flourish" (Whole Foods n.d.). Furthermore, the chain states its purpose is to improve access to healthy food for underserved neighbourhoods, despite little evidence demonstrating success of this claim.

The H Street Whole Foods Market finally opened on May 15, 2017 - a brandnew 40,00o square-foot store on the ground floor of a luxury residential building named "Apollo." The building was named after the Apollo Theatre, which originally opened in 1913 and was located in the same area as the new Apollo building. The theatre closed in 1955 and the land was later sold to Ourisman Chevrolet. It later became the site of Murry's grocery store and H Street Storage. The H Street location was the third Whole Foods Market within Washington D.C.'s city limits, and sixth in the D.C.-metro area. Although Whole Foods is a global brand, each store features aesthetic elements that reflect the neighbourhood they occupy, thus making their customers feel like they are in a local market.

A few months after the store's grand opening, I walked in to look around. It appeared to be like any other Whole Foods Market in terms of its layout, selection, and ambiance. A couple of aisles down from the organic produce section, next to the non-dairy milk products, was an immaculately organized, colour-coded display of gourmet chocolates. Above the multi-tiered tower was the phrase "Chocolate City" featured prominently in white block letters foregrounding a dark brown backdrop. Above the sign was a generic city skyline, resembling paper cut-outs, dipped in various hues of chocolate brown. The "Chocolate City" name was adopted by Black Washingtonians' as a sense of pride in the face of the horrifying political and economic conditions they faced in the mid-20 ${ }^{\text {th }}$ century. While the "Chocolate City" label originally referred to Washington, D.C., the music group Parliament's 1975 song of the same name opened up the designation to include cities like Newark, Gary, and Los Angeles where Blacks became a large population once white residents fled to the suburbs. In light of this popular and recognizable history, it became immediately clear that the "Chocolate City" sign at Whole 
Foods doubly authenticated remnants of the waning Black culture that had been prominent in the neighbourhood and aestheticized the meaning of blackness in this first majority-Black metropolis. This display deploys what I call black aesthetic emplacement, a mode of representing blackness in urban capitalist simulacra, which exposes how blackness accrues a value that is not necessarily extended to Black people and how social and political histories are casually decontextualized in the service of capital.

Instances of black aesthetic emplacement oftentimes share the same space with aesthetics of diversity, evoked by markers of "history." The "Chocolate City" tower was physically positioned alongside common aesthetic markers of a gentrifying landscape. At the new store, three colourful posters hang on the interior windows depicting abstract images of $\mathrm{H}$ Street, with phrases like "History \& Legacy," "Culture \& Arts," and "Heritage \& Tradition" emblazoned on them. The organization of images on the posters resembles a quilt. Small thumbnail pictures displaying scissors, presumably representing the many Black-owned barber and beauty shops that historically lined the corridor, a coffee cup, music notes, an admission ticket to the local Apollo Theatre, and other symbols that evoke history, community, continuity, and a rich culture. The posters also have pictures of H Street's historic Victorianstyle buildings, and in one of the images is the representation of the newly refurbished streetcar. These posters show a combination of the historic and contemporary; subtle and overt references to racialized objects, people, and locations; a seamless blend of the two evoke notions of authenticity as welcoming, accessible, diverse, and cool for white purveyors. The images are positioned so that shoppers will see them as they enter and leave, no matter which route they take (to the parking garage below ground or at street level).

After a few weeks, the management team at the H Street Whole Foods received significant backlash after images of their very own "Chocolate City" went viral on social media. As a result, "Chocolate City" became "Confectioner's Corner," with a brand-new tan and white colour scheme. Even though "Chocolate City" only lasted a couple of weeks, displays like these shed additional light on why the movement of white residents into Black neighbourhoods generates tension and feelings of exclusion (Boyd 2008; Hyra 2017; Lees 2008; Lees, et. al. 2008). The presence of these racial aesthetics disrupts narratives commonly associated with gentrification; namely displacement. With black aesthetic emplacement and aesthetic markers of diversity prominently on display, ready for immediate consumption, "revitalization," "renewal," and "redevelopment" enact violence upon those who lived and toiled around the neighbourhood in previous years, despite the euphemistic characterizations (Smith 1996; Kern 2016). 
The Whole Foods Market press release and the "Chocolate City" display exemplify how authenticity and diversity are mapped upon the space. They work together to invite attention, shape how the space should be seen, and attract commerce, while at the same time, evoking language of community and belonging. At Whole Foods Market, authenticity is a hyperreality, one that does not reflect a prior social reality, but a new one constructed from models or ideas about "the real" and "authentic" (Baudrillard 1994, 1998). Blackness is still a large part of this formulation, but it is in examples like these that we see blackness similarly aestheticized and depoliticized.

To think about why there is a push for diversity, it is also important to consider what diversity is actively working against. Historically, various turns to diversity have been brought about in reaction to conservative, nationalist, nativist movements in support of the "white majority." Diversity was touted as a liberal remedy to explicit forms of discrimination. It inherently avoids engagement with structural racism, sexism and economic inequalities (Berrey 2015). What makes the push for diversity an integral part of the neoliberal shift is its commodification and emphasis on individualism. Evoking diversity brings about social and economic rewards, primarily for white people. The Whole Foods Market ethos is a perfect reflection of that as they emphasize diversity, but also entrepreneurialism that is especially espoused by CEO Mackey, whose libertarian views speak to his advocacy of neoliberal principles in the running of the business.

\section{Authentic Abstractions of Race}

Questions of authenticity and cultural appropriation have become popular and contentious topics in the academy and in popular media, especially with the rapid growth of new media technologies in the digital age. Debates about the performance of Black style, dance, speech, and fashion call into question the value of blackness when produced for commercial consumption. Similarly, multiple studies provide ethnographic and statistical evidence of predominantly white gentrifiers having the political clout and racial privilege to reallocate resources and repair the infrastructure of ailing cities (Davis 1992; Smith 1996; Florida 2002; Brown-Saracino 2004; Lees, et al. 2008; Zukin 2010). Gentrifiers attempt to tidy up urban space by removing its residents and completing the task that urban renewal of the 1950s, 196os, and 1970s started. Similarly, with the displacement of long-time Black residents, gentrifiers occupy urban spaces to reap the benefits of a constructed urban 
life that involves selective reflections of nostalgia, cosmetic grit, and lifestyle amenities, all the while overlooking those who were displaced.

We saw from the example above that the aesthetics of stylistic diversity and black aesthetic emplacement work together within transitioning spaces to make them more approachable, appealing, and consumable. On H Street, the form of authenticity that is enacted through consumption does not necessarily follow the pattern of ethnic enclaves or districts, like your typical urban, American Chinatowns, Greektowns, or Koreatowns. Instead, it is a place that is distinctly multicultural; not privileging one race, culture, or ethnicity over another. Authenticity here is abstract, it is a representation of a desired social reality. The cosmetic grittiness and danger that Derek Hyra (2017) argues is vital to neighbourhoods that have adopted Black branding strategies, only operates at a surface level; residents and visitors do want to feel safe. The desire for authenticity is about the look, but not the feel of a particular neighbourhood. Urban should not look suburban but can feel suburban in its visual representation of safety (i.e., walkable, adequate lighting, welcoming consumer spaces, and other examples of new urbanism).

Authenticity shows up in various ways on $\mathrm{H}$ Street, specifically through a diversity aesthetic that has been mapped upon the neighbourhood and the city's blackness. Drawing on the history and revival of the Apollo building on $\mathrm{H}$ Street speaks to a desire for authenticity and purposeful iconographic drift. For example, the Apollo Theatre on H Street was simply a movie house from the early twentieth century that was pulled out of history and drifted to the contemporary imaginations of developers represented by words and images. This purposeful adoption, or drift, of mundane historical structures becomes a significant part of the work developers use to attract attention and investment. It also reflects the interest of "social homesteaders," gentrifiers who want to maintain a piece of the past as representing the social or cultural heyday of the neighbourhood, which usually involves negotiation over what spaces, structures, and people have value (Brown-Saracino 2004). Taking control of the narrative of this place privileges a certain history and erases others. Producing these kinds of nostalgic memories and histories gets represented in different ways. From the naming of the building after the Apollo Theatre, to the iconic and recognizable images on posters in Whole Foods Market; these are ways to "honour" history and tradition but also make people feel like they are connected to the space and its history. But the adoption of certain histories is selective. No one wanted to name the building after the car dealership it became after the Apollo was demolished, nor the storage facility that inhabited the space before the residential building was 
erected. Instead, authenticity ends up being a performance, and a chosen lifestyle, as well as an instrument of displacement (Zukin 2010).

Authenticity might be tied to history, but whose history? The quest for authenticity reflects a nostalgic longing for a constructed history that serves the present by presenting a particular version of the past. Ultimately, while some scholars argue that it is the desire for an authentic postindustrial aesthetic that draws in residents and tourists, and helps shape the development of gentrifying neighbourhoods, I am also saying that contestations over the meaning of authenticity in urban spaces both complement and supplement black aesthetic emplacement and cultural diversity by emphasizing origins as style.

Claims on the authentic also expose and empower whiteness to determine what and who fits. Cities are able to evoke authentic narratives of place if they effectively "create the experience of origins. This is done by preserving historic buildings and districts, encouraging the development of small-scale boutiques and cafés, and branding neighborhoods in terms of distinctive cultural identities" (Zukin 2010: 3 ). This occurs with the preservation of historic structures and districts that lead to the proliferation of new or revised places and spaces and the adoption of certain narratives of layered history. One of the ultimate ways to claim space and organize narratives is through (re)naming. For example, a December 2017 story from the local NPR station discussed the naming of new greenspace, organized by the area's growing number of dog owners, in the NoMA neighborhood (North of Massachusetts Avenue), adjacent to the H Street corridor. In order to name the park, the NoMa Parks Foundation encouraged public comment and then a vote. According to the president of the foundation, the name Swampoodle "won by a landslide" (Schweitzer 2017). Swampoodle was the name of the neighbourhood surrounding H Street mostly inhabited by immigrant Irish families who settled in Washington, D.C. following the famine of the 1840 s and 1850 s, and who also helped erect the Capitol. The neighbourhood was later destroyed with the construction of Union Station in 1907.

Local interest in recognizing a neighbourhood's true Irish origins effectively reconfigures the space to be devoid of the blackness that characterized the area in recent memory. Focusing on the neighbourhood being previously inhabited by Irish immigrants who sought refuge after the potato famine of the mid-1 $9^{\text {th }}$ century, and who built the Capitol, makes invisible the slaves and freedmen that also toiled alongside them. Saying that the Irish workers built the Capitol ties them to the land. It justifies their lingering presence. This form of past-making re-centres whiteness by marking territory. By 


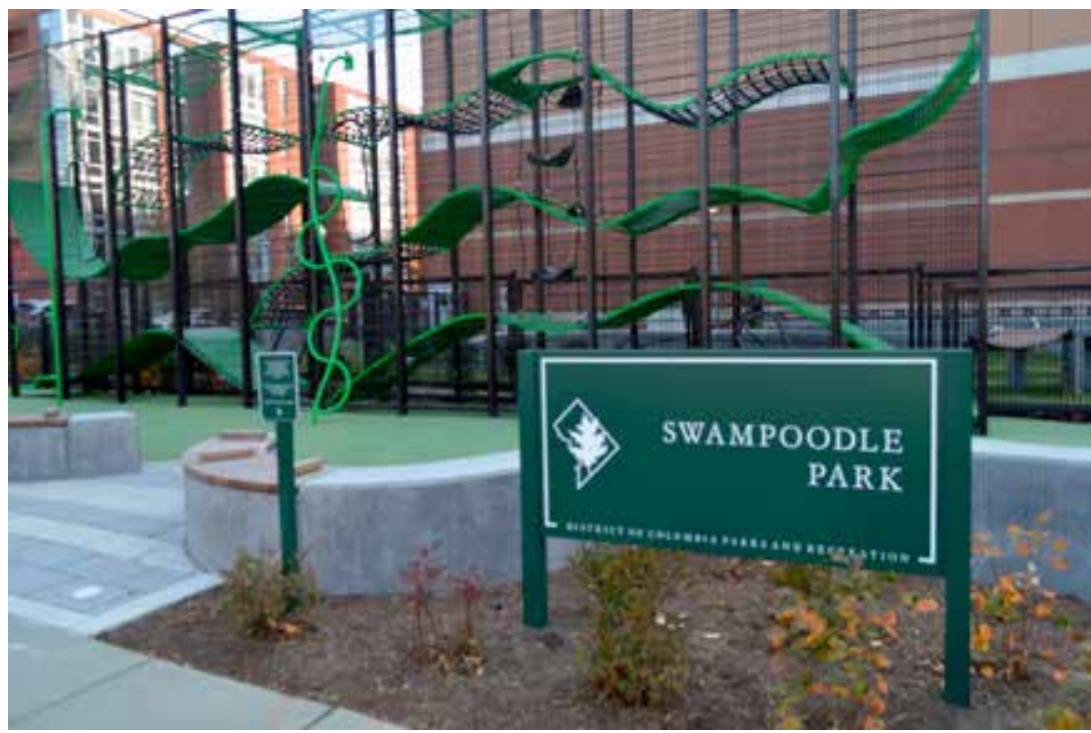

Figure 6.1: Swampoodle Dog Park and Kids Playground on $3^{\text {rd }}$ and $L$ Street, three blocks from the $H$ Street Corridor. Photograph by the author.

engaging in an active erasure of the space's more recent history, going back to a time before Black people "destroyed" the neighbourhood during the "riots," the park can take on a nostalgic meaning and drive decisions about how the space can be developed moving forward. Introducing blackness to the area brings up far too many memories of violence, oppression, and practices of inequality.

The whiteness of Swampoodle's Irish immigrants tells a different and more pleasing story. Whiteness not only represents the norm, but is also unthreatening, despite characterizations of the neighbourhood being "rough." Therefore, it is important to not only recognize the production and presence of blackness in these urban spaces, as the landscape shifts, it is instructive to notice the ways that whiteness (as ethnicity) appears aesthetically, in this case through naming, to encourage (or substantiate) the presence of more white people. For authenticity is an instrument of power (Zukin 2010: 3). The naming of Swampoodle Park should be considered within the context of the changes occurring in and around the area. There's nothing alarming about the naming of public space after an ethnic group that inhabited the area in the $19^{\text {th }}$ century, but again, the context under which NoMa and $\mathrm{H}$ Street are changing adds a different meaning. The naming dictates how the space should be remembered in case its history is overshadowed by contested events and populations. 


\section{Hipster Economics and the Aesthetic Politics of Belonging}

In a May 2014 piece on the Al Jazeera website, Sarah Kendzior lamented the encroachment of "hipster economics" on America's urban landscapes. She defines hipster economics by the practice of urban decay becoming "a set piece to be remodeled or romanticized" (Kendzior 2014). Kendzior argues that gentrifying hipsters view poverty through the lens of aesthetics and therefore concentrate on aesthetics rather than people since "people, to them, are aesthetics." If people are aestheticized, so are class relations, which are systematically "depoliticized and reduced to questions of lifestyle choices, consumption patterns, visual pleasures and 'good taste"' (Pow 2009: 373). The process of gentrification exposes how public spaces become privatized by white, middle-class interests, and the transformation of urban space demarcates the boundaries of who belongs and who does not.

John Jackson invokes Lefebvre's concept of qualified spaces that are unclaimed by market forces in his discussion of the privatization of public space. He says that privatization "is not solely about how spaces symbolize (as Black or white, rich or poor); it is also a rehearsal of social belonging tethered to people's everyday practices and senses of self. To look out onto one's public sphere and see what was another abandoned storefront (open space for all, especially the least successful) alchemized into a gourmet bakery for a growing middle class, is a different order of displacement entirely, a kind of psychological and semiotic displacement from the sites of one's own, formerly less-fettered, everyday pedestrianism" (Jackson 2005: 55). With the introduction of yoga studios, bicycle shops, hookah bars, tiny art galleries and vintage/antique furniture stores, on $\mathrm{H}$ Street, fewer and fewer shops speak to, serve, and reflect the everyday needs of the poor and working-class. Although Zukin et al. suggest that boutique businesses arrive in gentrifying urban space as part of an emerging market that institutionalizes the consumption practices of more affluent and educated individuals, Jackson makes a much more nuanced argument about the privatization of public space and how public spaces obtain private, personal, and political meaning for residents, especially long-term residents who are gradually leaving the neighbourhood (Zukin et al. 2009). Not only is physical displacement taking place as small businesses that were patronized by poor and working-class residents leave the corridor, but the affective dimensions of gentrification and displacement structure who belongs in the space and who does not. Nevertheless, it is in these spaces that market-driven consumption is depoliticized in favour of the aesthetics of "cool" - and where the streets become "little more than 
public playground for the authenticities monopolized by middle-class consumerism" (Jackson 2005: 55).

Around the same time Kendzior published her piece, Destination DC, the official tourism and destination marketing organization for D.C., unveiled their newest marketing campaign: "DC Cool." In a 2017 interview with me, Elliott Ferguson, Destination DC's President and Chief Executive Officer explained that the "cool" brand that Destination D.C. adopted purposefully reflected how recognizably "cool" D.C. has become, and it gave the organization an opportunity to "promote and expose [tourists] to things out of the three M's: monuments, memorials, and museums, because that does not always resonate as a sexy reason why people want to travel." Destination DC is an economic development organization that focuses solely on the $\$ 7$ billion hospitality industry. It is their primary role to attract visitors to the District and promote the city as a primary convention destination. The "DC Cool" campaign reflects the organization and the city's desire to not only advertise D.C.'s "cool people" and cultural diversity, but also its "sports, theatre, nightlife, retail, arts, restaurant scene, and outdoor activities."

What the campaign does not highlight are those changes to the cultural makeup and commercial landscape of "declining" districts that have undergone significant transformation in order to make way for the gentrifying hipsters Kendzior bemoans. What commercial districts like H Street are experiencing are a disappearing mode of social and cultural life in favour of an emerging retail ecology, or commercial gentrification, that features "new establishments with particular goods and services - such as clothing boutiques, art galleries, cafes, restaurants, and bars - that open to satisfy the needs of middle-class gentrifers," and displace long-time, established business, and people (Ocejo 2011: 285). One example is the April 2017 off-market sale of Smokey's Barbershop to the $11^{\text {th }}$ Property Group. The barbershop had been on $13^{\text {th }}$ and $\mathrm{H}$ Street since 1999. The building was sold to the $11^{\text {th }}$ Property group to make way for a mixed-use development, thereby reflecting an ongoing trend on $\mathrm{H}$ Street where small, Black-owned businesses are being replaced by developer-driven, mixed-use projects. On the same block, at the former site of the R.L. Christian Library, the Insight Property Group (who also developed the Apollo project discussed above) plans to construct a mixed-use that is a "100\% affordable project" with all 33 units being "a combination of $50 \%$ [area median income] and $30 \%$ units" (Bannister 2018). Although the units will be "affordable," Insight plans to bring similar retail options to the location as they did to the Apollo building.

The changing landscape of the corridor is reflected when projects like these become the norm. That the new buildings are being constructed on 
the site of a Black-owned barbershop and a public library speaks volumes: the end of local public services and a transition to a new economy that privileges exclusive commerce, gentrified culture, and consumption. These changes not only impact the commercial makeup of the space, but also its aesthetic geography.

\section{Consuming Diversity}

Culture and race in the age of neoliberalism affectively shape how we see, feel, and taste diversity, blackness, and authenticity. The aesthetic elements of neoliberalism make diversity a perfect rejoinder, especially in terms of the goods we can consume directly. Sociologists, geographers, and other social scientists have written at length about the role of consumerism, consumption, capital, and changing political economies of cities (Baudrillard 1998; Brown-Saracino 2009; Florida 2002; Hannigan 1998; Hyra 2017; Lees, et. al. 2008; Ley 1996, 2017; Zukin 1995, 2010). What undergirds much of these changes is the way that gentrification represents a phase in urban development in which consumption, aesthetics, and taste has led to an "imagineering of an alternative urbanism to suburbanization" in global cities (Ley 1996: 15).

Richard Florida describes approaches for remaking urban spaces as U.S. and Canadian cities introduced urban planning practices that targeted the addition of a "creative workforce" (Florida 2002). His theory about the "rise of the creative class" posits that a "new" upwardly mobile class will work and reside in places that have strong creative and arts industries, as well as racial/ethnic diversity, café culture, art districts, unique architecture, and a strong and vibrant nightlife. While Florida has been hired to consult with American and Canadian city planners in their rebranding efforts, his neoliberal approach to urban design and planning focuses on the creativity of individual "entrepreneurs" and absolves the government of responsibilities to support wage-earners in an economic environment "that increasingly privileges self-employed freelance labor" (Banet-Weiser 2012: 109).

In D.C., former Mayor Adrian Fenty's vision to buttress the city's growing creative economy resulted in the development of the "Creative DC Action Agenda," which his administration introduced in order to "support creative employment and business opportunities, to promote revitalization and enlivening of underserved areas through arts and creative uses" (D.C. Office of Planning). The discourse of "creativity" works in alignment with "diversity" and provides a charming backdrop for cultural consumption. 
Some narratives reinforce local discourses on shopping and dining that frame the consumer as an independent and active agent. These discourses, Arlene Dávila (2012) argues, "further a romanticized view of consumption and consumption sites as democratic spaces that are open to everyone, whether one comes to shop, browse, or hang out" (24). Adopting this view only hampers an investigation of the "existing social inequalities that are actively reproduced in these spaces" (Dávila 2012: 24).

H Street, like many post-industrial, urban commercial corridors, operates as a "space of consumption" (Zukin 2010). The role of commercial entrepreneurs is tied to the development of $\mathrm{H}$ Street privileging consumption in three meaningful ways. First, store owners represent the interests of a cultural community that operates in direct contrast with long-time residents. We see this with the explosion and expansion of boutique businesses that cater to an upper-class clientele, actively displacing stores that offer retail and services to long-term, lower class residents. Second, retailers (as well as developers and investors) enter the consumption space in search of economic opportunity. In the public imagination, everyday people are thought to be the agents of change. However, within revitalizing spaces that are considered ripe for economic opportunity, developers and investors work alongside business owners to enact change. Larger-scale development projects whose ground floors are occupied by custom coffee houses, craft-based retail, and high-priced restaurants, dictate the changing landscape, leading to the final way H Street privileges consumption: retailers act as social entrepreneurs as they establish social spaces that invite new residents and tourists, while alienating long-time residents and visitors (Zukin 2010: 19-20). In this way, spaces of consumption also draw on representations of authenticity in order to fulfil the needs of new residents, thereby enabling them "not so innocently - to stake their own claim to the neighborhood" (Zukin 2008: 734). On H Street, this was a gradual process. Disinvestment, urban renewal, and construction of the streetcar tracks, all contributed to the downfall of the corridor's commercial infrastructure that had supported the needs of its working-class, predominantly Black population.

Within this commercial space, consumption, authenticity, and aesthetics work together. Contemporary discourses of "healthy, clean, and sustainable living" help drive consumption of food products and patronage of certain stores, like Whole Foods, and places, like farmer's markets. These discourses are reinforced by an ethical mode of consumption that is commodified and marketed as responsible. How do these tastes become indoctrinated? Following the tradition of Pierre Bourdieu, the tastes become part of the culture; a structural phenomenon that has temporal and geographical 
consequences. The aesthetic itself may change across time and space, but the benefactors do not change much, especially along racial lines. That said, blackness is rarely something that reflects high culture or taste. In a modernized space, blackness can accompany or be used as a side dish, but is not usually the main course. Consumption is important, but what exactly is being consumed in these spaces? Quite obviously we can look at food as one element that is being consumed, but it is not just the food, it is also the experience. Even restaurants that feature cuisine from various parts of the world have adopted a diverse and eclectic way to incorporate various cultures onto one menu.

Within these neoliberal spaces of consumption, no longer are we interested in contained cultural spaces that have businesses that either cater to or represent a particular ethnic group, instead we seek diversity within one location, alongside the increasingly common, seemingly universal establishments that sell raw juice blends, cupcakes, coffee, and pet grooming services. As a space of diversity, the neighbourhood brings to life ideal diverse and creative public spaces to produce individuality, creativity, difference, and social interaction. But Black people fear improvements to Black spaces because the shift will invite others to take over. The conundrum of making the space more desirable is that others will discover it and want to take over, like in other neighbourhoods and cities.

\section{Conclusion: Festival, Foundations, and Revelry}

Each year in mid-September, H Street hosts its annual, one-day street festival. The street is closed to automobile traffic from the beginning of the corridor at $4^{\text {th }}$ Street through the $14^{\text {th }}$ Street. Held for nearly fifteen years, it is one of the largest events in the city and is a huge tourist draw. Over 250 booths line the corridor, filled with regional food vendors, local and regional artisans, non-profit organizations, and business merchants. The street is always crowded. Lines wind around the food trucks and food stands as local restaurants display their most popular fares. Bodies spill outside of the designated borders of pop-up cocktail and beer gardens. Tents are erected to advertise the campaigns of local politicians. Vintage cars act as artistic canvases - intricately designed and painted. Dozens of photographers wander the streets. Impromptu dance parties break out as local bands perform covers of both classic and new hip-hop and pop songs. Culture and cuisine are on display as thousands of people pack the streets (Figure 6.2). The festival is an apt representation of a "cosmopolitan canopy" 
that Elijah Anderson describes as a self-contained, social, exceptional space where people interact easily and "appreciate" diversity. The festival reflects a moment in time when a diverse collection of people of different races, cultures, and classes exist in the same social space (Anderson 2012). Festivals like these are supposed to represent the best of the neighbourhood or city. That is why they are exceptional; not a true reflection of the everyday or quotidian. People are often enthralled by these displays of diversity and camaraderie. The scene makes people feel good and safe. There is something desirable and inviting about diversity in this way.

Festivals have become an increasingly relevant component of the tourism industry. They encourage growth in economic activity, even during economic downturns. They are helpful in not only increasing economic growth, but also helpful in establishing neighbourhood identity and growing local tourism. They are part of the cultural economy, which is based on the production and consumption of cultural symbols like food, tourism, and art, and the spaces in which they are consumed (restaurants, galleries, offices, and the street). The annual festival on $\mathrm{H}$ Street firmly establishes the street as the ideal consumption space mentioned above - one that focuses on producing gentrified spaces for residents and visitors to socialize and hang out, but one that also caters to a particular lifestyle that actively reinvents the space.

H Street Festival was originally conceived as a form of social preservation. Over time, the meaning and intentions shifted to accommodate interests in economic growth opportunities. In the 1980s, when the H Street Festival first appeared, residents and local business owners hoped to focus on the neighbourhood's cultural heritage and economic independence in the face of state efforts to disinvest (various forms of political mobilization, racial/ cultural awareness, and demands for social justice and fair/equitable conditions in the face of urban decline). Organizing a celebratory event became increasingly important in the aftermath of the uprisings that precipitated a downward spiral of $\mathrm{H}$ Street's physical and economic conditions. At the time, the corridor was overwhelmingly Black and full of Black and some Asian small business owners, most of whom were able to take advantage of the crumbling economic infrastructure in the 1980 s and 199os.

Today, the H Street Festival is a visual smorgasbord of colour, culture, art, cuisine. It displays whimsy, joy, celebration, diversity. According to the festival website, the event has successfully helped commercial building vacancy precipitously drop from 75 percent to 5 percent by using "arts as an engine for the growth for the historic neighborhood." The festival is an opportunity to show off what is new along the corridor, but also a way to attract more residents and customers. The event generates a marked 


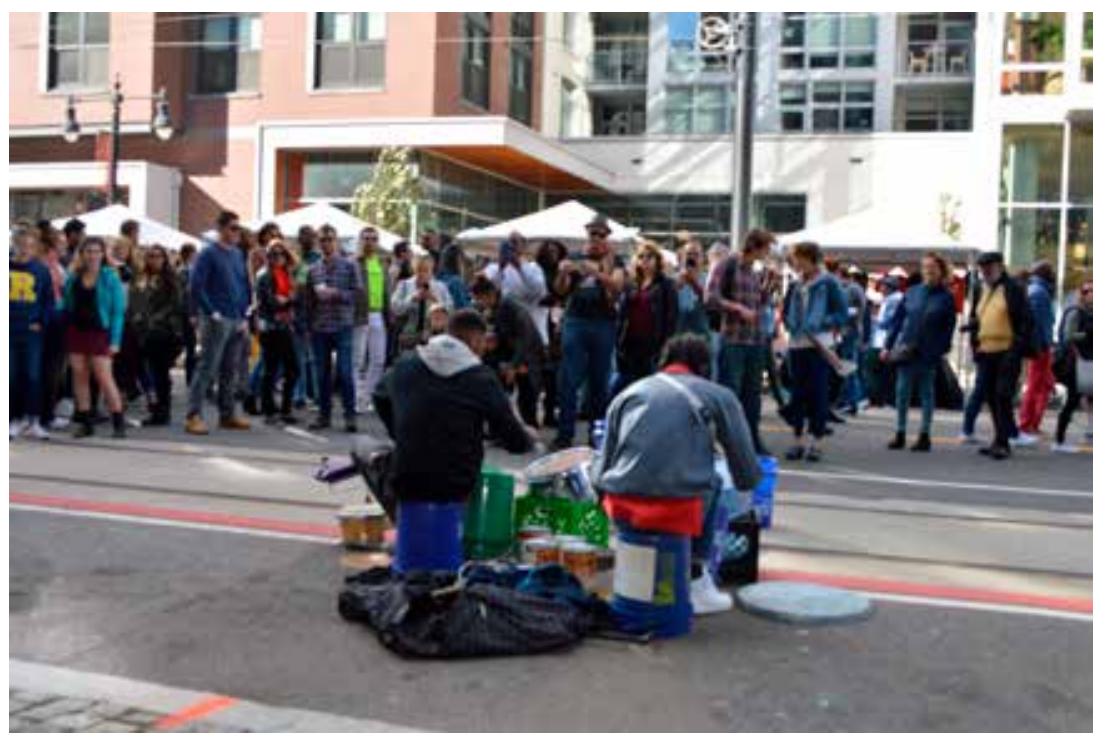

Figure 6.2: Festival and revelry on $\mathrm{H}$ Street. Onlookers watch street performers at the $\mathrm{H}$ Street Festival. Photograph by the author.

increase in applications for leases and interest in residences, hence the popularity of buildings like the Apollo. In this way, the festival puts culture on display in order to generate capital along the corridor. Nevertheless, while the festival helps draw in large, culturally and economically diverse crowds, the group of people who get to stay and live is much less diverse. For example, thirty-five of Apollo's residential units are designated as affordable. This means that tenants may only earn up to $5^{\circ}$ percent of the Area's Median Income (AMI). For this building, the figure the D.C. Department of Housing and Community Development (DHCD) used is $\$ 108,600$ for a family of four. As of 2017 , studio apartments started at $\$ 1800$, while the affordable units can be rented for $\$ 808$, only if the tenant makes less than $\$ 38$,o1o per year. Affordable housing offered at market rate is still expensive to some poor and working-class families as the AMI continues to shift upward.

The festival allows various actors and stakeholders to organize ways for the space to be seen, thereby establishing a clear relationship between economics and culture as being constitutive in developing urban spaces. Their desired view of the space combines history, celebration, growth, and diversity. What is significant about how we think and talk about diversity today is that while most people experience diversity in terms of race, they talk about it in terms of difference in exhaustive ways. As a discursive 
project, it is unable to address inequality, privilege, and power, especially when framed in terms of cultural consumption (Bell and Hartmann 2007).

With each passing year, the $\mathrm{H}$ Street Festival becomes more and more popular, with crowds packing onto the streets awaiting musical performances, tasting gourmet and carnival foods, and buying trinkets and clothing from the eclectic collection of street vendors. The festival represents a culmination of the diversity elements that draw traffic into the neighbourhood. It is this constructed multicultural urbanity that relies on a depoliticized ethnic cool that decontextualizes the history of the space.

As I have shown in this chapter, the role of diversity on H Street, and, in other areas, the push for diversity is ironically supposed to be a postracial (race neutral) project, but it is saturated with and structured by race. To produce $\mathrm{H}$ Street as a space of diversity requires an elaborate collection of bodies, social forces, and processes that rationalize the presentation of issues within particular contexts. Within this space, blackness, as distinct and a central component of diversity, becomes an aesthetic tool that can be reflected in and extracted from architecture, public space, and text.

\section{Note}

This chapter is adapted from Black in Place: The Spatial Aesthetics of Race in a Post-Chocolate City by Brandi Thompson Summers. Copyright (@) 2019 by the University of North Carolina Press. Used with permission of the publisher.

\section{Works Cited}

Anderson, Elijah (2012) The Cosmopolitan Canopy: Race and Civility in Everyday Life. New York: WW Norton \& Company.

Banet-Weiser, Sarah (2012) Authentic: The Politics of Ambivalence in a Brand Culture. New York: New York University Press

Bannister, Jon (2018) "Developer Q\&A: Insight Property Group Partner Trent Smith." Bisnow, March 13. Retrieved from: https://www.bisnow.com/washington-dc/ news/neighborhood/developer-qa-insight-property-group-partner-trentsmith-86080 (accessed 13 March 2018).

Baudrillard, Jean (1994) Simulacra and Simulation. Ann Arbor: University of Michigan Press.

Baudrillard, Jean (1998) The Consumer Society:Myths and Structures. New York: Sage. 
Bell, Joyce and Douglas Hartmann (2007) "Diversity in Everyday Discourse: The Cultural Ambiguities and Consequences of 'Happy Talk." American Sociological Review 72(6): 895-914.

Berrey, Ellen (2015) The Enigma of Diversity: The Language of Race and the Limits of Racial Justice. Chicago: University of Chicago Press.

Boyd, Michelle (2008) Jim Crow Nostalgia: Reconstructing Race in Bronzeville. Minneapolis: University of Minnesota Press.

Brown-Saracino, Japonica (2004) "Social Preservationists and the Quest for Authentic Community." City \& Community 3.2: 35-156.

D.C. Office of Planning (n.d.) “Creative D.C. Action Agenda." Retrieved from: https:// planning.dc.gov/page/creative-dc-action-agenda (accessed 5 March 2020).

Dávila, Arlene (2012) Culture Works: Space, Value, and Mobility Across the Neoliberal Americas. New York: New York University Press.

Davis, Joshua Clark (2017) From Head Shops to Whole Foods: The Rise and Fall of Activist Entrepreneurs. New York: Columbia University Press.

Davis, Mike (1992) City of Quartz: Excavating the Future ofLos Angeles. New York: Vintage Books.

Florida, Richard (2002) Rise of the Creative Class: And How It's Transforming Work, Leisure, Community and Everyday Life. New York: Basic Books.

Hyra, Derek S. (2017) Race, Class, and Politics in the Cappuccino City. Chicago: University of Chicago Press.

Jackson, Jr. John (2005) Real Black: Adventures in Racial Sincerity. Chicago: University of Chicago Press.

Kendzior, Sarah (2014) “The Peril of Hipster Economics.” Al Jazeera, 28 May. Retrieved from: http://m.aljazeera.com/story/2014527105521158885 (accessed 28 May 2014).

Kern, Leslie (2016) "Rhythms of Gentrification: Eventfulness and Slow Violence in a Happening Neighborhood." Cultural Geographies 23.3: 441-457.

Lees, Loretta (2008) "Gentrification and Social Mixing: Toward and Inclusive Urban Renaissance?" Urban Studies 45.12: 2449-2470.

Lees, Loretta, Tom Slater, and Elvin Wyly (2008) Gentrification. New York: Routledge. Ley, David (1996) The New Middle Class and the Making of the Central City. Oxford, UK: Oxford University Press.

Meyer, Eugene (2014) "Washington Retail District's Future Rides on Streetcars." The New York Times, 15 April. Retrieved from: http://www.nytimes.com/2014/04/16/ business/washington-retail-districts-future-rides-on-streetcars.html?_r=o (accessed 12 September 2014).

Modan, Gabriella Gahlia (2008) “Mango Fufu Kimchi Yucca: The Depoliticization of 'Diversity' in Washington, D.C. Discourse." City \& Society 20.2: 188-221. 
National Community Reinvestment Coalition (2019) Washington, DC.

Ocejo, Richard E. (2011) "The Early Gentrifer: Weaving a Nostalgia Narrative on the Lower East Side." City \& Community 10.3: 285-310.

O'Connell, Jonathan (2013) “Whole Foods Market Signs Lease for H Street NE Store and Eyes Another at Walter Reed." Washington Post, 5 November. Retrieved from: http://www.washingtonpost.com/business/capitalbusiness/whole-foods-marketsigns-lease-for-h-street-ne-store-and-eyes-another-at-walter-reed/2013/11/05/ cf22eaa4-4649-11e3-bfoc-cebf37c6f484_story.html (accessed 5 November 2013).

Pattillo, Mary E. (2007) Black on the Block: The Politics of Race and Class in the City. Chicago: University of Chicago Press.

Pow, Choon-Piew (2009) "Neoliberalism and the Aestheticization of New MiddleClass Landscapes." Antipode 41.2: 371-390.

Richardson, Jason, Bruce Mitchell, and Juan Franco (2019) "Shifting Neighborhoods: Gentrification and Cultural Displacement in American Cities." Washington, DC: National Community Reinvestment Coalition.

Schweitzer, Ally (2017) “Not Just a Silly Little Name: 'Swampoodle' Park Pays Tribute to D.C.'s Irish Past." WAMU, 18 December. Retrieved from: https://wamu.org/ story/17/12/18/not-just-silly-name-swampoodle-park-pays-tribute-d-c-s-irishpast/ (accessed 20 December 2017).

Smith, Neil (1996) The New Urban Frontier: Gentrification and the Revanchist City. New York: Routledge.

Winnubst, Shannon (2015) Way Too Cool: Selling Out Race \& Ethics. New York: Columbia University Press.

Whole Foods Market (n.d.) “Our Higher Purpose Statement.” Retrieved from: http://www.wholefoodsmarket.com/mission-values/core-values (accessed 18 March 2020).

Zukin, Sharon (1995) The Culture of Cities. Cambridge, MA: Blackwell.

Zukin, Sharon (2008) "Consuming Authenticity: From Outposts of Difference to Means of Exclusion." Cultural Studies 22.5: 724-728.

Zukin, Sharon (2010) Naked City: The Death and Life of Authentic Urban Places. New York: Oxford University Press

Zukin, Sharon, Valerie Trujillo, Peter Frase, Danielle Jackson, Tim Recuber, and Abraham Walker (2009) "New Retail Capital and Neighborhood Change: Boutiques and Gentrification in New York City." City \& Community 8.1: 47-64. 


\section{About the Author}

Brandi Thompson Summers is an Assistant Professor of Geography and Global Metropolitan Studies at the University of California, Berkeley. Her book, Black in Place: The Spatial Aesthetics of Race in a Post-Chocolate City (UNC Press, 2019), explores how aesthetics and race converge to locate or map blackness in Washington, D.C. She has published several articles and essays that analyze the relationship between race, power, aesthetics, and urbanization that appear in both scholarly and popular publications, including the International Journal of Urban and Regional Research (IJURR), ASAP/Journal, QED, Public Books, and The Funambulist. 


\title{
7. Art and the Aesthetics of Cultural Gentrification: The Cases of Boyle Heights and Little Tokyo in Los Angeles
}

\author{
Jonathan Jae-an Crisman
}

\begin{abstract}
The art world has been linked to gentrification. Such art is associated with a modernist aesthetics based on abstraction, individual experience, and exchange value. This chapter identifies a different kind of art based on an aesthetics of engagement in the historic immigrant neighbourhoods of Boyle Heights and Little Tokyo in Los Angeles. This aesthetics is linked to ethics, collective interaction, and the participatory community development of specific places. Furthermore, gentrification is often only understood as an economic process. The concept of cultural gentrification is presented to demonstrate how transformations in the symbolic sphere can trigger a loss of belonging. Art that is borne from the specific culture of a place, however, can open up new potential in combating gentrification.
\end{abstract}

Keywords: cultural gentrification, immigrant urbanism, social practice, engaged aesthetics, community organizing, art and politics

In 2016, protests by community activists - many of whom were artists - against a proliferation of galleries and art spaces in the Los Angeles neighbourhood of Boyle Heights reached a fever pitch because of the perceived connection between art and gentrification. Protests accompanied every gallery opening, "outsiders" on the streets such as those visiting the galleries were asked to leave, and at least one of the businesses was tagged with graffiti which decried "white art" (see Crisman and Kim 2019). Eventually, many of these galleries left the neighbourhood, or closed entirely. During this same time period and only a mile away, just across the Los Angeles

Lindner, C. and G.F. Sandoval (eds), Aesthetics of Gentrification: Seductive Spaces and Exclusive Communities in the Neoliberal City. Amsterdam: Amsterdam University Press, 2021 DOI 10.5117/9789463722032_CHO7 
River, community organizations in Little Tokyo were pooling resources to hire a full-time arts organizer who would focus on using art to prevent gentrification under the auspices of a coalition named Sustainable Little Tokyo. How were attitudes toward art and gentrification so strikingly different in these neighbouring communities?

The primary distinction between these two neighbourhoods has less to do with differing attitudes toward art and gentrification, which according to stakeholder interviews are remarkably consistent. Rather, the aesthetics of the particular art forms and practices experienced in each community drove these outcomes. In Boyle Heights, the new arts-related arrivals were largely associated with the high art world, global art market, and for-profit gallery system. This demonstrated an aesthetics not for members of the predominantly working class, Latinx community but, instead, for wealthier, whiter outsiders and, as such, was seen as an indicator of gentrification - and, in particular, cultural gentrification. The art forms and practices which were decried in Boyle Heights failed to adequately align with the historical and contextual forms of art and culture making which were indigenous to the neighbourhood, such as the long history of Chicano art and activism, leading to the loss of a sense of belonging. Indeed, many of the media-friendly activist actions undertaken by the protestors had more in line with the culture of the community than the white box galleries which had come to proliferate throughout the area.

In Little Tokyo, on the other hand, the art and activism launched through Sustainable Little Tokyo aligned with the history and context of the predominantly Japanese American and Asian American community, signalling desired forms of community action, place identity, and urban development rather than cultural gentrification and "outsider art." In this particular case, high art finds itself as "outsider art," while community art finds itself on the "inside" (Becker 1982), and culture was at least in part formed from a shared ethnic identity (Sandoval 2018). The organization displayed an engaged aesthetics of grassroots action which both allowed for these practices to be widely accepted within the community as well as strengthened the activist goals and outcomes of Sustainable Little Tokyo and its partners. The presence of this particular aesthetics and its practical outcomes had the effect of protecting a sense of ibasho in the neighbourhood, a Japanese term which connotes the psychologically comfortable feeling of being at home and of belonging - the antithesis of cultural gentrification, instead found in practices of Japanese American and Asian American placemaking (see Park and Leong 2008). In other words, the culture that forms out of the specificity of place, history, and identity has a profound effect on what is interpreted on the ground as an aesthetics of engagement versus an aesthetics of gentrification. 
This chapter will expand theories of art and urban change based on new definitions of aesthetics and of gentrification. This expanded theory will push beyond the standard theory which points toward art as something that causes gentrification toward identifying different kinds of art practices which can, in fact, be used to combat gentrification. It does so on the basis of two unconventional definitions. First, that of an aesthetics as based in ethics, action, and activism rather than autonomy, largely developed through art critic Grant Kester's work on social practice art - what we might term an aesthetics of engagement. And, second, that of gentrification as based in the symbolic and cultural sphere which harms a community's sense of belonging rather than the more widely understood economic forms of gentrification - what we might term cultural gentrification. I will point toward some historical and contemporary art practices which demonstrate these various registers in both Boyle Heights and Little Tokyo, developing a narrative which stands in contrast to popular understandings of art's role in the "creative city," sparking economic development and ultimately causing gentrification. I offer, instead, insight into art's potentials as a tool for achieving equitable outcomes in the process of urban development. These potentials are especially timely as ethnic and immigrant places in major cities around the world find themselves threatened by gentrification and erasure - not least of all including Boyle Heights and Little Tokyo - and these potentials offer insight for how communities might practice and make art in the service of holding on to their place in the city.

\section{A Theory of Art and Urban Change}

In her book Loft Living, sociologist Sharon Zukin explores the changing meaning of urban housing in the context of 1970s and 8os New York City where artists were moving into industrial loft spaces, creating a lifestyle with cultural and economic cache which she termed the "artistic mode of production" (Zukin 1982). This phenomenon went on to be intentionally used by cities and developers to push out existing industrial uses in favour of commercial and residential loft development which had a higher rate of return. Zukin later built on this analysis by reflecting explicitly on this process occurring at the nexus of spatial, cultural, and economic transformation as one of gentrification - establishing the link between culture and urban change long before current, ubiquitous discussions regarding gentrification (Zukin 1987).

Two decades after Zukin's book, Richard Florida published his widely read The Rise of the Creative Class, which linked the economies of the "creative 
class" with urban regeneration, calling for cities to remake themselves as bohemian paradises which could lure in authors, artists, software engineers, and other "creatives" - and scores of urban policymakers set out to do just that (Florida 2002; see also Brooks 2000; Currid-Halkett 2017). A number of urban planning scholars have similarly identified and examined the ways in which arts and culture can produce positive economic effects, noting their potential in driving growth and development (Currid-Halkett 2010). While many "creative cities" policies ended in failure, most notably including efforts to build Guggenheim Bilbao-like flagship cultural institutions in small towns which were later bankrupted, the overall trend of urban growth and change was perhaps too successful: gentrification has now become the watchword for a strange cross-section of urban denizens, including NIMBY homeowners who don't like to see any change, lower-income renters and activists who are concerned about displacement, and longstanding communities which fear a loss of control over their future development - especially historically ethnic and immigrant neighbourhoods such as Boyle Heights and Little Tokyo.

The general theory of art and urban change shared by Zukin, Florida, and others is this: art and artists increase the value of places in which they exist and work by contributing to its cultural and aesthetic cache. Boosters like Florida see this as a positive and either do not consider who benefits from this increased value, or naively assume that it will remain within the geography of the community. Critics like Zukin decry this production of value because the changes wrought and the benefits accrue to those who are not from the community, such as absentee landowners, or newcomers who can afford to move in and push out those who are already there. But this debate revolves around a classification of art within what sociologist Howard Becker termed "art worlds," or the professionalized sphere of for-profit artists, art institutions, and supporting industries (Becker 1982). It ignores the wider world of the arts which includes what Becker termed "folk" or "outsider" arts and artists, what others have called community or grassroots arts, and art practices which fall into the margins of art worlds under the rubrics of socially engaged or social practice art. This widened sphere points toward a different aesthetic regime which has vastly different implications for the relationship between art and urban change.

\section{Engaged Aesthetics and Collective Interaction}

The dominant relationship between politics and aesthetics within contemporary art and theory circles today, what we might term a "modernist 
aesthetics," stems from Kant's writings on taste and judgement which established artistic and aesthetic autonomy, separating mind and aesthetics from engagement and action. Aesthetic and ethical judgements both were seen as universal truths to be grasped by an idealized elite who had the capacity for disinterested evaluation of form itself: "A judgement of taste on which charm and emotion have no influence ... which therefore has as its determining ground merely the purposiveness of the form - is a pure judgement of taste" (Kant [1790] 1914: 73). This understanding is evident in writings from another key source which established modernist aesthetics: Frankfurt School critics and theorists, with writings such as Adorno and Horkheimer's “The Culture Industry” ([1944] 2002), and Benjamin's “The Work of Art in the Age of Mechanical Reproduction" ([1935] 1982). These essays grappled with the interconnections between mass media, fascism, aesthetics, and politics, using a Marxist approach to analyse and critique artistic objects, revising Kant's pure autonomy of art and aesthetics to integrate political economic contextualization. More recently, Jacques Rancière has refined the critical theories of aesthetics and politics within this lineage, reading Schiller's On the Aesthetic Education of Man ([1794] 2016) to argue for the political potential of art to bring about new frames of reference for the world, giving viewers of art new political consciousness (Rancière 2004, 2010).

Yet these admittedly seductive and inspiring readings of art and aesthetics remain beholden to the Kantian separation of an idealized essence from the "real" world, restricting art to the symbolic register as products of a genius mind - they are merely autonomies of another name. As art historian and critic Grant Kester has described, "the figure of the singular, auratic artist, reinforced by notions of artistic genius first formalized by Kant, remains the bulwark of the long history of modernism, and the epistemological template for much contemporary criticism and curatorial practice" (2011: 3). At its most promising, aesthetics is seen as a means for a dialectic cognitive experience between artwork and viewer which might bring about a new consciousness, yet never to cross over into the "real." As Rancière argues, art "may open up new passages for political subjectivation, but they cannot avoid the aesthetic cut that separates consequences from intentions and prevents there from being any direct passage to an 'other side' of words and images" (2010:159). While engagement on this aesthetic register holds potential for intervening in the symbolic sphere, it also gives away a great deal of art's potential in constructing new social relations, producing spaces for action, and even direct forms of activism as art. 
Kester has proposed an alternative relationship between art and politics, one that undermines artistic autonomy and the genius author as they are typically understood. Rather than remain beholden to the ideal of a pure aesthetics, Kester champions precisely the messy realism based on real, human interaction that horrified the Frankfurt critics and theorists. This "engaged aesthetics" returns to some of the lesser explored themes that drove Kant's original critique, namely the intersections between ethics, aesthetics, and action. For Kant, much like the modernist notion of an avant garde, a small group of enlightened thinkers with advanced capacities for judgement and taste were meant to influence ethical and aesthetic regimes such that their progressive influence would gradually spread throughout society, effecting an incremental change. But Kester mines new dialogical and socially engaged art practices to propose a new aesthetics based on engagement: art, itself, becomes a participant within political life.

These practices, by their very definition, do not fit within the confines of modernist aesthetics. Kester notes that such engaged artistic practices neither fit within static art theory models but, rather, unfold in new and entirely unexpected ways as people interact with one another (2012: 99). Art is still seen as part of the realm of experience and judgement, yet now it is no longer on the basis of a mute artistic object which provides a solitary experience in the mind of the viewer. Instead, it is borne out of a shared experience of dialogue, engagement, action, and life between artistic coproducers within this new aesthetic regime. As Kester writes in The One and the Many, this marks "a shift from an aesthetic discourse centred primarily on questions of visual signification to one concerned with the generative experience of collective interaction" (2011: 24). This generative experience is one that can connect to immigrant life in meaningful ways impossible for the modernist aesthetic regime and is one that bears similarity to the processes at work in the context of community organizing, activism, and shared struggle. An engaged aesthetics is precisely the regime at play in both the protest activities in Boyle Heights and the community organizing activities in Little Tokyo, demonstrating an artistic mode of production that has the potential to subvert the aesthetics of gentrification.

\section{Cultural Gentrification and Disbelonging in Boyle Heights}

The influx of art world activities in Boyle Heights triggered a visceral backlash by residents who felt that their place was threatened. This process is demonstrative of cultural gentrification - that is, changes to a place's 
aesthetics which threaten existing inhabitants' sense of belonging - distinct from but deeply intertwined with economic gentrification which tends to receive more attention in the literature. The aesthetics of the newcomers, with white cube galleries and symbolic markers of the contemporary art world, clashed with the long-established history of arts and culture in Boyle Heights stemming from its immigrant and Latinx aesthetics, threatening to erase a sense of belonging for long-time residents. Ironically, many of these new artists and art institutions espoused progressive and even radical politics in line with the modernist aesthetic regime theorized by Rancière and others, and engagement with cultural gentrification would have been one of the few tangible interventions that their work might have taken within an aesthetic regime operating on a symbolic register. Nevertheless, even a cursory survey of art and culture immanent to the neighbourhood, such as the one provided here, demonstrates an engaged aesthetics of collective interaction that stands in contrast to the newcomers' approach to art practice and circulation.

Boyle Heights has long been a destination for new immigrants to Los Angeles, being one of the few areas that was not restricted to non-Anglo residents through redlining, racial covenants, and other forms of housing discrimination. It was home to a thriving Jewish, Japanese, and Russian population and, increasingly over the years, it became home to Latinx immigrants and their families who now comprise the vast majority of the neighbourhood's residents (USC Price Center for Social Innovation 2019). As such it was a locus for the emergence of a Chicanx political and artistic identity during the 1970s. Shared symbolism and an aesthetics of parade and protest can be seen across social movements, such as the Chicano Moratorium, an anti-war movement during the Vietnam war which culminated in a 30,000-person march through East Los Angeles in 1970, and the Día de los Muertos festival inaugurated in 1972 by the important Boyle Heights-based arts organization Self Help Graphics and Art (Figure 7.1). The festival would be reimagined as a work of performance art in 1974 by the Chicano art collective Asco, and go on to be a site for artistic engagement by a number of Chicanx artists up through the present day.

Two of the artists who engaged and intervened in this experience of collective interaction included Harry Gamboa Jr. and Judy Baca. For these two artists, the shared space of the street festival or the protest was not the only site for interventions of an engaged aesthetic. Judy Baca and her arts organization SPARC were critical interlocutors in setting up mural projects throughout Los Angeles, most famously including The Great Wall of Los Angeles. This half-mile mural in the Tujunga Wash flood control channel was 


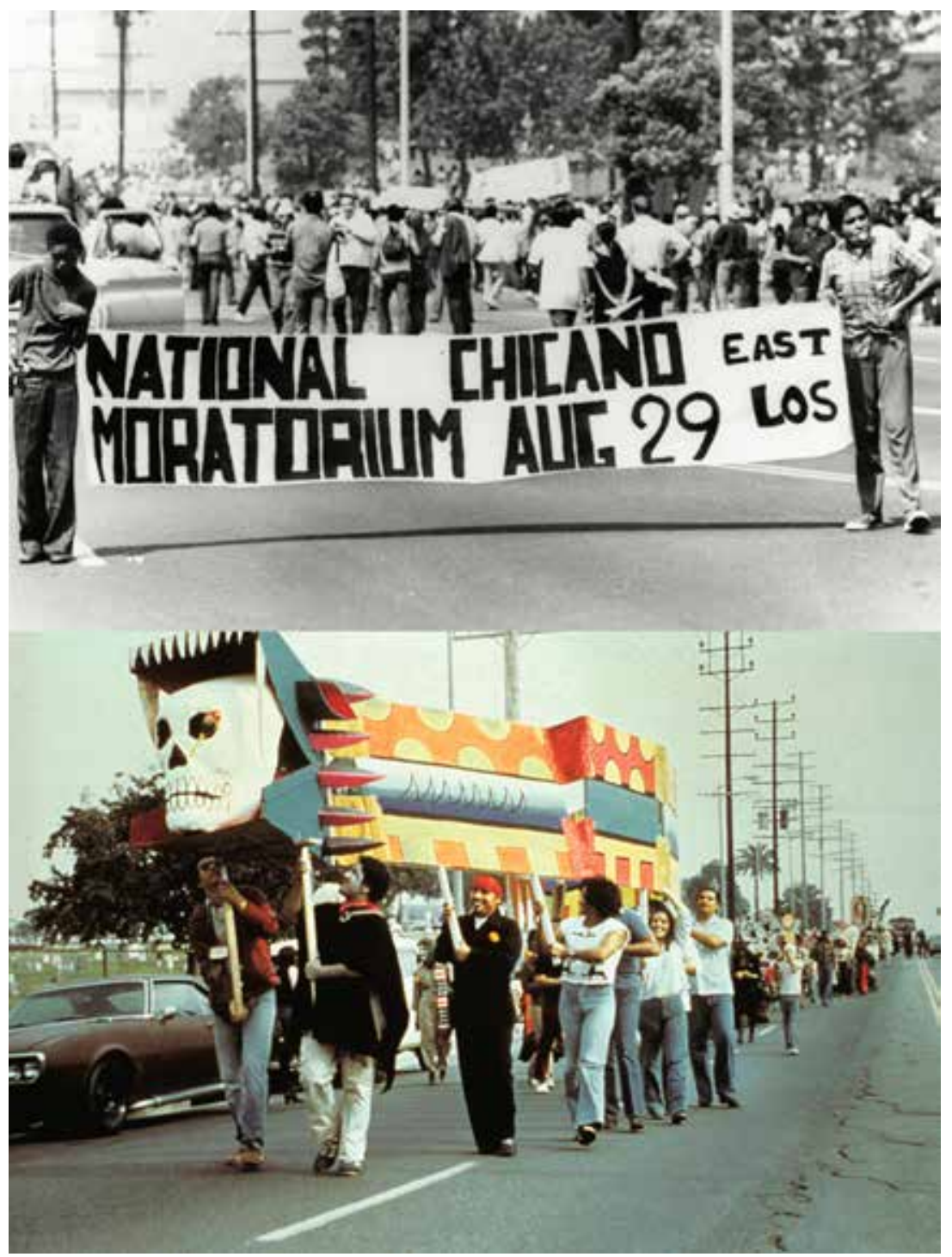

Figure 7.1: The Chicano Moratorium marching in East Los Angeles, 1970 (top, courtesy Los Angeles Public Library) and the Día de los Muertos festival hosted by Self Help Graphics, 1978 (bottom, courtesy Self Help Graphics \& Art).

produced over a period from 1974 to 1983 and while it was orchestrated by Baca, it exemplified an engaged aesthetics through the collective interaction of hundreds of historians, scholars, community members, and high school students, along with the Army Corps of Engineers and other public agencies. While the mural is a striking sight and might certainly spark some form of 
critical enlightenment between artwork and viewer, its most impressive quality is found within its materiality as documentation: it represents a narrative about hundreds of people working together and engaging with difficult histories of Los Angeles, a collective experience that certainly lives on in the minds of those who were part of the process, and one that has inspired countless others to undertake similar projects across the city of Los Angeles.

Gamboa's work, similarly, might have an end-point that is something closer to what we see in art worlds, with photographs exhibited on the white walls of a gallery or museum, but even here his process demonstrates an engaged aesthetics, to say nothing of the radical performance work that occupied his earlier career. In one ongoing project, Chicano Male Unbonded, Gamboa has connected with a divergent array of Chicano men to photograph them in public places, complicating and diversifying the popular imaginary associated with the once-derogatory but now reclaimed ethnic identity. Like Baca's work, Gamboa's process is one of numerous people, interpersonal engagement, collective experience, and a long duration of time. These elements add up to a form of engaged aesthetics that can produce new social relations, create new links across interpersonal networks, and do much of the same work as the most difficult aspects of community organizing. In short, this work is a recipe for art-based antigentrification activism even though its explicit purposes have little to do with this goal as such.

Now if this lineage of art and culture embedded in Boyle Heights is compared to the current wave of arts newcomers, aesthetic differences immediately emerge. In one typical example, gallerist Robert Stark opened his white wall Museum as Retail Space (MaRS) gallery, exhibiting contemporary visual artists such as the Los Angeles-based sculptor Laura Soto. Stark's description of a 2018 installation of Soto's work reads: “Invoking the body through evoking atemporal delicacies - honey, syrup, and cake as unitive of past, present, and future - Laura Soto's work might be looked at as both an extension, as well as antithetical, to the ideas of Romanticism. We return to subjectivity, but not the individual; rather, an animism of a communal body - the ocean from which our subjective power rises" (Stark 2018). Soto's admittedly sensuous and intriguing sculptural work remains beholden to the modernist aesthetic: its abstraction against white walls demands that viewers engage in an intangible, mental experiential space, and its mode of production - the solitary, studio-based practice of an art worlds artist - inhibits forms of co-creation or collective experience. It is not work, needless to say, that appears to be "for the community." Furthermore, 
Stark's analysis, while as politically transgressive as the modernist aesthetic can be, does little to prevent alienating visitors from outside the art world, to say nothing of his tongue-in-cheek gallery name which references the very monied and capitalist qualities of the art world which have so alarmed anti-gentrification activists.

The dominance of this aesthetic regime has come to bleed over into a range of other art spaces, "tainting" them by association, even including the historic Self Help Graphics which has long been embedded within the community but now finds itself under attack by the most extreme antigentrification activists. And most recently, non-art establishments have been associated with the art newcomers because of their shared aesthetics which are seen as threatening forms of cultural gentrification. For example, the Weird Wave Coffee shop, with its white walls, hipster aesthetic, and high-end coffee was categorized by anti-gentrification activists as a cultural entity and protested as such through rallies, flyers, and more than one brick through its windows. Interestingly, in an indirect response to the targeted attacks, the owners have gradually transformed the aesthetics of their establishment to more closely match those of the surrounding community, including less "hip" signage, the provision of food and other less "elite" products, and the creation of a community lending library in the shop which permitted a more engaged collective experience. Only time will tell if these revisions will inoculate the establishment from the perception that it has contributed toward cultural gentrification. The connection to the ethnic identity of a place may be a significant factor for the perceived cultural identification of an establishment, given that the La Monarca coffee shop just down the street from Weird Wave also serves high end coffee and pastries, and is even part of a 12-location chain, but it is widely known to be owned and operated by two Mexican immigrants who serve Mexican beverages and foods (see also Sandoval 2018).

Poet and arts administrator Roberto Bedoya has described even the purportedly positive effects of the arts in communities as "activities [that] support the politics of dis-belonging through acts of gentrification, racism, real estate speculation, all in the name of neighborhood revitalization," calling instead for an "aesthetics of belonging" (2013). Within his impassioned call, we can see the association between cultural gentrification and an aesthetics of disbelonging, contrasted with an aesthetics of belonging which is based in the particular cultures, social and ethical engagements, and practices of a place. However well intended or politically transgressive artists and arts institutions may be in the abstract, if they do not match the culture of a place, then they will still contribute toward cultural gentrification and 
an aesthetics of disbelonging, as their presence disregards and traumatizes the people around them who are so often struggling to hold on to their place in the capitalist city.

\section{A History of Arts Activism in Little Tokyo}

The current art-based organizing activities in Little Tokyo, on the other hand, fit within a long history of cultural activities within the community and, as such, exemplify an engaged aesthetics that is equipped to both contend with the threat of economic gentrification and counter processes of cultural gentrification. The earliest forms of what could be called arts activism in Little Tokyo came out of the arts and culture produced by religious institutions in the neighbourhood. These institutions provide continuity to the neighbourhood as rituals, festivals, and traditions sustain it from generation to generation. Additionally, these churches and temples acted as temporary shelters and centres for rebuilding activities when Japanese Americans returned to the area after being forcibly removed and incarcerated during World War II. Another institution which created such spaces of collective experience was the Nisei Week festival, first instituted in 1934. After the post-war return of Japanese Americans to Little Tokyo, Nisei Week was a strong-willed and transgressive public demonstration of culture as people marched in the street only a few short years after they had been rounded up and imprisoned on account of their ethnicity (Kurashige 2002). These various institutions were sites where a third culture germinated and blossomed, one which was neither Japanese nor American, but both Japanese and American, distinct even to the place of Little Tokyo. These forms of activism thus focused on community building and maintaining cultural traditions, rather than more antagonistic forms of activism which we might commonly recognize today.

The next wave of activism engaged systems of power more directly and was sparked by the coming of age of a younger generation of Japanese Americans, and the broader climate of the countercultural 196os. Events, protests, meetings, offices, political actions, and the like often occurred in the heart of Little Tokyo. Gidra, a monthly newspaper started by a group of Japanese American and Asian American students from UCLA that ran from 1969 to 1974, was one organization that was demonstrative of this period. It had a politically activist bent, advocating for anti-war and anti-capitalist positions, and for an Asian American political consciousness. While it was first based at UCLA, then in the Crenshaw neighbourhood (which 


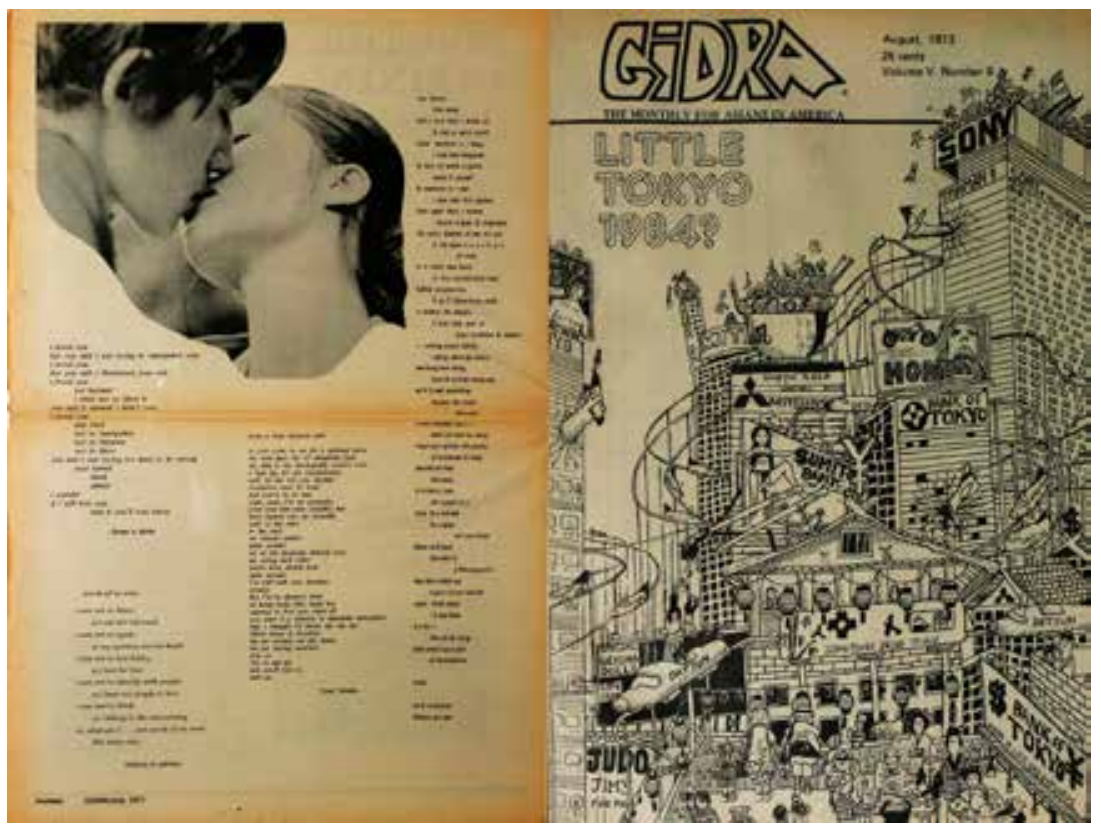

Figure 7.2: "People's page" (left, 1971) and cover art by David Monkawa (right, 1973) from radical Asian American monthly Gidra (courtesy Gidra and Densho Digital Repository).

was then heavily Japanese American), Gidra sustained a focus on Little Tokyo's politics, development, and history. The newspaper also grappled with everyday issues which were presented in an unfiltered way unusual for media, let alone the often conservative tilt of ethnic media organizations of the day, such as the intimate nature of conversations around friends lost to drugs, or interracial romance and ongoing stereotypes of both Asian American men and women. The rhetoric used regarding political stances, race relations, and other social concerns remains surprisingly contemporary nearly $5^{0}$ years later, from its condemnations of white supremacy, to its concerns about the representation (or lack thereof) of Asian Americans in popular media, to its strongly anti-capitalist positions. Its "People's Page" was included in every issue as a space for submissions of poetry and art, reflecting the intertwined nature of art and politics which was often taken for granted as a given in this era (Figure 7.2). More than just a newspaper, Gidra was a community of artist-activists, and staff went on to found and work in community and activist organizations, such as the Little Tokyo Service Center (LTSC), which have made Little Tokyo into what it is today (see Kido Lopez 2011). Indeed, following this period of political activism, another period of art-based activism through institution building followed, 
as international capital and other resources were savvily channelled into organizations which would be beneficial for the community, such as the Japanese American Cultural and Community Center (1980), the Japanese American National Museum (1992), and the Union Center for the Arts (1998).

The recently formed Sustainable Little Tokyo (SLT) is, in many ways, the culmination of this history of arts activism. It is a coalition of community organizations which advocates to ensure a "healthy, equitable, and culturally rich Little Tokyo for generations to come," and it has done so primarily through participatory planning, community organizing, and especially arts and culture (Sustainable Little Tokyo 2019). SLT began with a community visioning process in 2013 which responded to the imminent development occurring at three large, city-owned parcels of land in the neighbourhood: LA Metro's Regional Connector rail station site, the Mangrove block to the east of the station site, and the First Street North block to the north of the station site. The Regional Connector site, acquired through eminent domain, was formerly a historic block of 19th century brick buildings home to local institutions such as Atomic Cafe and Troy Cafe, hotbeds for punk rock talent in past decades. Given this new development, and with memories of past evictions and seizures through eminent domain still relatively fresh, community organizations in Little Tokyo knew they had to mobilize to get ahead of this impending development and stake their claim on the future of the neighbourhood. The community vision and other organizing efforts have been championed by long-time community organizers, activists, and organizations who have roots in the neighbourhood's Japanese American heritage, though these actors have also recognized the changing demographics of the community, opening up participation to a broader coalition of Southern California Japanese Americans, Asian Americans, and other sympathetic individuals who respect the area's heritage and engage ethically with the community as it exists today.

The first major art project undertaken by SLT (in collaboration with LTSC's +LAB) was Takachizu, Japanese for "treasure map," led by artists Rosten Woo and Maya Santos. The project's goal was to produce a community asset map of local cultural treasures. The project served multiple purposes: to demonstrate the wealth of cultural assets which are densely located in Little Tokyo, to advocate for their protection from outside development or other such threats, and to serve as a means of building and activating the community in discussions and reflections on the values of Little Tokyo. Woo describes Takachizu as an "archive of archives," noting the immense amount of historicizing, archiving, documenting, and community building which has taken place in Little Tokyo, but often remains in boxes, books, 
or photo albums in a community member's garage or attic - this effort has been key in creating a political consciousness around Little Tokyo's identity by bringing some of these items to a public light (Woo 2018). The process of collecting and mapping these items involved a series of community events and a designed "memory collection space" where items would be professionally photographed, and information cards filled out by the item's owner. The process, data collection, public display system, and website were all developed and designed to adhere to archival practices so that the cultural data could be preserved and disseminated. Some of the items uncovered during the project include past examples of arts activism in Little Tokyo that might have otherwise been lost to time, including a “Don't Be a Jerk" flyer distributed at MOCA Geffen to promote support for the local Budokan community recreation facility development project, and a guerrilla art campaign poster after Weller Court was sold to a private developer.

Most recently, at the end of 2018, SLT sponsored “ART@341," a 2-month long pop-up space in a former gift shop located in the heart of Little Tokyo's historically designated 1st Street. Led by an "Arts Action Committee" of artists and community members, the grassroots initiative installed an exhibition of the history of arts activism in Little Tokyo, and over 24 arts-related events such as poetry readings and jazz nights were held featuring over 50 different artists. According to SLT's records, over 1,00o people attended the events, and over 3,00o signatures were collected to use in a rally and march to raise awareness about the desire to maintain community control over future Little Tokyo development, and these activities and petitions were delivered to the city councilmember who, ultimately, retains make or break power to determine how the parcels will be developed. On the opening and closing nights of the space, the former proprietor of the now-demolished Atomic Cafe and DJ "Atomic Nancy" Matoba held a revival of the space, drawing in crowds to view the actions and activities of SLT (Figure 7.3).

While SLT continues to pursue its goals, and final plans regarding the development of the three parcels remain up in the air, its arts and culturebased activities have left a political mark in Little Tokyo and Los Angeles at large. The councilmember's office has been careful to tread lightly in future development plans, especially after it was surprised by the number of active participants and signatures collected from the community. Many shops throughout the community have SLT materials posted in their windows, signalling a cohesive political identity shared by the largely locally-owned and operated business community, and the dizzying array of local non-profit organizations ranging from the various religious communities to arts and culture entities have also signed on to support SLT in its goals. In all, the 


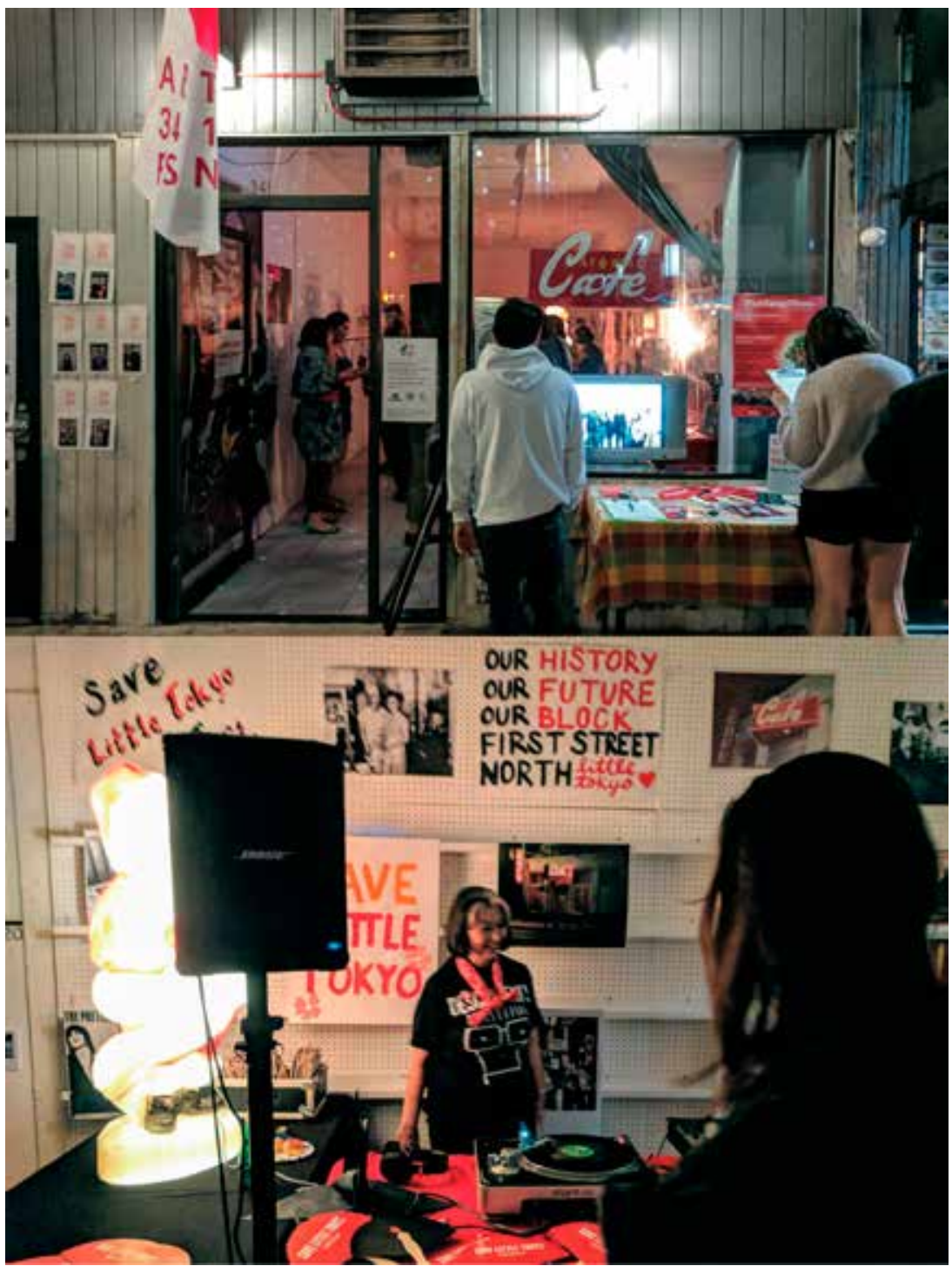

Figure 7.3: ART@341 storefront in Little Tokyo (top) and Atomic Nancy DJing at closing event (bottom). Photos taken in 2018 by author.

current arts activities fit within a long history of arts practices embedded within the community - practices which demonstrate an engaged aesthetics based in collective interaction and experience, activism and political engagement, and ultimately the support of ibasho and belonging which have the potential to stop or at least slow the most pernicious processes of gentrification. 


\section{Art and the Aesthetics of Cultural Gentrification}

While the reactions in Boyle Heights and Little Tokyo toward art and gentrification appear worlds apart - with protests against art and cultural institutions in Boyle Heights because they have been associated with gentrification, and with the active pursuit of arts-based activities in Little Tokyo because they are seen as having potential in slowing or even stopping unwanted development - they actually are both products of the same logic. Art and culture that is seen as associated with the modernist aesthetic regime dominant within the art world is not seen as for or by people coming out of immigrant urbanisms, and instead is associated with forces of gentrification. This regime is defined by its abstract representational systems, solitary processes of production and consumption, and white-cube gallery and museum infrastructure which contribute toward driving increased exchange value, echoing scholar George Lipsitz's notion of a "white spatial imaginary" (2007). Indeed, the changes that the artistic practices and cultural institutions based on this modernist aesthetic wrought in the symbolic landscape of neighbourhoods are a primary driver of cultural gentrification, which can often engender some of the most visceral reactions by community members - often even more so than the more conventionally understood economic gentrification and displacement - because of a loss of a sense of belonging. This process can spread over into practices and institutions that may not even directly have a hand in the so-called "artistic mode of production" but are seen as complicit in broader processes of gentrification within the capitalist and neoliberal city.

On the other hand, art and culture that is seen as emanating from a specific place and context will not necessarily trigger concerns about cultural gentrification because its aesthetics fit within a place and culture. And, moreover, if these forms of art and culture demonstrate an engaged aesthetics - that is, one based on ethics, collective interaction, agency, and political action - they hold potential in slowing or even stopping cultural and economic gentrification. Art and culture practices based in this aesthetic regime, such as those found within dialogical, socially engaged, and social practice forms of art - drive new interpersonal networks, social capital, community organizing, and the building of political power within immigrant urbanisms that provide a fighting chance to stake a claim over the future of one's place in the city. It is this potential for art and culture that is finding its way into the anti-gentrification protests in Boyle Heights which have so effectively engaged the media and the symbolic realm, and 
which have manifested within Sustainable Little Tokyo and its arts organizing programme which has a shot at providing community control for its development and, ultimately, its future.

\section{Note}

The author participated in the Arts Action Committee as part of his observation-based research and contributed research and curation toward the exhibition installed in the space. The author also wishes to thank Annette Kim who was instrumental in the development of the ideas around belonging and gentrification in Boyle Heights.

\section{Works Cited}

Becker, Howard (1982) Art Worlds. Berkeley: University of California Press.

Bedoya, Roberto (2013) "Placemaking and the Politics of Belonging and Disbelonging." Grantmakers in the Arts Reader 24.1: 20-21.

Benjamin, Walter ([1935] 1982) "The Work of Art in the Age of Mechanical Reproduction." In Francis Frascina and Charles Harrison, Modern Art and Modernism: A Critical Anthology. Thousand Oaks: SAGE Press.

Brooks, David (2000) Bobos in Paradise: The New Upper Class and How They Got There. New York: Simon \& Schuster.

Crisman, Jonathan and Annette Kim (2019) "Property Outlaws in the Southland: the Potential and Limits of Guerrilla Urbanism in the Cases of Arts Gentrification in Boyle Heights and Street Vending Decriminalization in Los Angeles." Urban Design International 24-3: 159-170.

Currid-Halkett, Elizabeth (2017) The Sum of Small Things: A Theory of the Aspirational Class. Princeton: Princeton University Press.

Currid-Halkett, Elizabeth (2010) "Symposium Introduction-Art and Economic Development: New Directions for the Growth of Cities and Regions." Journal of Planning Education and Research 29.3: 257-261.

Florida, Richard (2002) The Rise of the Creative Class: And How It's Transforming Work, Leisure, Community, and Everyday Life. New York: Basic Books.

Horkheimer, Max and Theodor Adorno ([1944] 2002) "The Culture Industry: Enlightenment as Mass Deception." In Dialectic of Enlightenment. Palo Alto: Stanford University Press, 94-136.

Kant, Immanuel ([1790] 1914) Critique of Judgement, 2nd edition. Translated by J.H. Bernard. London: Macmillan. 
Kester, Grant (2012) “The Noisy Optimism of Immediate Action: Theory, Practice, and Pedagogy in Contemporary Art." Art Journal 71.2: 86-99.

Kester, Grant (2011) The One and the Many: Contemporary Collaborative Art in a Global Context. Durham: Duke University Press.

Kido Lopez, Lori (2011) "The Yellow Press: Asian American Radicalism and Conflict in Gidra." Journal of Communication Inquiry 35·3: 235-251.

Kurashige, Lon (2002) Japanese American Celebration and Conflict: A History of Ethnic Identity and Festival, 1934-199o. Berkeley: University of California Press.

Lipsitz, George (2007) “The Racialization of Space and the Spatialization of Race: Theorizing the Hidden Architecture of Landscape." Landscape Journal 26.1: 10-23. Park, Kyeyoung and Russell C. Leong (2008) "How Do Asian Americans Create Places? From Background to Foreground." Amerasia Journal 34.3: vii-xiv.

Rancière, Jacques (2010) Dissensus: On Politics and Aesthetics. London: Continuum. Rancière, Jacques (2004) The Politics of Aesthetics: The Distribution of the Sensible. London: Continuum.

Sandoval, Gerardo Francisco (2018) "Planning the Barrio: Ethnic Identity and Struggles over Transit-Oriented, Development-Induced Gentrification." Journal of Planning Education and Research (August).

Schiller, Friedrich ([1794] 2016) On the Aesthetic Education of Man. New York: Penguin.

Stark, Robert Zin (2018) Gallery materials, Museum as Retail Space. Laura Soto. Los Angeles, CA.

Sustainable Little Tokyo (2019) “About." Sustainable Little Tokyo website. Retrieved from: http://sustainablelittletokyo.org/about (accessed 16 May 2020).

USC Price Center for Social Innovation (2019) Neighborhood Data for Social Change.

Retrieved from: https://ladata.myneighborhooddata.org (accessed 16 May 2020). Woo, Rosten (2018) Interview with author.

Zukin, Sharon (1987) “Gentrification: Culture and Capital in the Urban Core." Annual Review of Sociology 13.1: 129-147.

Zukin, Sharon (1982) Loft Living: Culture and Capital in Urban Change. Baltimore: Johns Hopkins University Press.

\section{About the Author}

Jonathan Jae-an Crisman is an artist and urban scholar whose work considers the intersections between culture, politics, and place. He is Assistant Professor of Public and Applied Humanities at the University of Arizona. 


\title{
8. In Residence: Witnessing and Gentrification in Susan Silton's Los Angeles
}

\author{
Susanna Newbury
}

\begin{abstract}
Los Angeles artist Susan Silton has created a type of performance practice based on the ethical imperative of reparative witnessing. Orchestrating deeply researched opportunities for participants to engage in elective communities, her art helps individuals see their roles in historic forms of crisis accountably. Several recent pieces reflect not only on global crises perpetuated by neoliberalism and US political fallout, but on a more specific, if tricky crisis: gentrification. Tracing Silton's own biographical relation to urban change, as well as the modes in which key works select specific sites of change as text or subtext, this article discusses the roles artists play in gentrification, as well as their potential for attending to its reparative aesthetics.
\end{abstract}

Keywords: arts district, reparative practice, real estate, Los Angeles, adaptive reuse

Los Angeles has been a flashpoint for conversations on art, race, ethnicity, and social justice for over forty years, and since that time artists have been positioned as strategic agents of urban change. In the city's Downtown those conversations have boiled over as the after-effects of gentrification - public policy aimed at economic development on a municipal scale - take hold. A former railroad complex became the Arts District in 2002. Bars and restaurants now spill east across Downtown's Alameda Street into Skid Row. Art galleries populate the industrial flats abutting historically working-class, immigrant Boyle Heights in what many residents see as 
a sign of coming change (Miranda 2018). The politics and aesthetics of Los Angeles gentrification are front and centre, pitting artists, activists, gallerists, and municipal politicians against one another as complicit or active agents of change (Shaked 2017). Wild real estate speculation brings with it charges of urban whitewashing, anti-Latinx racism, and art elitism while simultaneously worsening a homelessness crisis that sees, according to some estimates, nearly 5,000 people spending nights on downtown streets (Los Angeles Homeless Services Authority 2019).

This wave of gentrification and displacement is not new. Rather, what is seen today in Downtown LA is the result of over thirty years of urban policy planning and legislation aimed at recapitalizing the city centre. That artists play a part in this dynamic is also not new. In fact, artists are often singled-out as bearers of gentrifications in ways both generative (they escalate rental prices in their search for 'affordable' space and bring overpriced coffee bars in their wake) and regulative (they are awarded preferential housing status as a first step in a longer real estate development cycle). But what is often missing as these issues are debated in media and public - and the arts public is no exception - is a historical understanding of how this came to be. While artists can form part of an opposition to the economic restructuring of urban space (Deutsche 1996), they just as often go unaware of their active participation in this process - their self-placement within a complex web of transactions implicating and affecting this change (Peterson 2011). This apparent lack of awareness on the part of both existing residents and artists seeking affordable rents, has produced the caricature pitting the self-interest of the gentrifier against the collective (and often ill-fated) resistance of the neighbourhood. It's a caricature that leaves little room for interpretation.

One counter-example can be found in the work of Susan Silton, an LA artist who has made work that investigates the politics, aesthetics, and sites of artists' studios and movements as historical cycles of collectivity, belonging, and displacement. Her practice consists of conceptual projects that gather collaborators and audience members as co-authors for durational, site- and temporally-responsive performances. Typically organized in response to urgent political crisis, each performance is conceived in historical terms, a reprisal of earlier specific moments betraying similar symptoms in the present. Each performance, action, or object is absorbed into a constellation of texts, events, exhibitions, and publications orchestrated by Silton to create a profoundly intertextual experience of exploring meaning in the context of change. Within the past decade, she has focused on economic crises affecting cities and citizens in the United States and elsewhere. On the surface, the 
activities they join are elegiac and aesthetic. A group of women whistlers converged on a gallery in Culver City and a museum in Santa Fe, NM, their tunes re-telling the famous soundtracks of hypermasculine movies, like the Godfather (The Whistling Project, 2010-present). Eleven writers (I was one of them) researched short biographies of 118 artists, half living, half of whom committed suicide, compiled in an artist's book Who's in a Name? (2013) that remembers the overlooked. The dead artists' names had previously played on a scrolling marquee on Sydney's Australia Museum - Silton had entered them into Your Name in Lights, a 2011 participatory work by the artist John Baldessari that invited the anonymous submission of names to appear on the marquee in random order, a chance to literally see one's own name in lights. By squatting the piece, Silton gave each deceased artist the opposite chance - a renewed visibility in the afterlife in the name of remembrance rather than self-interest. The book, Who's In a Name? was illustrated with screen grabs of each name Silton assigned for submission, taken from the marquee's live-feed (Harren 2013). Her strategy of accompanying performance with other parts - borrowed texts, new essays, live lectures, video documentation, as well as the creation of new objects, seek to enact a different, discursive aspect of art production, one that makes explicit the complex contexts in which it unfolds.

Most recently, she has turned to Los Angeles, her home town, to focus on artists and their own responses to contemporary crisis events. While they vary from national politics to local issues, all can be grouped under fallout from the extreme forms of inequality produced under neoliberalism. With this perspective, migration, housing insecurity, and living conditions are all subjects that could be extracted from her work. But rather than making art that charts the visual look of such topics or seeks directly to intervene in imbalances of power neoliberalism produces, her work lies in a different, almost lyrical practice of calling attention and, in turn, beholding. Silton's framework of convening groups as witness to crisis generates a social praxis: a means of behaving ethically in complex relation to one another and to the outside world. One could think of her work as reparative in the sense recently proposed by literary critic Jess Row: staging a collective confrontation of a shared past in order to lay bare participants' complicity in allowing such dynamics of harm to continue into the present (Row 2019). Works like In everything there is the trace (2013), A Sublime Madness in the Soul (2015), and Quartet for the End of Time (2017) address themes of dispossession and remembrance in present-day Los Angeles by referring to displacements in time, particularly the economic depression and political totalitarianism of the 1930 and 1940 s. 
Though never explicitly named, the contemporary context such antecedents refer to is urban gentrification. Since 2013, many of her works have been designated site-specific, a discursive formation the art historian Miwon Kwon has defined as not just a functional location, but a "fragmentary sequence of events and actions through spaces," a conceptual as well as physical "vector" in which space produces meaning (Kwon 2004: 29-30). Silton sites her performances within this specific context - as both location and text for inquiry. In choosing to stage such events, recently, in charged spaces of divestment and recapitalization - South LA, Boyle Heights, the Arts District - her work complicates the intertwined relationship of art and urban redevelopment (Newbury 2021). But rather than passively accepting and perpetuating this state of affairs, Silton builds self-criticism into her work, gathering participants as a means of rejecting the normative complicity of artists in cycles of gentrification, and in its place enacting a rigorous examination of self-accountability as an ethical process of making.

In order to understand this, we must begin with a history of gentrification as a form of public policy. It is a slow process, twinned with large-scale economic restructuring, and can take both prosaic and virulent forms. Rezoning, historic preservation, and live-work conversion ordinances are all examples of components in a longer gentrification cycle. Most often, differences of race and class become polarized and antithetical positions in this cycle, particularly in cities where decades-long restrictive mortgage lending practices (redlining), racialized policing, and gang injunctions bind working-class communities of colour in geographic isolation. In a city like Los Angeles, which saw an overwhelming wave of post-World War II residential and commercial development that created suburban affluence and urban divestment as racialized opposites, gentrification poses the potential of a second phase of violence enacted on the working poor and people of colour, recapitalizing the city not for its standing residents, but for a new and wealthier population considered more ideal (Avila 2004). Of course, this project is not unique to cities of the twenty-first centuries, nor as racially binary as it may seem. Historian Daniel Widener, for example, has written of intermediate stages of urban gentrification during World War II as an enactment of anti-Japanese American policy, chronicling how Japanese-American owned properties in Los Angeles' Little Tokyo were appropriated by the city, leased to new landlords, and rented largely to the city's swelling population of African Americans following the Great Migration out of the US South (Widener 2003). Art Historian Kellie Jones has researched that African American population's geospatial imagining of home as the genesis of the distinct visual aesthetics of Black Art in LA's 
the post-war era, itself framed by racist, restrictive housing policies aligned with municipal attempts at urban economic restructuring euphemistically known as urban renewal (Jones 2017).

From 1946 through to this day, Los Angeles as a municipal entity has taken pains to represent white citizens' economic exodus from the city centre as rationale for redevelopment. To make the city 'vibrant' has meant attracting new forms of capital investment that would appeal to a proper class of new urban residents, marked in common by consumer affluence. Early in this process, art and artists were identified for their potential to lure such consumers back to the city - a theory so influential it has itself produced a literature on the stimulating power of the so-called 'creative classes' (Florida 2002, 2018). In LA, this attempt began downtown. After levelling the multi-ethnic working class neighbourhood of Bunker Hill in the 196os under the auspices of the Community Redevelopment Agency, the city spent over sixty years designing and redesigning the area in a hubristic attempt to usher in LA's new image as a powerhouse on the global stage (Davis 1990). Throughout it all, civic leaders imagined Bunker Hill evolving into a corridor for high culture. Implementation has been slow: the 196os saw the construction of the Mark Taper Forum and Ahmanson Pavilion theatre and music complexes, the 1980 s the founding of the Museum of Contemporary Art's main campus, the early 2000 s the completion of the Disney Concert Hall, and with each phase came an initial bounce of enthusiasm quickly followed by inertia; the area is too disconnected from the rest of downtown, too corporate, inauthentic, and not sufficiently pedestrian friendly. Today, the neighbourhood conversion is now in its final, speculative phase. Currently known as the Grand Avenue Corridor, it is lined with big-name cultural institutions backed by big-name funders. A last piece, the $\$ 1 b n+$ Frank Gehry-designed Grand Avenue Project, is under construction and, when completed, will form a luxury mixed-use residential tower complex whose proponents and detractors both already compare it to New York City's Hudson Yards (Lubell 2019). In this case, as in many, gentrification bypassed resettlement, funnelling private investment into multibillion-dollar projects now reading as showpieces of global capital more than they do the image of a thriving city (Peterson 2011).

But there was another enactment of gentrification started by the City of Los Angeles that pivoted not on large-scale renewal, but on residential real estate. Since 1981, such policy has been tested and implemented in an area of Downtown south and east of Bunker Hill, known today as the Arts District, previously the centre of LA's manufacturing economy since the early twentieth century. Laid along freight rail lines shadowing the Los Angeles 


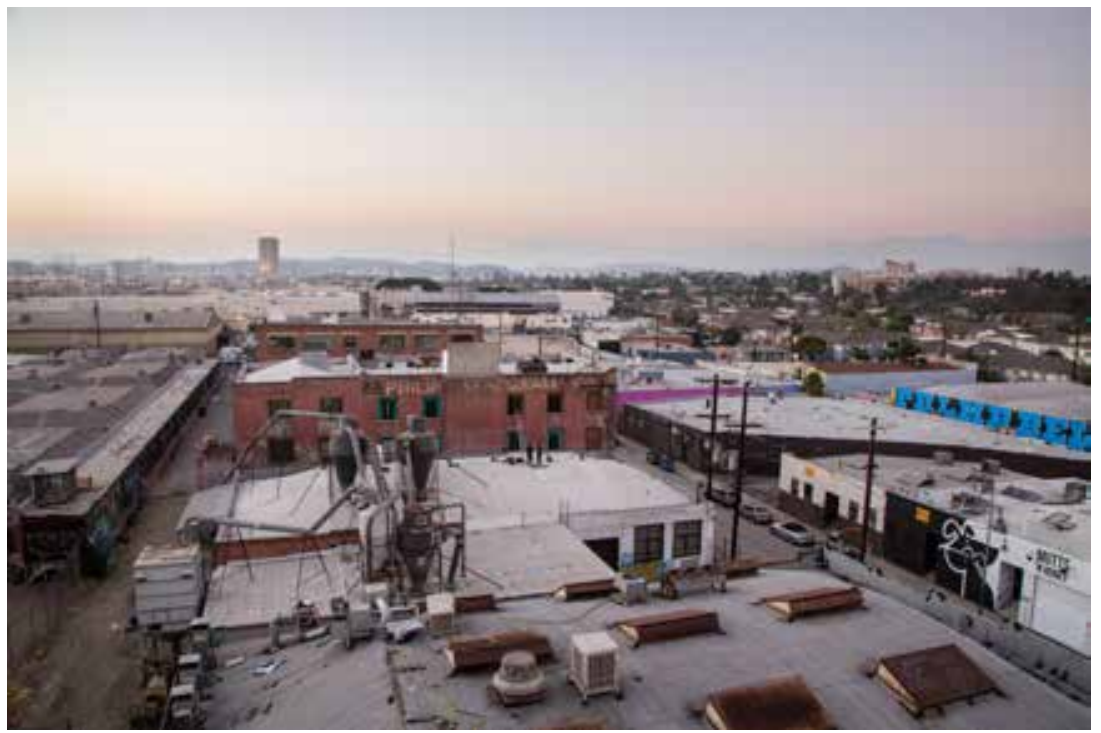

Figure 8.1: Silton's Anderson Street loft building, viewed from the Sixth Street Bridge, 2015. Courtesy of the artist.

River, the area consists of warehouses and factories, anchored by the Santa Fe Freight Depot. In the early twentieth century, it served as a distribution centre for the Inland Empire's citrus industry. After World War II, small manufacturers moved in, and a second wave of industry, this time focused on garment, tool, and cold storage for the Produce Market along Alameda Street. As trucking surged as a preferred means of conveyance between Downtown and the Ports of Los Angeles and San Pedro - a straight 20-mile shot south - many of the railyard's support structures went without tenants.

By the mid-1970s, offshoring and the outmigration of manufacturing in the United States rendered many such districts tenantless. Both state and local governments began responding by passing series of legislation aimed at shoring up the physical assets of such neighbourhoods - typically through live-work conversion ordinances that allowed for temporary adaptive reuse before any formal process of rezoning and private redevelopment could occur. Artists were identified as key agents of change as officials noticed their peremptory moves into such disused spaces and organized to legitimate their living arrangements (Zukin 1982). California passed laws allowing such conversions to bring properties up to contemporary health and building codes in 1979, and the City of Los Angeles followed up with an Artist in Residence Ordinance in 1982 that specified artists as a protected class of individuals charged with doing so (California Senate, 1979; LA City ord. 156279). 
In fact, such changes to law were spearheaded by artists themselves who had begun moving into the upper floors of disused manufacturing properties throughout the 1970s in search of cheaper rents, and organized to lobby both state and local governments for the changes (Peterson 2011). A temporary Museum of Contemporary Art founded in part by artists, today's Geffen Contemporary branch of MOCA, was opened at the area's northern edge, its buildings adapted from garage and warehouse into the raw aesthetics of studio spaces that today collectively signify the look of creativity (Newbury 2021). In subsequent decades, artists themselves pushed to formalize adaptive reuse ordinances following enactments of various property tax breaks for developers working in historic districts (Peterson 2011). A 1999 adaptive reuse ordinance put into place redevelopment incentives for individuals occupying Downtown buildings constructed before 1974 (LA City ord. 172571). And, in 2002, such adaptive reuse benefit designation was given to the Arts District (LA City ord. 17459, 174978). Today, many cities use such arts-forward legislation to jump-start economic development. A common result, however immediate or delayed, is broad-scale gentrification, the state-sponsored set of strategic policies directed at recapitalizing and privatizing urban space.

But in the process, artists become canaries in the coal mines. City ordinances are frequently updated as gentrification takes effect, and with them come redefinitions of who count as artists. Beyond independent workers utilizing their homes for the direct production of studio or conceptual projects, since 1999 those qualifying for artist status need only show employment related to the arts or its production, broadly defined, or employment in a variety of occupations ranging from architect, designer, and photographer to accountant, attorney, software engineer, and real estate agent (LA City ord.172792). As the definition of artist shifts to include professional classes, income levels eligible for rental units reserved for artists increase, creating a market where rents may be raised beyond the affordable designation many artists work within. In other words, artists, too, get gentrified out.

Susan Silton is one of those artists. An LA native, her first studio building had been, in fact, downtown, near the corner of East $8^{\text {th }}$ Street and San Julian Street bordering today's Flower and Fashion Districts. The building had been leased by her father - a 1930s Austrian Jewish émigré and Los Angeles clothing manufacturer - following the enactment of the 1982 Artist in Residence Ordinance. Silton purchased the property with two others, converted it into rented live-work lofts, and managed it between 1983-1987. In her early career, Silton worked as a graphic designer for the Los Angeles Theatre Company and other non-profit arts institutions, commuting daily 
in the heart of the area. She was a member of a group of queer artists integrating conceptual and performance art with discursive approaches to identity and belonging, centred on a sense of place. She frequented artist-run gallery LACE (founded downtown in 1978), local 24-hour watering hole Gorky's Café, owned and operated by Judith Markoff, a former librarian at South LA's Manual Arts High School, Al's Bar (begun by Allen Ruppersberg in Skid Row's American Hotel), and the lofts and studios of other artists who had moved to the area (Silton 2019). In the long-observed pattern discussed above, she formed part of a wave of artist gentrification in the area (Zukin 1982).

As much as this period of her life mirrored the generic pattern of a firstwave gentrifier, Silton had a deeper connection to downtown: it was where her father first landed in Los Angeles in the early 1940s, opening a clothing business on Santee Alley. He soon moved the factory to Main and Jefferson, then to $35^{\text {th }}$ and Broadway, a few miles south and just blocks across the Harbor Freeway from the University of Southern California. As a teenager Susan worked at the factory filing in the office, visiting the shop floor, and taking a front-row seat to the everyday life of industrial commerce. And she was witness, too, to the decline of the manufacturing business in the 1970 and early 1980 os as a consequence of industrial consolidation and globalization, when the family largely switched over to managing rental properties on LA's Westside. Her own history with Los Angeles's changing urban space, therefore, extends through many iterations and communities across decades.

Forming community is a hallmark of her contemporary work, which, as previously noted, tends toward the performative. As often, those performances are keyed, directly or indirectly, to contemporary politics. They are also keyed to important periods and places from the past. In 2013's performance In everything there is the trace, for example, Silton staged bi-weekly typing sessions, inviting participants to collectively rewrite John Steinbeck's 1939 classic The Grapes of Wrath on ten typewriters set with archival rag paper during an exhibition at the University of Southern California's Fisher Museum. Over a three-month period, two hundred people - some of whom knew each other, most of whom didn't - signed up for and participated in the re-typing project, reading and inscribing Steinbeck's accounts of migration, labour, and economic marginality in collective sessions. But the typewriters were set without ribbons, generating only impressed copies of the texts in which the words, like the history of those dispossessed, are merely a trace of experience. The result is neither reproduction nor representation of Steinbeck's work. Rather, it evidences an 
act of collective labour, articulated in the phantom strokes of keys leaving blank impressions as the only proof of existence.

We can also understand In everything as site-specific, in Kwon's discursive use of the term (Kwon 2004). USC is a major US university, a site committed to learning and knowledge, and a place where the past is investigated as history. It is also, famously, an agent of rapid urban change in its main campus South LA neighbourhood, in the early twentieth century home to the mansions of the city's elite, and since then a locus of an under-resourced population of African American and Latinx working poor, and in Boyle Heights, the location of the University's Keck Medical School. While Silton did not have control over the choice of site for this piece - she was invited to make the work as part of the Fisher Museum's 2013 exhibition Drawn to Language - the themes of her chosen topic nonetheless resonate there. In 2013, South LA was, like other communities of colour across the nation, reeling from the after-effects of the 2008 credit crisis, and experiencing extremely high rates of residential housing foreclosure due to predatory subprime mortgage lending. This dynamic spurred another intense forced migration, this time of people from their homes (Gottesdiener 2013). Though formal, the connection between Steinbeck's 1930s epic of deprivation and the area's 2010s epic dispossession was specific and poetic. A community gathered to bear witness to collective displacement within an art institution but generated nothing permanent.

Sometimes, as in the case of In everything there is the trace, Silton literalizes that movement as fodder for the work itself, even if it is also a consequence of her own life's contingency. A working artist, she often picks up camp and moves. After leaving her converted building on $8^{\text {th }}$ and San Julian in 1987 following a post-earthquake condemnation, Silton moved through several studio spaces across the city. In 2005 she relocated downtown once again, just under a mile away to Anderson Street, just north of the Sixth Street Bridge on the east side of the Los Angeles River. In the grand scheme of things, Silton's path was like any other person's engaged in the daily life of a rapidly globalized city: having helped establish the very arts community marketing the neighbourhood as desirable, the private market moved in, and she moved out (Hackworth and Smith 2001). But within her own history, and within her art practice, these geographic movements take on a different resonance both personal and professional. Her work often centralizes her own person and history as a producer into the subject of larger cultural investigation. And part of that investigation was into her own circumstances as an artist, one imbricated within the politics of residence. 
What does it mean for an artist to be 'in residence'? For many, it is a category of labour, a professional context in which to develop in exception. At the turn of the last century, to be 'in residence' was in fact to depart home for isolation in the countryside. In more contemporary terms, an artist 'in residence' may still involve a physical decamping from home, but most often results in placement within (often provisional) community. The political and practical implications of artists residencies mean that rather than holding in place, artists donate personality to institutions and agencies as much as the latter return the former with creative space to develop (Badham, 2017). In the United States, for an artist to be 'in residence' also has a juridical dimension, such as in the example of Artist in Residence ordinances that allow professional-class housing advantages, and in some case secure their housing stabilities under so-called 'Loft Laws.' It can even imply self-institutionalization for purposes of access (as in the case of Los Angeles' Woman's Building) or as aesthetic practice with social aims for a community in place (Chicago's Dorchester Projects serves as only one such example).

But in a sense, to be in residence implies a different politics of location: a rooting. And with that comes an ethics - a set of moral principles governing one's behaviour. Recent projects by Silton have more directly addressed the ethics of being in residence as an artist in the changing city. Two serve as examples of this reparative witnessing. A Sublime Madness in the Soul and Quartet for the End of Time, a double, one-night performance conceived and executed in 2015 and 2017, respectively, consist of carefully choreographed collaborative performances keyed to strategic development sites in contemporary Los Angeles, staged, crucially, at the moment of their physical destruction. The first took the form of an open-air mini-opera performed at the (now demolished) $6^{\text {th }}$ Street Bridge connecting Downtown LA and Boyle Heights. The second was a public performance of Olivier Messiaen's well known 1941 musical piece of the same name, Quartet for the End of Time, at an emptied Arts District warehouse about to come on the market for commercial/mixed use redevelopment.

Planning for A Sublime Madness in the Soul began in 2015, as Silton prepared to face the news that her Anderson Street studio building might be sold in tandem with an adjacent infrastructure redevelopment project to demolish the historic 1932 Sixth Street Bridge, a famous backdrop for film and television shoots. Like art, film and television packages a neighbourhood for the real estate industry, forming an essential part of long-tail gentrification by 'donating personality' in the form of a media profile (Smith 1996). In the case of the bridge, the personality it donated to films was that of a dystopian viaduct to city life, and throughout much of the past thirty years, the life 


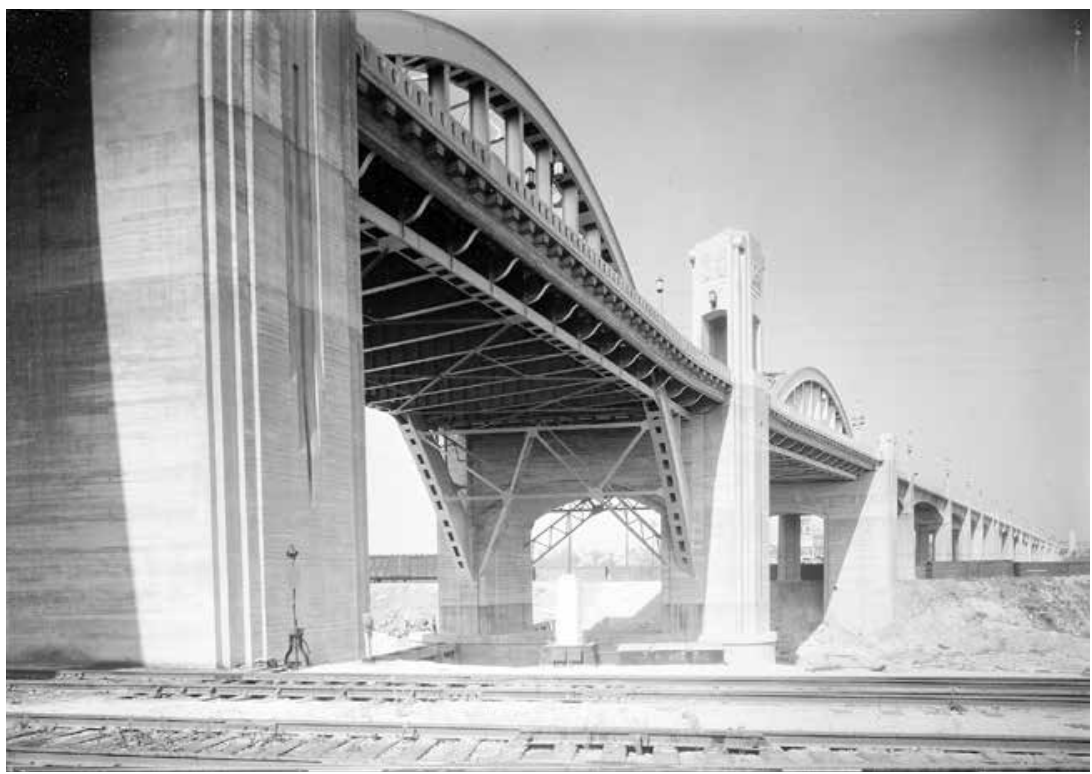

Figure 8.2: Sixth Street Bridge showing railroad tracks in the foreground, June 1933. California Historical Society Collection at the University of Southern California, Los Angeles, CA. CHS-35367. USC Digital Library.

symbolized by it was deteriorating. As was the bridge itself, designated unsound in 2004 and slated for demolition in 2016 (Fact Sheet, 2019). As part of an environmental impact study, the city had determined the long-planned demolition of the bridge would render her 1933 brick studio-warehouse building unsound, and she and the other artist-renters were at risk of being evicted after the building's proposed seizure by eminent domain (Impact Study 2011; LA City ord. 182958; LA AIN 5171-012-902). The cultural writing had been on the wall for several years, as new galleries began to move in up the street and other buildings went up for sale, anticipating the windfall of cultural rezoning and transit redevelopment on the area (Miranda 2016). Increasingly cognizant of the structural role artists played in this process, and of their own precarity as a consequence, Silton devised a farewell for the two structures, and for the neighbourhood as an artists' space.

Working with the singer and performance artist Juliana Snapper, Silton prepared a mini-opera libretto of found dialogue, taken from screenplays addressing money, power, and greed. Snapper composed an improvisational score for four singers, each to be positioned in the two windows of Silton's studio and the two windows of the adjacent studio looking out over the bridge. The work, which Silton designed to be performed in the darkness of night, relied on each window lighting up at the moment its inhabitant began 
to sing, exposing the interior of the building in flashes. As in a formal opera house, the libretto lines were projected in white text onto the pop-up roof annex above, creating a parallel experience of sonic presence and textual protest. Amplified out the windows of the functionally vacant building, music and lyrics pounded into the night sky, interrupting the flow of auto traffic across the bridge, the sounds of trains ambling toward nearby Union Station, mixing with barking dogs and the tinny alarm bells of the light rail approaching an intersection. The building, otherwise silent, for a last moment reordered the sensorial life of the neighbourhood.

A Sublime Madness was not performed in a vacuum - Silton invited an audience via Facebook (Silton 2018), word of mouth, and printed flyers. The work could be seen from a variety of spatial positions within a visual sightline of the building near the eastern anchorage of the Sixth Street Bridge, edged in narrow sidewalks with occasional extended pockets gathered around streetlights. At the appointed start time, a set of two musicians approached each other from either side, playing songs all having in some way to do with capital and community. The instrumental overture announced the work to the crowds that gathered as dusk fell, watching and listening as Sublime Madness played out against one of LA's outrageous purple-orange sunsets. During one of the two performances, traffic slowed as a vintage car club, tracing its usual Saturday route over the Bridge from downtown back to East LA, came to a halt, listening as their radios mixed into the scene. They did so on a piece of physical infrastructure that provided a soon-to-be-impossible view. Demolition began on the bridge in 2016 to make way for a highly-landscaped park on the site of the former anchorage, which will be absorbed into Frank Gehry's proposed LA River Redevelopment, the material legacy of a 1930s public works project demolished for 2020 s public experience - itself belonging to the aesthetics of gentrification. Silton's night in 2015 vanished as well as a memory.

The work's title, however, recalls another memory. 'Sublime madness in the soul' comes from the final pages of theologian Reinhold Niebuhr's Moral Man and Immoral Society, originally published in 1932, coincidentally the year of the Sixth Street Bridge's construction (Niebuhr 1932: 275). In the book, Niebuhr reflects on unchecked global inequality, the increasing prominence of a politics of hate, and the possibility of social justice in a world where an individual's capacity for love, in the religious sense, is threatened by a culture of self-interest. His argument rests on an understanding of a sharp distinction between moral and social behaviours of individuals and defined groups (national, racial, economic) of which they form part. Reflecting on cases from the American enslavement of peoples 


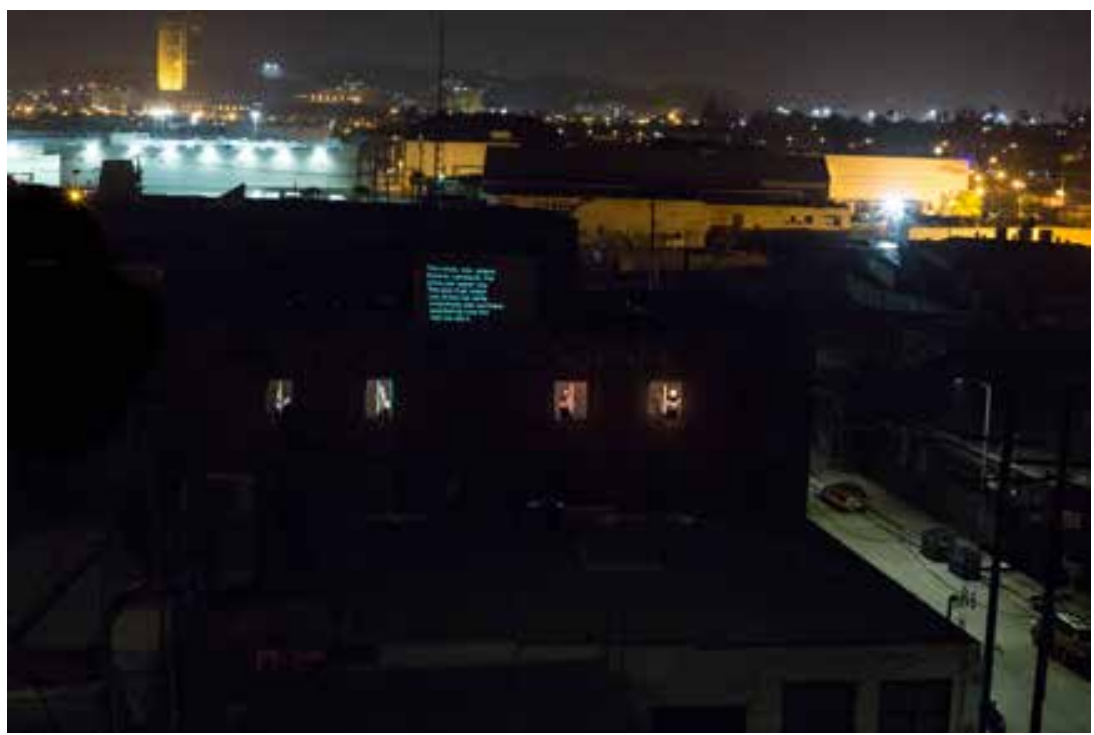

Figure 8.3: Documentation from Susan Silton, A Sublime Madness in the Soul, 2015. Photo: Alexandra Brown. Courtesy of the artist.

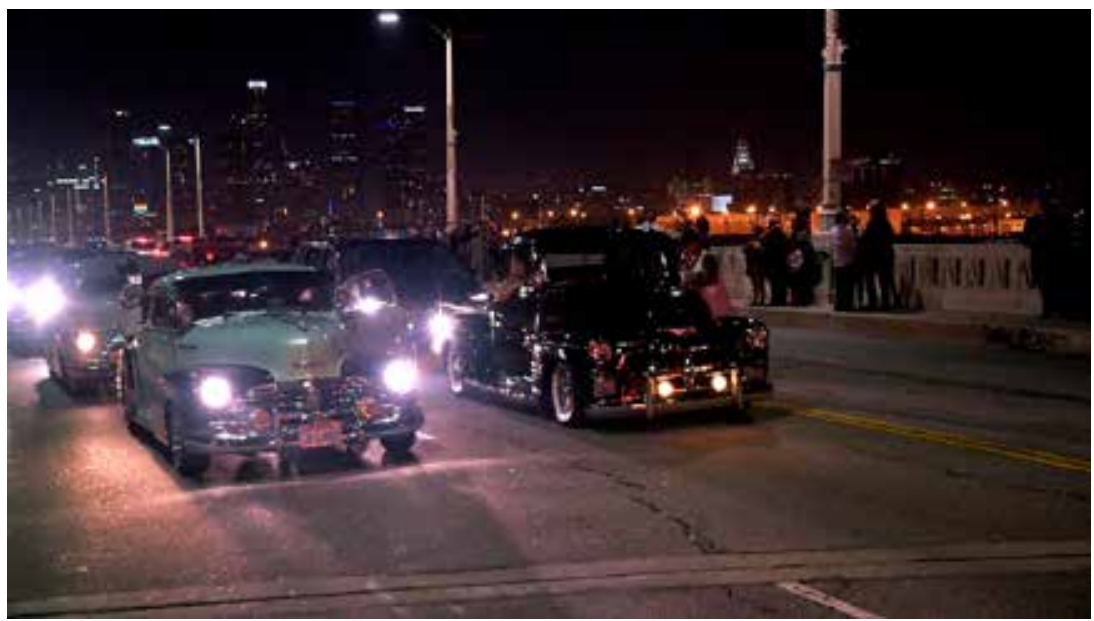

Figure 8.4: Still from night of performance of Susan Silton's A Sublime Madness in the Soul, August 22, 2015. Video still on 6th Street Bridge. Video still: Alina Skrzeszewska. Courtesy of the artist.

of African descent to Spanish colonialism in Latin America, and fallout in European politics from the first World War, Niebuhr concludes that it is possible for individuals to behave morally, even if the groups in which they participate do not. As a consequence, individuals may not recognize when collective power exploits weakness, and the acts of justification an 
individual may go through to reconcile immoral group behaviour is "one of the tragedies of the human spirit," an "inability to conform collective life to individual ideas. As individuals, men believe they ought to love and serve each other and establish justice between each other. As racial, economic, and national groups they take for themselves whatever their power can command" (Niebuhr 1932: 9). The only response to the overwhelming grip self-interest has on individual behaviour, he writes, is for an equivalent power to eradicate it.

One of the worst forms of social injustice he identifies is economic power's grip on political life. Niebuhr sees this as the cause of the most intractable forms of injustice. To him, the solution is revolution powered by the insanity such inhuman behaviour generates:

The discovery of elements of common human frailty in the foe and, concomitantly, the appreciation of all human life as possessing transcendent worth, creates attitudes which transcend social conflict and thus mitigate its cruelties. It binds human beings together by reminding them of the common roots and similar character of both their vices and their virtues. These attitudes of repentance which recognize that the evil in the foe is also in the self, and these impulses of love which claim kinship with all men in spite of social conflict, are the peculiar gifts of religion to the human spirit. Secular imagination is not capable of producing them; for they require a sublime madness which disregards immediate appearances and emphasizes profound and ultimate unities. (Niebuhr 1932: 275)

Gentrification is one such form of economics gripping political life in an era of self-interest. Its effects of displacement disaggregate individuals who might share common experience, and places them into groups where more prominent affinities (race, class, education, and so on) separate and antagonize, perhaps to the extent that they no longer see beyond appearances. An artist's angry eulogy for her residence, her studio, is at the same time lament for one group and sign of impending crisis for another. By gathering groups to witness not destruction but the textural palimpsest of mediations on greed, $A$ Sublime Madness created, if only temporarily, a reordered community defined by temporal coexistence rather than by social position. The 'sublime madness' the performance expressed was, in a sense, a reparative one. Artists reframed creative celebrations and condemnations of greed identified in the works of others, and reframed them as pretext to eviction. In so doing, those same artists and friends who attended had to face, in some way, their own complicity in that process - their ability to be 


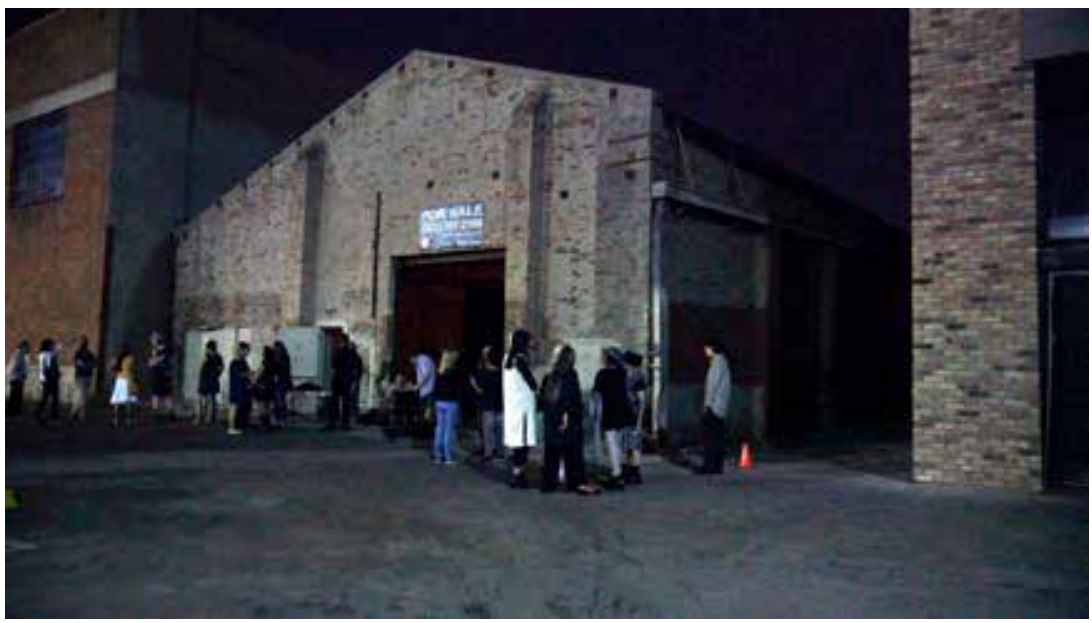

Figure 8.5: Documentation of 1399 Factory Place exterior, site for a performance of Susan Silton's Quartet for the End of Time, 2017. Courtesy of the artist.

present, to witness and participate in the making of art prepared the area for their own future exclusion. Furthermore, they were then coincidentally joined by Latinx residents of Boyle Heights, East LA, and neighbourhoods beyond made newly visible as future sites of economic displacement. At least in theory, such collectivities force the parties to consider their mutual implication in and oppression by the dynamics of gentrification that brought Silton to Anderson Street in the first place: the intersection of capital development, de facto ethnic cleansing, and pursuit of creativity that masquerades as the market.

Today, art, like real estate, becomes an expedient tool of capital formation, and Silton's recent work like Sublime identifies and illustrates that expediency as a condition worth scrutiny. She continued exploring these themes in her 2017 work Quartet for the End of Time, conceived shortly after the 2016 US presidential election as rage and lament. Staged on the cleaned-out ground floor of a pre-market Arts District warehouse, Silton directed two live concerts of the work, originally composed and performed by and for World War II POWs and their guards in a German Stalag (Ross 2007: 358-359). Silton's version was accompanied by an original dance score prepared by the choreographer Flora Weigmann, who formed part of the all-women cast of performers on both nights. As the musicians played on a spot-lit section of the sparse floor, level with and surrounded by the audience, a quartet of four dancers entered the light, moving around them, their gestures and facial expressions peering out, around, and over the audience, searching, like a blind chorus, for recognition in the darkness that appeared not to 
come. Its 2017 performance seems like a sombre elegy for a vanishing era, and a warning of things to come, almost as if the two did not belong to the same continuity of time.

Silton's purpose was clear: to stage an historical work created at a time of deep political turmoil. But her staging of the work as a specific experience of site is also canny, if tongue-in-cheek, given the Arts District location and some of the transformations of sites as aesthetic consequences of gentrification, in which artists like Silton take part. In this sense, the warehouse site should be taken seriously as both audience and participant, as if the dancers peering into the darkness wanted some recognition for their spatial surroundings, too. The warehouse's location was purposeful: she wanted a non-professional space in a neighbourhood whose original function as waystation for the transfer of persons and goods now serves that purpose for the creative class, commuting daily to jobs in marketing, advertising, and architecture rather than in manufacturing or art making (Silton 2018). And, that intent bears out today as well as it did on the warehouse's construction in 1890 (LA AIN 5164-002-011). What was a railyard storage house is now a filming site as it awaits sale next to the new Los Angeles headquarters for Spotify (Jay Luchs Real Estate Brochure 2019). Part of Silton's inquiry, then, is into the overlooked backdrop for this change: the financialized real estate market that takes artists as its first-stage developers and sometimes unwitting collaborators in social transformation. Her Quartet asked its audience to observe their role in easing that transition, or, even, making it viable in the first place, gathered as they were - gallerists, artists, curators, and others - to witness and instantiate a moment of cultural capital in an empty building up for sale.

The sites of Sublime Madness and Quartet trace between them a geography of displacement: the line they connect describes the movement of arts-based development out of the central city and into its historically immigrant, working class residential neighbourhoods. Hovering over this discussion of Silton's practice is the rise of community protest over the expansion of arts district space and programming into the same areas; the conflict over the gallery-backed spaces and their assumed collateral impact on resident populations' ability to remain in community there. Silton's work, however embroiled in and constituent of gentrification in municipal play since the early 1980 s, also serves a reflexive purpose: to lay bare the workings of such practices within comparative historical politics. The 1930 construction of the Sixth Street Bridge, for example, facilitated the growth of Boyle Heights and its connectivity to labour markets, just as its redevelopment will for different populations in the 2020s. Whereas A Sublime Madness in the Soul was a late-stage opportunity for gathering, Quartet for the End of Time offered 
a temporary yet interruptive moment to recognize how the operations of a given site silently reorganize the anonymous daily life of urban users.

'Bearing witness' is the perfect phrase for Silton's work. In insisting on the conceptual-performative framework of duration and engagement, Sublime and Quartet depend on a collective beholding of choices enacted or observed in a given situation. The situation is always the same: art at the brink of social vanishing becomes the vantage for self-reflection. This idea of witnessing also has profound moral and ethical implications when we consider the social, cultural, and economic sea changes underpinning the work in the first place: art's increasing role as a financial instrument of global economic speculation. Artists have a choice to be present for their own convenient positioning as agents of economic change. The recognition of that power is something Silton herself is concerned with as an ethical imperative, and which she conceptually integrates into each level of her work, even the linguistic. If Niebuhr's philosophy revolved around a requirement that use of power serve justice rather than profit, the role of the artist in such situations of injustice should be rooted in strength of community versus the individual, and the necessity of scrutinizing and critiquing the contemporary world in light of that moral imperative (Niebuhr 1932).

This echoes an impulse in Silton's earlier work to explore the boundaries of self and other, mediated through her queer body personally experienced or received. It's a different way of being public - thinking about the repercussions of a person or their activity beyond the boundaries of their own experience. At a very basic definition, perhaps that's what a public is: an awareness of a multiplicity that doesn't just reframe the individual, but rather establishes an intimacy between otherwise disinterested parties brought together to bear witness to each other's presence. Silton's work positions artists among these responsible groups for witnessing and action. In a 2018 interview, she explained:

The money changing hands within our field is responsible for the economic boom changing downtown in this particular iteration, and it is displacing many communities made up of both long-term residents and working artists. That demands more attention and discussion on our part because without anything to stabilize it, this will mean the displacement - and therefore, the invisibility - of most artists I know. The only artists that will continue to have visibility in that world will be those in the $1 \%$.

This prioritization of profit above all [...] in an unregulated way, contributes to the conditions that [isolate artists' zero-sum] mindset. That's 


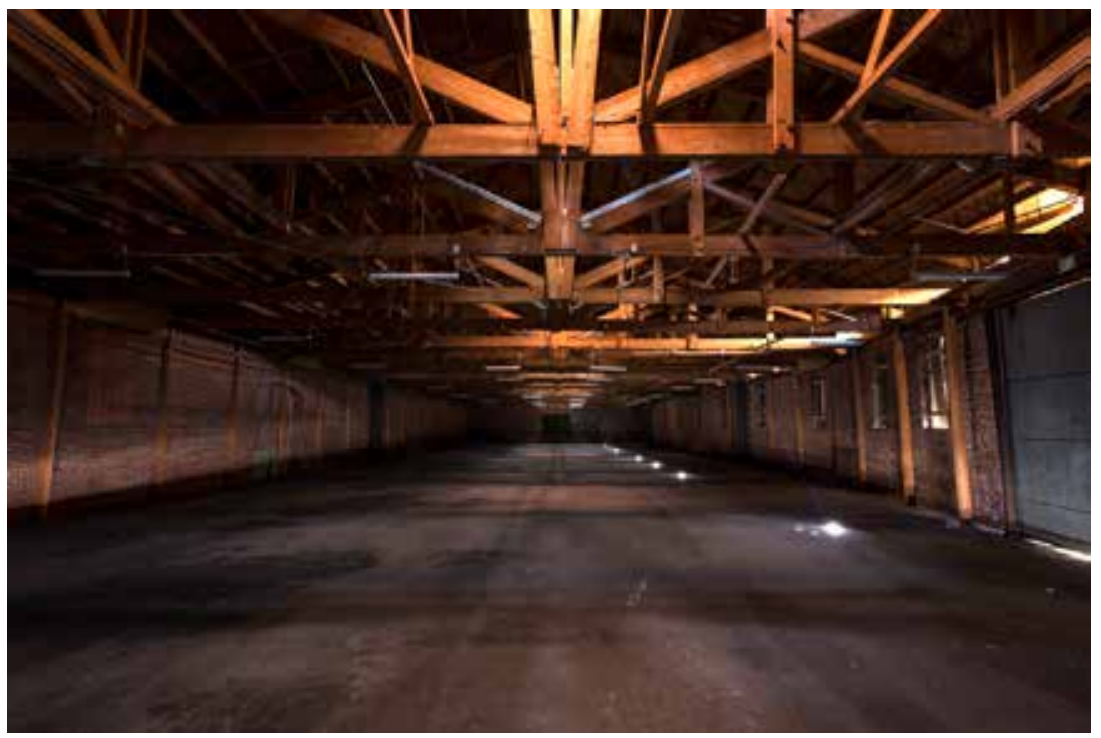

Figure 8.6: Site location, interior, for Quartet for the End of Time, 2017. Photo: Chris Wormald. Courtesy of the artist.

where our primary attention should be at this moment: how can we have a conversation that's really transparent. I feel those with privilege in the art world at the highest levels have an opportunity to guide that conversation. (Silton 2018)

In other words, for Silton, there is an existential imperative for artists to investigate and understand how economic and political power coalesce within a very small, privileged community. As a corollary to that, there is an imperative for artists to understand how speculation is an operative mechanism of our time, and how artists themselves are heavily implicated in it.

Literary critic Jess Row proposes sadness and acknowledgement of the infliction of hurt as a reparative position: a way of addressing the root of sadness the subject herself is involved in inflicting on others (Row 2019). The idea fits in well with Niebuhr's study of the dynamics of morality and immorality between individual and group. The question posed by protesters, as well as Silton herself, is less about the politics of art than it is about the issue of artists' complicity in urban redevelopment at a moment for the potential erasure of historic communities. In this sense, a reparative witnessing would involve addressing that complicity, integrating it into a structural understanding of their existence in the first place. The politics of observation in view of history are precisely the point. With In everything 
there is the trace, revivifying Steinbeck's epic of displacement and migration sheds light on contemporary versions taking place mere blocks from the site of a university art museum, itself partaking in cultural erasure as it simultaneously provides a space for its ethical identification. In Sublime, Silton models the site-responsive artwork as a space of exception: a place temporarily institutionally reorganized for the production and export of a specific product, in this case, performance-based art that temporarily reorganizes perception of how art and development go together. Quartet manages to become both elegy and warning, a nod to the extreme politics of ethnic cleansing gentrification staged at a ground zero for the erasure of community in the name of profit. Her work is responsive to change in a way that doesn't necessarily seek to alter its course, but to lay bare the politics of its occurrence. Counteracting complicity requires and insists on an awareness of its consequences as they play out in real time and disappear, and Silton's work is no exception.

\section{Works Cited}

Badham, Marnie (2017) “The Social Life of Artists Residencies." Seismopolite 18. Retrieved from: http://seismopolite.com/the-social-life-of-artist-residenciesworking-with-people-and-places-not-your-own (accessed 11 October 2018).

City of Los Angeles Bureau of Engineering (2019) "Sixth Street Viaduct Project Fact Sheet," August. Retrieved from: https://d3n8a8pro7vhmx.cloudfront.net/6stbrp/ pages/1/attachments/original/1565034702/NEW_FACT_SHEET_2019_final_8.5.19. pdf? 1565034702 (accessed 2 April 2020).

Davis, Mike (1990) City of Quartz: Excavating the Future in Los Angeles. New York: Verso.

Deutsche, Rosalyn (1996) Evictions: Art and Spatial Politics. Cambridge: MIT Press. Florida, Richard (2002) The Rise of the Creative Class: And How It's Transforming Leisure, Community, and Everyday Life. New York; Basic.

Florida, Richard (2018) The New Urban Crisis. New York: Basic.

Gottesdiener, Laura (2013) "The Great Eviction." The Nation, 1 August.

Hackworth, Jason, and Neil Smith (2002) "The Changing State of Gentrification." Tijdschrift voor economische en sociale geografie 92, no. 4 (November): 464-477. Harren, Natilee (2013) "Susan Silton: 500 Words as told to Natilee Harren." Artforum, 12 July. Retrieved from: https://www.artforum.com/interviews/susan-siltondiscusses-who-s-in-a-name-41902 (accessed 28 March 2020).

Jones, Kellie (2017) South of Pico: African American Artists in Los Angeles in the 196os and 197os. Durham: Duke University Press. 
Kwon, Miwon (2004) One Place after Another: Site-Specific Art and Locational Identity. Cambridge: MIT Press.

Jay Luchs Real Estate (2019) Properties for Sale 1242 Palmetto Street and 1399 Factory Place Informational Brochure. Retrieved from: https://www.jayluchs.com/ properties/for-sale/1242-palmetto-street-and-1399-factory-place (accessed 28 March 2020).

Los Angeles Homeless Services Authority (2019) “2019 Greater Los Angeles Homeless Count Data Summary, Skid Row." 2 August. Retrieved from: https://www. lahsa.org/documents?id=3527-hc2019-skid-row-data-summary.pdf (accessed 4 April 2020).

Los Angeles City Council Ordinance 156279.

Los Angeles City Council Ordinance 172571.

Los Angeles City Council Ordinance 172792.

Los Angeles City Council Ordinance 174549.

Los Angeles City Council Ordinance 174978.

Los Angeles City Council Ordinance $18295^{8}$.

Lubell, Sam (2019) "Can Big Names and Big Money Make the Grand a Great Civic Place?” Los Angeles Times, 22 May.

Miranda, Carolina (2016) "Out! Boyle Heights Activists Say White Art Elites Are Ruining the Neighborhoud." Los Angeles Times, 14 October.

Miranda, Carolina (2016) "The Art Gallery Exodus from Boyle Heights and Why More Anti-Gentrification Battles Loom on the Horizon." Los Angeles Times, 8 August.

Newbury, Susanna (2021) The Speculative City: Art, Real Estate, and the Making of Global Los Angeles. Minneapolis: University of Minnesota Press.

Niebuhr, Reinhold (2013) Moral Man and Immoral Society: A Study in Ethics and Politics. $2^{\text {nd }}$ ed. Lexington, KY: Westminster John Knox Press.

Peterson, Marina (2011) "Utopia/Dystopia: Art and Downtown Development in Los Angeles." In Marina Peterson and Gary McDonough (eds) Global Downtowns. Philadelphia: University of Pennsylvania Press, 209-233.

Ross, Alex (2007) The Rest is Noise: Listening to the Twentieth Century. New York: Farrar, Straus \& Giroux.

Row, Jess (2019) White Flights: Race, Fiction, and the American Imagination. Minneapolis: Graywolf.

Shaked, Nizan (2017) "How to Draw a (Picket) Line." Hyperallergic, 14 February.

Silton, Susan (2018) Conversation with the author, September.

Silton, Susan (2019) "Artists at Work," interviewed by Susanna Newbury. East of Borneo, 15 July. Retrieved from: https://eastofborneo.org/articles/artists-at-worksusan-silton/ (accessed 4 April 2020).

Smith, Neil (1996) The New Urban Frontier: Gentrification and the Revanchist City. New York: Routledge. 
State of California Department of Transportation (2011) "Sixth Street Viaduct and Seismic Improvement Project Final Environmental Impact Report." October. Retrieved from: http://clkrep.lacity.org/onlinedocs/2011/11-1789_RPT_BOE_1019-11-2.pdf (accessed 24 February 2020).

Widener, Daniel (2003) “'Perhaps the Japanese Are to Be Thanked?': Asia, Asian Americans and the Construction of Black California." positions 11.1: 135-181.

Zukin, Sharon (1982) Loft Living: Culture and Capital in Urban Change. Baltimore: Johns Hopkins University Press.

\section{About the Author}

Susanna Newbury is Associate Professor of Art History, Theory, and Criticism at the University of Nevada, Las Vegas, and the author of The Speculative City: Art, Real Estate, and the Making of Global Los Angeles (University of Minnesota Press, 2021). 



\title{
9. Satellite Dishes, a Creative Incubator, and the Displacement of Aesthetics in Amsterdam
}

\author{
Daan Wesselman
}

\begin{abstract}
This chapter examines an aesthetic clash in the neighbourhood of Bos en Lommer in Amsterdam. One side of the street features decorated satellite dishes attached to social housing, which constitutes a battleground for otherness. Such dishes are broadly opposed in Dutch public and institutional discourse for being "ugly," which amounts to xenophobia expressed in aesthetic terms. Opposite is a disused school building recently converted to an art-space-cum-hostel called WOW Amsterdam, a "creative incubator" that injects aesthetic difference and thereby the politics of gentrification into the area through foregrounding art, fashion and consumption. I argue that this clash shows how aesthetics are politics, and that the newly-inserted global gentrification aesthetic - following the creative incubator formula - displaces the aesthetics, and politics, of the battle for otherness across the street.
\end{abstract}

Keywords: Amsterdam, satellite dishes, creative city, displacement, distribution of the sensible

In an otherwise unremarkable street, in a generally unattractive neighbourhood in Amsterdam West, a colourful political clash is quietly taking place. On one side of this street, decorated satellite dishes are attached to the balconies of a mid-twentieth-century, government-subsidized social housing apartment block, for example with butterflies or flowers painted on them (Figure 9.1). On the other side of the street, immediately opposite the apartment block, is a former school building recently converted to a 


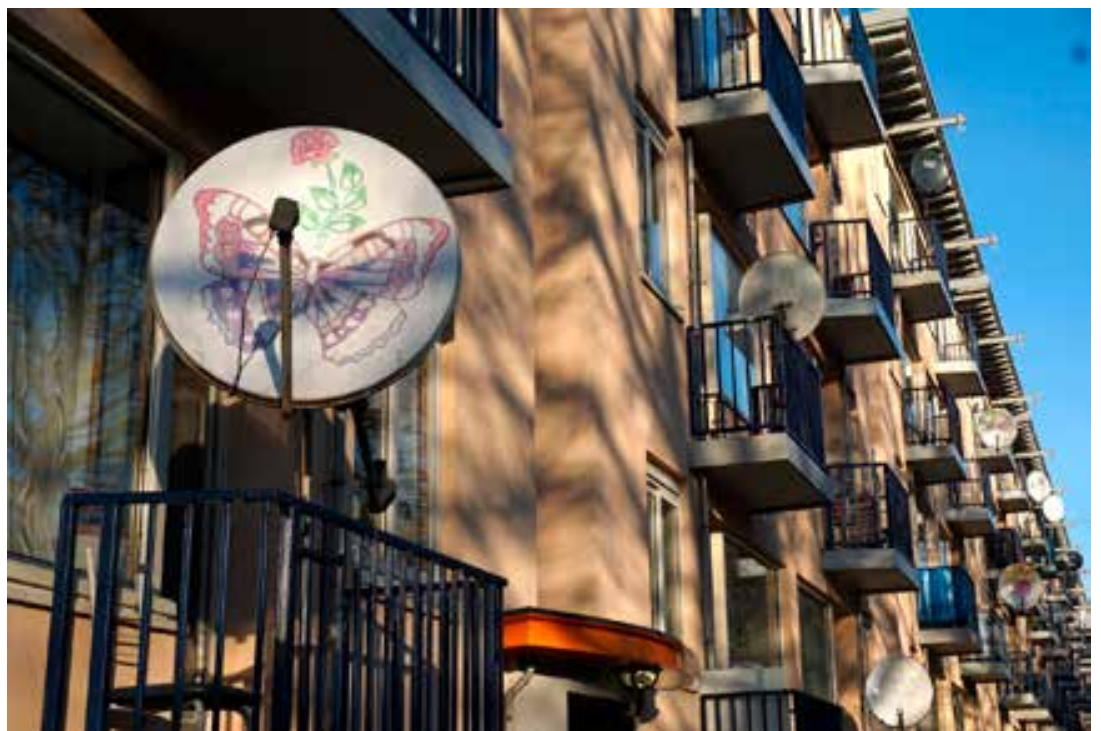

Figure 9.1: Decorated satellite dish in the Ferdinand Huyckstraat. Image by the author.

hostel-cum-art-space called WOW Amsterdam (Figure 9.2), with colourfully designed signage on the front of the building. The reused building is a prime instance of a "creative incubator" (broedplaats in Dutch): a municipally designated site, frequently in a disused building, for artists' studios, galleries and cultural activities, and in the case of WOW also with accommodation for artists and a hostel for tourists (see Peck 2012 for a thorough account of Amsterdam's incubator policy). The mainly residential surrounding area consists of unassuming - many people say drab and dull - social housing, so if you don't know the area, you could easily think that these colourful exceptions to the area are related. For example, you might think that artists from WOW painted the satellite dishes, to add colour and break the monotony of the appearance of social housing. In this chapter I argue that, while both sides of the street are colourful patches within their surroundings, their aesthetics are entwined with two very different politics: the dishes express a resistance to the oppression of otherness, whereas WOW inserts the aesthetics and politics of gentrification in this area. Even though there is no overt conflict between the two sides, the result of this clash is that gentrification is crowding out the battle for otherness in terms of aesthetics and (or as) politics.

While both sides seem akin in their colourfulness, the decorations on the dishes don't actually have anything to do with WOW, since they predate the conversion of the school building into a creative incubator by 


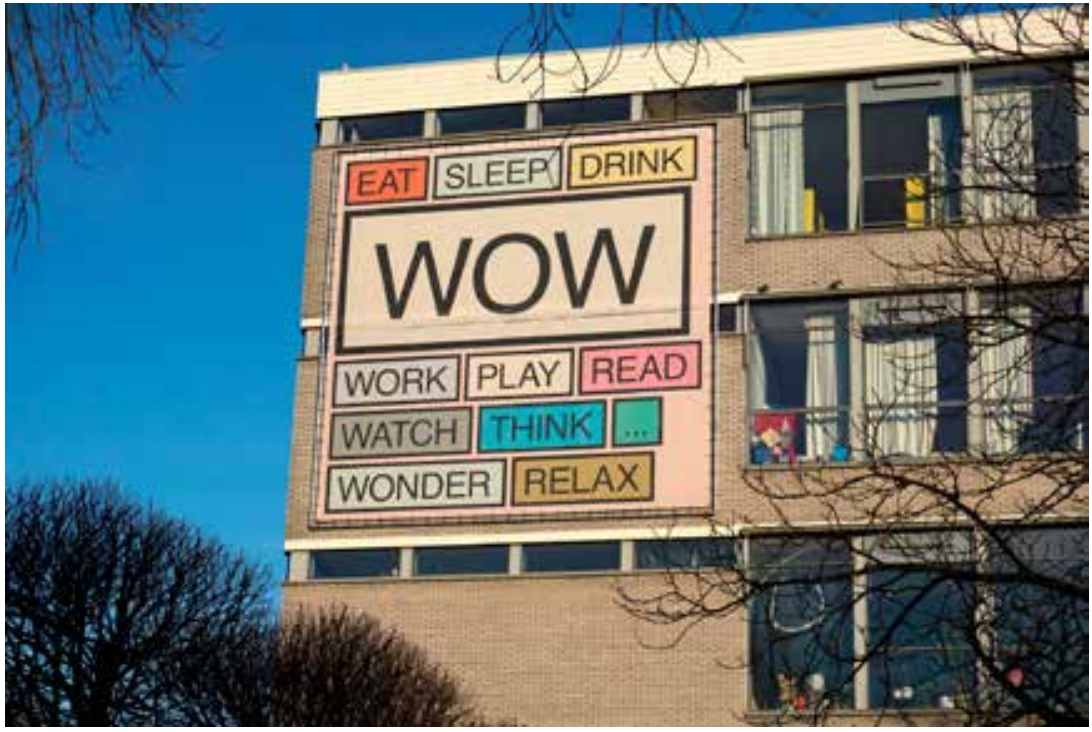

Figure 9.2: Signage on the exterior of WOW Amsterdam. Image by the author.

several years. More importantly, the decorations on the satellite dishes themselves constitute a site of political struggle. Unlike other cultures where such dishes can be a positive sign of wealth or connection to other parts of the world (see Dibazar 2016 on satellite dishes on rooftops in Iran), in the Dutch context they are almost uniformly considered eyesores and are commonly perceived to signify migrants and a bad neighbourhood. In the past 30 years, these dishes have been broadly opposed - e.g. in housing association policy - frequently in a rhetoric of "fighting" them primarily because they are ugly. As I will unpack more extensively below, this general perception of satellite dishes in public and institutional discourse bespeaks an opposition to otherness: xenophobia and racism thinly veiled by the aesthetic judgement "ugly." The dishes indicated that the migrants aren't watching Dutch television, which was often taken as a symbol of "failing multiculturalism" - yet the chief argument against the dishes, in public and institutional discourse, remains that they are ugly. The decorations on the dishes are thus a response to make pretty on the surface what is deemed ugly on the surface, part of a complex and layered political discourse.

The aesthetics of WOW are equally political in nature, in the sense that they are part of a strategy aimed at altering a neighbourhood. When viewed critically, the creative incubator generally acts as a cultural-artistic crowbar for gentrifying a neighbourhood. As a government-led gentrification policy, it involves aesthetics in two ways. Firstly, WOW foregrounds activities geared 
towards aesthetics - in the sense of having to do with visual beauty - as a space for art exhibitions, art production, fashion, cultural events, and tourism. Secondly, as a space WOW features a particular aesthetic - in the sense of a distinctive look and design - of a hip, reused space in line with a global gentrification aesthetic that instrumentally foregrounds that look of reuse itself. Hence, the aesthetics of this project, in both regards, are inseparable from the politics of WOW as a bridgehead for gentrification and the changes it brings to the area. WOW is therefore a political-aesthetic insertion in the neighbourhood that combines the formula of the creative incubator with a global aesthetic of gentrification.

On both sides of the street, then, politics and aesthetics are deeply intertwined, but with radically different political stakes: a battle for otherness is taking place in the decorated satellite dishes, and WOW is a gambit in municipal gentrification policy. Hence, the question is how these two sides of the street relate to each other. My argument in this chapter is that while the aesthetics of WOW do not directly engage with the dynamics at work in the decorated dishes, the effect is nonetheless that the politics of the decorations are overshadowed, crowded out, by the insertion of a large-scale, culture-led gentrification project. Following the work of Rancière (2004, 2009), this case study therefore underscores how aesthetics itself is a matter of politics. While gentrification research has frequently focused on displacement of people in gentrification process (Marcuse 1986; Slater 2006; Newman and Wyly 2006; Shaw and Hagemans 2015), I argue that WOW works as an instance of the displacement of aesthetics through gentrification.

\section{A Bad Neighbourhood with Satellite Dishes}

Firstly, some context about the neighbourhood is necessary before unpacking this case study. The neighbourhood, part of the larger area called Bos en Lommer, was part of a large-scale expansion of Amsterdam, envisioned in the General Extension Plan of 1934, but built in the early 1950s, in the post-WWII reconstruction period when funds were limited. The area chiefly consists of rows of cheaply built social housing, in modernist apartment blocks - basically north-south oriented oblong boxes - generally five storeys high, aimed at housing the working class (for a history of the area see Van Rossum 1993). However, unforeseen suburbanization of the working class in the 1960 os left much of the housing stock vacant. This meant that a concurrent influx of migrant workers and their families could be housed there instead (Cortie 2003). Ever since, the neighbourhood 
has been characterized by a high proportion of residents with a migrant background, predominantly Moroccan and Turkish, which entails a great number of satellite dishes attached to balconies and façades. The residents use the dishes to view television channels - often in Arabic or Turkish - that aren't available through basic cable. Hence, the satellite dish is a marker for non-white residents, particularly associated with low-income areas of social housing.

In 2007 the neighbourhood was designated the worst in the country, based on a government ranking that factored in issues like average income of the residents, level of education, size and age of houses, vandalism, and survey data on satisfaction and desire to move elsewhere (Ministerie van Infrastructuur en Waterstaat 2007). This governmental ranking - highly criticized at the time - profiled neighbourhoods on the basis of criteria that were in many respects a given for the areas. For example, social housing regulations entail a necessary correlation between maximum apartment size and level of income, and consequently a correlation with level of education and frequently race and migrant background as well. Stigmatization in terms of class and race was the result. Still, the government designation consolidated the general perception that this was a bad area. The satellite dish is relevant in this regard, since it is commonly regarded as a symbol for a bad neighbourhood. The chief complaint about the satellite dish is that it is ugly, which amounts to xenophobic and affectively charged rhetoric in aesthetic terms. Especially since the 1990s, there has been a consistent public and institutional discourse - e.g. in housing association policies and in legal proceedings - that has opposed these satellite dishes. The common sentiment is candidly explained in this example taken from Amsterdambased newspaper Het Parool:

Ten, fifteen years ago the satellite dish symbolized everything that was wrong with the multicultural society... Stories about migrants were invariably illustrated with images of tenement buildings with white dishes as far as the eye could see. The message: there's poor integration here, and a strong orientation towards Turkey or Morocco [...] the ongoing battle against the satellite dish is always waged under the banner ofdefacement. Dishes are prohibited because they affect a neighbourhood's image, but also because damage to the buildings occurs while placing them. According to [a chairperson of a tenants' association] those are important reasons to want as few satellite dishes attached to buildings. "But also because the dish represents decay and a lack of integration." (Kruyswijk 2015, emphasis added) 
The common discourse thus seems to concentrate on the satellite dish not so much in its materiality, but on its representational function as sign of otherness. More to the point, the dish becomes the focal point for a combative rhetoric, presented as a symbol of problems of multiculturalism that negatively affects a neighbourhood and thereby requiring an 'ongoing battle' against it. The dishes are not themselves decaying - some of them are brand new, and in fact the installation of new dishes frequently faces the greatest opposition - nor do they realistically point towards a lack of 'integration'. In fact, a study commissioned by the authoritative Netherlands Institute for Social Research (Van den Broek and Keuzekamp 2008) debunked any notion that these satellite dishes and the associated television watching behaviour realistically related to any lack of integration. These notions of decay and problems of integration are part of a xenophobic rhetoric, which takes the material presence of these objects to be a negative sign of otherness and subsequently casts resistance to this material-presence-assign in aesthetic categories: the dishes are opposed under the banner of 'defacement', of making the neighbourhood ugly. If one places this common discourse against satellite dishes alongside the governmental designation of part of Bos en Lommer as the worst neighbourhood in the country, one can see the political charge that these dishes symbolically have: not only as a condensation point for xenophobic rhetoric, but also a representation of urban decay.

The connection between aesthetics and politics at work in the satellite dishes can be further understood with some examples from legal discourse. Since the 1990s, dozens of court cases in the Netherlands have revolved around these dishes, typically involving disputes about the removal of a dish between housing associations and their tenants. The outcomes of these cases have varied, depending on the details of the particular case. If anything, these legal battles show that the institutional opposition to satellite dishes is not clearly winning. Yet the arguments made in these cases are telling. The objections from the housing associations commonly revolve around not following regulations or permission procedures regarding installation of dishes, as well as aesthetic arguments that satellite dishes negatively affect a building's or area's general image. The tenant's defence frequently turns to Article 10 of the European Convention on Human Rights, which lays down the freedom of expression and includes the freedom "to receive and impart information and ideas without interference by public authority and regardless of frontiers" (European Court of Human Rights 2010). The typical court case thus revolves around weighing regulations and aesthetic objections against human rights. 
As in popular discourse, defacement is the key term legal disputes too. It should be noted that the Dutch term - "ontsieren," literally "unprettying" - denotes the undoing of a pre-existing beauty that usually goes undiscussed. The term is therefore structured such that it focuses on changes to a presumed status quo. A recent court case before the Amsterdam Court of Appeal, widely considered to set an important legal precedent, provided a more specific definition of defacement in the case of satellite dishes. The chief argument that led to ruling in favour of the housing association in this case was the sufficient availability of alternatives for watching foreign-language television via the internet - a ruling that has become more prevalent in recent years. Nonetheless, the court took on aesthetic arguments as well:

In the weighing of interests the court takes into consideration that the installed satellite dish is clearly visible on the façade of the building, even if the dish is not white. The building is, as [the housing association] has rightly argued, situated in an image-defining location on the IJ [waterfront] and, being an old warehouse, is characterized by sleek architecture. This sleek architecture is interrupted by the presence of satellite dishes, which can thereby be considered defacing. [The housing association] therefore has a reasonable interest in opposing the presence of the satellite dish on aesthetic grounds. (Rechtspraak 2015, emphasis added)

This part of the ruling clearly grounds itself in visual categories: visibility in public space, colour, general image of the waterfront, and architectural style. Other factors that might play a role in housing are not raised, for example the fact that everyday life means inhabiting a space and making it one's own. On the basis of visual and aesthetic categories, then, the ruling assumes that the sleekness of the architecture - for which the Dutch term "strak" could also be translated as "tight" or "rigid" - as a pre-existing order, whose pre-existence is taken as a given. Interruption of that order is subsequently judged to be defacing. This part of the ruling thus follows the structure of "defacement" in presuming a particular prior aesthetic and regarding the dish as an aesthetic imposition that sullies the underlying beauty. Furthermore, the negative aesthetic judgement of the dish hinges not on an inherent property of the dish - it is not deemed ugly in itself - but on the fact that the dish is an object out of place: it does not aesthetically belong there. As with the public discourse that dismisses the dishes as eyesores, the court's ruling focuses mainly on the dish as ugly addition, not on the building's beauty. 
The opposition to the satellite dish, in popular discourse and in law, should be understood in light of Rancière's work on the connection between aesthetics and politics. On a surface level, the opposition to the dishes as ugly clearly casts political opposition in aesthetic terms, in the sense of pertaining to beauty (or its opposite). However, Rancière's understanding of politics and aesthetics is more fundamental and pervasive, which he developed with specific reference to modern art, but is employable more broadly (e.g. Dikeç 2012, illustratively uses Rancière's work to understand the representation of the banlieues in French media). Rancière argues that the realm of the sensible - that which can be seen, said, and understood - is structured through an organization of what registers as sensible in the first place. He calls this the "distribution of the sensible" which "reveals who can have a share in what is common to the community based on what they do and on the time and space in which this activity is performed" (Rancière 2004: 12). Simply put, the distribution of the sensible includes as visible those who have a place in the shared socio-political order and have a voice, and excludes as invisible those who do not register and have no voice. Politics, for Rancière, then becomes not a matter of institutional relations of power, but of "the configuration of a specific space, the framing of a particular sphere of experience, of objects posited as common and as pertaining to a common decision, of subjects recognized as capable of designating these objects and putting forward arguments about them" (2009:24). Aesthetics are politics, and vice versa, in the process of shaping urban space and determining who has a place and a voice there and who hasn't.

In this light, it becomes clear that what is at stake in the satellite dishes is precisely a political-aesthetic clash over otherness, in terms of a distribution of the sensible. The presence of the dishes on the façades constitutes a symbolic shaping of urban space in which the practices of the residents are made visible. They make sensible the otherness of the residents, which is also precisely the basis for the opposition to the dishes: designating the dishes "ugly" and "defacing" is precisely an endeavour to render mute those others in their capacity of shaping their urban environment. The dish as eyesore that represents decay, as in the newspaper example cited above, takes the everyday practices of the residents out of the picture (the image of a neighbourhood), rendering their voices mute. Likewise, the legal ruling cited above stipulates what is deemed commonly apparent and what is not. Architectural style is taken into account and practices of everyday life are not. More to the point, the general image-defining property of the building is valued - which implicitly extends to real-estate value - whereas an everyday object from a migrant resident is deemed an unsightly imposition by virtue 
of being a visible addition. Hence, the aesthetic judgement not only has legal consequences, but is also deeply political in nature in that it allocates which objects - and thereby which people - belong in public space and which should not be visible. The opposition to the dishes therefore amounts to a distribution of the sensible that in this case oppresses otherness.

This finally brings me back to the decorated dishes in the street in Bos en Lommer. I argue that these decorations should be regarded as a response that takes the political-aesthetic discourse against satellite dishes head on. On an immediate and simple level, the decorations respond to the common disapproval of the dishes as being eyesores by making them prettier. More substantially, though, the decorations highlight precisely the superficial rhetoric of the opposition to them, because undoing the perceived ugliness of these dishes does not in fact substantially undo the problem. After all, it is not aesthetics in the simple sense of beauty vs. ugliness that is at stake, but rather aesthetics as politics - the distribution of the sensible which accords what and who belongs in public space and not. Hence, the decorations call attention precisely to the xenophobia inherent in the judgement of the dishes as ugly impositions. In the same gesture, the decorations call attention to the material presence of the dishes in the first place, a making-visible precisely of an everyday object of the people who reside there. Hence, by prominently adding colour, these dishes evince a dense and layered battle for otherness, as a form of resistance that offers a redistribution of the sensible, by highlighting the political-aesthetic struggle taking place within them.

\section{WOW as Creative Incubator}

Across the street, an entirely different political-aesthetic battle is taking place, with entirely different stakes. Since 2014 the former school building has been in use as WOW Amsterdam. It has become a successful instance of the municipal "creative incubator" - broedplaatsen in Dutch - policy (see Gemeente Amsterdam 2019). Typically, these projects involve disused buildings or sites which are municipally designated for reuse as art spaces, businesses in the creative industry, and for cultural activities. In the case of WOW, this former school building now provides exhibition spaces, temporary artists' accommodation, a restaurant, cultural and educational activities, and a hostel for tourists. Hence, WOW is a municipally-designated project, in an area consisting largely of (originally) state-funded social housing. As Peck (2012) explains in his account of the emergence of this policy in the late 1990s, Amsterdam consolidated existing developments in the city's 
cultural landscape - e.g. rooted in projects originating from the squatters movement - into creative city policies, making use of the hype surrounding Richard Florida's ideas on the creative class in the early 200os. The creative incubator policy in Amsterdam, for Peck, shows that "creative policies are contributing to the extension and consolidation of culturally normalized neoliberal-urban rule. They purposefully legitimize and rationalize highly targeted and fiscally modest urban investments, justified on the basis of putative (but in practice highly elusive) economic returns" (2012: 482). As Peck explains, these projects require relatively little financial investment, making the policy a cheap way to potentially raise the profile (and realestate value) of a neighbourhood. While the link between art, culture and gentrification is a long-standing one - e.g. classically explored by Zukin (1982) and for more on other initiatives in Amsterdam that employ art in the process of urban redevelopment, see Lindner and Meissner (2015) - the creative incubator is thus an example of art-led urban regeneration but also clearly of a government-led form of gentrification.

In this regard, the case of WOW should also be viewed within the broader context of government-led gentrification in the Netherlands. As Uitermark et al. (2007) discuss, Dutch government-led gentrification policies target "practically all disadvantaged urban neighbourhoods" (126) in which the goal is not merely to advance the middle classes or to increase the tax base, but rather "gentrification is a means through which governmental organizations and their partners lure the middle classes into disadvantaged areas with the purpose of civilizing and controlling these neighbourhoods" (127). Such policies are not geared towards financial gains per se, but are employed as tools for the ideological goal of civilizing and controlling - in other words: disciplining - neighbourhoods that are considered bad. Under the banner of increasing "liveability," government-led gentrification policies amount to political interventions in the everyday lives of the inhabitants of a neighbourhood, for example by reshaping urban space and changing who can live there. WOW Amsterdam, therefore, can be seen as an instance where creative policies and government-led gentrification policies intersect as a means of intervening precisely in the neighbourhood that was designated the worst in the country. While it is beyond the scope of this chapter to further analyze the recent developments in the local housing market and subsequent demographic changes, a significant portion of the social housing stock in the neighbourhood is being demolished, replaced, and sold off into the private market by the housing associations. In this regard, the dynamics of the creative incubator policy are in line with Atkinson and Easthope's findings (2009) in several Australian cities where they discern "the often tacit 
understanding of the ways in which encouraging artists provides a seedbed for a kind of staged gentrification," which goes hand in hand with "a greater optimism toward the role of arts and communities in the development of the city, but also the much clearer elevation of artists as the temporary vanguards of creative strategies, often displaced by the subsequent raising of rents through commercial and residential gentrification" (71).

The combination of art-culture-tourism in WOW further extends the policy-level conjunction between politics and aesthetics by partaking in what can be understood as a global gentrification aesthetic. Mathews (2010) argues that the "inclusion of the arts as a seedbed for gentrification has led to the rise of controlled and contrived spaces designed around the public consumption of art, artists, and art spaces. Flagship architecture, cultural quarters, festivals, and public art displays are used to promote a liveable' and 'beautified' urban core, aspects that are highly valued in attracting the middle and upper-middle classes" (672). This can be cast in terms of what Lees et al. (2008) discuss as the "gentrification aesthetic": a "gentrifying or gentrified neighborhood has a certain 'feel' to it, a certain look, a landscape of conspicuous consumption that makes the process readily identifiable" (113). A further understanding of the gentrification aesthetic, beyond aesthetics referring simply to matters of visual appearance and beauty and focusing more on consumption, is developed frequently with reference to Bourdieu (e.g. Jager 1986; Bridge 2001, 2006; Ley 2003) as a middle-class aesthetic disposition oriented towards cultural capital, which is economically valorized. Such a "look" and aesthetic are recognizable components of many of Amsterdam's creative incubators. Obviously, the prominence of art and fashion in the case of WOW makes it a space for the consumption of culture.

More importantly, in my view, this gentrification aesthetic is apparent from the building of WOW itself. The existing building is left mainly intact, still recognizable as a large school building, but prominently marked as reused for a different purpose (e.g. in the huge sign on the front of the building in Figure 9.2). The effect of this "look" is twofold. Firstly, it conveys reuse itself as a marker of urban redevelopment, with processes of change being valued in themselves. This can be seen in the emphasis on temporariness and dynamism, as on WOW's website, for example (see Figure 9.3). Secondly, this "look" conveys that the reuse is artistic/cultural in nature, rather than commercial, for example. Even the most commercial side of WOW, the tourism, is framed in terms of consumption of art and culture, as will be discussed in more detail below.

In this chapter, however, I emphasize the inherently political aspect of the gentrification aesthetic itself. Within gentrification processes and policies 
like the creative incubator, the foregrounding of the visual, the beautiful, or the fashionable "look" of an area should, I argue, be viewed as a political organization of urban space. My turn to Rancière shifts attention to the idea that the gentrification aesthetic is not only a matter of a response to or consumption of culture and the arts. Rather, the global gentrification aesthetic, especially in government-led cases like WOW, is structured such that it entails who has a place and a voice - e.g. middle-class citizens and the globally operating creative class - and who does not. The inclusionary and exclusionary dynamics of gentrification are part and parcel of the aesthetics of gentrification itself. In practical terms, the creative incubator policy serves to make visible the redevelopment of an area of the city, allocating to artists and the creative class a new share in public space. Yet while the figure of the artist or cultural producer is the poster child for projects like WOW, one should not automatically attribute agency or empowerment to artists and producers in the process of gentrification. As Ley (2003) argues, "to blame artists for the gentrification that so often follows their residency in a district is a misplaced charge; it is the societal valorisation of the cultural competencies of the artist that brings followers richer in economic capital" (2541). Unlike the Canadian context Ley writes about, in the Dutch context the societal valorisation is not dependent upon market dynamics but is inherent in the government-led nature of the creative incubator policy. Hence, as Peck (2012) argues, "for their very credibility ... creative-cities policies must tap into, and valorize, local sources of cultural edginess, conferring bit-part roles to creative workers as a badge of authenticity for the policies themselves" (468). What the creative incubator renders visible, therefore, is above all the policy and discourse of creativity in the service of neoliberal politics of urban redevelopment. The visibility of art and culture in these projects should therefore be understood as itself representational in class terms: the point of such gentrification policies is to make visible the redistribution of the share that the middle class can or will have in a redeveloped neighbourhood. In simple terms, in foregrounding the aesthetic in art, culture and fashion, the aesthetics of WOW therefore communicate above all "gentrification is going on here."

\section{WOW: Difference and Aesthetic Displacement}

Perhaps the key feature of WOW - and of the creative incubator policy in general - is that it explicitly injects difference into the neighbourhood. This is underscored on WOW's Facebook page under "About": "WOW is 
where tourists open to cultural exchange rub shoulders with recent art school graduates, and where community influencers walk the halls with tomorrow's agents of change" (WOW Amsterdam 2017). Every element of this self-description underscores the difference between WOW and its neighbours. Firstly, whereas the migrant population of the neighbourhood is aging, WOW squarely emphasizes youth, both in focusing on recent art school graduates - graduating school is evidently not indicative enough of youth - and in the type of tourist it aims to attract, with its shared dormitories described as "clean and mean rooms in primary colours, for city people and art lovers" (WOW Amsterdam, n.d.). Secondly, the focus is on art and culture in a neighbourhood that has very little to offer in that regard. This implies on the one hand that WOW is a destination itself as an art and culture enclave within this neighbourhood. Apart from the announced shoulder-rubbing with artists, the shared dormitories are described with "What's more? Lots of possibilities to meet other creative people!" (WOW Amsterdam, n.d.), indicating again that WOW itself is a destination particularly for the globally mobile creative class. In addition, this emphasis on art and creativity is an attempt to rhetorically reshape the city, to extend the "artscape" of Amsterdam - traditionally concentrated in the city centre - to include the neighbourhood of Bos en Lommer. Lastly, the lingo of "influencers" as encountered on social media, which joins forces with tomorrow's agents of change (in whatever realm), underscores that making a difference lies at the heart of WOW as a project. WOW is thus explicitly predicated on difference to its surroundings, with that difference itself recursively geared towards transformation and with art and culture as its primary domain - actively reshaping who has a place where in the city.

This difference with the surrounding neighbourhood is also reinforced visually, prominently in the signage on the front of the building (see Figure 9.2). The rectangles in the sign do not break with the rectangular, modernist architecture, but the once-stark but now slightly faded colours of the boxes do. They inject a note of colour, like the decorated satellite dishes do, in an otherwise drab area. Moreover, the range of verbs on the sign stands in a curious relation to the neighbourhood as a primarily residential area. WOW's sign amounts to an inventory of activities of everyday life - eat, drink, sleep, work, play, read, watch, think, wonder, and relax. This inventory of possible actions in WOW is strikingly mundane, unlike the art-and-change-oriented discourse with which WOW presents itself online. The question is then to whom this sign is directed. If it were directed to the artists residing in WOW, something like "create," "design," or "exchange" might seem more pertinent. If it were directed towards the 
tourists, the message seems hardly distinctive and also incongruous with the presentation elsewhere of WOW as unique. Likewise, the sign does not seem to be a message straightforwardly directed towards the people of the neighbourhood, who might go eat there or watch art but are very unlikely to sleep in the hostel. In my reading, then, the sign on WOW's façade is not a message directed towards anyone in particular, but rather serves as a catalogue of everyday life so as to integrate WOW into the everyday life of the area: just as people lead their everyday lives in this residential area, so too does everyday life take place in WOW Amsterdam. Of course, this integration is superficial and contradictory, since the everyday practices of residents who inhabit the area differ significantly from the artists in their temporary studios and the tourist practices of the (young, hip, art-minded) guests of the hostel. The sign therefore suggests continuity with the area but in so doing instead underscores the difference between WOW and the rest of the neighbourhood.

Furthermore, the sign on the building's exterior points to crucial point of difference, namely that the aesthetics of WOW are to a certain extent attached to their locality - the specificity of this particular creative incubator - but are geared towards extending globally. In contrast, the surrounding neighbourhood remains decidedly local in character. As a mainly residential area consisting of social housing, it is not an area that has traditionally contributed to Amsterdam's self-styled brand as a global city, which is oriented particularly towards neoliberal capital and finance. This branding is frequently historically anchored in the city's mercantile past in the seventeenth century, and generally ignores histories of colonialism and migration. Culturally, the focus has been on cultural heritage - located in more central areas and the creative industries. This branding notably downplays the migrant backgrounds of the residents of poorer areas (pre-gentrification, at least) such as Bos en Lommer. WOW not only differs because it attracts tourists from across the world, but this global outreach is also enacted aesthetically, as becomes clear from WOW's website (see Figure 9.3). The design of the signage on the building's exterior, with its colourful rectangles, is extended on the website, where it makes up the navigation menu, for example. The coherence of the design between material and virtual space can be read in two directions. On the one hand, the website continues the aesthetics of the building's signage online, extending the local aesthetics globally. On the other hand, particularly from the perspective of a tourist whose first encounter with WOW is likely its website, for the purpose of making a reservation, the graphic design of the sign can be seen as extension of the online presence of WOW, making the local an instantiation of a global aesthetic. 


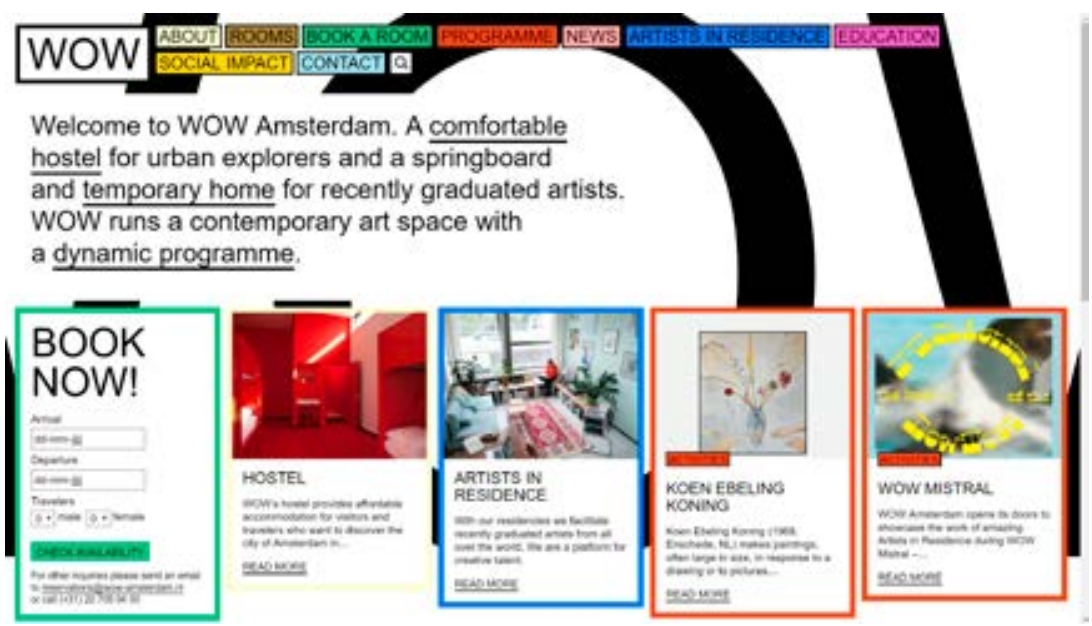

Figure 9.3: WOW Amsterdam website (n.d.). http://wow-amsterdam.nl. Retrieved 10 September 2019. Screenshot by the author.

This global aspect of the aesthetics of WOW is a vital point of contrast between WOW and the political-aesthetic battle taking place in the decorated satellite dishes on the other side of the street. As an intervention in a bad neighbourhood, WOW interrupts the distinctly local character of the area with an aesthetic of both gentrification and globalization. It not only colourfully alters the look of the area, but also serves to make this an area for a particular type of tourist: young people, hipsters, and those belonging, or aspiring, to the globally operating creative class. The insertion of this creative incubator in this neighbourhood has thus led to a new presence of tourists in the area, often confusedly looking for public transport which, ironically, is no longer immediately available in front of WOW because of a much-criticized redesign of public transport, frequently to the detriment of poorer areas outside of the city centre (like Bos en Lommer) and to the benefit of tourist areas in the city centre. WOW and its tourist presence radically alter the "look" of the area, which in political-aesthetic terms should be understood as a redistribution of the sensible. The aesthetics of the building and the tourists in the area visually establish who has a place and a voice there: this has become an area for and of the creative class. I argue that one can view the young and art-minded tourists as analogous to the satellite dishes, to a certain extent: both are additions to or impositions on the pre-existing political-aesthetic makeup of the area. The general logic of aesthetically opposing the satellite dishes is that they are impositions that alter the pre-existing aesthetics - they do not belong there and are therefore deemed ugly, at least rhetorically. The introduction of tourists, or the imposition of 
a massive sign on the front of WOW's building for that matter, is no less an alteration of the pre-existing political-aesthetic arrangement in the neighbourhood. Like the migrant residents, the tourists can be viewed as global others, but with the crucial difference that the aesthetic presence of the migrant residents in the shape of their satellite dishes is broadly opposed in highly charged public and institutional discourse, whereas the presence of the tourists has the political-aesthetic neoliberal stamp of approval. The global aesthetic of gentrification has gained a firm foothold, whereas the local political-aesthetic signs of otherness remain under pressure.

Finally, this brings me back to both the similarity in terms of colourfulness and the vast divide in terms of politics between both sides of the street. Colourfulness on both sides of the street is crucial, but it means something else entirely for the decorated dishes and WOW respectively. For the dishes, the aesthetics appear light-hearted on the surface, but entail a dense and layered struggle against socio-political marginalization. Aesthetic opposition to the dishes for being "eyesores" amounts to xenophobic oppression of the everyday practices of migrant residents. The dishes themselves are a battleground for otherness, and the decorations are a political-aesthetic response against the dominant discourse. The politics of the decorations are importantly also markedly local: they pertain to a particular set of objects, belonging to this particular group of people with a migrant background in this particular part of the city dominated by social housing. The constellation of aesthetics and politics is therefore specifically tied to this location. In contrast, for WOW's colour effectuates an aesthetic departure from the neighbourhood on a larger scale, fitting in with gentrification developments within the city as a whole. The colourfulness of WOW stands in contrast with the unassuming neighbourhood, but more importantly the politicalaesthetic change brought about by the insertion of a creative incubator as a bridgehead for gentrification largely serves to counteract any specificity to the location: it inserts a global gentrification aesthetic according to the formula of the creative incubator.

This has significant consequences for the possibilities of aesthetics-aspolitics in the area. In practical terms, WOW is the larger presence because of the size of the building, and emblematically also because of the size of its sign compared to the size of a decorated satellite dish, but also because of the broad (government) backing it enjoys. The dominant aesthetic regime of the area, therefore, is determined much more by WOW than by the decorated satellite dishes. The insertion of the creative incubator in this area is thereby effectively a redistribution of the sensible in that it determines what can readily or commonly be registered and how. Visually 
the dominant association has become that between aesthetics and the politics of gentrification rather than an aesthetics of (and as) resistance. The colourful alteration of the dishes is diminished in its political-aesthetic impact, because colour has largely come to signify something else in the neighbourhood. In other words, the politics within the decorated dishes are rendered mute: the global aesthetics of WOW as a dominant presence crowd out the political-aesthetic battle for otherness taking place across the street. The effect of this gentrification project, therefore, is the displacement of local aesthetics-as-politics.

\section{Conclusion}

In a study of aesthetic aspects of gentrification in Singapore, Chang (2016) argues that "gentrification aesthetics also involves the adding of requisite 'right look' and the expunging of undesired looks" (537). In my case in Amsterdam that does not immediately seem to be happening materially: WOW is successful as an institution but that has not led to conflict with the other side of the street - no particular complaints about the dishes, nor has there been much opposition to the conversion of the school building to a creative incubator, for that matter. In that sense, both sides of the street sit happily side by side. However, in terms of politics and aesthetics the two sides of the street are incompatible. For WOW, the prominence of art and culture is part of its "look" of gentrification, which is an aesthetic spearhead for a creative city and gentrification policy that intervenes in the neighbourhood designated the worst in the country. It visually and aesthetically restructures the area in the interest of neoliberal urban politics. For the dishes, aesthetics is the domain for a battle for otherness, where oppression within public and institutional discourse meets aesthetic resistance in the form of the decorations. The arrangement of who has a place and a voice in this urban space is encapsulated in the contrast between the institutionally opposed satellite dish on the one hand, and on the other hand the politically sanctioned hipsters, middle-class art consumers, and tourists walking in the neighbourhood as a new and instantly recognizable visual presence. The project of WOW does not contribute to the institutional opposition to the dishes - after all, "edginess" is vital for a creative incubator - but the insertion of a globally oriented gentrification aesthetic shifts the dominant aesthetic of the neighbourhood. So while the look of the dishes is not expunged materially, the difference with the other side of the street has the effect that gentrification is displacing the aesthetics-as-politics of the area. 
Note

All translations from Dutch by the author.

\section{Works Cited}

Atkinson, Rowland and Hazel Easthope (2009) "The Consequences of the Creative Class: The Pursuit of Creativity Strategies in Australia's Cities." International Journal of Urban and Regional Research 33.1: 64-79.

Bridge, Gary (2001) "Bourdieu, Rational Action and the Time-Space Strategy of Gentrification." Transactions of the Institute of British Geographers 26.2: 205-216.

Bridge, Gary (2006) "It's Not Just a Question of Taste: Gentrification, the Neighbourhood, and Cultural Capital." Environment and Planning A 38.10: 1965-1978.

Chang, T.C. (2016) “'New uses need old buildings': Gentrification Aesthetics and the Arts in Singapore." Urban Studies, 53.3: 524-539.

Cortie, Cees (2003) “The Metropolitan Population: Origin and Mobility." In Sako Musterd and Willem Salet (eds), Amsterdam Human Capital, Amsterdam: Amsterdam University Press, 199-216.

Dibazar, Pedram (2016) "Leftover Space, Invisibility, and Everyday Life: Rooftops in Iran." In Christoph Lindner and Miriam Meissner (eds), Global Garbage: Urban Imaginaries of Waste, Excess and Abandonment. Abingdon: Routledge, 101-116.

Dikeç, Mustafa (2012) "Immigrants, Banlieues, and Dangerous Things: Ideology as an Aesthetic Affair." Antipode 45.1: 23-42.

European Court of Human Rights (2010) “European Convention on Human Rights.” Retrieved from: https://www.echr.coe.int/Documents/Convention_ENG.pdf (accessed 20 February 2019).

Gemeente Amsterdam (2019) "Amsterdams atelier- en broedplaatsenbeleid 2019-2022." Retrieved from: https://www.amsterdam.nl/bestuur-organisatie/ volg-beleid/kunst-cultuur/talentontwikkeling/.

Jager, Michael (1986) "Class Definition and the Aesthetics of Gentrification: Victoriana in Melbourne." In Neil Smith and Peter Williams (eds.), Gentrification of the City, Boston: Allen \& Unwin, 78-91.

Kruyswijk, M. (2015). De schotels zijn nog lang niet weg [The dishes won't disappear for ages]. Het Parool, 25 Feb 2015.

Lees, Loretta, Tom Slater, and Elvin Wyly (2008) Gentrification. Abingdon: Routledge. Ley, David (2003) "Artists, Aestheticisation and the Field of Gentrification." Urban Studies 40.12: 2527-2544. 
Lindner, Christoph and Miriam Meissner (2015) "Slow Art in the Creative City: Amsterdam, Street Photography, and Urban Renewal." Space and Culture 18.1: 4-24.

Marcuse, Peter (1986) "Abandonment, Gentrification, and Displacement: the Linkages in New York City." In Neil Smith and Peter Williams (eds.), Gentrification of the City, London: Unwin Hyman, 153-177.

Mathews, Vanessa (2010) "Aestheticizing Space: Art, Gentrification and the City." Geography Compass, 4.6: 660-675.

Ministerie van Infrastructuur en Waterstaat (2007) "Wijkenselectie voor de wijkenaanpak - Indicatoren 40 aandachtswijken. 24 April. Retrieved from: https://www.rijksoverheid.nl/documenten/kamerstukken/2007/o4/24/ wijkenselectie-voor-de-wijkenaanpak-indicatoren-40-aandachtswijken (accessed 13 January 2020).

Newman, Kathe and Elvin Wyly (2006) "The Right to Stay Put, Revisited: Gentrification and Resistance to Displacement in New York City." Urban Studies 43(1), 23-57.

Peck, Jamie (2012) "Recreative City: Amsterdam, Vehicular Ideas and the Adaptive Spaces of Creativity Policy." International Journal of Urban and Regional Research, 36.3: 462-485.

Rancière, Jacques (2004) The Politics of Aesthetics: the Distribution of the Sensible. Trans. Gabriel Rockhill. London: Continuum.

Rancière, Jacques (2009) Aesthetics and its Discontents. Trans. Steven Corcoran. Cambridge: Polity Press.

Rechtspraak (2015). “ECLI:NL:GHAMS:2014:5417." 2 February. Retrieved from: https:// uitspraken.rechtspraak.nl/inziendocument?id=ECLI:NL:GHAMS:2014:5417 (accessed 13 January 2020).

Shaw, Kate and Iris Hagemans (2015) “'Gentrification Without Displacement' and the Consequent Loss of Place: The Effects of Class Transition on Low-income Residents of Secure Housing in Gentrifying Areas." International Journal of Urban and Regional Research 39.2: 323-341.

Slater, Tom (2006) "The Eviction of Critical Perspectives from Gentrification Research." International Journal of Urban and Regional Research, 30.4: 737-757.

Uitermark, Justus, Jan Willem Duyvendak, and Reinout Kleinhans (2007) "Gentrification as a Governmental Strategy: Social Control and Social Cohesion in Hoogvliet, Rotterdam." Environment and Planning A 39.1: 125-141.

Van den Broek, Andries and Saskia Keuzenkamp (2008) Het dagelijks leven van allochtone stedelingen [The Everyday Life of Immigrant City Dwellers]. The Hague: Sociaal en Cultureel Planbureau.

Van Rossem, Vincent (1993) Het algemeen uitbreidingsplan van Amsterdam: Geschiedenis en ontwerp [The General Extension Plan for Amsterdam: History and Design]. Rotterdam: NAi publishers. 
WOW Amsterdam (2017) “Our story." On Facebook, 29 November. Retrieved from:

https://www.facebook.com/WOWamsterdamNL/ (accessed 12 September 2019). WOW Amsterdam (n.d.) "WOW." Retrieved from: https://www.wow-amsterdam.

$\mathrm{nl} /$ (accessed 12 September 2019).

Zukin, Sharon (1982). Loft Living: Culture and Capital in Urban Change. Baltimore: Johns Hopkins University Press.

\section{About the Author}

Daan Wesselman is a Lecturer in Literary and Cultural Analysis at the University of Amsterdam and a researcher affiliated with the Amsterdam School for Cultural Analysis. His research revolves around materialdiscursive interfaces between the body, the city, and everyday life, seeking to methodologically bridge the humanities and urban studies through a focus on concepts like heterotopia, the right to the city, and the posthuman. Recently, he co-edited - with Simon Ferdinand and Irina Souch - the volume Heterotopia and Globalisation in the Twenty-First Century (Routledge, 2020). 


\section{Part 3}

Agency, Voices, and Activism 



\title{
10. Boulevard Transition, Hipster Aesthetics, and Anti-Gentrification Struggles in Los Angeles
}

\author{
Jan Lin
}

\begin{abstract}
I examine street-level dynamics of gentrification in Northeast Los Angeles, where artists and residential pioneers who contributed to neighbourhood revitalization have subsequently been threatened with displacement by speculator-investors and corporate developers. In the "neo-bohemia" of Northeast L.A., the aesthetics of countercultural and ethnic subcultural expression have been appropriated by hipster entrepreneurs and gentrifiers. Neoliberal urban policies like public incentives for market rate housing and transit oriented development have sparked accelerated gentrification, countered by anti-gentrification movements from Latinx protestors who view art galleries and hipster aesthetics as harbingers of gentrification. The aesthetics of art and theatre are also part of the toolkit of anti-gentrification activists as they take to the streets to claim their right to the city.
\end{abstract}

Keywords: neo-bohemia, hipsters, neoliberal capitalism, displacement, Latinx community, anti-gentrification

For decades, Los Angeles was an epitome of the decentralized sprawling post-war automobile oriented metropolis. It diverged from the pattern of US cities like Chicago and New York and European cities like London and Amsterdam with strong central business districts and pedestrian civic centres. Some 30-40 years after appearing in US East Coast cities and Europe, gentrification now has become a growing phenomenon in Downtown L.A. and inner-ring neighbourhoods as Angelenos are drawn to the city

Lindner, C. and G.F. Sandoval (eds), Aesthetics of Gentrification: Seductive Spaces and Exclusive Communities in the Neoliberal City. Amsterdam: Amsterdam University Press, 2021 DOI 10.5117/9789463722032_CH10 
centre as an antidote to the daily challenge of long commutes in the urban sprawl. Neighbourhoods of Northeast Los Angeles like Highland Park and Eagle Rock, with their historically significant Arts and Crafts architecture, bohemian arts scenes, racial/ethnic diversity, and small business vitality, have drawn young professionals and entrepreneurs escaping the cultural and residential conformity of shopping malls and tract home developments in exurban locations. Hipsters and newcomer gentrifiers are lured by the "authentic urbanism" (Zukin 2010) and small-town intimacy of the Northeast L.A. boulevards, which are crossroads of ethnic culture (Latinx and Asian) and vintage Americana.

I contribute to urbanist theory regarding a "stage model of gentrification" where artistic and residential pioneers and immigrant households foster a period of aesthetic and commercial revitalization but are later threatened with displacement, with accelerating dynamics of gentrification brought by speculator flippers and corporate developers. The aesthetics of countercultural protest and subcultural expression have been appropriated and seductively marketed by newer residential and commercial entrepreneurs. The hipster is more a consumer of rebellious aesthetics than a countercultural artistic producer. There has been the rise of anti-gentrification activism as Latinx protestors see art galleries as harbingers of gentrification and a new form of colonialism. Newer generation Latinx communities encounter a starkly different city than their predecessors in the early 1970s. Gentrification epicentres like Northeast L.A. give a revealing window on the nature of class struggle in the twenty-first century. In this era of neoliberal urbanism, neighbourhoods have emerged as new creative landscapes of production and flashpoints of interethnic contention over urban use values, forcing new questions and challenges for citizens, coalition builders and policy makers.

I examine the aesthetics of gentrification in Northeast L.A. through the prism of its boulevards that are main stems of embodied social practice and barometers of economic and cultural transition. I illustrate the convergence of trends including neighbourhood activism, urban biking, and transitoriented development (TOD) that have recently renewed the public culture of Northeast L.A. boulevards. These trends are mirrored more broadly in neighbourhoods throughout metropolitan Los Angeles. I then turn to explore the role of artists and entrepreneurs in creating a hipster "neo-bohemia" that has promoted a "geography of buzz" attracting visitors, new residents, and investors to the boulevards. Finally I reveal the intersecting practices of state planners and capitalist interests that have led to neoliberal urban restructuring of the Northeast L.A. built environment and the clashes over the accelerating displacement of residential households and small businesses. 


\section{Boulevard Transition in Urban Historical Context}

The boulevards and neighbourhoods of Los Angeles experienced an urban history cycle of investment, disinvestment, and reinvestment from the turn of the twentieth century to the turn of the new millennium. Urbanist authors such as Hoover and Vernon (1959) and Schwirian (1983) fostered "life cycle" theories recognizing how neighbourhoods go through historical stages of birth, maturation, decline, and renewal. The fierce critic of post-war freeways and urban renewal Jane Jacobs, who helped inspire a generation of community activists, espoused similar views in her seminal book, The Death and Life of Great American Cities (1961). Marxist geographers such as Neil Smith (1979) opined that the post-war movement of capital to the suburbs and depreciation of the inner city through abandonment and redlining created a "rent-gap" between inner city and suburbs that set the stage for the subsequent "back to the city" movement behind gentrification. David Harvey (1989) also addressed the contradictions of urban capitalism and spotlighted master planners as engineers of "creative destruction" who viciously slum cleared inner city neighbourhoods while activating the Enlightenment spirit of heroic modernity in redevelopment schemes from mid-nineteenth-century Paris to mid-twentieth-century New York.

A neighbourhood life cycle perspective similarly informs the concept of a "stage model of gentrification" that was kindled by studies of US cities experiencing reinvestment in the late 1970s (Clay 1979; Gale 1979) and has also been applied to European cities (Lees et al. 2008). The stage model of gentrification emphasizes how pioneering home buyers and small business owners are subsequently displaced or superseded by speculator-investors and corporate developers. The stage model contributes to an understanding that gentrification doesn't just happen anywhere, but occurs especially in focal neighbourhoods where residential pioneers and risk-averse commercial entrepreneurs invest their capital and sweat equity in efforts of rehabilitation and restoration of disinvested building stock. Aesthetical revitalization is furthermore buoyed by the beautification efforts of artists and neighbourhood activists engaged in architectural and cultural historical landmarks preservation.

Northeast L.A. (NELA) is a prime example of the stage model of gentrification where an earlier period of aesthetical revitalization was subsequently followed by a phase of gentrification and displacement. The Arroyo Seco region of Northeast L.A. was the first major art colony of the metropolis as West Coast hub of the Arts and Crafts architecture and design movement, but had fallen into economic and cultural decline with mass suburbanization and white flight in the mid-twentieth century. The Arroyo arts scene began 
a revival in the 1970s with the emergence of Latinx art collectives such as Mechicano Art Center and Centro de Arte Publico. They established in Northeast L.A. their traditions of public art, revolutionary Chicanx expression, and civil rights struggle for social justice nurtured in the original heart of the community in Boyle Heights and East L.A.. They helped restore regional public culture and neighbourhood stability and stimulated the return of white artists who established the Arroyo Arts Collective in 1989, followed by the Eagle Rock Center for the Arts in 1997. The Avenue 50 Studio opened in 1999, providing a new venue for Latinx art and raising its aesthetic legitimacy and public recognition for subcultural and street art genres like folk Catholicism, ethnic vernacular, tattoo art, muralism, and graffiti. The juxtaposition of the cultural past and present is evident at the annual Lummis Festival, which features contemporary multicultural music and arts against the backdrop of historic homes and regional heritage. Tours organized by the Arroyo Arts Collective exhibit the work of contemporary artists in their studios and historic Arts and Crafts homes at the annual Discovery Tour. The NELA Second Saturdays Art Night offers the most regular monthly tour of art galleries and mom and pop retail businesses.

We have also seen the rise of community-based efforts to enhance public space like the Take Back the Boulevard campaign of the Eagle Rock Association, which seeks to slow traffic, add bike lanes, and enhance pedestrian access. Broader public bicycling around L.A. has been enlivened since 2010 by CicLAvia events that close the streets to automobile traffic for several hours for bicyclists, pedestrians, and skaters. These urban bicycling events were inspired by the Ciclovías that originated in Bogotá, Colombia, in 1976. The Los Angeles Times architecture critic Christopher Hawthorne wrote a series of stories (2012-2013) chronicling the renewal of public life on several of L.A.'s iconic boulevards, including Atlantic, Sunset, Crenshaw, Lankershim, and Wilshire. He describes a cultural and economic renaissance resulting from the combined efforts of architects, planners, small business owners and community activists. He credits the L.A. Metropolitan Transportation Authority efforts to fund light-rail, subway, and bus networks armed with new funding from sales tax measures approved by L.A. county voters. He describes the rise of a "post-suburban" civic identity in contemporary L.A.. Mayor Eric Garcetti made further commitments to boulevard revitalization with the establishing of his "Great Streets" programme in 2013 to fund design permitting and infrastructure changes to make streets more bicycle- and pedestrian-friendly, attract businesses, and boost quality of life.

CicLAvia gets kudos for promoting carbon-free "green" modes of urban transportation and social mixing among the citizenry. But in working-class 


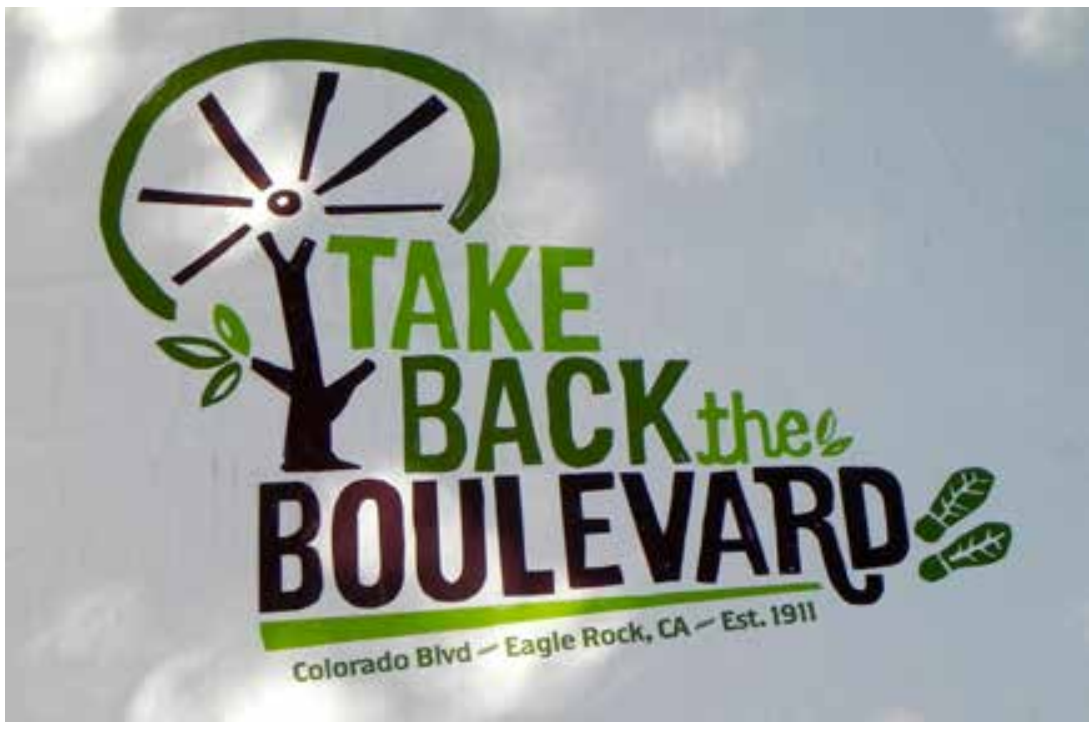

Figure 10.1: Take Back the Boulevard campaign poster. Photograph by the author.

immigrant neighbourhoods like Boyle Heights, CicLAvia is also perceived by some residents and business owners as a phenomenon that brings white middle-income tourists, who subsequently become homebuyers and commercial entrepreneurs and accelerate the gentrification process, while promoting displacement in the transitional neighbourhood (Bermudez 2014). There was local outcry against a May 2014 flier distributed by Adaptive Realty, an LA-based company for a bike tour of the neighbourhood that asked "Why rent downtown when you could own in Boyle Heights?" The flier also cited Boyle Heights as a "charming, historic, walkable and bikable neighborhood," "put down as little as $\$ 40 \mathrm{~K}$ with decent credit," and "2 seconds from the Arts District." Company president Moses Kagan cancelled the event in response to the public controversy. The situation in Boyle Heights reveals the tendency for bicycle advocacy to reinforce white middle-class interests in urban transportation policy and the need for greater attention to racial and social justice and inclusionary strategies in urban planning (Golub et al. 2016).

\section{Artists, Hipsters, and the Geography of Buzz}

The growth of the Northeast L.A. arts scene together with the revival of the boulevards has sparked popular perception of hipster neighbourhoods 
drawing residents and entrepreneurs from nearby higher income artistic bohemian neighbourhoods like Silverlake and Echo Park. Dave Gardetta (a graduate of Eagle Rock High School who returned to be an English teacher at his alma mater while also developing a career as a journalist) wrote a perceptive Los Angeles Times Sunday Magazine cover story in 2001, which chronicled the community's shift from a small-town "Mayberry, R.F.D." to "Hipster, U.S.A," while raising some nuanced questions about the effects of impending growth and development. As a harbinger of the new trend, he drew attention to the opening of S̈̈ork coffee bar by Patricia Neal, a Los Feliz expatriate. A more boosterish Los Angeles Times Weekend Calendar cover story followed (Carpenter 2006) titled "Making Eagle Rock a Hip Nest," drawing attention to the family-friendly retail business and home property environment of the neighbourhood and described: "If the Silver Lake aesthetic is hip, twenty-something and single, Eagle Rock's reflects just the next stage in life. It's just as hip, but thirty-something and married with kids." The "hipster" colonization of Northeast Los Angeles represents another beachhead in the "wave" of gentrification that has swept through neighbourhoods like Venice, Leimert Park, Boyle Heights, and Echo Park (Zahniser 2006).

The growth of the hipster scene has more recently shifted to York Boulevard, which runs between Highland Park and Eagle Rock. The New York Times published a 2009 article spotlighting Highland Park as a "New Culture District in Los Angeles" (Brisick 2009). The Los Angeles Times followed with an article describing Highland Park as "A Hub of Hip, Really" (Nakano 2012). These articles draw attention to the arrival of recent retail entrepreneurs from more affluent neighbourhoods dealing in vintage and hand-made products, with a "do-it-yourself" spirit evident in marketing of artistically refurbished dresses at the Orecul77 (the "hipster tailor shop" owned by Tawni Lucero) and glass-making classes at Cathi Milligan's Glass Studio.

I follow Richard Lloyd (2010) in describing the hipster scene in Northeast L.A. as a "neo-bohemia." Northeast L.A. is a neo-bohemian variant with "neotraditional" and "green" elements drawing people through the qualities of the original small-towns and inner-ring suburbs that are the antithesis of the tract homes and shopping centres of the post-war mass society. People are drawn to the historic residential and commercial architecture, intimate neighbourhoods, community gardens and art parks, and pedestrian- and bicycle-friendly streets that teem with a variety of independently owned small businesses. They are lured by the air of authenticity which is both ethnic (Latinx and Asian) and vintage Americana in character (vintage products include historic homes, clothing, musical instruments, and vinyl 


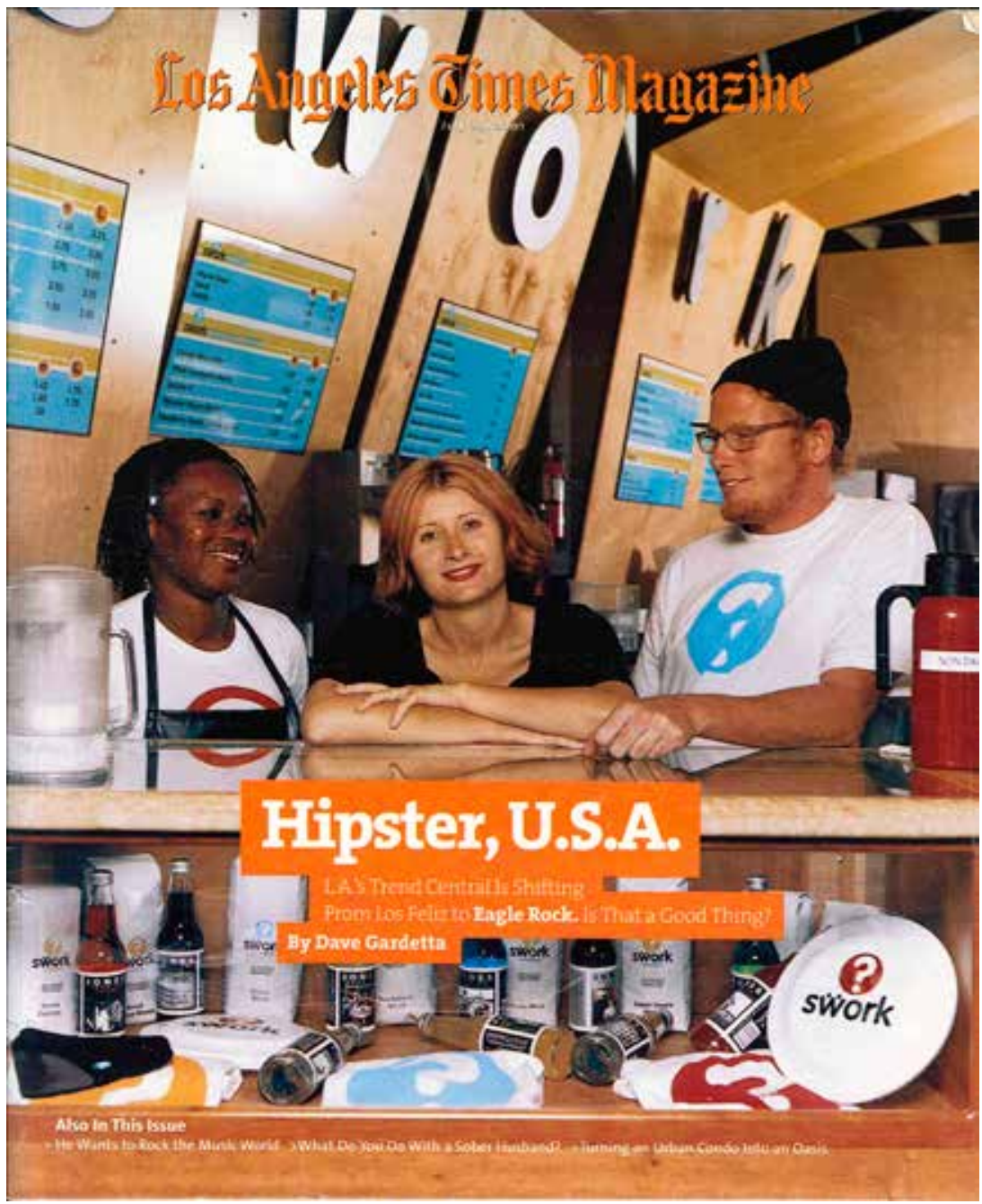

Figure 10.2: Los Angeles Times Magazine story on Eagle Rock in 2001.

records). Foodies are drawn to the authentic thrill of ethnic, fusion, and vegetarian/vegan restaurants. The Northeast L.A. authentic urbanism of the "indie hipster" cultural scene helps satisfy a white middle-class consumer demand for the experience of "living on the edge" and an expressive spirit of cultural rebellion. Buying from small "mom-and-pop" independent businesses can reflect a rejection of large corporate chain store and "big box" merchandisers.

Gentrification in Northeast L.A. also has a Latin edge. The National Public Radio station, 89.3 KPCC, aired a story on 29 April 2013 about Café 
de Leche, an independent coffee shop at the corner of York Boulevard and Avenue $5^{0}$ owned by Anna Schodorf, a Latina of Nicaraguan origin, and her white husband, Matt Schodorf, that has become recognized as a hipster hangout and somewhat of a symbol of gentrification. The couple had met in Highland Park, married, and had kids when they decided to open the coffee shop. Anna professed not to be a gentrifier and that "I'm the café and he's the leche." She comments that some local bloggers had questioned the legitimacy of the name, because the Spanish parlance for "coffee with milk" is usually "café con leche," while she had opted for the Nicaraguan regional phrasing, "café de leche." Carmen Castillo, an employee who grew up in Highland Park and has worked there for five years, said, "It's like my mom; my mom will not come in for a cup of coffee." She said that she was conflicted about the changes going on in Highland Park, as she loved the new businesses that enlivened the boulevard but was worried about never being able to buy a home in the neighbourhood she grew up in.

The phenomenon of Latinx being agents as well as victims of gentrification has also been recognized in Boyle Heights, the traditional commercial heart of the barrio that is now experiencing rapid gentrification with the emergence of a Latinx middle-class and the completion of the Metro Gold Line extension to East Los Angeles in November 2009. An August 2013 New York Times article by Jennifer Medina refers to the process as "gentefication" (a Spanglish term integrating gente, the Spanish word for "people" with gentrification) and the Chicanx hipsters as "Chipsters." The label was applied in a splashy Telemundo (Los Angeles Channel 52) story on "Chipsters" aired on 26 October 2012, which reported on the new destination marketing trend in the Boyle Heights neighbourhood among retailers, bars, and restaurant owners that appropriates the iconography of the historical struggle for Chicanx recognition and empowerment in East Los Angeles in a hip and fashionable Latinx middle-class shopping and entertainment environment. The "gentefication" of Northeast Los Angeles is also under way in Highland Park and Eagle Rock, with the growth of a population of middle-class Latinx home and business owners.

\section{Sociology of Hipsters and Bohemia}

In a set of essays, What Was the Hipster? A Sociological Investigation, Mark Greif and his co-editors (2010) look retrospectively at the phenomenon of the "hipster" which they suggested first surfaced in 1999. In a chapter titled "Positions" (that was also released in similar form around the same 
time in New York magazine), Grief points out that "hipster" is primarily a pejorative insult referring to poseurs and scenesters without a revolutionary core, trends-spotters, cool-hunters, and hangers-on who are attracted to bohemian neighbourhoods and draw their feelings and inspiration from a smaller minority of authentic hard-working artists, writers, and politicos. Grief geographically locates hipsters in neighbourhoods like Manhattan's Lower East Side, Brooklyn's Williamsburg, Jamaica Plain in Boston, Capitol Hill in Seattle, the Inner Mission District of San Francisco, and Echo Park and Silverlake in Los Angeles. Playfully mixing pop cultural parody and serious intellectual referencing, he identifies an eclectic array of hipster consumer motifs and talismans like trucker hats, skinny jeans, flannel shirts, Pabst Blue Ribbon beer, "porno" or "pedophile" moustaches, lumber-jack beards, Americana T-shirts for church socials, collecting taxidermy, Vice magazine, the films of Wes Anderson, locavore food preferences, and indie rock. Rather than fetishizing blackness like the hipsters of the 1950s (like Norman Mailer who wrote the widely-cited essay, "The White Negro"), Greif says millennial hipsters fetishize the whiteness of the lower-class suburban or rural white culture. Rather than being artistic producers of bohemian culture, hipsters are rebel consumers of déclassé culture.

In his book on Wicker Park, Chicago, which he describes as a neo-bohemia, Richard Lloyd (2010) draws attention to the way that neighbourhoods act as generative spaces for cultural production, where aspiring artists can nurture talent, support each other, build local audiences, and acquire wider commercial success by drawing the attention of gatekeepers such as artists and repertoire (A\&R) men in the music industry. He describes how musicians and artists initially colonized Wicker Park, learning to navigate the mean streets and drawn by the appeal of "grit as glamour," and willing to work downscale jobs like waiting tables and bartending to pay the bills while establishing artistic careers. While historically artists of bohemia were more alienated from the prevailing social order, Lloyd says that neo-bohemian artists are less alienated, including the creative entrepreneurs at the cutting-edge of the multimedia and digital economy.

There has been attention in geography and regional planning studies to the "creative economy," that tends to agglomerate in urban clusters that become forces for economic development, counterbalancing some of the broader declines in traditional manufacturing industries. Richard Florida (2002) argues that creative economies foster innovation and aggrandize local endowments of human capital that are not easily substitutable in other locations, and are thus more resistant to the outsourcing that besets manufacturing industries. He locates his "creative class" in high-technology 
corridors and university towns that foster social tolerance and nurture talent and innovation. Creative cities and neighbourhoods can generate media exposure and a "geography of buzz" that can attract audiences and idea-driven firms (Currid and Williams 2009). Terry Clark (2011[2004]) describes cities as "entertainment machines" replete with cultural scenes comprising a variety of cultural amenities that draw residents, tourists, conventioneers, and shoppers.

Elizabeth Currid (2009) notes artists are tied to social networks in the neighbourhood rather than by industry in the phenomena of bohemian and subcultural scenes. She argues that artists create artistic distinction through a process of forming an initial artist colony that subsequently enables their region to capitalize on its own cultural identity (Currid 2009: 376). She also draws attention to how artists create public goods such as youth involvement and educational programmes. She says that art scenes form clusters of "constructed amenities" that, in addition to natural amenities like parks, are key forces in cities becoming centres of consumption. The lure of bohemia is its access to authenticity, but art also helps to gentrify neighbourhoods because it attracts people with disposable incomes.

\section{Hip Businesses and Buzz on the Boulevards}

Classic icons of the urban gentrification landscape are hip cafes and restaurants, retail stores and "boutiques," art studios and galleries, and also bike shops that help create a buzz about the particular neighbourhood. They are among the most visible barometers of the economic revitalization and gentrification process and are typically aligned along commercial boulevards creating a sense of intimate pedestrian encounter along particular block faces, such as York Boulevard between Avenue $5^{0}$ and 52, which was historically dubbed "York Village" by locals. In Eagle Rock, where Colorado Boulevard is wider like a two lane highway with a median, neighbourhood activists have been more intent on slowing down traffic and adding bike lanes through the Take Back the Boulevard campaign. Business life in Highland Park is centralized around a larger prominent commercial downtown on North Figueroa Street between Avenue 50 and 6o. Businesses are more dispersed along Eagle Rock Boulevard as it runs southwards to Glassell Park. All these boulevards have been colonized by new businesses in the era of commercial revitalization and gentrification in the last 15 years.

The presence of a row of commercial shop fronts on urban streets creates the same sense of pedestrian mingling and public intimacy found in classic 
European colonnaded commercial walkways or the covered stoae typical of the Greek agora. The same effect can be found in the Arab suq, and in the commercial streets and merchant emporia of Asian and African cities. On the Parisian boulevards of the mid-nineteenth century was born the flaneur or boulevardier, who sauntered along the boulevard while drinking in the urban spectacle and exploring the diverse and variegated interiors of its commercial arcades. The flaneur was a celebrated protagonist in the novels of Charles Baudelaire and the intellectual writings of Walter Benjamin in his encyclopaedic manuscript The Arcades Project. They wrote about the experience of detachment and alienation from the aristocratic order experienced by the flaneur in nineteenth-century Paris as a general condition of urban modernity. This invites comparison with the contemporary urban hipster, who pursues the buzz of authentic urban experiences and subcultural life on the boulevards of twenty-first-century Los Angeles as an escape from the conformity of post-war mass suburban neighbourhoods and corporate chain store shopping centres of the suburban periphery. If Charles Baudelaire or Walter Benjamin were exploring Northeast L.A. in the twenty-first century, we could imagine them as bicycle flaneurs.

I cite the urban planner Doug Suisman, who discusses the idea of the boulevards of Los Angeles as a historically significant "armature" of public life especially during the streetcar and early automobile era, when the Miracle Mile of Wilshire Boulevard was a grand urban planning prototype for the Linear City of the future that made symmetric and unified disparate elements. But the boulevards became distanced from that promise during the decades of freeway building and urban sprawl, when many Los Angeles boulevards became disinvested and symbols of urban decline and social unrest. After decades of work on street design and urban revitalization planning, Suisman describes streets as a planner's "fuselage" that he architecturally depicts as configurations of roadways, sidewalks, and building fronts through which people move in their daily rounds, creating spontaneous social mixing and cross-ventilation of purpose (2014: 73-77). The well-designed aircraft fuselage, if engineered properly, can result in the achievement of airplane flight. It could be said that the well-designed street planning fuselage, if engineered properly, can result in enlivened public spaces that will generate buzz and the social efflorescence of the successful hip and culturally vitalized community. In Northeast L.A. the fuselage of street revitalization on the block fronts of the boulevards includes bike lanes and traffic slowing, enhanced pedestrian access, sidewalk "porches," and corner parklets. The small business fuselage includes a mix of hip cafes and restaurants, retail boutiques, and arts related businesses. 


\section{Gentrification, Displacement, and the Right to the City}

The neighbourhood transition process had been more gradual during the decades from the 1970s to the 2000s, as pioneering homebuyers, artists, and mom and pop entrepreneurs restored properties and culturally revitalized the NELA neighbourhoods that had become disinvested in the wake of suburbanization and white flight. As the revitalization stage gives way to the gentrification stage in urban restructuring, investment typically accelerates such as in NELA in the wake of the Great Recession after 2010, when there was growing entry of speculator-flippers, corporate developers and architects, and governmental housing and urban development programmes including transit oriented development (TOD) and transit villages. The demand-side social agency of pioneers and risk-averse single-family home buyers increasingly shifts to the supply-side forces of capitalist investment and neoliberal public/private partnership.

As the urban growth machine propels gentrification forward in NELA, it exhibits sharpening socioeconomic and racial overtones, as immigrant working-class Latinx families are increasingly threatened with displacement by rent increases, mass evictions and social uprootedness. Working class households and multi-family networks are also subject to secondary displacement as property transactions and new construction in neighbourhood hotspots stimulate broader property value shifts in surrounding blocks and block groups. The creative frontier of urban restructuring in NELA exhibits a growing destructive violence that illustrates what David Harvey (2012) describes as global capitalism's tendency to foster "accumulation by dispossession" through privatization of public lands and public housing, slum clearance, property foreclosure, and marginalization of the urban poor. He furthermore reflects upon how marginalized and dispossessed people around the world have ignited social resistance and insurgent movements to demand their "right to the city" as urban inhabitants despite their lack of property rights.

The emergence of the Northeast Los Angeles (NELA) Alliance with their first protest march and demonstration along Highland Park's York Boulevard in November 2014 gave public voice to neighbourhood opposition to gentrification and displacement and the need for more affordable housing. With their calls that "Gentrification is the New Colonialism" and that "Housing is a Human Right" the largely Latinx constituency of the NELA Alliance express the frustration of a disenfranchised minority against the appropriation of its neighbourhood homeland and culture by powerful outsiders. They have held organizational meetings, tenant's rights workshops, panel discussions, 


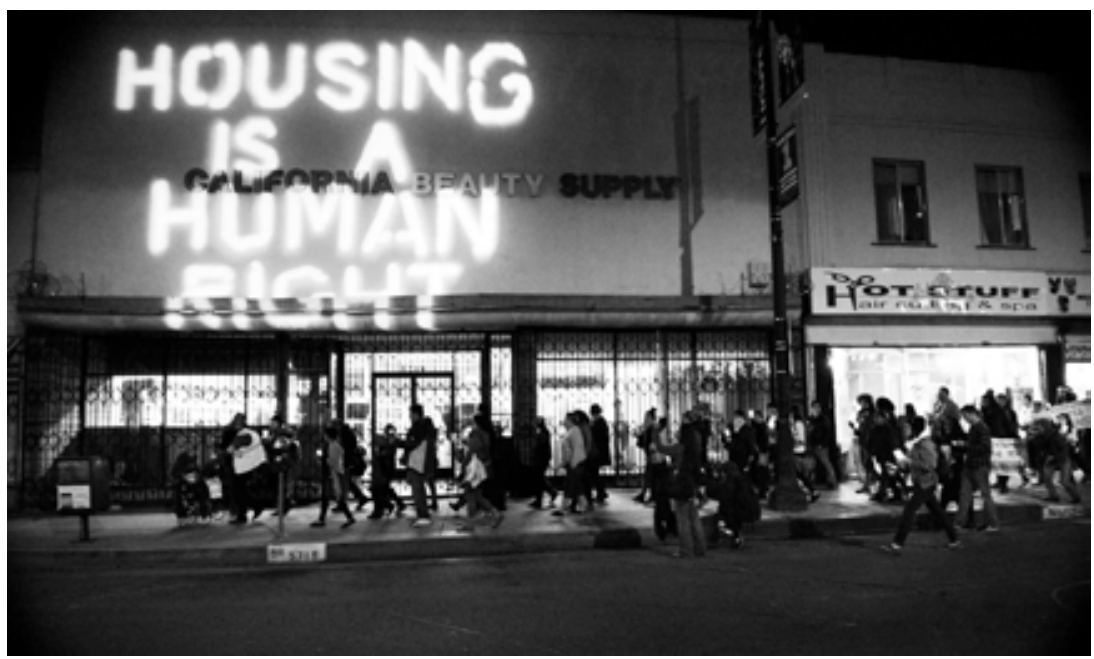

Figure 10.3: "Housing is a Human Right" projection during course of silent procession on 12 December 2014. Photo: John Urquiza.

testimonials, and theatrical events to educate and mobilize the immigrant low-income community. Another group, Friends of Highland Park, contested the development of a transit village along the Metro Gold Line they believed wouldn't serve the immigrant residential and business community.

There is a sense of class struggle amidst the relentless economic violence of capitalism that is reminiscent of Karl Marx and Frederick Engel's famous description in The Communist Manifesto of the global power of the bourgeoisie to revolutionize the mode of production and force the capitulation of the proletariat and their cultural traditions until "all that is solid melts into air." The production of urban space is crucial to the continued expansion of capitalism, yet this process is full of tension and struggle (Lefebvre 1991). The contradictions of urban capitalism as a force of creative destruction have been described by David Harvey and Marshall Berman through epic historical cases like public works prefect Baron Haussmann and his destruction of dense working class neighbourhoods to create the boulevards in mid-eighteenth-century Paris and power broker Robert Moses and his clearing of dense working class communities in New York City in the mid-twentieth century, in favour of bridges, intercity expressways, and the opening up of the suburbs. Fast forward to the twenty-first century, and the malevolence of gentrification is described by Hackworth (2007) as the material and symbolic "knife-edge" of neoliberal capitalism amidst the government retrenchment from the Keynesian egalitarian liberalism of the twentieth century. The capitalist city is a 
main battleground for neoliberal transition as local governments "roll back" Fordist-era housing programmes and social services while "rolling forward" post-Fordist incentives for investment and urban entrepreneurialism (Brenner and Theodore 2002). Under neoliberal gentrification we see the opposing clash of capitalist struggle between exchange value interests for investors, property owners, and state tax revenues versus use value interests for residents, workers, and urban inhabitants (Logan and Molotch 1987).

\section{Friends of Highland Park vs. the Highland Park Transit Village}

Transit oriented development (TOD) is a growing tool of urban public policy to tie public transit ridership to economic development and housing near mass transit stations like the Highland Park stop on the Metro Gold Line. The City-owned vacant land is operated by the Department of Transportation as surface parking lots and plans gradually progressed over several years for a transit village of three buildings with 80 residential units comprising 20 market-rate condos and 60 affordable apartment housing units. The Highland Park Overlay Zone board approved the project in early 2013 and the L.A. Planning Commission granted the developer McCormack Barron Salazar conditional use permits for taller, more densely built housing, which sparked some outcry and debate in the community with regard to the transit village's size, aesthetics, congestion and loss of public parking. The L.A. City Council backed the Planning Commission's decision for higher density and furthermore approved the project to be released from lengthy review of impact on the environment, traffic, and city services.

Community opposition mobilized the Friends of Highland Park, led by a trio self-described as the "three musketeers" including business leader Jesse Rosas, Lisa Duardo, a fierce speaker with ties to the arts community, and Lloyd Cattro, who examined the environmental issues. The movement had support from respected N. Figueroa Street business leaders like Miguel Hernandez of Antigua Bread, Carlos Lopez of Las Cazuelas Restaurant, and William Yu of California Fashion. Duardo attended legal workshops conducted by Advocates for the Environment, jointly sponsored by the Sierra Club at Loyola Marymount University. To pay for legal costs, the Friends of HP raised some $\$ 30,000$ through fundraising initiatives at local restaurants and bars, business events, and the NELA Alliance. With counsel from land-use attorney Dean Walraff, the Friends of Highland Park retained fiery attorney Vic Otten to file a California Environmental 
Quality Act (CEQA) lawsuit against the transit village. An initial trial court judgment dismissed the CEQA filing. But it was reversed by the California Court of Appeal in December 2015, in a decision that set aside the City's Mitigated Negative Declaration and Notice of Determination and required the preparation of an environmental impact review (EIR) that complies with CEQA requirements. Described by Friends of Highland Park as a "David vs. Goliath" victory, the ruling sent the City agencies and developer back to the drawing board. Latinx community struggles over TOD transit villages have also occurred in Boyle Heights in East L.A., San Diego's Barrio Logan and Oakland's Fruitvale neighbourhood (Sandoval 2018).

\section{Eviction Order and Rent Strike at Marmion Royal}

Another contentious housing situation emerged next to the Highland Park Metro Gold Line station at the sixty-unit Marmion Royal apartments. In May 2016, the building was sold to Skya Ventures and Gelt Inc., a development company owned by Gelena Skya and Keith Wasserman, who announced plans to clear the apartments to renovate and rebrand the building as Citizen HLP, increasing rents by more than $\$ 1000$ a month. Seven families voluntarily relocated, while nineteen were served with evictions, and others were feeling harassed by water shut-offs. Extended multi-family networks among the tenants are under threat of being broken. The property managers working for the Wassermans, Moss \& Company, repeatedly told residents they had to leave when their leases expire. The majority of these residents were working-class Latinx families and included several Section 8 tenants at risk of homelessness without their housing vouchers (Smith 2016).

On July 19, a demonstration of about 100 people was held next to the Marmion Royal apartment building, led by the NELA Alliance. Adolfo Camacho, who has lived at the Marmion Royal for three years and in Highland Park for thirty years, said six people would be evicted from his household, including 4 children. His sister-in-law lived in another apartment. Chris Alvarez, who worked at the television station KTLA in Hollywood, said he would likely have to move to Monrovia or Lancaster and endure a much longer commute to his job. He grew up in Highland Park and had lived at the Marmion Royal for fifteen years. He said that he and his wife were seven months pregnant and he fretted about moving when she was in her third trimester. He worried that he would be separated from his mother and sister, 
who lived two blocks away, during this crucial time. After more testimonies, the participants proceeded to march in the streets with chants of "Save Our Homes" and "Housing Now" to the office of Councilman Gil Cedillo, where they demonstrated for a while before returning to the Marmion Royal. Erick Berdejo said, "I grew up here. I've been here 10 years since the age of 9. We're decent people, we work to pay rent. And for them to tell us we got to move because we can't afford the rent, that's wrong!" David Canecho, a resident of twenty years at the Marmion Royal said, "We're not the only ones in L.A. going through this. I went to high school in Highland Park, then to college at Chico State and came back, but now I can't live here. It's up to us to stand up and stick together!"

With educational workshops and organizational support from the NELA Alliance, the Los Angeles Tenants Union, and legal advocacy from attorney Elena Popp of the Eviction Defense Network, 47 of the remaining residents signed a petition to fight their evictions and organize the Marmion Royal Tenants Union. They called for a rent strike to try to pressure the Wassermans into a collective bargaining agreement putting their rent money into a blind trust while they negotiated with Skya Ventures. Over the next few months, demonstrations, testimonials, and candlelight vigils helped to publicly dramatize the struggle of the Marmion Royal Tenants Union. In August, NELA Alliance sponsored an educational panel at Avenue $5^{0}$ Studio, an exhibition, a performance, and artistic procession through the streets titled "Dancing Cantos of an Evicted Pueblo."

Fundraising efforts with support from local businesses like Las Cazuelas restaurant helped to raise nearly $\$ 8000$ for legal fees and court costs. Some white professional residents came forward to assert they thought management was more willing to negotiate with them on rent increases, giving Elena Popp an avenue to argue for a case of discrimination against the Latinx and black residents. But in December 2016 a Los Angeles Superior Court judge, Rupert A. Byrdsong, ruled against a claim of discrimination against five tenants being evicted (Smith 2016). Remaining members of the tenants union vowed to continue their support. NELA Alliance members appealed through neighbourhood social networks to find new housing for tenants facing eviction. Candlelight vigils helped to nourish their solidarity amidst the trauma of actual or impending displacement during the Christmas holidays. They staged a candlelight vigil at the residence of Gelena Skye and Keith Wasserman in Sherman Oaks on the evening of 30 December 2016. The evictions proceeded into the spring of 2017 , however, and the last tenants were out by June 2017. The renovated building is now called Moxie + Clover Apartments. 


\section{Art, Latinx Displacement, and Anti-Gentrification Protest}

The Latinx community has experienced shifting fortunes as the neighbourhood lifecycle has transitioned from revitalization to gentrification in the last 50 years since the social movements of the late 1960 s and early 1970 . The political activists and countercultural artists of the Latinx community in the days of the student revolts and anti-war activism were propelling a social awakening and artistic renaissance as East L.A. became a more politically and culturally coherent community. Latinx artists and households were residential pioneers among empty-nesters as they filtered into the greying neighbourhoods of Northeast L.A. in the 1970s and 199os, in the wake of white flight and out-movement to new residential subdivisions in the outer city. They helped to stabilize the housing stock and local economy and culturally revitalize the neighbourhoods of Northeast L.A. The gentrification dynamics of the new millennium confront Latinxs with a different set of economic and social conditions as the community now competes with more affluent returning white households and hipsters that are learning the appeal of Los Angeles East Side neighbourhoods. While middle-class Latinx homeowners and businesses are better able to compete with white middle-class newcomers, the poorest Latinx households face increasingly difficult and sometimes desperate situations of displacement, eviction, and falling into homelessness. Race and class schisms are increasingly apparent in the contemporary landscape of gentrification in Northeast L.A.

The race and class divide is even more polarized in Boyle Heights, the heart of Latinx East L.A. where groups such as Defend Boyle Heights and Boyle Heights Alliance Against Artwashing and Displacement (BHAAAD) began protests against art galleries as perceived harbingers of gentrification in the fall of 2015. Over the next several months, they targeted mock eviction notices and street demonstrations against ten primarily white-owned galleries that have established a budding art scene on South Anderson Street, a gritty former industrial zone along the east bank of the L.A. River. The galleries included Hollywood players like the United Talent Agency, which opened a 4500 square foot gallery called UTA Artist Space that opened with an inaugural exhibit of paintings and photos by Larry Clark, the director of Kids, the controversial 1995 docu-drama about sex and drug use among street teenagers. Also targeted was Chimento Contemporary, a smaller space opened by Eva Chimento, a Latina from Brooklyn who has had associations with the arts scene in Boyle Heights since she was a teenager (Nazaryan 2017). The protestors carried banners with slogans like, "Gentrification is Class Warfare" and sported signs and T-shirts that read "Gente Si! Gentrify No." 
In the fall of 2016 a few galleries were vandalized, including a spray-painted profanity against "White Art" at the entrance of the Nicodim Gallery. Defend Boyle Heights denied responsibility but the Los Angeles Police Department (LAPD) started up an investigation of the incident as a possible hate crime. LAPD tried to facilitate dialogue between protesters and gallery owners. Some saw the spray-painting as political speech rather than hate crime (Mejia 2016).

In Highland Park, members of the Northeast L.A. Alliance have protested in the streets and delivered mock eviction notices to businesses they viewed as symbols of gentrification, but they haven't tried to drive out art galleries with sustained opposition as in Boyle Heights. Different race and class dynamics may explain contrasting protest dynamics and attitudes towards art galleries in Boyle Heights as compared to Highland Park. Also significant is that Avenue $5^{\circ}$ Studio, a recognized Latinx stakeholder and Highland Park's longest running art gallery, provides space in its community room for Northeast L.A. Alliance panel discussions, film screenings, exhibitions, and production of artworks used in their theatrical street processions.

The phenomenon of street processions has been a recurring form of artistic and political expression in the Latinx community adapting a traditional ritual of folk Catholicism to contemporary purposes. The Northeast L.A. Alliance has staged theatrical processions since its inception in 2014 to protest gentrification and displacement with symbols like a giant puppet representing a greedy landlord and silent candlelight processions like their "Las Posadas" re-enactment of the biblical search of Mary and Joseph for shelter on Christmas Eve. For the NELA Alliance, theatrical processions were employed along with a larger ensemble of protest tactics and organizational capacities like political demonstrations with picket signs, flash mobs, mock evictions, lobbying efforts with public agencies, tenants' workshops, and public meetings. These artistic rituals have been helpful in bridging generational divides and building a cross-ethnic sense of community among activists and residents. The efflorescence of community in arts activism helps to reinforce the moral dimensions of political cries for affordable housing and urban rights.

Aesthetical revitalization of the boulevards was a key precursor to the acceleration of gentrification and accompanying displacement dynamics in neighbourhoods of Northeast Los Angeles. Art galleries and hipster aesthetics are increasingly seen as Trojan horses of the gentrification frontier in the city's Latinx communities. But the aesthetics of art and theatre are also part of the toolkit of anti-gentrification activists as they take to the streets to resist their residential dispossession and cultural appropriation 
and claim their right to the city. The Northeast Los Angeles Alliance has attracted media attention to housing displacement in Highland Park and increased public awareness of the racialized nature of the gentrification process and the need for affordable housing for immigrant and low-income households across the metropolis.

The community opposition to the Highland Park Transit Village next to the Metro Gold Line has furthermore raised questions about the process and outcomes of transit oriented development (TOD) and market-incentivized housing construction. Mass transit and TOD has helped to mitigate urban sprawl and air pollution, and enhanced economic development and boosted livability in many older L.A. neighbourhoods that were previously disinvested during earlier decades of white flight and suburban outmovement. But these urban planning trends have also engendered a growing clash between the developers of market rate housing for returning whites versus affordable housing for immigrants and working-class families in neighbourhoods serviced by public transit through Los Angeles (Chapple and Loukaitou-Sideris 2019). Struggles over TOD-induced gentrification have also ignited anti-gentrification actions in the Latinx communities of Boyle Heights in Los Angeles, Barrio Logan in San Diego, and the Fruitvale neighbourhood of Oakland. Public participation by Latinx neighbourhood stakeholders helped to make these transit investments more communitydriven and created opportunities for community benefits (Sandoval 2018). These TOD experiences point the way towards more equitable and socially just urban planning policies and the promise of inclusionary neighbourhood revitalization.

\section{Note}

This chapter is adapted from my book, Taking Back the Boulevard: Art, Activism and Gentrification in Los Angeles (New York: New York University Press, 2019).

\section{Works Cited}

Bermudez, Esmeralda (2014) “Will CicLAvia Bring Buy-Cyclists to a Wary Eastside?" Los Angeles Times, 27 September.

Brenner, Neil and Nik Theodore (2002) "Cities and the Geographies of 'Actually Existing Neoliberalism.” Antipode 34·3: 349-379. 
Brisick, Jamie (2009) “Highland Park: A New Culture District in Los Angeles.” The New York Times, 9 July.

Carpenter, Susan (2006) “Making Eagle Rock a Hip Nest." Los Angeles Times, Weekend Calendar, E26-E29.

Chapple, Karen and Anastasia Loukaitou-Sideris (2019) Transit-Oriented Displacement or Community Dividends? Understanding the Effects of Smarter Growth on Communities. Cambridge, MA: MIT Press.

Clay, Phillip (1979) Neighborhood Renewal: Middle-Class Resettlement and Incumbent Ugrading in American Neighborhoods. Lexington, MA: D. C. Heath.

Currid, Elizabeth (2009) “Bohemia as Subculture; 'Bohemia' as Industry: Art, Culture and Economic Development." Journal of Planning Literature 23: 368-382.

Currid, Elizabeth and Sarah Williams (2009) "The Geography of Buzz: Art, Culture and the Social Milieu in Los Angeles and New York." Journal of Economic Geography (July): 1-29.

Florida, Richard (2002) The Rise of the Creative Class: And How it's Transforming Work, Leisure, Community and Everyday Life. New York: Perseus Book Group.

Gale, Dennis E. (1979) "Middle Class Resettlement in Older Urban Neighborhoods: the Evidence and the Implications." Journal of the American Planning Association 45: 293-304.

Gardetta, David (2001) “Hipster, U.S.A.: L.A.'s Trend Central Is Shifting From Los Feliz to Eagle Rock: Is That A Good Thing?” Los Angeles Times Magazine, 29 July, 10-15, 35-36.

Golub, Aaron, Melody Hoffman, Adonia Lugo and Gerardo Sandoval (2016) Bicycle Justice and Urban Transformations: Biking for All? New York: Routledge.

Greif, Mark, Kathleen Ross and Dayna Tortorici (eds) (2010) What Was the Hipster? A Sociological Investigation. New York: $\mathrm{n}+1$.

Hackworth, Jason (2007) The Neoliberal City: Governance, Ideology, and Development in American Urbanism. Ithaca: Cornell University Press.

Harvey, David (1989) The Condition of Postmodernity. Cambridge, MA: Basil Blackwell.

Harvey, David (2012) Rebel Cities: From the Right to the City to the Urban Revolution. London: Verso.

Hawthorne, Christopher (2012) “On the Boulevards: Atlantic on the Move." Los Angeles Times, 13 May.

Hoover, Edgar and Raymond Vernon (1959) Anatomy of a Metropolis. Cambridge, MA: Harvard University Press.

Jacobs, Jane (1961) The Death and Life of Great American Cities. New York: Vintage Books.

Lees, Loretta, Tom Slater and Elvin Wyly (2008) Gentrification. London: Routledge. 
LeFebvre, Henri (1991) Writings on Cities. Translated and edited by Eleonore Kofman and Elizabeth Lebas. Cambridge, MA: Blackwell Publishers, Inc.

Lloyd, Richard (2010) Neo-Bohemia: Art and Commerce in the Postindustrial City, 2nd edition. New York: Routledge.

Logan, John and Harvey Molotch (1987) Urban Fortunes: The Political Economy of Place. Berkeley: University of California Press.

Medina, Jennifer (2013) "Los Angeles Neighborhood Tries to Change, but Avoid the Pitfalls." New York Times, 17 August.

Mejia, Brittny (2016) "LAPD Investigating Boyle Heights Vandalism as Possible Hate Crimes Sparked by Gentrification Fight." Los Angeles Times, 3 November.

Nakano, Craig (2012) "York Boulevard, Highland Park: A Hub of Hip, Real." Los Angeles Times. Home and Garden. L.A. at Home, 9 March.

Nazaryan, Alexander (2017) “The 'Artwashing' of America: The Battle For the Soul of Los Angeles Against Gentrification.” Newsweek, 21 May.

Sandoval, Gerardo (2018) "Planning the Barrio: Ethnic Identity and Struggles Over Transit-Oriented, Development-Induced Gentrification.” Journal of Planning Education and Research 1-15.

Schwirian, Kent (1983) “Models of Neighborhood Change." Annual Review of Sociology 9: 83-102.

Silver, Daniel and Terry Nichols Clark (2013) “Buzz as an Urban Resource." Canadian Journal of Sociology 38.1: 1-31.

Smith, Doug (2016) "A Flashpoint in L.A.'s Gentrification Drama: Protesting Highland Park Tenants Face a Mass Eviction." Los Angeles Times, 11 October, A1.

Smith, Neil (1979) "Toward a Theory of Gentrification: A Back to the City Movement by Capital, not People." Journal of the American Planning Association 45.4: 538-548.

Suisman, Doug (2014) Los Angeles Boulevard: Eight X-Rays of the Body Public. San Francisco: ORO Editions, 25th Anniversary Reprint.

Zahniser, David (2006) "Welcome to Gentrification City," LA Weekly, 4 August.

Zukin, Sharon (2010) Naked City: The Death and Life of Authentic Urban Places. New York: Oxford University Press 


\section{About the Author}

Jan Lin has been Professor of Sociology at Occidental College since 1998. He is author of Reconstructing Chinatown (1998), The Power of Urban Ethnic Places (2011), and co-editor of The Urban Sociology Reader $\left(2^{\text {nd }}\right.$ edition, 2012). He was Principal Investigator for a grant funded 1999-2002 by the U.S. Department of Housing and Urban Development for the Northeast LA Community Outreach Partnership Center. His work and students' work on Northeast LA has been featured online by KCET-Departures of Los Angeles. His book Taking Back the Boulevard: Art, Activism, and Gentrification in Los Angeles was published in 2019 . 


\title{
11. Speculative Spaces in Grand Paris: Reading JR in Clichy-sous-Bois and Montfermeil
}

\author{
Gillian Jein
}

\begin{abstract}
This chapter engages with the spatial politics of aesthetics in the Parisian suburbs of Clichy-sous-Bois and Montfermeil. It examines how JR's street art brings into view the lines of tension informing neighbourhood change. Firstly, the chapter explores how urban aesthetics have become important to gentrification analysis and looks at the commodification of socially engaged aesthetic practices via the "creative cities" ethos. In the subsequent sections, the chapter introduces a relational reading of JR's artistic practice in "ClichyMontfermeil." The central questions guiding the enquiries are as follows: What can street art tell us about the antagonisms shaping processes of speculation in these towns? What can its aesthetic presence reveal about shifts in spatial imaginaries that are disarticulating the banlieues as "deviant," "no-go zone" to rearticulate them "as a hunting ground for seasoned investors" (Clerima 2019)?
\end{abstract}

Keywords: Grand Paris; Clichy-sous-Bois; street art; speculation; agonism

The problem in the banlieue is that they don't look at us with the right kind of eyes.

- Dieth cited in Sterlé 2017

The image itself is, in fact, a weapon.

- Thompson 2015: 32

In February 2018, an article appeared in New Statesman wherein a journalist described his trip to the "least-visited neighbourhood" of Paris (Newens 2018).

Lindner, C. and G.F. Sandoval (eds), Aesthetics of Gentrification: Seductive Spaces and Exclusive Communities in the Neoliberal City. Amsterdam: Amsterdam University Press, 2021 DOI 10.5117/9789463722032_CH11 
Framed as an attempt to access "real Paris," "surely," he proclaimed, "the most authentically Parisian part of the city must be the part least tainted by tourism: a place where no visitor ever goes" (Newens 2018)? In April of the same year, this quest for "authenticity" found echoes on the travel blog Culture Trip. Again, the journalist pronounced her "odyssey" to dodge Paris's tourist traps and brave "the darkest corners of Paris" by venturing to "the city's least-visited neighbourhood" (Cuttle 2018). In both cases, this "darkest corner" referred to Clichy-sous-Bois, a banlieue or suburban town of 30,000 inhabitants situated 15 kilometres east of central Paris, in the department of Seine-Saint-Denis. These journalists equate "authenticity" with two geo-historical features of Clichy-sous-Bois. The first is its geographical marginality. At the time of these articles' publication, the town remained notoriously "enclaved," underserved by Parisian transport networks, without train line, metro, major autoroute, or tramline. Irregular bus services meant it took up to 90 minutes to travel those 15 kilometres. The second reason is this neighbourhood's historic role in the civil riots that erupted on 27 October 2005 in the town's high-rise social housing estate, la Chêne Pointu. The violence, catalyzed by the death of two local teenage boys, Zyed Benna and Bouna Traoré, spread to disadvantaged suburbs across France prompting the government to declare a state of national emergency. The deaths of Zyed and Bouna, of Mauritian and Tunisian descent, became symbolic of the profound economic, social, and racial inequalities confronting those living on the post-industrial margins of France. Depending on the politics of observers, the events were interpreted as evidence of the threat these neighbourhoods posed to the Republic, or as signs of the Republic's abandonment of its poorest and postcolonial populations (Koff and Duprez 2009). Thus, given its problematic position within the annals of recent French history, what can the marginalized and stigmatized neighbourhood of Clichy-sous-Bois tell us about gentrification?

First, let us consider that these journalists' journeys are remarkable not because they are unusual - this kind of "dark tourism" and "off the beaten track" journeying is an increasingly mundane travel practice. Rather, their writing performs as discursive symptom of a vast state-led infrastructural urban project, "Grand Paris," that is rearticulating the social imaginaries of Seine-Saint-Denis. This department forms a significant prong in the government's metropolitan programme, which has been working to reframe the centre-periphery imaginaries of the banlieues' relationship to central Paris. This Haussmannian-scale regeneration programme, first mooted by Nicolas Sarkozy in 2007, undergirds infrastructural ambition with an aesthetics of cultural and architectural "rehabilitation," and draws 
closely on the rhetoric of Richard Florida's "creative cities" model (Florida 2002) to alter the spatial imaginaries of this former "no-go" zone (De Vries 2015). Thus, despite their claims to novelty, these press articles are by no means isolated cultural artefacts. Rather they form an Anglophone extension to Grand Paris' discursive armoury of publications, manifestos, cultural organizations, festivals, tours, and artistic interventions that over the past fifteen years have been working to rearticulate Paris' peripheral territories.

In this chapter, I engage with this shift in spatial imaginaries through the lens of aesthetic practice in Clichy-sous-Bois and the neighbouring town of Montfermeil, and more particularly through a relational reading of two street art exhibitions by renowned "photograffeur" JR. Given the early stages of these territories' infrastructural regeneration, this is an attempt to explore gentrification avant la lettre, implicating aesthetic practice in one of gentrification's pre-emptive signs: speculation. While "speculation" commonly refers to anticipating land values or debt financing, the word's etymological roots connect it to ways of looking. Derived from the Latin specer (to look), before its financial connotations, we find "looking closely," "contemplation," "observation," and "rapt attention" (Online Etymological Dictionary): a prescient reminder of the role that looking and, by extension, the aesthetic, play in the determination of value and visuality - the social processes of making people and places visible or invisible (Foster 1988). To pay attention to spatial discursivity is to approach place not as some settled, steady ground, but rather as a speculative site. It is, furthermore, to argue that how places and people are made visible, and how marginal communities make themselves visible are political questions. This is to reframe the old issue of "what do images look like, what do they say?" to place emphasis on the image's relationality and ask, instead, "what do images look at?" - what kinds of pasts are they concerned with, what futures do they speculate? - and, "what can images do?" - what kinds of actions do images promote, what tensions do they reveal?

In the Grand Paris context, this kind of approach allows us to engage critically with this new metropolitan urbanism's discourses of "creativity," "authenticity," and "integration," and to explore the ways art and design practices can be at once resistive to, but also complicit in, corporate and state-led placemaking practices. This has two implications. First, it suggests we take seriously the role of cultural production in contributing to the meaning, experience, and value of the built environment. Second, it requires us to abandon any transcendentalist interpretive framework separating aesthetics from political or social life, and instead, following 
Jacques Rancière, to emphasize what might be termed, "the spatial politics of aesthetics" (Rancière 2004).

This chapter engages with the spatial politics of aesthetics in Clichy-sousBois and Montfermeil by examining how street art, through its site-specific aesthetic, brings into view the lines of tension informing neighbourhood change. Read here as a site-specific intervention whose meaning evolves in temporal concert with political and historical conditions, street art provides a means to grasp how artistic practices operate within existing hegemonic power structures that (re)configure urban social space (Mouffe 2013: 79). The chapter is underpinned by Chantal Mouffe's theoretical notion of agonism, which emphasizes antagonism between competing points of view as necessary to the political life of democratic societies, and lines of tension as crucial to the development of equitable alternatives within neoliberalism's profit priorities. Mouffe's agonism affords us a position from which to theorize street art as a productively tension-filled procedure, remarkable for how it brings into view the conflicts attendant in neighbourhood regeneration.

Bringing to light tensions in meaning over place is to approach gentrification as a spectrum of interrelated processes, evidenced by paying attention to the situated aesthetics of cultural practices in neighbourhoods over time. Thus, in a first section, this chapter explores how urban aesthetics have become important to gentrification analysis and looks at the commodification of socially engaged aesthetic practices via the "creative cities" ethos. This is significant in the case of Clichy-sous-Bois and Montfermeil, where culture-led redevelopment is prevalent, and where the trauma of the recent past is rearticulated through Republican planning discourse. In the sections that follow, the chapter introduces a relational reading of JR's street art in Clichy-Montfermeil. A relational framework analyzes JR's images as multivalent sites of meaning, examining the visual substance of the singular image as well as its implication in other aesthetic and infrastructural procedures. The central questions guiding these enquiries are as follows: What can street art tell us about the antagonisms shaping processes of speculation in Clichy-sous-Bois and Montfermeil? What can its aesthetic presence reveal about shifts in spatial imaginaries that are disarticulating the banlieue as "deviant," "no-go zone" to rearticulate it "as a hunting ground for seasoned investors" (Clerima 2019)? Reading these images in relation to territorial shifts, I explore then how JR's "photograffs" articulate a response to these banlieues' evolving regimes of visibility, creating a line of tension straddling resistive and normative dimensions, and bringing into view gentrification as an agonistic process within Grand Paris. 


\section{Thinking Agonistic Urbanism, Rethinking Artistic Practice}

In gentrification literature, aesthetics has long been a means to identify signs of land appropriation by one class and the consequent displacement of another. The middle class's reappropriation and revalorization of London's working-class housing stock was essential to Ruth Glass's original concept (Glass 1964). If Glass focused on demographic change, Sharon Zukin's theorization of the "aesthetic mode of production" in New York demonstrated how artistic communities create urban value, predicating capital accumulation on processes of cultural consumption (Zukin 1982). David Ley broadens Zukin's perspective through deployment of Pierre Bourdieu's notion of the "cultural field," or cultural production's imbrication in the power dynamics of society. Ley analyzes the coincidence of economic and cultural capital in gentrification, what he terms "the cultural code of gentrification," which exists as a "field of relationships, practices, and historical traces" (Ley 2003:3532). Ley's reading eschews traditional art historical interpretations of value, positioning the artwork instead within a "historical space of genres, techniques and patterns of recognition" where it circulates amidst an assemblage of social power relations (Ley 2003: 2542). Ley's work demonstrates the socio-cultural production of land values, and raises awareness of western cities' growing economic investiture in cultural capital from the 1960 s onwards. In this reading, under capitalist market forces, the valorization of space through aesthetic procedures implicates even activist artistic practices in neighbourhood commodification through aestheticization, so that "the edge becomes the new centre" (Ley 2003: 2541). However, while Ley attends to the role of aesthetics in gentrification, his case studies from the late sixties and seventies invite us to extend this timeline to address the post-Fordist expansion of regeneration schemes advocating creativity as part of land revalorization procedures.

We need, then, to address the influence of Florida's "creative cities" agenda and its reorientation of creativity to neoliberal strategies for city regeneration. This reorientation is highly relevant in the French case. While Grand Paris extends the scale of Florida's focus through its ambition to reassert Paris's hegemony on the world stage, his thesis coheres with the programme's emphasis on generating new "cultural geographies" (Senate 2010) for economic sustainability. It also speaks to the French state's collaboration with global advertising and private investment firms, and the promotion of alternative tourism as well as innovation and creativity poles in Seine-Saint-Denis.

Florida famously describes creativity as the "defining feature of economic life" in post-Fordist societies, an essential component to ensuring 
the economic growth of cities in an increasingly competitive global context (Florida 2002: 21). In this scenario, cities are engaged in a "talent war" and must adapt their urban landscapes, creating flexible, aesthetically trendy, and culturally diverse environments to attract this new aspirational, flexible, "cool," and tolerant "creative class." Crucially, unlike the yuppies of the eighties, creatives (broadly understood by Florida to include anybody from tech giants to local musicians) are unmotivated by corporate incentives. Rather than money, their priorities are grounded in a search for urban stimulation, authenticity, diversity. Openness and tolerance are key to creating this class' preferred progressive environment and enhancing urban attractiveness, so that these qualities become affective instruments for the "redevelopment and gentrification [of] distressed urban neighbourhoods" (Florida and Gates 2003: 131). From Florida's perspective, gentrification constitutes an emancipatory mechanism for downgraded localities, with creativity rescuing the city from post-industrial degradation. This diminished angle, of course, fails to attend to the trauma that state-organized gentrification can bring through processes such as forced eviction, relocation and the displacement of long-established, often marginalized communities (Peck 2005). Furthermore, this marketization of creativity not only commodifies land, but marginality itself. The "edge" is aestheticized, delocalized so as to circulate in a globalized creative economy.

The creative cities agenda, then, calls into question the possibility for aesthetic practices to act as meaningful forms of resistance to neoliberal urbanism. As Mouffe asks, "Once the centrality of the cultural terrain [to capital] is acknowledged, how can cultural and artistic practices contribute to the counter-hegemonic challenge to neo-liberal hegemony?" (Mouffe 2013: 91). In a politico-historical context where "creativity" becomes another instrument in the corporate planning toolbox, the critical aesthetic gesture risks being recuperated and neutralized. However, we might frame this question in another way and ask what such recuperations can tell us about how speculation works in specific contexts. What needs to occur before gentrification can take place? Can street art tell us less straightforward, more antagonistic tales about the experience of urban governance?

\section{Re-Visioning the "Violent Neighbourhood"}

JR is one of the most prolific and well-known street artists working today, but, before his rise to fame, his first illegal exhibition "Portrait of a Generation" took place in Clichy-sous-Bois and Montfermeil. JR's practice is defined 
by large-format, black-and-white photographs that are pasted onto walls, roads, and myriad other architectural forms in rural or urban locations; a technique that has become known as "photo-graffiti." Much of the work involves engagement with local communities. The artist achieved mainstream attention when a photograff from "Portrait of a Generation," namely "Ladj Braquage," was featured in Tate Modern's break-through exhibition, "Street Art," in 2008, signposting the art world's institutional acceptance of the form. JR gained global recognition in 2011, when he won the TED prize of $\$ 100,000$. While much press coverage of the artist (Day 2010; Jaeglé 2019) praises the artist's aesthetic infiltration of marginal, often "invisible" places, it is also clear that his participatory ethos is consistent with the generalized aesthetic shift in the early 2000 s towards localized, co-creative forms of practice. Before achieving notoriety, however,JR began as a taggeur (graffiti writer), and his first experiment with the large-scale photograff format took Clichy-sous-Bois and Montfermeil as its substance and site. Indeed, before turning to examine in close-up JR's debut photograff, "Ladj Braquage" (2004), it can be noted that the artist has consistently returned to these suburban terrains (Jardonnet 2017b). His ballet Les Bosquets (a collaboration with the New York City Ballet) was filmed here in 2015, and other recent collaborations with filmmaker Ladj Ly suggest that this site has been formative in the artist's concern to "capture the spirits of individuals who normally go unseen" (JR 2011).

It is not only those unseen, but also the challenge to normative regimes determining visibility or invisibility, that characterizes much of JR's portraiture. In "Ladj Braquage" (Figure 11.1), produced when the artist was 18, we see an iconic example of how aesthetics might disarticulate normative ways of seeing the banlieues at the turn of the century. The image shows a tall, black man who appears to be pointing a machine gun directly outwards at the viewer. The young man is face forward, his gaze fixed on the viewer, chin down, weapon barrel pointing directly at us. In the background, stands a group of five black boys, also staring at us, some with their hands in their pockets, while two make hip-hop gestures. The walls behind are covered in graffiti. At a glance, the composition, the confrontational gaze, and the gun confirm global media stereotypes of delinquent youth, of aggression, hostility, and the latency of violence.

These visual tropes speak, then, to another set of images: the visual regime of the "ghetto" - a regime that for Clichy-sous-Bois and Montfermeil is articulated in relation to a particular set of historical and spatial circumstances and which can be traced to the emergence of a discursive imaginary associating the banlieues with delinquency and deprivation since the early 


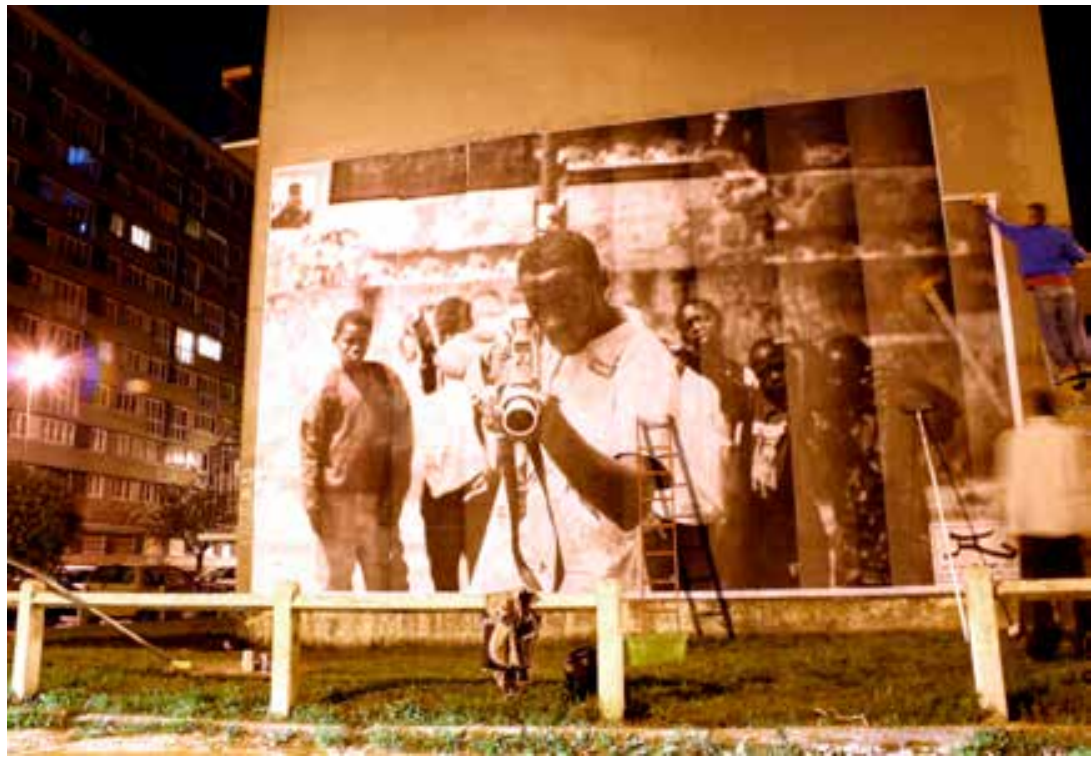

Figure 11.1: 28 Millimeters, Portrait of a Generation, Pasting of Ladj Ly by JR, Montfermeil, Les Bosquets, 2004 C JR.

1980s in France (Dikeç 2007). The discourse circulated widely in the local, national, and, later, international press, and was at best patriarchal, at worst rampantly racist (Body-Gendrot 2010). This developed in response to the economic crisis of the seventies, a rise in anti-immigrant sentiment and a succession of laws to curb migration and citizenship for foreigners resident in France (Hargreaves 2015). This socio-spatial marginalization is politically complex and bound up with France's unwillingness to acknowledge either the slow violence of postcolonial trauma, or the limits of its national model of citizenship where the realities of religious and ethnic diversity now stretch the tenability of "the one and indivisible Republic." These complex cultural realities became spatialized in Seine-Saint-Denis, previously the heart of Paris' industrial economy, where post-industrialization and decolonization resulted in high concentrations of poverty, foreign-born populations and those of immigrant descent. These social tensions become intensely visible during the riots of 2005, when hundreds of journalists descended on Clichysous-Bois and Montfermeil, transmitting spectacular footage of burning vehicles, heavily armed riot police and hooded adolescents expressing years of invisible rage. These images bring the question of semiotic violence to the fore, and a clear visual rhetoric emerges within the bank of imagery ordering the representation of the incidents globally, and influencing representations of urban rioting more generally. 
One image in particular, by photographer Eric Travers, achieved iconic status appearing repeatedly in the media, not only to illustrate the actual events, but also other unrelated stories. A Google image search throws up $3,370,000,000$ results for this image, ranging from its appearance in the Guardian for a story covering the 2012 French presidential election; in 2013 on a website "Egalité et réconciliation" [Equality \& Reconciliation] calling for riots as a means of governance; on a Swedish forum to discuss immigrant riots in 2017; and on a far-right French website, "Riposte Laïque" [Secular Retaliation] in 2019 (Chrisafis 2012; Egalité et reconciliation 2013; Lussay 2019). Crucially this image's iconography is manufactured using a long-range lens, and built around a silhouetted, faceless figure. On the one hand, this facelessness works to de-individualize, to generalize, to render figurative a certain body of violence, what we might term "the rioting body." An abstraction, these hooded, silhouetted bodies are totemic. The rioting body relegates the other to the sub-human, so that personhood is never recognized. Thus, in conventional understandings of the face as the site of communication, the possibility of recognition or reciprocity with the viewer seems to be denied from the outset. Here, the camera aestheticizes violence and a media gaze emerges, a gaze predicated upon hierarchical modes of distribution whereby those who look are never made available for scrutiny, where the viewer is never implicated in violence's unfolding. Simultaneously, the camera's abstraction of the body enables a kind of blank monstrosity to emerge. The person is creatured, removed from normative landscapes of identification. In the 2005 context, JR's ghetto tropes recall therefore the media's spectres of threat. This is the first reading.

However, if we take a second look at "Ladj Braquage," we must grasp the visuality of this violence from another angle - that of the banlieusard [inhabitant of the peripheries] - and at another level, whereby violence becomes less a spectacular and sudden "event," and instead something characterized by processes more structural and slow. For Ladj is not holding a gun at all, of course, but a video camera. With this realization, the status of the image shifts, and rather than "ghetto," a reflexive space comes into view. The double take and the presence of the camera heighten the viewer's consciousness of photography as act, bringing into awareness the produced nature of the visual. Secondly, this appropriation of violent tropes is a comment on the violence of photographic images. The camera-gun invites this association, recalling Paul Virilio's theorization of the camera as a vision machine, a technological perpetrator of symbolic violence, whose interface enables the distantiation of actual violence (Virilio 1988). JR effectively acknowledges the camera's violence, but in this image, the 28 millimetre 
lens posits the face as an alternative mode of subjectivity; this aggression is self-conscious, dramatized, performed, a deliberate playacting. The image resonates with the media's visual order to better jam or short-circuit the transparency of that order. In so doing, it attributes consciousness of the media gaze to the photo's subject, as well as suggesting that subject's agency as they turn the visual regime on its head.

This image encourages a return to the media's violent protagonists, and from the perspective of the rioters, it becomes clear that facelessness is a choice. The hood is an apparatus to evade capture, and a collective statement. We recall here that for Gilles Deleuze and Félix Guattari "the face is a politics" (Deleuze and Guattari 1980: 222) - an alignment of hegemonic attributes (whiteness, symmetry, visibility) that designate which faces are acceptable or unacceptable. The face, to appropriate Mouffe's explicitly political vocabulary, exists within a regime of vision, one which for our context consists in stereotypes or invisibility, people divested to a series of normative reductions (Mouffe 2013). In "Ladj Braquage," therefore, the camera is made doubly visible. It is a media weapon - that which frames and forces into category - but also an arm to be reappropriated, opening onto a reflexive questioning around who makes whom visible and how. In this space of enquiry, we are alerted to the possibility that hegemonic visuality can be contested, the camera's point-blank range suggesting the counter-capture of the media gaze, a cultural kidnapping of visual weaponry. Indeed, Slavoj Žižek in his analysis of the 2005 violence, points to visibility as the rioters' critical purpose:

The riots were simply a direct effort to gain visibility. A social group which, although part of France and composed of French citizens, saw itself as excluded from the political and social space proper wanted to render its presence palpable to the general public [...] They found themselves on the other side of the wall which separates the visible from the invisible part of the republican social space. (Žižek 2008: 77)

Seen thus, JR's photograff becomes iconic of violence not as a singular event, but as a slow, structurally embedded, and, finally, agency-driven process that must be considered in duration and in relation to the hegemonic visual sphere. A reflexive resistance is at work here, then, bringing these banlieues into view as a territory of real fictions, articulated over time, and where violence and visibility, where lighting fires and framing shots, are imbricated each in the ontological existence of the other. In this schema, street art becomes an evidently powerful site for the articulation of ideological 
struggle, for the fight to be recognized, to participate, where people, as Raymond Williams eloquently puts it, might "writ[e] themselves into the land" (Williams [1958] 1989: 4).

\section{Rearticulating the Banlieues}

Where "Portrait of a Generation" writes the banlieues' struggle into the land, however, urban policy since the early 2000 s has sought to erase signs of the postcolonial and postindustrial trauma impacting these towns. Since 2003, both municipalities of Clichy-sous-Bois and Montfermeil have been subject to intensive state-led urban policies aiming to use regeneration not only to address social inequalities but to address the fractured identity of the Republican capital that became even more urgent post-2005. Before turning to JR's 2017 mural, it is important for our relational reading to outline how the Grand Paris programme affects these towns, and more specifically how questions of planning intersect with those of visuality.

First, both towns and their department figure prominently in the parliamentary debates on Grand Paris since 2010 (Projet de loi 2010). Of the 61 sites designated for redevelopment across the Ile-de-France, 24 of these are in Seine-Saint-Denis. Line 16 of the new Grand Paris Express metro infrastructure will unite towns in the department. Second, the mayor of Clichy-sous-Bois, Olivier Klein, has been appointed to a vicepresidential role on the Grand Paris Métropole planning committee. Impetus for completion of these projects has been driven by the success of Paris's bid to host the 2024 Olympic Games, which will see the Olympic village housed in Saint Denis and other sites spread across the department. This has ensured large-scale private investment and the unusually swift implementation of planning projects. Property developers and investment companies have seized the opportunity to be involved in "the biggest urban real estate and infrastructure project in continental Europe since Baron Haussmann" (Mirabaud Group 2018), with over $€_{30}$ billion invested in operations. Private investment coupled with state debt is speculation-driven, based on projections of growth around the 68 new metro stations, while Seine-Saint-Denis will provide new housing for an over-extended urban core, where property prices in central Paris now reach over $€ 10,000$ per square metre (Hasse 2019). One consultation anticipates new housing in the extended metropolitan area to yield $€_{7.2}$ billion of private investment in coming years (Moutarde 2019). The revalorization of land, the provision of mobility infrastructures to attract 
private investment and the substantial upgrading of suburban cultural amenities are all, therefore, central to the implementation of the new urban morphologies of Grand Paris.

Attractivity is intimately bound up in questions regarding the visuality of Clichy-sous-Bois and Montfermeil. To attract investors, it has been essential for the towns to counteract images of violence and marginality crystallized by the media's iconographies. Jérôme Bouvier, a journalist and long-time advocate for Clichy-sous-Bois, recognized the reciprocity of image and investment during the riots:

I was fascinated by the question of mediatization because there were 450 journalists on site, 80 television channels. In Clichy, I saw things I had only observed before in Sarajevo or Kabul [...] I said to Claude Dilain [then mayor of Clichy-sous-Bois]: [...] "For 20 years, Clichy-sous-Bois will symbolize a place where kids in hoods burned cars. That image is more destructive than any others, you'll never manage to convince investors to come here. People will carry that image with them." (cited in Vivant 2018: 111)

The architectural aesthetics of these towns' regeneration has been defined by attempts to erase that image. Processes of demolition, displacement, and reconstruction have seen state and EU investment of over €6oo million, with a further $€ 450$ million earmarked for ongoing projects.

Thus far, this has involved the demolition of the high-rise housing estates of Les Bosquets (5000 inhabitants, Montfermeil) and Les Forestières (510 apartments, Clichy-sous-Bois), the latter now the bull-dozed terrain for the new metro station, "Clichy-Montfermeil" scheduled to open in 2024. On 14 December 2019, the $T_{4}$ tramway came into operation. While new mobility and housing infrastructures enhance attractivity, they have also been responsible for the expulsion of thousands of vulnerable families from their homes. Signs of disquiet are visible in a neon pink graffiti reading "Les Forestières" on the wall facing onto the metro's building site, a ghostly reminder of the estate's existence. The process of speculation in Clichy-sous-Bois and Montfermeil is thus defined by an aesthetics of demolition and displacement. However, eradicating symbols of violence, but also sites of community and memory, is of course highly problematic. For example, the voices of the 1500 inhabitants displaced when their homes were demolished remain silent. While in other regenerating towns, many municipalities have sponsored aesthetic initiatives to preserve the heritage of the neighbourhoods affected by renovation, in Clichy-sous-Bois and 
Montfermeil, such memorial work is rare despite an increasing creative presence (Vivant 2018).

Other key architectural symbols of degradation, such as the thirteenstorey office block, the Utrillo Tower (Montfermeil), and the housing estate of La Chêne Pointu (6ooo inhabitants, Clichy-sous-Bois), have been or are scheduled for imminent demolition. The Utrillo Tower, constructed in 1970 during the office-building boom, was purchased by the state in 2011 and torn down in 2017. Preparations for demolition of La Chêne Pointu, where the violence of 2005 originated, are underway at the time of writing, with the state and municipality investing over $€_{450}$ million in the project. Under the remit of Grand Paris, private investment for a new multi-use centre, "Centr'Halles au plateau," has been secured, with a shopping mall, $1422 \mathrm{~m}^{2}$ of private accommodation, businesses, and plots for urban agriculture. Another project on the site of a former gypsum quarry, "Un belvédère métropolitain," will erect new private residences as well as a park and agrocultural amenities (orchards, apiaries, and goat pastures) (Société du Grand Paris 2017). Both projects are due for completion in 2025. Cumulatively, while incomplete, these projects have contributed to an increase in speculation and an unheard-of rise of $6.6 \%$ in real estate values over the past five years (Villamy 2019).

Alongside infrastructural and architectural reorganization, culture has been a driving force in laying the foundation to attract investors. The first phase of a flagship, globally oriented, arts centre, The Ateliers Médicis, has been built on the site of the former Les Forestières estate. Phase two of this project will begin upon completion of the metro, with a permanent building erected on the Utrillo Tower site. The Ateliers Médicis is modelled on the prestigious Villa Médicis in Rome, the French Academy and traditional training ground for French artists since its foundation by Louis XIV in 1666. In its current guise, it is housed in a modern wooden building, its balconies overlooking the neighbouring equestrian centre and lower Clichy. The Ateliers Médicis have been central to configuring a visual and artistic identity for Grand Paris, commissioning an annual photographic competition, "Regards du Grand Paris," as well as facilitating Ladj Ly's Kourtrajmé cinema school, and most recently an ambitious summer festival, first held in 2019. This festival engaged French as well as international artists and the curators work closely with other flagship cultural enterprises, such as the Magasins Généraux in Pantin (the cultural wing of global advertising agency BETC) while their activities are promoted extensively by Enlarge your Paris - an "alternative" tourist operation that has proven fundamental in curating Grand Paris' cultural identity. As the centre's organizers state, 
"The Ateliers Médicis, the name symbolic of the hope of a (new) renaissance, is placing its faith in the liberating power of culture" (Encore Heureux et al. 2018: 289). If Ateliers Médicis' cultural provision and prestige is important to changing the image of Clichy-sous-Bois, their statement that culture equates to liberation is less than straightforward within the new urban context that seeks to optimize land values. For these strategies are unpinned by policies of "mixité" [mixing], or the redistribution of class and, as Renaud Epstein points out, race, to encourage the return of middle-class, white "native French" families to the towns (see Epstein 2013). Ateliers Médicis is therefore imbricated in the cultural politics of mixity; by choosing a remote area for its site, and in conjunction with new infrastructures, this project is set to reorient the geographical centres of French contemporary art, and aims to attract audiences and practitioners from central Paris and the rest of the world to the area.

For Olivier Klein, cultural provision is a first step to enticing business investment. As Klein says, "one cannot simply decree the existence of a town centre, it will take time to attract large brands and robust commercial enterprises" (Ruggeri 2019: 5). Given the time-scales for the Grand Paris Express and the demolition-reconstruction of La Chêne Pointu, "a significant cultural programme” (Ruggeri 2019: 5) is key in rearranging the town's visuality into a more productive form, rearticulating the image of Clichysous-Bois from "a place where kids in hoods burned cars" to a space ripe for seasoned investors. While these processes are ongoing, the role of cultural production in this scenario is highly agonistic.

On the one hand, cultural co-practice and engagement with inhabitants has been important in bringing to light and dealing with the riots' trauma, as well as to resisting stereotypes and stigmatization. On the other hand, however, these projects are players within a much broader metropolitan agenda which seeks to instrumentalize culture's resistive revalorization of the area so as to enhance economic speculation. This is to say that art's production of an alternative identity for Clichy-sous-Bois now aligns, in the light of Grand Paris, with speculation-driven planning agendas. Where they differ of course is in their intended beneficiaries. Ateliers Médicis is concerned to reach "out to inhabitants - especially young people - who feel society has turned its back on them (Encore Heureux et al. 2018: 289). But this creative labour forms part too of "biopolitical capitalism" (Mouffe 2013: 18), assisting in reordering bodies and places so they might yield more profitable results. Thus, culture's resistive reworking of territorial aesthetics is inseparable from, and indeed necessary to, capitalist requirements for "attractivity." 


\section{Complicating Resistance or the Violence of Inclusion}

It is within this new speculative landscape that we return to JR's latest intervention in Clichy-sous-Bois and Montfermeil. Of course, in addition to a drastically transformed urban fabric, the cultural status of street art and the artist himself have dramatically shifted. Where "Portrait of a Generation" was illegal, and JR sued by Montfermeil's mayor, Xavier Lemoine, JR is now firmly part of the cultural establishment. A 1oo foot-high Ladj Braquage has towered over Londoners at Tate Modern (2008). JR's prints now sell for up to $\$ 60,000$ (Sotheby's 2018). The Louvre pyramid has been pasted to disappear (2016). Robert de Niro has co-produced and starred in JR's film Ellis (2015) and JR has co-directed Visages Villages (2017) with New Wave auteur Agnès Varda. The man in Ladj Braquage, Ladj Ly, has also become a world-renowned filmmaker with the release in 2019 of Les Misérables, a feature film set in Montfermeil, which won the Jury Prize at the 2019 Cannes Film Festival and was nominated for Best International Feature at the $92^{\text {nd }}$ Academy Awards (Obsenson 2020). Street art too has become part of the French Republic's iconographic apparatus. In 2018, Emmanuel Macron commissioned Franco-British street artist, Ysuelt Digan, to redesign Marianne, the allegorical goddess of Liberty and symbol of the Republic. Throughout Seine-Saint-Denis, street art is now part of many aestheticization projects, as an interim on building site hoardings or part of larger renovation projects such as the Magasins Généraux in Pantin, now a rapidly gentrifying suburb, and more permanent spaces dedicated to alternative tourism, such as the "Street Art Avenue" running along the Canal Saint Denis.

Such is the contextual background, therefore, when we come to focus on JR's 2017 mural, "Chronicles of Clichy-Montfermeil," a $150 \mathrm{~m}^{2}$ black-and-white pasting of over $75^{\circ}$ portraits of participants from the towns. The mural was exhibited in 2017 at the Paris museum of contemporary art, the Palais de Tokyo, before being relocated to avenue Jean Moulin, the road which links both towns. JR approached locals, passers-by, and neighbourhood officials asking them to pose alone or in groups, emphasizing the participatory, co-creative aspect of the production, with each person invited to adopt a stance they felt best represented them. Their photographs were taken against a green screen before being collaged together, into collective, themed arrangements decided by the artist. In what follows, I focus on this mural's representation of history and its visual imbrication with Republican aesthetic references as a means to grasp the tensions it brings to light.

As the word "chronicles" suggests, this mural presents a visual historical account of Clichy-Montfermeil in time, taking 2005 as its starting point. 
The temporality of the image is highly complex, with references to the past, present, and future layered atop one another. Significantly, the violence of 2005 is not set apart. While largely situated towards the bottom centre of the mural, the bodies and back-drop segue into other sections, so while present, "the event" remains a relatively small part of the overall composition. Here, smoke, fire, and bodies in dynamic motion form the backdrop to a number of significant, front-facing, full-body figures. These include an older, bearded Ladj Ly adopting the now-iconic pose from "Ladj Braquage," staring down the barrel of the camera-gun. Other young men from the 2004-2006 series "Portrait of a Generation" (of which "Ladj Braquage" formed a part) also make an appearance, their older selves mimicking the poses from that series. In addition, the figure of Bouna Traoré's older brother (Figure 11.2) appears in this grouping, crouching forward, his hands covering both ears as though to block out the turbulence behind. These referential vignettes activate a series of visual echoes, resonances of earlier aesthetic-political disturbances. In its orchestration of these echoes, the work creates a memory knot whose chain of visual references ricochets back and forth between images to resist closure. Significantly, unlike the individual portraits of 2004-2006, these full-length figures are flanked on all sides by dozens more anonymous faces and figures, insurgents - some hooded, others with their arms outstretched in a lobbing motion - and riot police - cyborg-like, their faces hidden behind helmets and tinted face shields. Here then the events of 2005 become, quite literally, multifaceted, with faces on both sides represented, the lines of definition between "victim" and "perpetrator" blurred in the visual noise, which, rather than blame, suggests chaos, loss, and the singularity of the events which have marked the neighbourhood.

The critical gesture of the mural at this point lies in its inscription of this past into the present and future of Clichy-Montfermeil. In this temporal and multi-faceted complexity, it stands out, for official recognition has been largely restricted to commemoration of Bouna's and Zyed's tragic deaths. In this mural, it is violence itself - its disruption, energy, self-awareness and justification - that is memorialized, just as the duration and porosity of that violence is suggested via the blending of these figures into the black-and-white, accumulative aesthetic of the panorama overall. And, while there are references to the past, the mural's temporal layers are richly suggestive of the everyday lives of inhabitants. We see a group of teenage girls and boys taking selfies, men and women in lively conversation, women pushing prams, drug dealers, prize-fighting boxers, café owners, social workers, town councillors, dancers, fire fighters, bin men. This is a portrait of community groups undertaking ordinary activities in an ethnically 


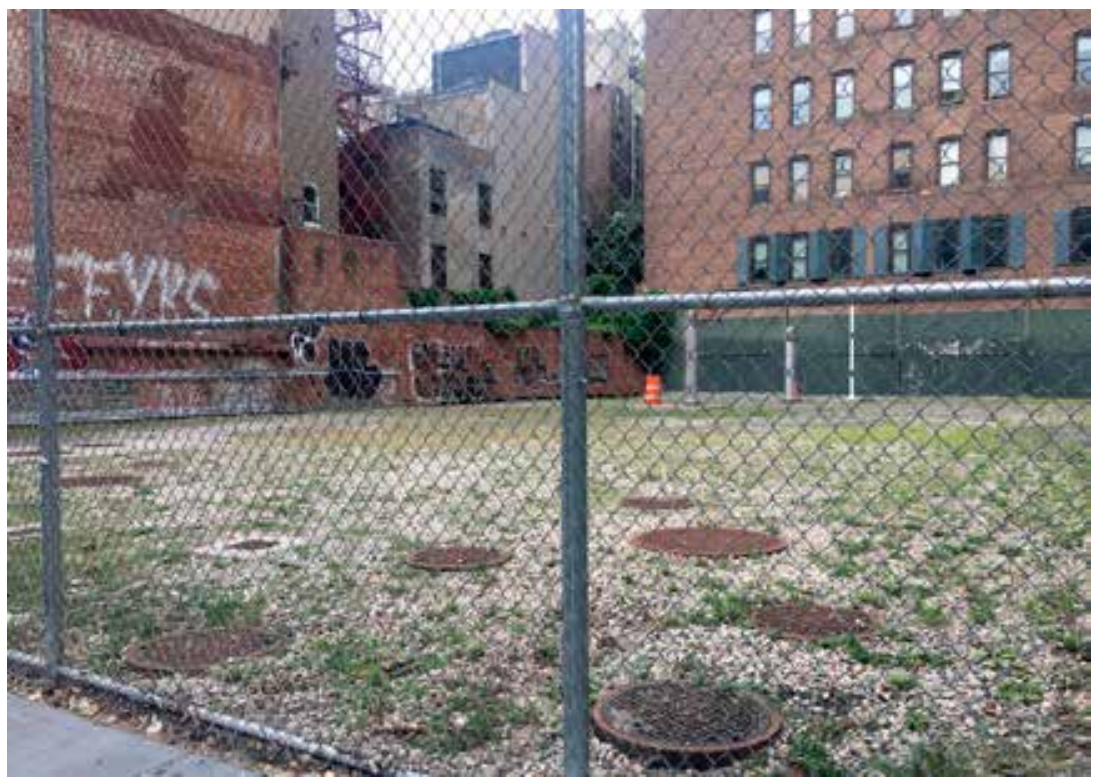

Figure 11.2: Clichy-Montfermeil Chronicles, Mural detail at Montfermeil, France, 2017 @ JR.

diverse neighbourhood, with people from North and West African, White and Jewish origin present. There are also visible signs of religious affiliation, with Muslim women wearing hijabs - a controversial gesture in France, where "ostentatious" religious signs are technically forbidden in public spaces. On the mural's top tier, we find references to the future; construction workers in hard hats, a group of young kids, backs to the camera, standing atop a roof, looking into the distance towards a shiny new building to the right. In a more inclusive mode of framing, JR moves the focus away from the young, aggressive men of "Portrait of a Generation" to embrace the multiplicities of community life.

However, if this mural's photographic portraits are highly realist, their compositional arrangement evokes a more allegorical treatment, and it is here that tensions emerge between the celebration of a community for itself and the suggestion of that community's inclusion in existing urban 
hegemonies and a consensual Republican vision. "Allegory," which refers to "the description of one thing under the image of another" (Online Etymological Dictionary), becomes apparent when we examine the directional rhythms of gesture, gaze and grouping, and recognize these figural references to the neo-classical and Romantic paintings of the early French Republics.

Indeed the mural's dynamism derives from its arrangement in a series of vertical thrusts, highly reminiscent of Jacques-Louis David's (1748-1825) monumental paintings. Notably, "The Intervention of the Sabine Women" (1799), David's representation of warring bodies, energetic outstretched arms, and, ultimately, a nation fatigued by war resonates with JR's figural gestures and Bouna's brother's expressed desire for quiet. Similarly, David's depiction of the French Republic's founding moment, "Oath of the Tennis Court" (1791), finds resonance in JR's compositional arrangement of a prominent group of children in football uniforms. Like David's composition, a central figure, in this case the football coach, stands at the group's centre, his arm raised, index finger pointing skyward. The children are arranged in a pyramidal structure around him, their gaze skyward, the vertical thrust of their bodies' configuration consistent with David's neoclassical convergence of diagonals. This structural correspondence is echoed thematically, for if David suggests that this oath is central to the regeneration of the French nation, here too the suggestion is that the children of the banlieues are key to the nation's future. Here, and in other similarly arranged groupings, the gaze trails off to the middle-distance - perhaps to some future outside the frame.

This reading is confirmed and complicated by the mural's most obvious inter-medial reference, that of Eugène Delacroix's "Liberty Leading the People" (1830). As well as the composition, JR's statement that he drew inspiration for this mural from Mexican muralist Diego Rivera (1886-1957), who also drew on Delacroix's famous allegory in his painting, "Communards" (1928), reinforces this point. Like Delacroix, JR uses a number of pyramidal groupings to organize the upper sections of the mural, giving the impression of groups, and providing balance and rhythm to the dramatic collision of bodies below. The allegorical figure of Liberty is echoed to the left of the mural by the figure of young girl, held aloft by her peers, arm outstretched as she holds a taper with which to light an electric street lamp, forming a right diagonal (Figure 11.3). To her left, beneath, a boy stretches his arm towards her, while he is flanked by a girl whose arm faces downwards to form a seamless diagonal line. Their arms' line is mirrored by the tiered arrangement of street lamps behind them which shed light downwards to the crowd below. The convergence of these diagonals forms an apex, while the clear anachronism of the girl's taper to turn on an electric lamp 


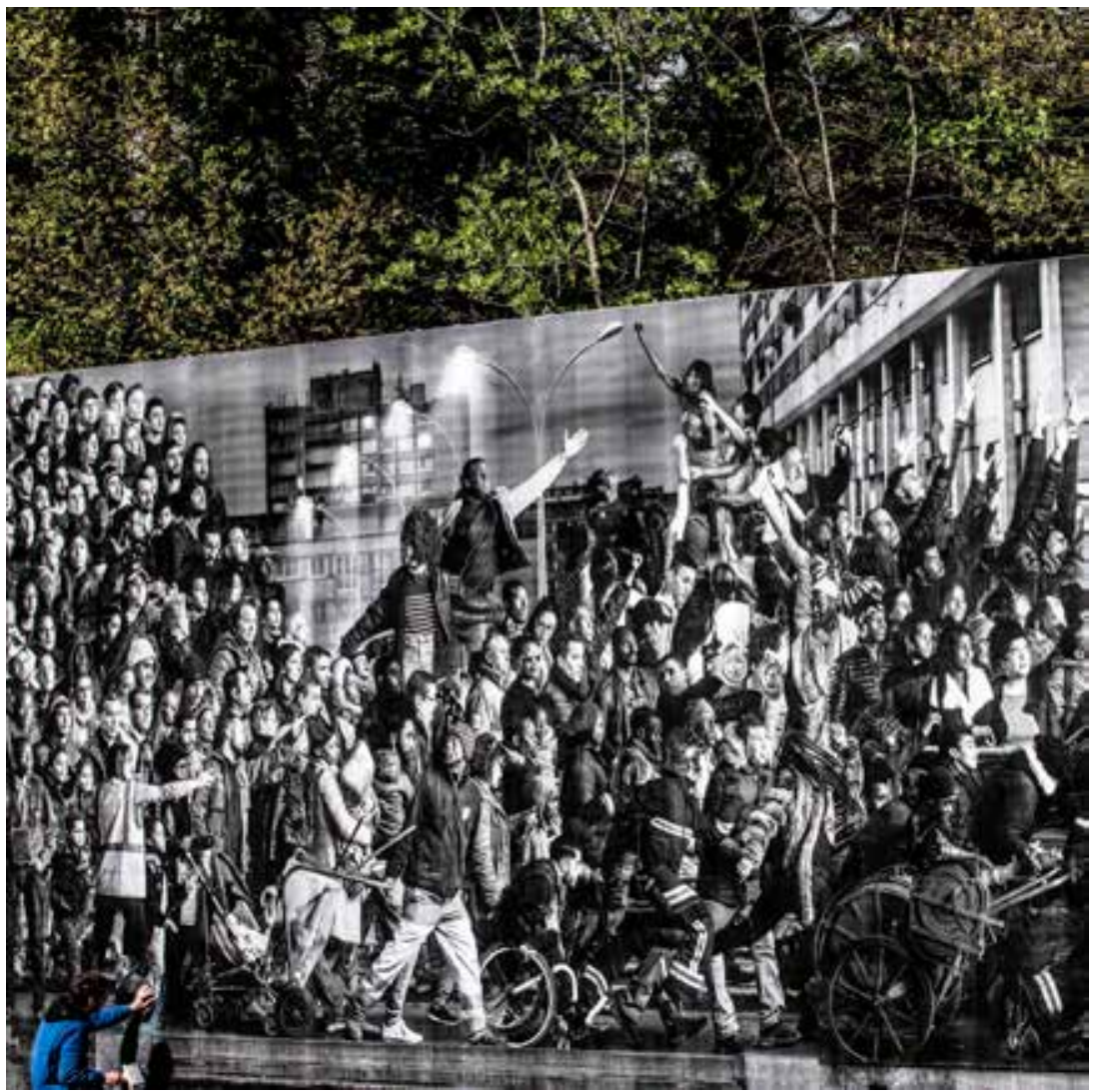

Figure 11.3: Clichy-Montfermeil Chronicles, Mural detail at Montfermeil, France, 2017 @ JR.

reinforces the allegorical reference to the Romantic painting, suggesting a link to Paris' denomination as the "City of Lights," and the lamplighters of the past. Other artefacts, such as the old-fashioned fire hose beneath, suggest the metonymical thread here, while the combination of bodies below this scene are all reminiscent of Delacroix's depiction of the barricades, and justification for the revolution of 1830 . Furthermore, in the same way that Delacroix's figural Liberty controversially combined realistic mimesis with allegory, here photographic realism is tempered by the metonymical gestures of the girl, suggesting her as a contemporary incarnation of Liberty, her black skin and braided hair suggesting a racially diverse Republic.

However, the presence of Republican iconography is tension-filled, both from the perspective of ideological multi-culturalism and given the new neoliberal metropolitan context. Traditionally, the French Republican model is based on the association of equal citizens, a universalism based on the 
rights of individuals inspired by Enlightenment ideals and the political imagination of the French Revolution. Historically, this involved a conscious project of erasing cultural and linguistic differences. In today's terms it can be seen in the Republican refusal to acknowledge multiculturalism or to recognize any form of "particularism." Furthermore, if JR's posits a multiracial Republic, this mural does not suggest a deviation from existing power structures. Rather it might posit that the riots of 2005 now form part of the memory bank of Republican iconography, so that the aestheticization of violence can be seen to reinforce the political legitimacy of the Republican tradition. This is buttressed by the presence of Xavier Lemoine, the figure wearing a Republican sash, mayor of Montfermeil and vice-president of the right-wing Christian Democratic Party. Lemoine has been unambiguous in his advocation of linguistic and cultural assimilation in public as well as private spaces, and sees the growing Islamic population as catastrophic to the existence of the Republic. Republican hegemonies are reinforced by the presence of Olivier Klein, mayor of Clichy-sous-Bois, while the presence of a woman holding a pamphlet advertising the Grand Paris Express alludes to the neighbourhood's imminent reconnection to the capital.

In addition to the mural's internal features, the unveiling and promotion of this piece are problematic from the point of view of a straightforwardly resistive politics. For, having seen the work in the Palais de Tokyo, then President, François Hollande, requested that he inaugurate the mural's installation in Clichy-sous-Bois. Thus, the piece was erected as a permanent installation opened by Hollande in March 2017 to a large crowd of inhabitants and visitors (including JR, Ladj Ly and La Haine director Matthieu Kassovitz), where he announced that it would be included in the "patrimoine;" a special designation for cultural artefacts deemed part of French national heritage (Jardonnet 2017a). In his speech, the President's hopeful message acknowledged past trauma, but ultimately emphasized the transformative effects of regeneration and the identification of this community with the Republican nation, declaring dramatically, "You are France" (Agence France Presse 2017).

Given the ways JR's mural reconfigures the myths of Republican ideology, it is here that the question of "integration" and whether or not we are simply returned to a version of the "One and Indivisible" French Republic emerges. JR's Chronicles complicates the narrative of 2005, suggesting the imbrication of these events in the history of French social revolt, and their significance, therefore, in terms of the future history of the nation. Creating an artwork out of the banlieue itself in order to problematize such political visual regimes, the riots are reconfigured for cultural and collective memory. There is a 
triple tension here, then, between governmental impulses to demolish the material symbols of past trauma, loss, and violence; a desire to recuperate the past by reframing it in terms of Republican traditions of revolt; and the suggestion that the future can bring the banlieues' complexities into consensual line with Republican universalism.

\section{Conclusion}

Paying attention to the banlieues' discursive and aesthetic rearticulation since the emergence of Grand Paris in 2007 requires us to see in this planning programme not only an economic model of neoliberal urbanism, but also an ideological project that speaks to neoliberalism's intersection with national Republican values. Designed to revolutionize the borders between Paris and its peripheries, Grand Paris, in the words of its political architect Sarkozy, has the intention to "put an end to the banlieues, so as to integrate them with Paris" (Sarkozy cited in Jaigu 2009). The rhetoric here speaks not only to territorial integration, but to the symbolic coherence of the nation. For "Paris" is also a symbolic territory synonymous with the central state, whereby the reorganization of place is a means through which to maintain the hegemony of the Republic. As Sophie Gonick shows, Parisian planning practices have long used infrastructures to circulate not only goods and services, but bodies and power, "radiat[ing] power outwards, creating collective identity in a nation [...] marked profoundly by regional [and, we might add, transnational] differences" (Gonick 2011: 33). And Grand Paris is also an ideological project, framed within a discourse of national integration and, from there, the restoration of France's global influence.

The regeneration of Clichy-sous-Bois and Montfermeil is thus implicated in the success of a much larger-scale project to ensure national cohesion and Paris' global competitiveness. Christian Blanc, the minister responsible for drafting the earliest iteration of Grand Paris in 2010 describes the state's vision that Grand Paris become "a political and economic world centre [...] a cultural, scientific, and educational hearth whose influence extends to the entire world" (Project de Loi 2010:1). As secretary general Gilles Castore (AMIF) states, Grand Paris concerns "the whole of France" (Projet de Loi 2010 ), while one of the project architects, Christian de Portzamparc, describes Grand Paris as a "blueprint for civilization" (Projet de Loi 2010: 12). Grand Paris, therefore, poses a new and distinctive phase of development for the post-industrial, racially diverse suburbs. Its emphasis on supply-side production prompts us to question the limits of aesthetic resistance and 
particularly traditionally "underground" modes of sub-cultural expression. Grand Paris effectively promotes the "alternative" to enhance economic value, while politically the "alternative" becomes a means to express the mythologies of Republican consensus.

Thus, while socially-engaged art practices have been crucial in advancing action in the field of identity politics, in an era where socially liberal agendas are instrumentalized for fiscally and ideologically conservative ends, we must retrace our steps to look at the evolution in meaning as art on the street becomes enmeshed in the new value chain of creativity. More specifically, as a form that originated on the margins of social production, but which has evolved into a mainstream urban phenomenon, forming part of gentrification aesthetics, the tensions apparent in JR's "Chronicles of Clichy-Montfermeil" problematize the dualism of "emancipatory" (Caulfied 1989; Florida 2002) or "revanchist" (Smith 1996) interpretations of gentrification. Indeed, street art is compelling for its insinuation of antagonism between positions into the urban fabric - for its desire to alter the violence of visual tropes surrounding a community. But its collaboration with planning requires that violence's distancing into history and mythologies that would refuse that community's complex cultural pluralism. Rather than "emancipation" or "revanchism" that is, speculation and gentrification as a "good" or "bad" thing - discussing neighbourhood change through street art's politico-aesthetics requires us to acknowledge the knotty antagonisms that emerge when "underground" aesthetics intersect with hegemonic urban regimes, signalling the presence of what we might term an "agonistic urbanism."

\section{Works Cited}

Agence France Presse (2017) "Hollande demande aux habitants de Clichy-sous-Bois d'être 'fiers." LaDépeche.fr. 19 April. Retrieved from: http://www.ladepeche.fr/ article/2017/04/19/2559188-hollande-demande-habitants-clichy-sous-bois-etrefiers.html (accessed 21 August 2017).

Article 1 of the French Constitution. Retrieved from: http://www.legifrance.gouv. fr/affichTexte.do?cidTexte=LEGITEXTooooo6071194 (accessed 10 January 2013).

Baginski, Anastasia and Chris Malcolm (2009) "Gentrification and the Aesthetics of Displacement." Field:A Journal of Socially-Engaged Art Criticism, 14. Retrieved from: http://field-journal.com/issue-14/gentrification-and-the-aesthetics-ofdisplacement (accessed 20 December 2019).

Bernard, Philippe (2005) "Banlieues: la provocation colonial." Le Monde, 19 November. Retrieved from: http://abonnes.lemonde.fr/cgi-bin/ACHATS/ARCHIVES/ 
archives.cgi? ID=1e308500c9b210cdcd1dbd5bb771ad8fbb1eb6802529oca2 (accessed 10 May 2011).

Body-Gendrot, Sophie (2010) "Police Marginality, Racial Logics and Discrimination in the banlieues of France." Ethnic and Racial Studies 33.4: 656-674.

Cameron, Stuart and Jon Coaffee (2006) "Art, Gentrification and Regeneration: From Artist as Pioneer to Public Arts." European Journal of Housing Policy 5.1: 39-58.

Caulfied, Jan (1989) “Gentrification and Desire." Canadian Review of Sociology and Anthropology 26.4: 617-632.

Clerima, Ludovic (2018) "Immobilier: le Grand Paris Terrain de Chasse pour les Investisseurs Aguerris." Le Monde, 25 September. Retrieved from: https://www. lemonde.fr/argent/article/2018/og/25/immobilier-le-grand-paris-terrain-dechasse-pour-les-investisseurs-aguerris_5359929_1657007.html (accessed 28 September 2018).

Chrisafis, Angelique (2012) "French Elections 2012: the View from the Banlieues." The Guardian, 20 April. Retrieved from: https://www.theguardian.com/world/2012/ apr/20/french-elections-2012-view-banlieues (accessed 18 December 2019).

Cuttle, Jade (2018) "Find the "Real" Paris in Clichy-Sous-Bois, the City's Least-Visited Neighbourhood.” Culture Trip, 5 April. Retrieved from: https://theculturetrip. com/europe/france/paris/articles/find-the-real-paris-in-clichy-sous-bois-thecitys-least-visited-neighbourhood/ (accessed 6 July 2018).

Day, Elizabeth (2010) “The Street Art of JR.” The Guardian, 7 March. Retrieved from: https://www.theguardian.com/artanddesign/2010/mar/o7/street-art-jrphotography (accessed 19 February 2012).

Deleuze, Gilles and Félix Guattari (1980) Mille Plateaux: Capitalisme et Schizophrénie 2. Paris: Éditions de Minuit.

De Vries, Karl (2015) “Paris Attacks Prompt Fears France's Muslim “No-go" Zones Incubating Jihad." Fox News, 12 January. Retrieved from: https://www.foxnews. com/world/paris-attacks-prompt-fears-frances-muslim-no-go-zones-incubatingjihad (accessed 10 December 2015).

Dikeç, Mustafa (2007) Badlands of the Republic: Space, Politics, and Urban Policy. London: Blackwell.

Dupont, Marion (2018) “Le Futur Va Dans le Mur.” Le Monde, 4 February. Retrieved from: http://abonnes.lemonde.fr/idees/article/2018/02/04/le-futur-va-dans-lemur_5251625_3232.html (accessed 9 February 2018).

Edkins, Jenny (2015) Face Politics. London: Routledge.

Egalité et réconciliation (2013) “L'Émeute Comme Arme de Gouvernance." Égalité et Réconciliation, 13 November. Retrieved from: https://www.egaliteetreconciliation.fr/L-emeute-comme-arme-de-gouvernance-21287.html (accessed 18 December 2019). 
Elzas, Sarah (2018) "Grand Paris, or How Paris Is Trying to Become a Metropolis." Spotlight on France Podcast, broadcast on 8 February. Radio France International, retrieved from http://www.rfi.fr/en/culture/20180205-how-olympics2024-driving-grand-paris-plans (accessed 8 February 2018).

Florida, Richard (2002) The Rise of the Creative Class: And How It's Transforming Work, Leisure, Community and Everyday Life. New York: Basic Books.

Foster, Hal (ed.) (1988) Vision and Visuality. Seattle: Bay Press.

Glass, Ruth (1964) London: Aspects of Change. London: MacGibbon \& Kee.

Gonick, Sophie (2011) “Disciplining the Metropolis: Grand Paris, Immigration, and the Banlieue." Berkeley Planning Journal 24.1: 26-45.

Hargreaves, Alec G. (2015) "Empty Promises?: Public Policy against Racial and Ethnic Discrimination in France." French Politics, Culture \& Society 33.3: 95-115. Hasse, Benoît (2019) "Immobilier à Paris: 10000 Euros du m2, On Y Est!" Le Parisien, 2 April. Retrieved from: http://www.leparisien.fr/paris-75/immobilier-aparis-10-0oo-eur-du-m2-on-y-est-presque-01-04-2019-8044239.php (accessed 4 June 2019).

Jaeglé, Yves (2019) “Exposition: JR, du Métro au Monde Entier." Le Parisien, 13 February. Retrieved from: http://www.leparisien.fr/culture-loisirs/exposition-jr-dumetro-au-monde-entier-13-01-2019-7987377.php (accessed 15 July 2019).

Jardonnet, Emmanuelle (2017a) "Une Fresque Monumentale Signée JR et Ladj Ly Déployée à la Cité des Bosquets." Le Monde, 20 April. Retrieved from: http:// www.lemonde.fr/arts/article/2017/04/20/une-fresque-de-jr-et-ladj-ly-a-lacite-des-bosquets_5114419_1655012.html\#GDKrcUr3ZP5MdZ1x.99 (accessed 21 August 2017).

Jardonnet, Emmanuelle (2017b) “JR: 'Clichy-Montfermeil Est un Village Français Comme un Autre." Le Monde, 20 October. Retrieved from: https://www.lemonde. $\mathrm{fr} /$ televisions-radio/article/2017/10/20/jr-clichy-montfermeil-est-un-villagefrancais-comme-un-autre_5203911_1655027.html (accessed 10 January 2018).

JR (2011) Interview on "Journal de 13h." France 2, 6 August. Retrieved from: http:// www.youtube.com/watch?v=tLzit86-igc (accessed 10 May 2011).

JR (2016) Interview with Hugo Vitrani. Mediapart. Retrieved from: http://www. palaisdetokyo.com/fr/evenement/jr-o (accessed 16 July 2017).

Koff, Harlan and Dominique Duprez (2009) "The 2005 Riots in France: The International Impact of Domestic Violence." Journal of Ethnic and Migration Studies 35.5: 713-730.

Ley, David (2003) "Artists, Aestheticisation and the Field of Gentrification." Urban Studies 40.12: 2527-2544.

Lussay, Alain (2019) “Emeute." Riposte Lä̈que, 6 November. Retrieved from: https:// ripostelaique.com/chez-praud-une-bande-de-proniqueurs-contifiants.html/ emeute-2 (accessed 18 December 2019). 
Mirabaud Group (2018) "Mirabaud Grand Paris: Présentation du Concept." Youtube, 21 November. Retrieved from: https://www.youtube.com/ watch?v=OUgOcTxgRCg\&feature=emb_logo (accessed 10 October 2019).

Mouffe, Chantal (2007) "Artistic Activism and Agonistic Spaces." Art \& Research 1.2: 1-5. Retrieved from: http://www.artandresearch.org.uk/vin2/mouffe.html (accessed 10 November 2019).

Mouffe, Chantal (2013) Agonistics: Thinking the World Politically. London: Verso.

Moutarde, Nathalie (2019) "Inventons la Métropole du Grand Paris 2: les 23 Lauréats Dévoilés." Le Moniteur, 2o June. Retrieved from: https://www.lemoniteur.fr/ photo/inventons-la-metropole-du-grand-paris-2-voici-les-23-projets.2042810/ laureats-imgp2-site-du-parc-d-activites-economiques-des-berges-de-seine-aargenteuil-val-d-oise.1 (accessed 24 June 2019).

Newens, Chris (2018) “I Went to Paris's Least-visited Neighbourhood - Here's What I Learned Along the Way." New Statesman, 14 February. Retrieved from: https:// www.newstatesman.com/world/europe/2018/o2/i-went-paris-s-least-visitedneighbourhood-here-s-what-i-learned-along-way (accessed 6 July 2018).

Obenson, Tambay (2020) "Les Misérables: Writer-Director Ladj Ly Hopes to Inspire Revolution With His Feature Debut." IndieWire, 10 January. Retrieved from: https://www.indiewire.com/2020/o1/les-miserables-ladj-ly-interview-1202201131/ (accessed 11 January 2020).

Online Etymological Dictionary. Retrieved from: https:/www.etymonline.com/ word/speculation (accessed 30 September 2018).

Paris Property Group (2018) "Le Grand Paris: Hunting Ground for Seasoned Investors." This Paris Life blog, 25 September. Retrieved from: https://parispropertygroup.com/blog/2018/le-grand-paris-hunting-ground-for-seasoned-investors/ (accessed 29 September 2018).

Peck, Jamie (2005) "Struggling with the Creative Class." International Journal of Urban and Regional Research 29.4: 740-770.

Peck, Jamie (2013) “Explaining (with) Neoliberalism.” Territory, Politics, Governance 1.2: 132-157.

Porier, Jérôme (2018) “Grand Paris, Où Acheter?” Le Monde, 25 September. Retrieved from: https://www.lemonde.fr/argent/article/2018/o9/25/grand-paris-ouacheter_5359656_1657007.html (accessed 28 September 2018).

Pouliquen, Katel (2005) “Déclic Urbain.” L'Express, 17 November, section Magazine. Rancière, Jacques (2004) The Politics of Aesthetics: The Distribution of the Sensible. Translated by Gabriel Rockhill. London: Continuum.

Ravel, Judith (2008) Qui a Peur de la Banlieue? Montrouge: Bayard Editions.

Ruggeri, Charlotte (2019) "De Clichy-sous-Bois au Grand Paris Express: Regards d'un Maire sur un Grand Projet d'Aménagement Francilien. Entretien avec Olivier Klein." Urbanités, 11 February, 1-5. 
Slater, Tom (2006) "The Eviction of Critical Perspectives from Gentrification Research." International Journal of Urban and Regional Research 30.4: 737-757. Smith, Neil (1996) The New Urban Frontier: Gentrification and the Revanchist City. London: Routledge.

Sotheby's (2018) Lot 18. JR, “28 Millimètres: Face 2 Face, Nuns in Action, Separation Wall Security Fence, Palestinian Side, Bethlehem.” Auction: Creating a Stage: The Collection of Marsha and Robin Williams. 4 October. Retrieved from: https://www.sothebys.com/en/auctions/ecatalogue/2018/creating-astage-collection-of-marsha-and-robin-williams-no9977/lot.18.html?locale=en\# (accessed 4June 2019).

Sterlé, Carole (2017) “Les Mille Visages de Monfermeil Vus par JR et Ladj Ly." Le Parisien, 31 March. Retrieved from: http://www.leparisien.fr/montfermeil-93370/ les-mille-visages-de-montfermeil-vus-par-jr-et-ladj-ly-31-03-2017-6814233.php (accessed 21 August 2017).

TED (2015) “TED Speaker: JR.” Retrieved from https://www.ted.com/speakers/jr (accessed 14 May 2015).

Thompson, Nato (2015) "The Art of JR," 30-44 in JR, Can Art Change the World? London: Phaidon.

Villamy, Olivia (2019) "Immobilier en Seine-Saint-Denis: Clichy et Montfermeil Séduisent de Nouveaux Acheteurs." Le Parisien, 12 December. Retrieved from: http://www.leparisien.fr/seine-saint-denis-93/immobilier-en-seine-saint-denisclichy-et-montfermeil-seduisent-de-nouveaux-acheteurs-12-12-2019-8216046. php (accessed 15 December 2019).

Virilio, Paul (1988) La Machine de vision. Paris: Galilée.

Vivant, Elsa, Karine Sahler, and Clément Postec (2016) L'Ouvroir, June. Retrieved from: http://www.clementpostec.com/wp-content/uploads/2014/12/L_Ouvroir. pdf (accessed 29 November 2019).

Vivant, Elsa (2018) "Les Fantômes de la Tour Utrillo: Métonymie de l'Action Urbaine à Clichy-sous-Bois et Montfermeil." Géographie et Cultures 106: 115-132.

Žižek, Slavoj (2008) Violence. New York: Picador.

Zukin, Sharon (1982) Loft Living: Culture and Capital in Urban Change. Baltimore: The Johns Hopkins University Press.

\section{About the Author}

Gillian Jein is Senior Lecturer in French Studies at Newcastle University. She works in the field of the urban humanities and her current research examines the relationship between visual culture and regeneration in "Grand Paris." 


\title{
12. On Empty Spaces, Silence, and the Pause
}

\author{
Rebecca Amato
}

\begin{abstract}
Before there is an aesthetic of gentrification, there is disinvestment. In between both is the production - and perception - of empty space ready to be filled. The production of empty space has a long history in New York City, from settler colonialism to urban renewal to gentrification under the neoliberal regime of today. Techniques such as filtering, investing in the aesthetic potential of aging neighbourhoods, and declaring vacancy, have helped fuel the process of gentrification. More recently, that process has accelerated to insure New York's world city status by promising that every underutilized parcel will be filled with the tallest buildings, the greenest construction, and the densest use of land. Yet the city still has room for alternative visions that embrace a pause in the growth machine, such as cooperative centres and community gardens. These efforts, threatened though they are, provide models for inclusive cities where neoliberalism does not.
\end{abstract}

Keywords: vacancy, neoliberalism, brownstoners, colonialism, community garden, cooperative

Before there is an aesthetic of gentrification, there is disinvestment. In between both is the production - and perception - of empty space ready to be filled. In the context of the United States in the 196os and 1970s, images of disinvestment, reproduced in all manner of media, were dominated by cities cavernous with abandoned factories and apartment buildings, acres of overgrown weeds, rubble-strewn yards, and smouldering ruins. The press compared urban spaces, once densely populated, with war zones like Vietnam during American occupation and Dresden during World War II. Such tales gripped spectators with the tragedy of a hubristic, now-fading

Lindner, C. and G.F. Sandoval (eds), Aesthetics of Gentrification: Seductive Spaces and Exclusive Communities in the Neoliberal City. Amsterdam: Amsterdam University Press, 2021 DOI 10.5117/9789463722032_CH12 
civilization. They also served as the backdrop of gentrification and a precipitating agent for the rise of neoliberalism.

At the same time, the narrative of cities in decline overlooked two critical elements. First, disinvestment was and is produced by specific actors, such as the real estate industry, banks, speculators, investment trusts, federal policymakers, and city agencies, to devalue and deplete urban areas and their residents, only to spur growth when and where it is desirable to do so. It is not an accident of the land market, nor is it a naturally occurring phenomenon. In New York, municipal leaders actively disinvested in suffering neighbourhoods through strategies of what New York Senator Daniel Patrick Moynihan called "benign neglect" and New York City Housing Preservation and Development Commissioner Roger Starr labelled "planned shrinkage." Their arguments relied on the assertion that poor and minority populations were either architects of their own destruction or unjustified drains on public funds. By pulling back from the neighbourhoods in which these residents lived, the city not only stripped poor, usually Black and Latinx New Yorkers, of basic resources, it also colluded in producing empty spaces in the urban fabric, ready to be filled. This production of empty space as a catalyst for future growth has a long history in colonial projects and an elaborate present in the neoliberal era of gentrification, which I will explore below.

The other element that the narrative of cities in decline missed was the way in which claims of empty space and subsequent approaches to filling it were contested. Residents of abandoned New York neighbourhoods consistently worked to reclaim, repair, and cultivate the assets they still controlled through cooperative management and community self-help. They protested, often passionately, the loss of city services, but they did not wait for the city to do its job. Instead, when government failed, many New York neighbourhoods devised their own alternative systems of care, including gardening, construction training, and repair of crumbling buildings. These traditions endure even as what sociologist Harvey Molotch has called the "growth machine" churns out new ways of producing empty spaces. Here, I also look at two examples of cooperative management in New York City and consider the ways in which such efforts pause and disrupt not only neoliberalism, but also gentrification and its aesthetics.

\section{A View from the Harbor}

Before contemplating gentrification, it makes sense to trace New York City and its long-celebrated ethos of growth to its colonial origin story. 
After all, displacement and dispossession - two consequences of modernday gentrification - echo the kind of historical erasure that colonization delivered centuries before. Today, from a boat in the middle of New York harbour, hovering somewhere between estuary and ocean, one can see the dense towers of Manhattan nibble at the very edges of the island. But neither the density nor the island's edges existed in quite the same way at the moment of Dutch settlement in 1624. Jasper Danckaerts, a Dutch traveller and religious idealist, arrived in this same harbour in 1679, marvelling at the "bay swarm[ing] with fish, both large and small, whales, tunnies, and porpoises, whole schools of innumerable other fish" (Danckaerts 1913: 36). Danckaerts had come to New York seeking a suitable site to establish a utopian religious colony. His Labadist Christian faith, which promoted humility, the communal sharing of property, and manual labour, meant persecution back in the Netherlands. Once transported to the New World thanks in part to Danckaerts' scouting mission, the Labadists celebrated religious freedom only briefly, eventually dissolving their tiny settlements one by one. Even in 1679, however, Danckaerts was not the first utopian to see possible futures in the archipelago that would become New York and New Jersey - nor would he be the last. The harbour view kindled the imaginations of countless other immigrants arriving at Castle Clinton and later Ellis Island in the nineteenth and twentieth centuries. It inspired Walt Whitman to write of Manhattan in 1855 as if the harbour were its most notable feature: "City of hurried and sparkling waters! City of spires and masts! City nested in bays!" (Whitman 2009: 405). And it reassured the Rockefeller Brothers, David and Nelson, that Manhattan island was elastic enough to grow larger with landfill and that the powerful waters of the harbour could be tamed by slurry walls. Such affirmations gave Manhattan the World Trade Center and Battery Park City in the 1970s (Glanz and Lipton 2003).

But none of these dreams came without troubling reminders that these islands contained existing ways of life, nor, of course, were they limited to the harbour. And different utopians had different ways of reconciling what already existed. While Danckaerts might have celebrated the natural bounty of New York harbour and accepted that the skilled native peoples' "Sakemaker" (or sachem) was the same as his God, for the most part, newcomers to the area instead chose to make the extant social fabric disappear. This tradition has endured. The 1758 Treaty of Easton resulted in the final expulsion of the Lenni-Lenape from lands they had nourished for thousands of years (Kraft 1986). In 1853, the city's Common Council evicted 1,6oo predominantly African-, Irish-, and German-American working-class residents from the area that would become Central Park because, as the 
New-York Post reasoned, the new park promised "greater pecuniary benefits, direct and indirect ... and ever-enduring influence in adding to attractiveness and elevating the character of the metropolis, and thus fitting it for high destiny" (quoted in Rosenzweig and Blackmar 1998: 78). A hundred years later, Robert Moses, justifying creative destruction in a dense New York City, infamously declared, "You can draw any kind of picture you want on a clean slate and indulge your every whim in the wilderness in laying out a New Delhi, Canberra, or Brasilia, but when you operate in an overbuilt metropolis, you have to hack your way with a meat ax" (Caro 1974: 849). (Never mind that neither New Delhi, Canberra, nor Brasilia were built on unpeopled, "clean slates" either.)

It is perhaps a trick of colonial eyesight to filter out or vilify details like other human beings, natural and social ecosystems, and spiritual significance when it comes to a compelling opportunity to grow possible futures in a new land. But New York has rarely corrected this vision, nor has the city's propensity to exploit a problem with a gigantic spatial fix, whether it be social crisis or economic stagnation, strayed from an original impulse toward empire building. For those who clutter the current path of gentrification with demands to remain in their neighbourhoods, save their churches, live in homes they can afford, preserve their gardens, shop at the local grocery, or simply enjoy a trip on the ferry without having to work themselves to a pulp to afford urban life, the problem in New York is not the inability to grow possible futures. It is the failure to imagine a kind of growth that also includes them.

\section{Filtering}

To claim that gentrification is only another version of colonialism is perhaps cliché or, at the very least, heavy-handed. Yet, it is not difficult to see gentrification under the current neoliberal order as a kind of empire-building. In a 2013 New York Times op-ed, historian Kenneth T. Jackson argued that opposition to rezoning Manhattan's East Midtown for the construction of new skyscrapers was tantamount to threatening the city's status as "the financial, cultural, media, retailing, and fashion capital of not just the country but the world" (Jackson 2013). In New York, at least, neoliberalism produces an urban imaginary that promises that every underutilized parcel will be filled with the tallest buildings, the greenest construction, the most curated public spaces, and the densest use of every scrap of land available - that is, New York must dominate the global stage (Zukin et 
al. 1998; Cinar 2007; Greenberg 2008). At the same time, neoliberalism insures its command by making claims of scarcity that, it affirms, can only be solved through private investment and entrepreneurial ingenuity, and decelerated through new construction. If Manhattan's Hudson Yards or the slim, supertall towers of Midtown do not echo the empire of the past, neoliberalism tells us, then New York is finished. Pauses and silences are simply nostalgia. Displacement is simply a necessary filtering to meet the needs of global domination.

The term "filtering" has particular meaning in real estate. It refers to the process by which housing built for higher-income residents gradually depreciates to the extent that it becomes affordable to people with more modest incomes. In fact, much of the argument for rezoning New York City for the construction of taller, denser, more expensive residential towers is that increased residential supply will eventually filter down to those with lesser means. This suggests, of course, that the initial residents of new, high-end housing move on to presumably more attractive and salubrious surroundings so that their now-devalued property becomes available to new, less-wealthy consumers. In this way, filtering is understood as the natural way that private markets can produce low-income housing over time without directly building or investing in it. Put differently, filtering signifies the repositioning of a less-desirable product - that is, housing or a neighbourhood that has depreciated so much in value that it is no longer attractive to those with means - as one that is actually alluring to a new audience of consumers.

While filtering is very much part of the present-day discourse around affordable housing, the geographer Neil Smith also described the process back in 1979 when he published his influential essay, "Toward a Theory of Gentrification: A Back to the City Movement of Capital, Not People." From his perspective and historical context, the real purpose of filtering was not to provide housing to people with fewer resources, but rather to move capital from one urban, regional land market (the "inner-city") to another (the suburbs) to protect and grow return on investment. Moreover, Smith argued that the disparity between the under-valuation of "inner-city" land and its potential profitability, which he called the "rent gap," produced a scenario in which the return of capital to the inner-city through redevelopment became a fail-safe profit-generator. Land close to the city centre, which had been devalued, or filtered, through under-maintenance, block-busting, redlining, and landlord abandonment in the decades of suburbanization, did not lose its inherent worth simply because it had been leap-frogged. It was just banked until such time as values could rise again. The profit 
to be absorbed from this practice relied on the land itself - commodified and limited as it was. In other words, the filtering process then, as now, may have incidentally provided housing for people of lesser means, but its purpose was not to do so. Its purpose was to manipulate the land market so that wherever private investors moved their capital, they would avoid risk and their money would could continue to grow.

That Smith so keenly observed the ways agents such as banks, speculators, and the real estate industry fuelled this process in 1979 was prescient, not only because it foreshadowed the deep analysis of neoliberal governance that would later take root in the United States in the 1980s, but because the media image of cities was still one of decline and crisis. Despite the emergence of scholarship on gentrification that could be traced, famously, to sociologist Ruth Glass in London in 1964, American cities into the 1970 s were still battling what they perceived as blight and an unrelenting outflow of capital (Glass in Lees, Slater, Wyly 2010: 7; Teaford 1990: 231-252). Even when municipal governments attempted to capitalize on the quaintness of neighbourhood character to revitalize their cities, most attempts, as historian Jon Teaford has illustrated, failed. Neil Smith understood that banks and large private developers would not return their capital to the city until the "rent gap" was wide enough to assure satisfactory profit. Gentrification, to rephrase Smith's argument, occurred when urban spaces had been so sufficiently emptied of struggling residents and decaying properties that they could be "recycled" and begin "a new cycle of use" (Smith 1979: 545). For him, gentrification was not a story of consumption, but one of producing empty space and then filling it.

This was also his answer to those theorists of gentrification who believed consumers - usually, young, white professionals or artists who wished to reject the homogeneity of suburban life - were the shock-troops of gentrification. To him, they were more like the infantry set loose upon the battlefield after the bombs have already cleared the way. This is not to say their sense of taste and aesthetic preferences were not critical. For one thing, the basically sound (and attractive) buildings that stood or, in many cases, decayed upon land in the city's core, were often restored by these consumers. In his case study of Society Hill in Philadelphia, Smith identified the Old Philadelphia Development Corporation (OPDC), a private-sector, non-profit committee of banks, insurance companies, and the steel industry as a producer and marketer of emptied urban space (Smith 1979: 547). Its consumers, however, were those who were drawn to "restore their buildings to historic standards" with the assistance of the OPDC and Philadelphia Redevelopment Authority, which distributed "renovation guidelines" and 


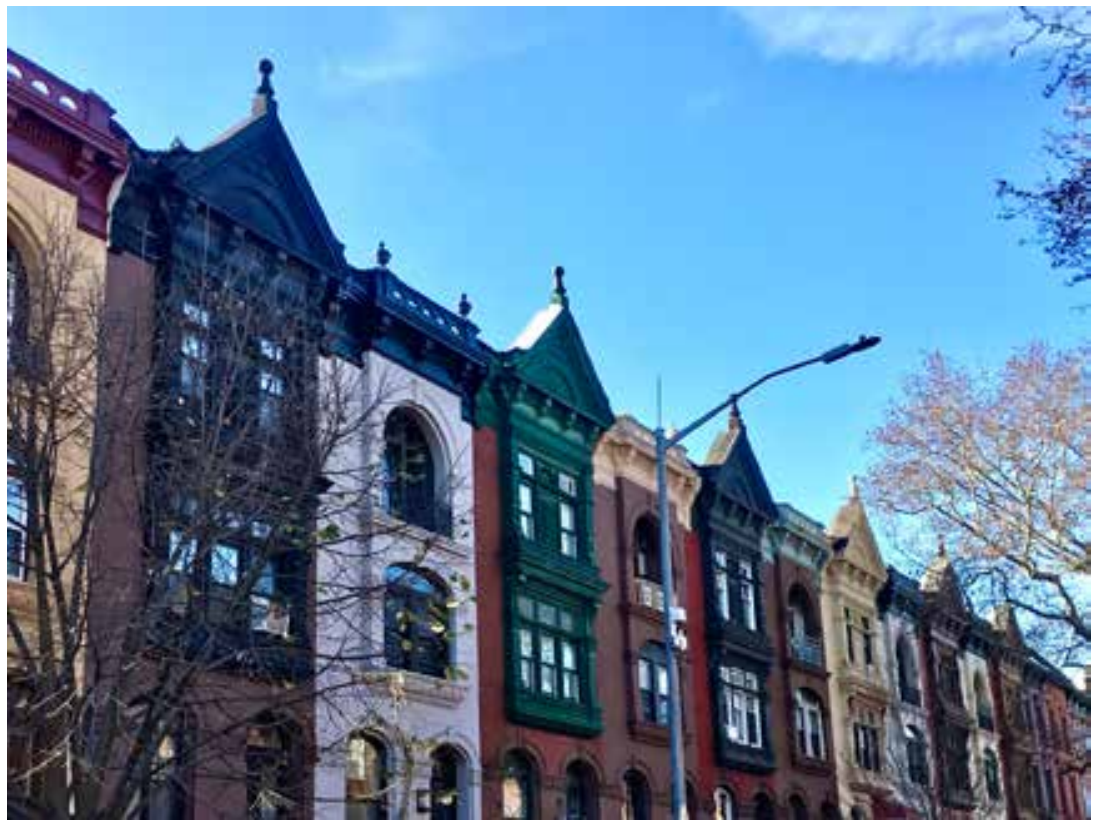

Figure 12.1: Brownstones. These row houses in Bedford-Stuyvesant, Brooklyn, feature parapets alternating with finial-topped gables. Brownstone Brooklyn neighbourhoods like this one attracted rehabbers as early as the 1960s. Photograph by Andre Carrotflower.

"salvaged a number of mantels, doors and windows" to freely distribute to rehabbers (Central Philadelphia Development Corporation: 3). At the same time, the restoration projects of Society Hill homeowners were not done simply for aesthetic purposes. "In the decision to rehabilitate an inner city structure," Smith wrote," the preference for profit, or, more accurately, a sound financial investment" is still more compelling than a polished-up facade (Smith 1979: 540).

The ordinary rehabbers of Smith's era - not just those in Philadelphia's Society Hill, but also the "brownstoners" of Brooklyn, the artists of Soho, the bohemians of Chicago's Lincoln Park - may have had utopian visions and aesthetic sentiments, but colonial and capitalist eyesight remained intact even for them. As historian Suleiman Osman has argued, some rehabber groups in Brooklyn in the 1970s formed block associations and worked with realtors to "attract new residents" to their "reawakening' neighborhood[s]" by inventing new, historically resonant neighbourhood names. The Boerum Hill Association, for example, invented the name "Boerum Hill" in the mid-196os, to reaffirm the area's presumed Dutch history and minimize the ubiquity of its contemporary, predominantly working-class, Latinx population. Realtors in a nearby Italian-American brownstone neighbourhood, 
which bordered the impoverished waterfront community of Red Hook, took Boerum Hill's cue by inventing its own name, Carroll Gardens, to firm up its association with green space and the American Revolution (Osman 2011: 198-201). Hundreds of miles west in Chicago, as Daniel Kay Hertz has explained, the rehabbers of Lincoln Park contended that the neighbourhood's "authentic" middle-class, Victorian-era charm would fall victim to neglect from its mostly poor white, Puerto Rican and Black residents without their social and cultural capital. They too believed they needed to market their "up and coming" neighbourhood to their peers because, as Hertz puts it, "Middle-class people would only purchase homes in places that they believed other middle-class people would purchase homes" (Hertz 2018: 58-59). Once the gentry was fully anchored in such communities, they also turned toward battling the interventions of local government to build affordable housing through urban renewal. In Brooklyn Heights, many homeowners who protested the construction of public housing through urban renewal planning dodged accusations of classism and racism by anchoring their critiques in aesthetic reasoning: "The solution to the problems of low-rent housing does not lie in the scaleless, intrusive, ill-designed brick monsters that we have come to know as the 'projects," wrote one local architect. Another resident proclaimed, "Brooklyn Heights has gained national attention by virtue of its remarkable degree of preservation ... Why, then, arbitrarily jeopardize an irreplaceable asset with an anomaly, when there are two hundred square miles of land area from which to select a much more suitable site for project housing" (Osman 2011: 156-157). These discourses of gentrification as aesthetic conservation or gentrification as the restoration of historical meaning saw little value in conserving or restoring existing populations. The filtering out of whole communities of working people was merely an unfortunate side effect of "reawakening neighborhoods." And for large-scale investors whose far-sighted manipulation of the land market already predicted increased "inner-city" valuation, displacement of the poor only further insured greater profit in the long run.

Half a century later, the gentrification recipe has not changed so much as matured. In Brooklyn Heights, skirmishes over the construction of affordable housing persist, although now the aesthetic issue brownstone homeowners have identified is the need to preserve waterfront views (Fishbein 2016). A neoliberal phalanx of city government and its planners, multinational banks, investment trusts, and wealthy consumers efficiently and relentlessly identify city spaces as underperforming, neglected, sparsely occupied, and ripe for reinvestment. Nowadays such spaces need not be abandoned to be perceived as empty, nor is their historical significance reason enough to 
"conserve" them. A single-family home in brownstone Brooklyn, a synagogue with low attendance, an urban farm, and an aging, low-rise commercial strip can all appear empty to agents seeking density and rapid return on investment. While banks, mortgage lenders, and realtors might have helped grease the wheels for individual rehabbers to pursue aesthetic preference in the past, today's neoliberal aesthetic is simply one of efficiency. If gentrification looked like a restored brownstone or an artists' loft in 1979, today it looks like a wall of partly vacant, prohibitively expensive, anonymous glass towers - little different from the "scaleless, intrusive, ill-designed brick monsters" of urban renewal, but connoting a far different class of occupant.

\section{Vacancy}

Like "filtering," the term "vacancy" has a particularly mercurial meaning in the current neoliberal context. A declaration of "vacancy" is also a powerful way to produce empty space in a jam-packed, growth-minded city. Vacancy has long provoked fear in the way "blight," "slum," and "inner-city" did in earlier times. Vacant property is an eyesore, public health hazard, financial liability, and inevitable sign of decline. It is viral, impossible to contain, an invitation to crime, a problem only entrepreneurial minds can solve. Fearful of all of these liabilities, local governments attempt to identify at-risk properties through a variety of methods. These include measuring census tract changes, searching tax liens, tracking foreclosures, monitoring neighbourhood complaints, and conducting visual surveys. Once properties have been targeted, municipalities spring into action, seeking innovative ways to fill the vacancies. In struggling cities such as Chicago, Newark, and Detroit, for example, the ubiquity of vacant lots and buildings has resulted in city programmes aimed at off-loading them to private owners. Chicago's "Large Lots" programme has so far sold 1,240 lots for \$1 each on its South and West Sides, while Newark's "Love Lots" programme resulted in the 14 February 2015 sale of 98 parcels for $\$ 1,000$ each to couples who promised to build housing on the site (Bonkamp 2018; Stillman 2016).

New York City, with its highest recorded population of 8.6 million people and almost legendary luxury construction boom is not immune to vacancy either, even in the midst of apparent plenty. The City's “Zombie Homes Initiative," launched in 2016, estimates between 2,000 and 4,000 vacant and abandoned homes in the five boroughs, while the city's general vacancy survey shows nearly 250,000 empty apartments in otherwise functioning buildings (Etherington 2008). Vacancy is not limited to residential properties. 


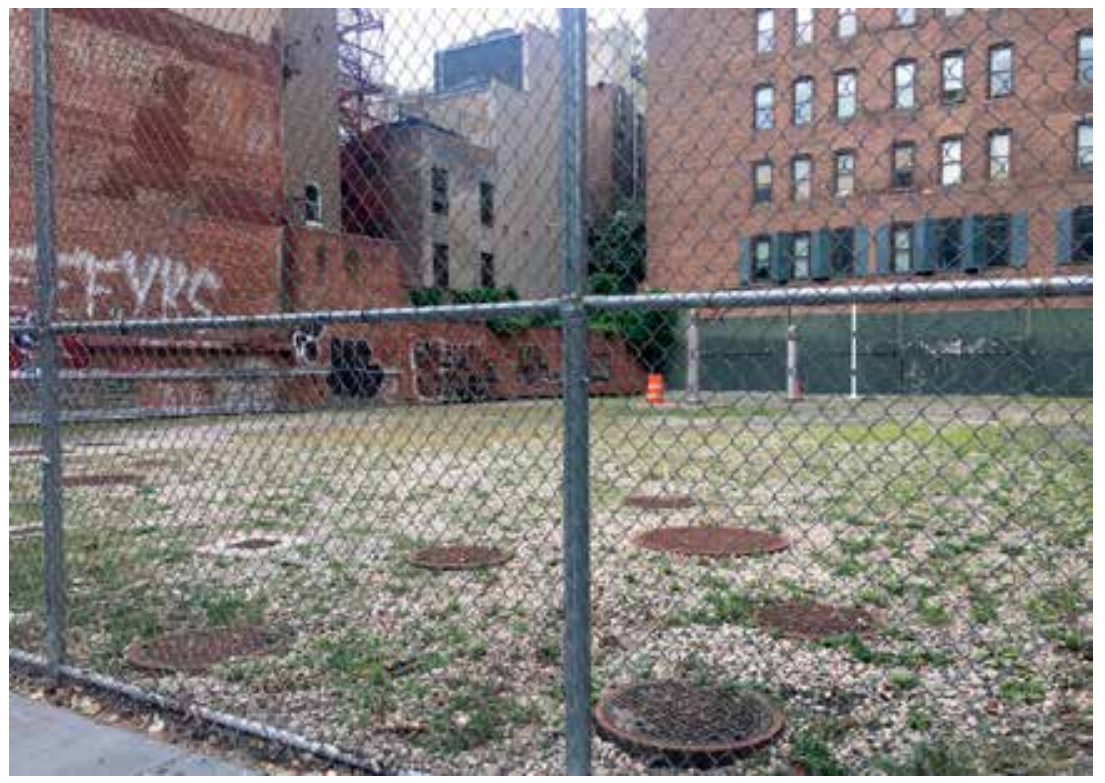

Figure 12.2: Vacant Lot, E. 4th Street Between Bowery and 2nd Avenue. Located next to New York's Merchant House Museum, this vacant lot at E. 4th Street between Bowery and Second Avenue is privately owned, but plans for developing it are unclear. The developer for the garage on the other side of the museum lost a legal battle to build an eight story hotel in 2018. Photograph by the author.

Recently, Manhattan Borough President Gale Brewer has co-sponsored a bill to require landlord registration of vacant and abandoned storefronts. Her concern is not limited to the mom-and-pop tailors and corner stores that New Yorkers of the Jane Jacobs generation praised for "taking care of the streets" (Jacobs 1992: 39). It is also for the designer shopping districts in the West Village and Soho - formerly neighbourhoods of incipient gentrification, now areas of "high-rent blight" - where emptiness belies the steady profits they still yield (Brewer 2019). The empty Marc Jacobs boutique on Bleecker Street does not present the same predicament as the overgrown urban prairie on Chicago's West Side, but both engender similar anxieties about vacancy as an early manifestation of decline.

But there are different kinds of empty space and different ways of seeing vacancy. Planning Scholars Karen Chapple and Miriam Zuk, who run the Urban Displacement Project at the University of California, Berkeley, have noted that, since vacancy is an umbrella term that describes a variety of urban spaces, it is nearly impossible to track. The aggregated data and visual observation collected by jittery local governments to pin down vacancies are not, as Chapple and Zuk explain, always comprehensive or 


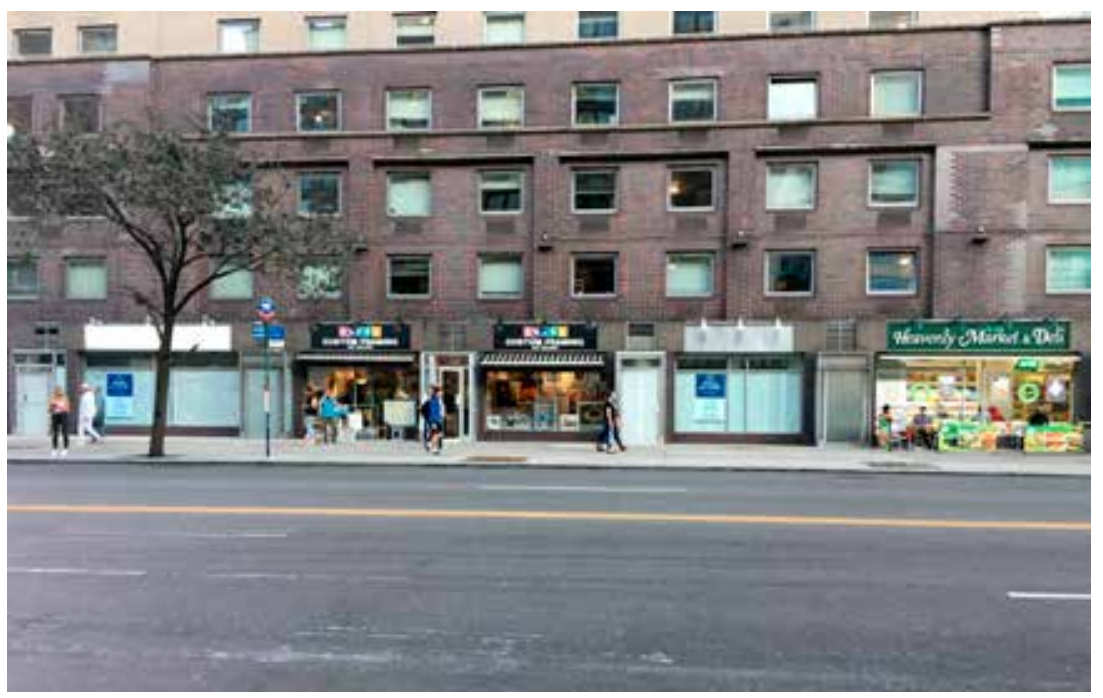

Figure 12.3: Vacant Storefronts, East Village. A thriving commercial strip fairly recently, this East Village thoroughfare has lost or flipped several small and medium-sized businesses in just the last two years. Photograph by the author.

accurate. In assessing the data-driven early warning systems that some non-profits, university think tanks, and cities have developed to assist with anti-displacement campaigns, Chapple and Zuk write of "the challenge of accounting for 'sites of reserve,' or property that landlords hold for decades in anticipation of future profit. As they lay fallow for decades, warning systems may suggest disinvestment, but locals know better" (Chapple and Zuk 2016: 126). Similarly, but for a different reason, the now-retired, New York City-based non-profit 596 Acres identified 1,018 publicly-owned lots that city documents recorded as "vacant," sometimes years after local residents had begun developing the lots as urban farms, gardens, open-air gallery spaces, playgrounds, and free parking lots. In other words, what aerial views and GIS maps - the harbour views of the twenty-first century - describe as "vacant" or empty space may be abundant when observed on the ground and over time.

A socially produced agreement that vacancy is an uncomplicated problem that needs immediate solution, usually through construction, is a prerequisite for neoliberalism to come to the rescue. Not only can private investors fill empty spaces with all manner of new development, they can mask one kind of vacancy with quite another. Manhattan's 432 Park Avenue, now the fifth tallest building in New York City, demonstrates how this is done. Constructed on the site of the former Art Deco-era luxury hotel The 
Drake, which was demolished for the purpose of redevelopment in 2007, $43^{2}$ Park Avenue is ninety-six stories in height and contains over 400,000 square feet of usable interior space. Carved out of that space are only 104 residential units, while the remainder of the building is intended to house retail, such as high-end perfumier Amaffi and Phillips Auction House. As Fortune magazine explained when the building was completed in 2014, "It is widely believed that the building will only be one-quarter occupied at all times, even though it will be completely sold out. Keep in mind that these are pied-a-terres that begin at $\$ 7$ million each and include several full-floor parcels in the $\$ 75$ million range" (Brown 2014). Five years later, this prediction of sizable vacancy coupled with soaring profits seemed to be accurate, so much so that the city attempted to pass a ridiculously modest pied-a-terre tax for second homes valued in excess of $\$ 5$ million. The legislation failed under mounting pressure from New York's real estate industry.

\section{Silence}

If neoliberalism warns that New York will meet certain death if it does not hock its empty spaces and public wares to the highest bidding developer, then those with a different urban imaginary - one that sees plenty where neoliberalism sees scarcity, community where GIS surveys see vacancy are ready for their moment of silence. Across New York City, community groups and like-minded friends are occupying spaces judged to be vacant and transforming them into resources available and accessible to all. They are taking the time to listen to their neighbours and deeply acknowledge the history beneath their feet, much as it seemed Dutch seafarer Jasper Danckaerts was poised to do in 1679 . Newcomers to the city in many cases, they are building utopias that do not depend on the destruction of what already exists. Rather, their objective is to bring what already exists back to life and fight for those people and places that gentrification seeks to displace.

Two of these efforts, CHARAS/El Bohio in Public School 64 on Manhattan's Lower East Side, which operated from 1977 to 2001, and the Smiling Hogshead Ranch, which was founded in 2011 and is still flourishing, demonstrate that community self-reliance, stewardship, and cooperation do have power in New York City. These sites, like the emerging community land trusts, cooperative groceries, and nascent New York City Real Estate Investment Cooperative, are idealistic in their dedication to re-commoning resources, but are not without precedent. As historian Joshua Freeman (2000) has explained, what many consider New York's mid-twentieth 
century golden age of social democracy depended on the cooperative traditions supported by the city's trade unions. There was a world before neoliberalism, and cooperative projects in New York today remind us there can be again.

CHARAS/El Bohio was officially established in Public School 64 in 1977. The name El Bohio, or "the hut" referenced the area's Puerto Rican roots, and CHARAS, the political and cultural organization that operated it, was eponymously named for its founders Chino Garcia, Angelo Rodriguez, Roy Batiste, Anthony Figueroa, and Sal Becker (Mottel 1973: 22). CHARAS pre-existed El Bohio and had emerged in the 1960 s as a counterpoint to Lyndon Johnson's War on Poverty, critiquing large-scale, top-down, state management of poverty relief (Vaughan 1967). By the late-1970s, when both federal and municipal governments had deserted the poor with the withdrawal of financing and a policy of "planned shrinkage," CHARAS used the opportunity to develop a system of community self-reliance and popular education. At the El Bohio school building, which the group was able to lease from the city in collaboration with the housing group Interfaith Adopt-a-Building, CHARAS supported occupation of the area's other abandoned buildings through tenant organizing, construction, conservation training, and cooperative neighbourhood planning. El Bohio's classrooms and auditorium hosted free and low-cost educational programmes in job training, theatre and musical performance, martial arts, dance, photography, film, and political organizing. Advancing the meaning of a public school, CHARAS opened its doors to anyone willing to teach and learn, all the while sprouting a network of local activists whose commitment to sustaining the neighbourhood's vitality stood in opposition to privatization.

For residents of the Lower East Side, or what many of the Puerto Rican, Spanish-speaking neighbourhood termed "Loisaida," community-determined activity at El Bohio not only built on their own collective resilience and promotion of local power through self-help and voluntarism. It was a direct and explicit critique of gentrification that drew from the anti-colonial discourse of the Puerto Rican independence movement. Indeed, poet and CHARAS activist Bimbo Rivas worried that "the colonial dependency state of mind" that had been foisted upon him and his Puerto Rican neighbours was "one of Loisaida's greatest enemies" (Rivas 1979). In contrast to the colonial view of empty spaces as potential private property, CHARAS and its allies advanced an interpretation of property as a common asset, aesthetically worthy because it fed everyone indiscriminately, a site of sufficiency rather than excess. This interpretation allowed for a counternarrative to the neoliberal definition of "equity" as one defined by the marketplace. From 


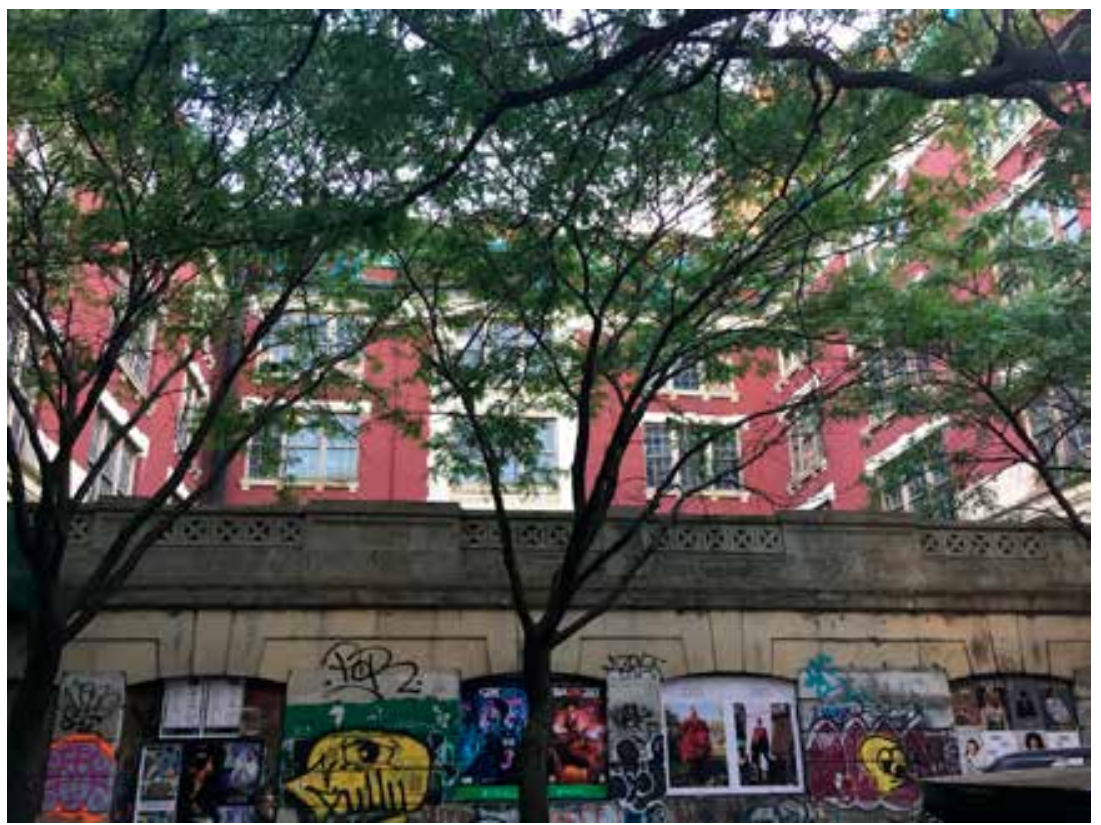

Figure 12.4: CHARAS/El Bohio. CHARAS/El Bohio was closed in 2001 and has remained empty and mostly unrepaired ever since. Speculator Gregg Singer, who purchased the property in 1998, stands to make back at least three times his investment when he sells. Photograph by the author.

CHARAS's perspective, equity was best understood by its other definition, “justice," and was produced by Lower East Side residents' investment of time and aesthetic imagination.

In the same decade that CHARAS/El Bohio was first occupied, garden activists the "Green Guerillas" were "seed bombing" neglected Lower East Side lots and developing community gardens with the help of their neighbours (Von Hassel 2005: 96). The city eventually acknowledged their work by formulating a registration process for gardening called the "Garden Lease" or "Garden License," that, as the city surmised, would appease locals while relieving it of maintenance responsibilities for abandoned property (Martinez 2010: 27). A similar short-term lease was what kept CHARAS in El Bohio for two decades. By 2011, Gil Lopez, a transplant from Florida who had spent much of his life gardening, also encountered the option to sign a garden license, this time with the Metropolitan Transit Authority. Lopez had expected to join a community garden as soon as he moved to the city, but found them frustratingly few and over-subscribed. With a background in landscape architecture and planning, he began to access city records to identify lots classified by the city of New York as vacant. His goal was to choose a site, test its soil to learn whether it was viable, and begin 


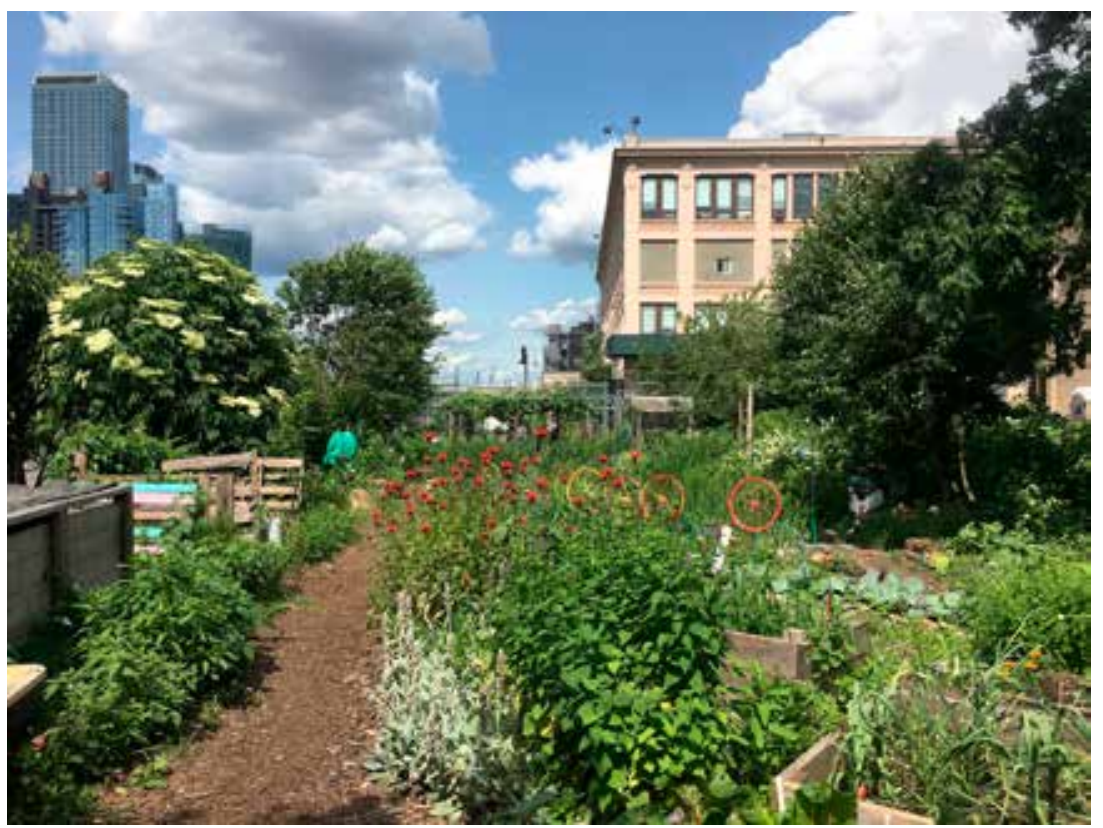

Figure 12.5: Smiling Hogshead Ranch, LIC behind. A view from inside Smiling Hogshead Ranch with new development in Long Island City in the background. The ranch faces potential eviction in the coming years as redevelopment of Sunnyside Yards right across the street gets underway. Photograph by the author.

planting row crops, fruit trees, and berry shrubs (Lopez 2019, interview with author). It became a site for gathering and contemplation where a spiritual connection to repairing the land was more valuable than planting the most obviously attractive flora. As he tells it, he understood his project as a form of direct action in service of growing food in a city with too few gardening opportunities. But, as he learned the history of the "Green Guerillas" and began working with a variety of activists, including Occupy Wall Street, he theorized his work as part of a continuum of practice that included renewing the land and advancing community control.

When Lopez, along with ten friends, started planting on the three-acre area located on the Montauk Cutoff of the Long Island Railroad in Long Island City and called it the Smiling Hogshead Ranch, they were making a claim to land in a city overdetermined by a particular kind of land value. They adopted an unofficial mission of community autonomy, respect for the land's history, care and repair, self-determination, and democratic participation in land use decisions. As Lopez, puts it, "For many communities, growing their own food is a direct response (or direct action) to counter the structural inequities built into policy decisions ... What we choose to do with 
the food we grow is not something the government gets to tell us" (Gil Lopez blog, https://verdantcities.wordpress.com). Yet, as Lopez soon learned, the government did have a stake in what the garden did. Signing a garden license, as the Ranch's directors were required to do in 2014, made it increasingly clear that, as Neil Smith discovered decades before, commodified land has value even if no one is using it.

\section{Pause}

The next chapters of the stories of CHARAS/El Bohio and Smiling Hogshead Ranch are predictable if one accepts a neoliberal logic. Because neoliberalism carries on the growth tradition of exploiting apparent problems like vacancy to create profit, it should come as no surprise that CHARAS/El Bohio was evicted by the city in 1998 so that real estate investor Gregg Singer could purchase and develop the building as-of-right for a then-outlandish $\$ 3.15$ million. Singer's plan was to use the city's "dormitory law" to gain a zoning variance that would allow him to increase his profit from the land sale (Anderson 2004). That never happened, but Singer can still expect to make a profit. The New York City Department of Finance has assessed the market value of the empty and deteriorating Public School 64 at $\$ 6.8$ million for 2019-2020, although a nearby vacant commercial triple-lot of comparable size sold in 2018 for $\$ 12$ million (New York City Department of Finance, Property Assessments 2019-2020). Singer could earn anything from double to quadruple his investment just by waiting. Meanwhile, Lopez and his collaborators at the Smiling Hogshead Ranch, who planted their crops more than a decade after CHARAS/El Bohio closed, are wary that the same could happen to them. In the decades since garden licenses were first offered, the city has cancelled them whenever it has been politically or economically profitable to do so. Lopez has argued that the Department of Housing Preservation and Development (HPD), which is responsible for the city's housing agenda, is too often "weaponized ... to issue injury to the community gardening movement” (Gil Lopez blog, https://verdantcities. wordpress.com). While this is true, the city hardly needs to use its housing agency to convince the Metropolitan Transit Authority to cancel its lease and sell off its parcels. Just across the street from Smiling Hogshead Ranch, the highly anticipated Sunnyside Yards development, which promises "world class institutions, major public space, jobs and affordable housing," is only months away from breaking ground (Murray 2019). True to New York's legacy of empire-building, the master planners of Sunnyside Yards, like those 
of Hudson Yards before it, cannot help but summon superlatives when it comes to a compelling opportunity to grow possible futures in a new land.

Even so, there are other ways to read these stories of resistance. While neoliberalism tells us, as Margaret Thatcher warned in the 1980 s, that "there is no alternative," community-based cooperative projects testify to the opposite. Moreover, they urge us not to believe that growth and creative destruction are the only ways to sustain New York's vitality. Indeed, it has been at moments of pause that the city has responded inclusively, graciously, and with inventiveness to the needs of the majority of New Yorkers. Rent regulation and public housing, for example, rose from the depths of tenant organizing and Communist party agitation during the Great Depression, while the city's Housing Development Fund Corporation cooperatives were established after the fiscal crisis of the 1970s. The credit union movement spread dramatically after World War II and cooperative grocery programmes prospered in Depression-era Harlem. One also cannot forget the care, mutuality, and shared hopes for recovery that came with the terrible silence and pause of September 11, 2001. The mounting waves of gentrification that followed that day can, in retrospect, buttress the argument that neoliberalism has prevailed. But that would deny the fortitude of activism that has since fought for - and won - stronger rent regulation protections, the nullification of Manhattan's Inwood rezoning (a model for others), and the swift withdrawal of plans for an Amazon headquarters in Long Island City, Queens. All of these victories can be read as demands for a pause in the growth machine.

This will be important to keep in mind as New York City's luxury real estate market begins to "soften," as economists put it, at an alarming rate. As Streeteasy.com reported in late-summer 2019, most new investors in the luxury market were renting their units in hopes that demand would pick up enough for them to reap a sizeable profit. At the same time, however, $25 \%$ of new condominiums constructed since 2013 remained unsold and more than sixty-three additional condominium buildings under construction in 2019 awaited sales (Long 2019). As the twenty-first century marches on, the city faces what Gothamist calls a "luxury glut" just as the Wall Street Journal reports that New York's population has begun to dip for the first time in a decade (Kim 2019; De Avila 2019). As in cities across the globe, cranes continue to perch atop rising buildings on New York's skyline even if no one quite knows who they are building for. Slow-downs at that level portend slow-downs deeper in the housing market as well.

Times like these insist that we reflect upon what growth can mean in a city when it is taken both more literally, as when Smiling Hogshead 


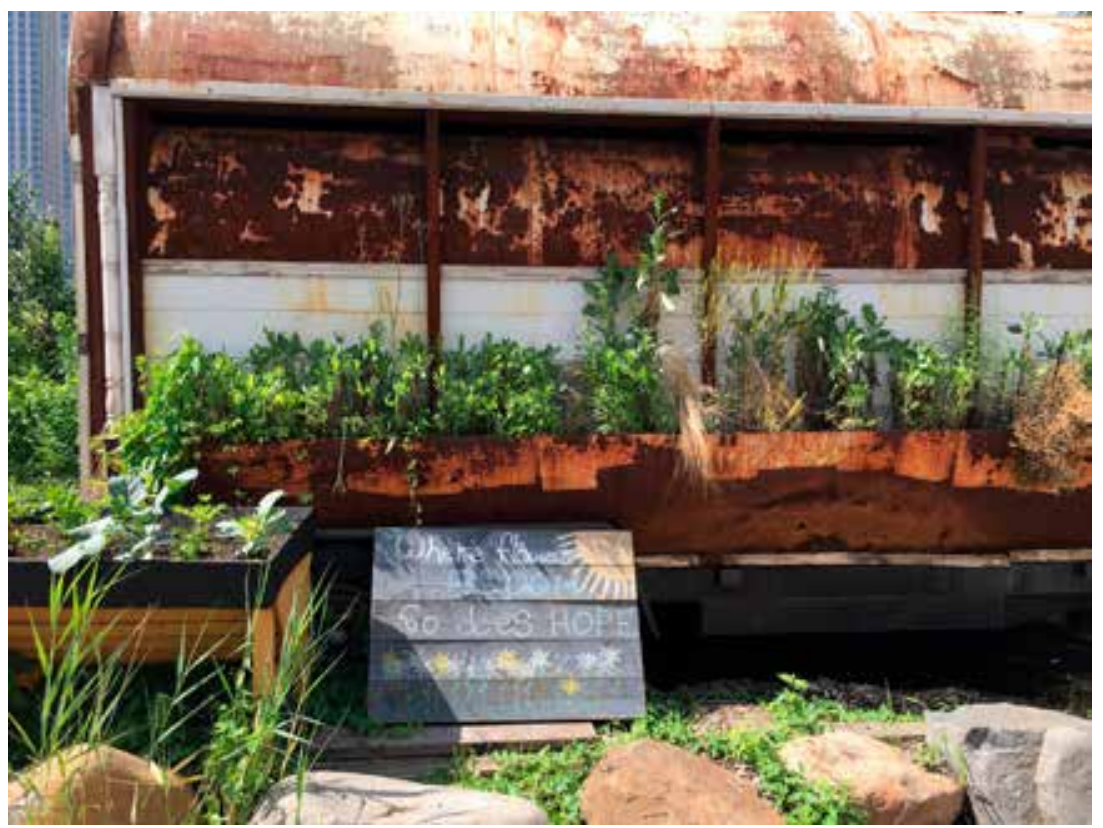

Figure 12.6: Smiling Hogshead Ranch, Where Flowers Bloom. At one of the entrances of Smiling Hogshead Ranch, a sign reminds visitors that "Where Flowers Bloom, So Does Hope." The ranch does not have fences or other clear boundaries as a statement against enclosure of private property. Photograph by the author.

Ranch advises that "where flowers bloom, so does hope," and with greater humanity. After all, newcomers to New York harbour were not wrong to see possible futures in a new land. They simply needed to recognize that other futures were already underway and that no land is ever new or empty. If we can learn to conserve more than parapet or a lead-lined stained-glass window as we build our cities of the future, we might just have a chance.

\section{Works Cited}

Anderson, Lincoln (2004) "Towering Dorm Is Proposed on the Former CHARAS Site." The Villager, 20 March (accessed 11 April 2019).

Bonkamp, Samantha (2018) "Chicago Selling 3,ooo-plus Properties Through $\$ 1$ Vacant Lot Program.” Chicago Tribune, 18 May (accessed 2 September 2019). Brewer, Gale (2019) "There Oughta Be a Law: We Need a Database to Track Vacant Storefronts." Retrieved from: https://www.manhattanbp.nyc.gov (accessed 11 April 2019). 
Brown, Joshua (2014) “Meet the House that Inequality Built: 432 Park Avenue." Fortune, 24 November (accessed 14 September 2019).

Caro, Robert A. (1974) The Power Broker: Robert Moses and the Fall of New York. New York: Knopf.

Central Philadelphia Development Corporation (2006) "OPDC/CPDC: 50 Years Remaking the Center City."

Chapple, Karen and Miriam Zuk (2016) "Forewarned: The Use of Neighborhood Early Warning Systems for Gentrification and Displacement." Cityscape 18.3: 109-130. Cinar, Alev and Thomas Bender (eds) (2007) Urban Imaginaries: Locating the Modern City. Minneapolis: University of Minnesota Press.

De Avila, Joseph (2019) “New York City's Population Dips for the First Time in Over a Decade." Wall Street Journal, 18 April (accessed 14 September 2019).

Danckaerts, Jasper (1913)Journal ofJasper Danckaerts, 1679-168o. C. Scribner's Sons. Etherington, Cait (2008) "NYC Zombie Houses: Why More Homes Are Vacant and Abandoned." 6sqft, 8 May (accessed 11 April 2019).

Fishbein, Rebecca (2016) “NIMBY's Get State to Block Affordable Housing at Brooklyn Bridge Park." Gothamist, 27 February (accessed 13 September 2019).

Fisher, Amber (2018) "City Sells Thousands of Vacant Lots for \$1 on South, West Sides." Patch, 18 May (accessed 9 April 2019).

Freeman, Joshua Benjamin (2000) Working-class New York: Life and Labor since World War II. New York: New Press.

Glanz, James and Eric Lipton (2003) City in the Sky: The Rise and Fall of the World Trade Center. New York: Macmillan.

Hertz, Daniel Kay (2018) The Battle ofLincoln Park: Urban Renewal and Gentrification in Chicago. Cleveland: Belt Publishing.

Jackson, Kenneth T. (2013) “Gotham's Towering Ambitions.” New York Times, 29 August. (accessed 14 September 2019).

Jacobs, Jane (1992) The Death and Life of Great American Cities. New York: Vintage Books.

Kim, Elizabeth (2019) "Report: NYC Has a Luxury Glut Problem." Gothamist, 13 September (accessed 14 September 2019).

Kraft, Herbert C. (1986) The Lenape: Archaeology, History, and Ethnography. Vol. 21. Newark: New Jersey Historical Society.

Lees, Loretta, Tom Slater and Elvin K. Wyly (2010) The Gentrification Reader. London: Routledge.

Long, Grant (2019) “NYC's Unsold Condos: Thousands of Units Linger on Market as More Are Built." One Block Over by Streeteasy, 13 September (accessed 14 September 2019).

Martinez, Miranda J. (2010) Power at the Roots Gentrification, Community Gardens, and the Puerto Ricans of the Lower East Side. Lanham, MD: Lexington Books. 
Molotch, Harvey (1976) "The City as a Growth Machine: Toward a Political Economy of Place." American Journal of Sociology 82.2: 309-332.

Mottel, Syeus (1973) Charas: The Improbable Dome Builders. New York: Drake Publishers, Inc.

Murray, Christian (2019) "City Presents Sunnyside Yards as An 'Enormous Opportunity', Many Remain Unconvinced." Sunnyside Post, 31 March (accessed 11 April 2019).

New-York Post (1853) New-York Post, 20 September 1853, quoted in Rosenzweig, Roy and Elizabeth Blackmar (1992) The Park and the People: a History of Central Park. Ithaca, N.Y.: Cornell University Press.

Osman, Suleiman (2011) The Invention of Brownstone Brooklyn: Gentrification and the Search for Authenticity in Postwar New York. Oxford: Oxford University Press.

Rivas, Bimbo (1979) “Loisaida: The Reality Stage.” WIN, 20 December.

Rosenzweig, Roy and Elizabeth Blackmar (1992) The Park and the People: a History of Central Park. Ithaca, N.Y.: Cornell University Press.

Smith, Neil (1979) "Toward a Theory of Gentrification A Back to the City Movement by Capital, not People." Journal of the American Planning Association, 45.4, 538-548.

Stillman, John (2016) “Why Hasn't Anyone Built on Newark's \$1,ooo Love Lots?” Urban Omnibus, 17 February [accessed 11 April 2019].

Teaford, Jon (1990) The Rough Road to Renaissance: Urban Revitalization in America, 1940-1985. Baltimore and London: The Johns Hopkins University Press.

Vaughan, Roger (1967) “The Real Great Society." Life, 15 September, 76.

Von Hassell, Malve (2005) "Community Gardens in New York City: Place, Community, and Individuality." Urban Place: Reconnecting with the Natural World, 91-116.

Whitman, Walt (2009) Leaves of Grass, 1860: The 15oth Anniversary Facsimile Edition. Iowa City: University of Iowa Press. ProQuest Ebook Central (accessed 16 September 2019).

Zukin, Sharon, Robert Baskerville, Miriam Greenberg, Courtney Guthreau, Jean Halley, Mark Halling, Kristin Lawler, et al. (1998) "From Coney Island to Las Vegas in the Urban Imaginary: Discursive Practices of Growth and Decline." Urban Affairs Review 33.5: 627-654.

\section{About the Author}

Rebecca Amato is a historian whose research and writing focus on the intersections between cities, space, place, and memory, with a special focus on the public humanities. Her work has appeared in the journals Urban 
Omnibus and Radical History Review, as well as More Art in the Public Eye (Duke, 2020) and A People's Guide to New York City (University of California, 2021). She has been a staff member and consultant at a variety of history institutions in New York, including the Brooklyn Historical Society, the American Social History Project, the Lower East Side Tenement Museum, and the Museum of the City of New York. She holds a PhD in United States History from The Graduate Center of the City University of New York. 



\title{
13. The "Smart Safe City": Gendered Time, Violence, and Displacement in India's Digital Urban Age
}

\author{
Ayona Datta
}

\begin{abstract}
Speed is fundamental to shaping visions of the modern city and of contemporary urban life. Notions of speed and acceleration have produced distinct conceptualizations of gentrification as a route to city sanitization and beautification. In this chapter, I examine what speed looks like from the margins, when seen through the struggles of young women in the urban peripheries who are coping with the precarity of working in the city, while negotiating deeply entrenched gender power relations within the home. By examining how speed is conceptualized through the trope of the "smart safe city" and what this means for those living in the digital and urban margins, I examine how a negotiation of time becomes fundamental to those left in the margins of gentrification.
\end{abstract}

Keywords: safe city, smart city, urban peripheries, gendered time, margins, speed

\section{The Smart Safe City}

In 2014, a national 100 Smart Cities mission in India noted that the Smart City "has high levels of public safety, especially focused on women, children and the elderly; men and women of all ages feel safe on the streets at all hours (Guideline 6.2)" (Ministry of Urban Development, GoI 2017). In Delhi, its capital city, the proposals were translated as follows: to make the central business district "Dark Spot Free," install 310 CCTV surveillance cameras in all major markets and 700 CCTV surveillance cameras in 72 residential 
colonies, and improve pedestrian safety. These cameras were installed in Delhi's Central Business District, in its middle-class colonies and markets that already had visible police presence. Significantly, "safety" particularly for women in public places, is seen as a time-bound event - measured by incident monitoring and response rates and its remote tracking in Integrated Command and Control Centres (ICCC).

The coming together of the smart city (i.e. digital infrastructures) and safe city (i.e. addressing violence against women) logics into a hybrid "smart safe city" upholds what Thomas (2018) has labelled as "Government 2.0" - a new type of governance transformed by the use of ICT to tackle deep seated urban and cultural/societal concerns. This promotes a "consumption of security" (Virilio 2006: 139) through the production of a "new composite portrait of the citizen - no longer the one who enriches the nation while consuming, but the one who invests first and foremost in security, manages his own protection as best he [sic] can and finally pays more to consume less." In this chapter, I argue that this is also a form of technocratic gentrification where, by asking citizens to download safety apps and use them for their safety, the Delhi government creates "digital enclosures" that reflect but also go beyond the ghettoization of marginal social groups. The smart safe city as a new logic of gendered fear of violence is a gentrified city excluding crime and violence to its marginal spaces and populations.

Gentrification as a term has been well debated and produced rich scholarship particularly in the last two decades. In a recent paper Elliott-Cooper, Hubbard, and Lees (2020) suggest that "we need to work with a more rigorous conceptualisation of displacement that is, at the same time, inclusive enough to consider the variety of forms it takes in the context of contemporary urban gentrifications" (493). As a programme within Delhi's wider smart city initiatives, Delhi's safe city proposals can be seen as a new "ICT mediated social order" (Gurumurthy and Chami 2014) where displacement is part of the safety imperative where women's bodies are made to "willingly position themselves within, and actively contribute to, an urban security calculus" (Leszczynski 2016). Here the smart safe city is the prerogative of a technocratic gentrification through a "future popular self-governance of civil fear" (Virilio 2006: 138) across digital and analogue spaces of the city. Here, the logics of both smart and safe city works by counting, measuring, and connecting the spatio-temporalities of intimate violence to the material and virtual surveillance of streets and neighbourhoods.

Unlike the smart safe city defined by the boundaries of CCTV cameras and ICCC surveillance, violence, and indeed safety, looks very different for women living in the margins of this technocratic urban transformation. 
Daily struggles with water and energy shortages, lack of public toilets, and unreliable public transport make safety itself a utopian aspiration. The smart safe city is experienced as another form of violence. While violence is spatio-temporal, and experienced as generational, historical, cyclical, and corporeal, the smart safe city excludes them through its digital enclosure. Their social, cultural, infrastructural, and technological displacement from the gentrified urban spaces, increasingly surveilled through CCTV and ICCC, creates new forms of exclusions and marginality from the city. This is the violence of a gentrified city made "safe" through smart technologies.

\section{Gendered Time, Violence, and Displacement in the Gentrified City}

Time is fundamental to processes of gentrification. Speeding of time (in its calculability, connectivity, and acceleration) has produced distinct conceptualizations of space-time compression in global processes of capitalism, neoliberalism, and planetary urbanization. Time as a fourth dimension is more significantly shaping approaches to state orchestrated sweeping urban transformations in the global south. Concerns with speeding up time are producing new urban tropes such as urban futures, smart cities, and big data, as well as vocabularies of fast forwarding, future proofing, leapfrogging, and so on. Whilst there is much debate on what constitutes "planetary gentrification" (Lees, Shin, and Morales 2016) and whether the process of displacement and exclusion in the global south can indeed be framed as gentrification at all (Ghertner 2014), this body of work has been largely silent on the imperative of time vested in discourses and practices of gentrification and urban transformation. Further, there is little that we know of the gendered, classed, and geographic unevenness of time in the margins, and thereby its relation to all forms of structural and gendered violence in processes of displacement. There is thus still a need for more in-depth, comprehensive, visual, and textual analysis of how temporality and practices of time-keeping, time-poverty, and time-management ontologically frame the rhythms of gendered violence, and what this means for those displaced from the grid of the smart safe city.

Such an analysis is important because digital technology is producing a whole new image of the future city through smart safety apps, which has rendered the peripheries with splintered infrastructures (Graham and Marvin 2001). The significance given in contemporary city visions to strategies of "fast urbanism" (Datta 2017) has paradoxically framed 
city beautification schemes that lead to mass scale slum evictions as a representation of future time, although we know that its real impact (i.e. displacement) is evident in the transformation of the urban peripheries. Despite a deep commitment to studying cities as key sites of globalization, neoliberalization, and capital accumulation, time remains undertheorized in studies of gentrification and urbanization alike. In a context where cities are increasingly used as "growth machines" (Chien and Woodworth 2018), it is the margins which illustrate the "timescapes of daily life that continues to perpetuate inequalities between communities"(Kitchin 2019).

In postcolonial contexts, time has been central to the conceptualization of the binary between tradition and modernity (Chakrabarty 2000) - the former seen as slow and the latter as the speeding up towards a technological future. Colonial subjects viewed or understood their social world through the values associated with Western clock time, commoditized and rationalized spatio-temporalities imposed as norms on their spaces and territories to rule and discipline. As recent studies of the future have confirmed (Adam 2008; Amin 2013; Anderson 2010; Sardar 1993), the control of time is a route to gaining and reinforcing power over populations and territories. Milovejić (2008) argues that "social groups able to impose their own approach to time to others, through normalization and universalization of 'hegemonic' time also succeed in 'controlling' both the present and the future in indirect ways." Indeed, control over gendered time means the power to manipulate subjective identities (of childhood, youth, single life, motherhood, parenthood, worker, community) and fit them within spatial scales of the city, periphery, home, neighbourhood, and so on.

In the postcolonial moment, gendered power is evident simultaneously in the "colonization with time" and "colonization of time" (Adam 2004). This colonization extends to the times and spaces of subjecthood, being, and belonging in the urban future. A gendered colonization of time is the time of policy that has time-bound targets from national and urban governments. This was evident in the early 199os with the imperatives of UN Smart Economics policies that sought to empower women by bringing them into the workforce as an economic common sense. In this framing, women's time was colonized through policy timelines and indicators, GDP growth, and measurements of age and growth of female workforce (Chant 2013). The colonization of gendered time - daily routines, the rhythms of the family, cycles of work, education, and social reproduction - is evident in the New Urban Agenda and UN Sustainable Development Goals (SDG), as well as in reports of UN Special Rapporteurs, OECD, G8, and the European Council. This colonization of time reappears in the time-based approaches to 
governing and transforming the city through digital infrastructure projects of the smart safe city.

A gendered colonization with time can be seen in the participation of subaltern subjects in producing time as an exchange value through time management, time economies, surplus time, time pass, and time poverty. This brings with it new complexities "around social time, new expectations of speed and violence of gendered spaces" (Adam 2004: 120). Although subjects uphold the colonization with time in their daily routines, their organization of everyday lives along different temporal trajectories suggests a degree of alterity with Western clock time. For example, while women might be able to access urban services and livelihoods through advances in technology, they nevertheless struggle with the socio-cultural constraints imposed by the power of clock time in travel timetables, family routines, water supply hours, toilet opening hours, and mobile network access times. This produces new subjects compliant with the spatio-temporalities of urban transformations (such as governance, infrastructural systems, mobile payment systems, biometrics, digitization, etc.) but they also transform the practices of citizenship to align with gender and class struggles from the margins.

\section{Time-Mapping Methods}

This chapter is part of a wider project that aims to understand how top-down imaginaries of the smart safe city could be understood through the digital lives of women living in the urban margins. It was carried out in partnership with an NGO working with feminist methods, running youth training camps, and domestic violence counselling for almost two decades. We also formed a partnership with a social ICT enterprise which had developed an app to collect data on infrastructure and social use of space, as a way to inform gender sensitive planning and governance. The app was also used to collect information about the use of spaces via safety walks with women that then could be represented and geo-located on a map. This data was translated into safety scores that could be represented on a map of the city. Using this app, the ICT enterprise had already collected data on over $4000 \mathrm{~km}$ of roads across Delhi, which resulted in around 50,000 audit points in Delhi, which included the neighbourhood under study.

In the first phase, we focussed on two resettlement projects in Delhi's urban peripheries, where the NGO partner had a presence. We conducted semi-structured interviews and mental mapping with over 30 women. The 


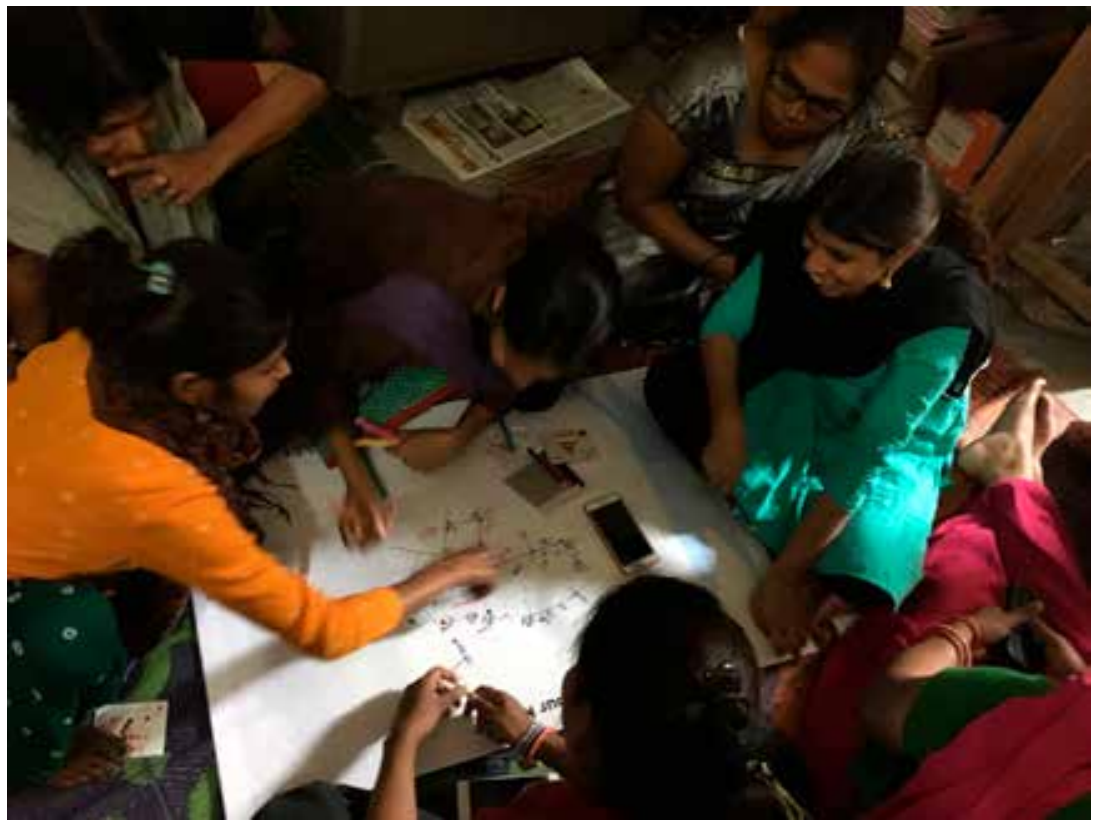

Figure 13.1: Time mapping during a participatory workshop. Photograph by the author.

safety audit data was made available to us by the ICT enterprise to discuss with the women during interviews. After a period of analysis, we conducted a time-mapping workshop with these women (Figure 13.1), through which we recruited 11 women to participate in an extended period of curating their daily experience of navigating the city via WhatsApp. A representative from our NGO partner set up a closed WhatsApp group where the women were requested to upload their diaries on a regular basis. This resulted in a rich multimedia sharing of experiences of moving around the city through text (in English and Hindi), videos, and voice recordings.

The participants were women who were young (between 17-25 years old) urban citizens. They had mostly attended youth training programmes offered by our partner NGO working in the colony and many of them had participated in the Safety walks run by the ICT enterprise. They had either grown up in the colony or their families had been evicted from the city slums when they were very young. As a result they saw themselves as "urban" citizens with little connection to rural origins or slums. They therefore tried to live in the colony on their own terms, negotiating with their parents continuously to relax the times of curfews over their bodies and mobility. They were all precariously employed - in poorly paid service or NGO jobs. There were strong restrictions on their mobility, although 
they were still some of the most mobile women in their colony as a result of their involvement in the NGO activities which took them to different parts of Delhi or India.

None of these women had access to desktops or laptops, so their only experience of the digital age was through the interface of the mobile phone. They used their mobile to download news and videos on YouTube or WhatsApp and were also subject to continuous forwarded messages. Use of IE browsers or Google Chrome was not very common, which was a challenge when they had to find jobs or access government schemes or educational opportunities. Their limited English language skills also meant that browser searches were time-consuming and laboured processes.

The multimedia content from the WhatsApp diaries, the mental maps, and the interview narratives suggest that time was a key constraint that women struggled with on a daily/hourly basis. This was acutely felt during regular debriefing meetings with our research assistant on Sunday evenings. Most of the women were engaged in evening college or adult education classes, or in employment. They would invariably be late because of delays in public transport, or be unable to come because the timings clashed with their work schedules or classes. It was also challenging to get them to update their diaries regularly. This itself was a very strong indicator of their time poverty, since it was evident that they were all very enthusiastic about the project, but struggled to participate. The findings below are therefore produced from these restrictions of time, space, and digital and language capacities.

\section{Delhi's “Networked Margins"}

Gentrification scholars have recently sought to understand processes of urban transformation as unfolding in India and the global south as forms of planetary gentrification (Lees, Shin, and Morales 2016). While there are certainly places in Indian cities where gentrification patterns are seen, I agree with Ghertner (2014) when he argues that not all of these processes can be placed under the broad rubric of "gentrification" - a term that has emerged from the specifics of capital accumulation and rentier urbanism in the West. This is particularly the case when we examine the impacts of urban transformations on slum populations evicted from city slums and pushed to the urban peripheries with very different intersectional power relations in place. Ghertner suggests the rubrics of "urban revolution" to capture land and associated transformations in social power relations in the peripheries. Indeed, rather than gentrification of the inner city, 
land in Delhi's peripheries is being capitalized from the commons and turned into a real estate market of gated developments, luxury housing, and elite farmhouses such as in Gurgaon or Noida. Yet when slum evictees are displaced to the peripheries, their allotted land is left unserviced and underdeveloped and turned into new urban ghettos. While the focus of research in urban peripheries has tended to draw our attention to the absence of infrastructures - water, sanitation, electricity, domestic energy, and so on - there is little acknowledgement of the forms of exclusion and displacement that marginal populations continue to face in the peripheries.

Whether we accept that the gentrification rubrics apply in the global south or not, what is clear is that neither gentrification nor urbanization scholars account for new forms of exclusions wrought through the introduction of digital and mobile technologies. Since India's liberalization in the 199os, there has been a "silent revolution" (Hoelscher 2016: 32 ) in the ICT and telecoms sector, with rapid adoption of mobile phones, particularly amongst the young urban population. Indeed there is a higher aspiration for mobile phones amongst the poor, since in the unaffordability of laptops or tablets, the mobile phone for them remains the main route to accessing information and services, as more and more of these have moved to the digital sphere. In India, two national policies - 100 Smart Cities and Digital India - have pushed for connectivity and communication across digital and analogue spaces in ways never possible before.

Yet the aspirations of an equal digital space have been largely unmet in the urban peripheries. While the proliferation of cheap android phones and smartphones bought in the second-hand market have positioned young women in the peripheries as a new social class of digital consumers, physical infrastructure in the colony is often absent, broken, or reflects the slow time of service delivery (water, sewage, sanitation, electricity, and broadband fibre-optic cables). Thus the speed of connectivity via mobile telephony offers access to information and knowledge without material improvements in urban basic services. At the same time, the promise of digital technologies also remains unfulfilled, with a slow speed of network coverage in the peripheries, dropped calls, and older models of mobile phones that slow down app interfaces. These dialectics between dis/connectedness across physical and digital infrastructures show how spatial asynchronicity is now an everyday feature of urban life in the margins.

This has led to radical reconceptualization of the peripheries into what Shah has called the "networked margins" (Shah 2015: 9) - places that are simultaneously networked digitally (through access to mobile phones) while substantially disconnected from the grid of urban infrastructures. There is a 
dialectic relationship between old and new urban transformations that positions the peripheries as networked yet marginal. This is seen historically in the speed of transformation of Delhi's urban peripheries since the 1990s when waves of slum demolition programmes forcefully evicted squatters from different parts of the city to resettlement colonies along the metropolitan boundaries. Much has been written about the injustice of these evictions following a judicial order by the Supreme Court (Datta 2012), and the struggles that early evictees faced when relocated to the peripheries, where there was little access to basic infrastructure and transport connections with the city (Bhan and Menon-Sen 2008). Squatters were resettled in 2002 in the colony we studied and were allotted only 12 sqm of land for building their houses. Electricity was provided four years after resettlement and public toilets are still inadequate in several areas of the colony (The Hindu 2004).

Growth of Delhi's urban peripheries over the last two decades has meant increased transport connections via new metro and bus linkages, new local modes of transport such as the "e-rickshaws," and thus increased freedom and mobility for women in these resettlement colonies. This paradoxically has also reinforced their vulnerability to violence both online and offline. Women's role as wage earners outside the home as well as caretakers of infrastructure and services within low-income neighbourhoods is well documented (Datta and Ahmed 2020; Datta 2012, 2016). Their simultaneous vulnerability to violence both inside and outside the home was also ironically a consequence of the perception of their moral corruption due to access to a wider compass of knowledge and information via the mobile phone. This form of displacement is characteristic of the digital urban age where, despite connectivity, poor urban women remain disconnected from much of the city's services and infrastructure and consequently from knowledge and information. This cannot be captured within the limited rubrics of gentrification, but needs a more expanded vocabulary of temporal marginality incorporating digital and material displacement, as I discuss next.

\section{Mapping Gendered Time}

For women living in the urban margins and commuting to the city each day, their time was the space for struggles, and the centrality of time struggles in their life produced a perception of violence as spatio-temporal. This is what Adam has called "women's time" - the time of "theory and practice, experience and explanation, lived orientation and material expression" (Adam 2004: 2). While the safety apps represent instantaneous time, the representation 


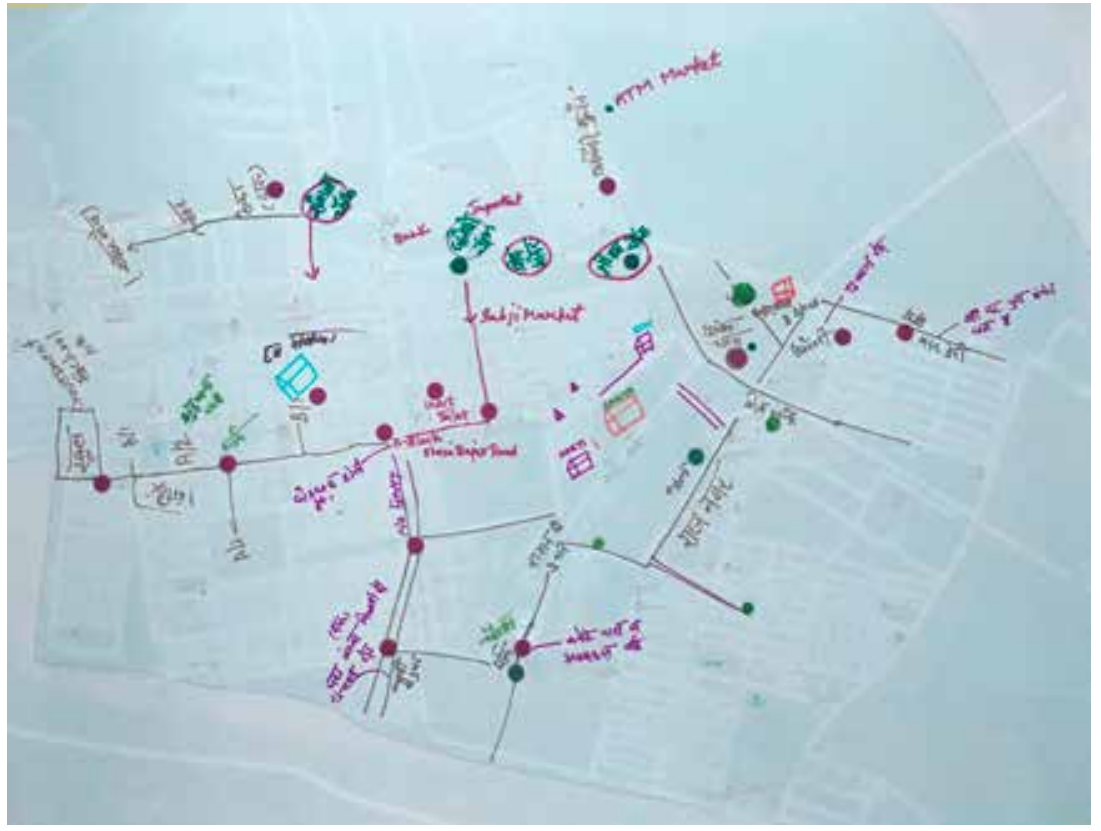

Figure 13.2: Participatory time-mapping. The red dots and lines represent spots and routes respectively, where they are sexually harassed or catcalled. Photograph by the author.

of our participants' daily lives was all about the flows of time across safe and unsafe spaces. The participatory maps with women participants suggest an in-depth knowledge of the neighbourhood referencing not what is, but how they perceived, felt, or imagined the time-spaces of violence.

Women did not speak of their time as clock time, but rather as gendered time - the time which is full of constraints and struggles. Time in the participatory maps (Figure 13.2) was cartographic and visual, and represented with coloured ink as safe or unsafe. This was discussed as gendered time, since these dangers were experienced and expressed as an aspect of their personal routes and routines through the neighbourhood. Temporality played an important role in this gendering, particularly when deciding when and where to step out of their homes, which routes to take to get in and out of their neighbourhood and where not to go at which times of the day.

Figure 13.3 shows how the women's neighbourhood was mapped as gendered time. The triangles stand for men and circles for women. Further, the blackened symbols represent night time. The map suggests how most public spaces in the neighbourhood-gym, crossroads, Church, mobile phone shops, ATM, and so on - are male spaces in the evening. Indeed, the park was significant in that there were hardly any women there at any time of 


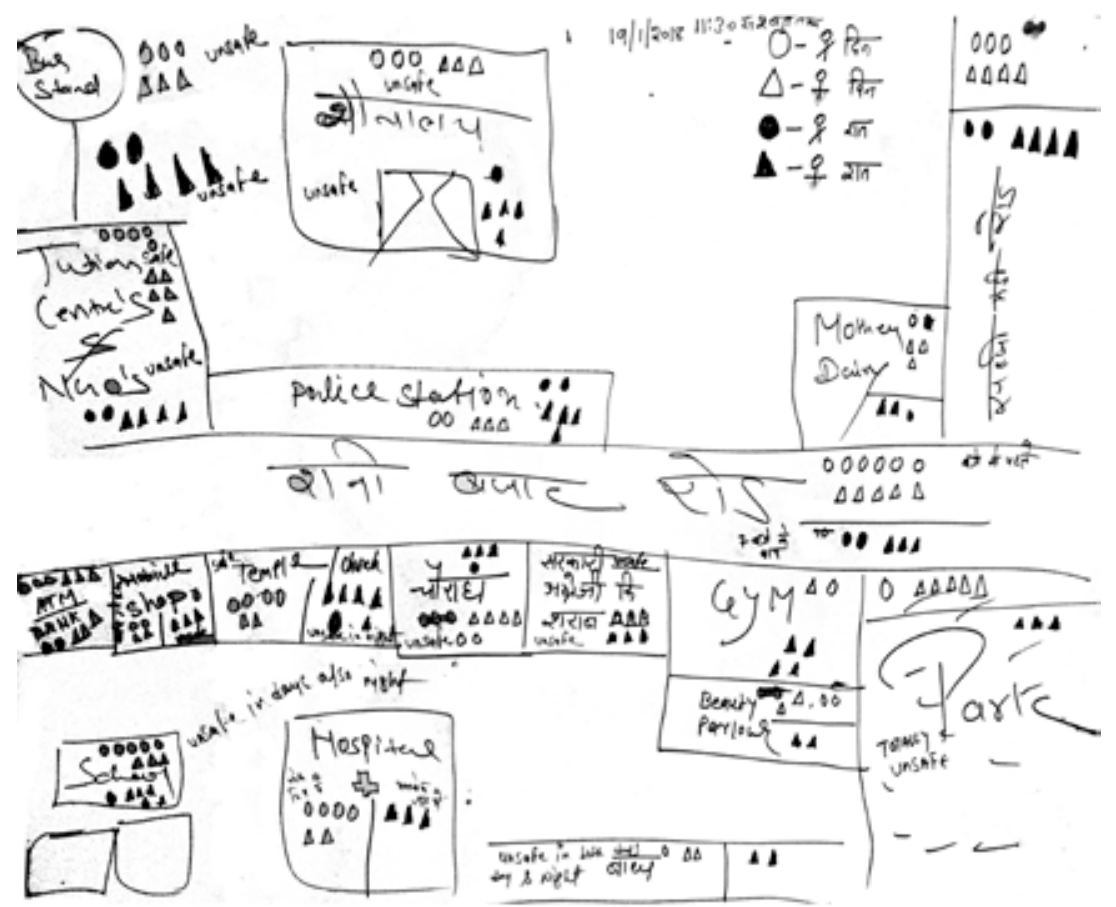

Figure 13.3: Time-mapping conducted with women participants. Source: Jagori

the day. The police station was even more significant in being a male space particularly at night, and therefore the police station itself was perceived as unsafe and threatening.

When safety scores captured are generated through safety apps, they are reflective of class and infrastructural biases. Crucially the peripheries remain largely unmapped and therefore outside the boundaries of the smart safe city. As part of the time-mapping when participants were trained in the safety app and asked to audit their neighbourhood for safety, it reflected their everyday embodied experiences of familiarity and exclusion from the neighbourhood spaces. Places they mapped were also places they had to pass through daily and those unmapped were where they did not visit or were unfamiliar with. These maps illustrate their displacements from both digital and analogue spaces in the neighbourhood. Figure 13.4 shows this participant safety audit overlaid with the WhatsApp diary entries where they give detailed narratives of gendered violence.

These time maps present the algorithms of the participants' everyday struggles, as well as their intimate knowledges of time-space. These timemaps also curate and visualize violence as experienced and embodied 


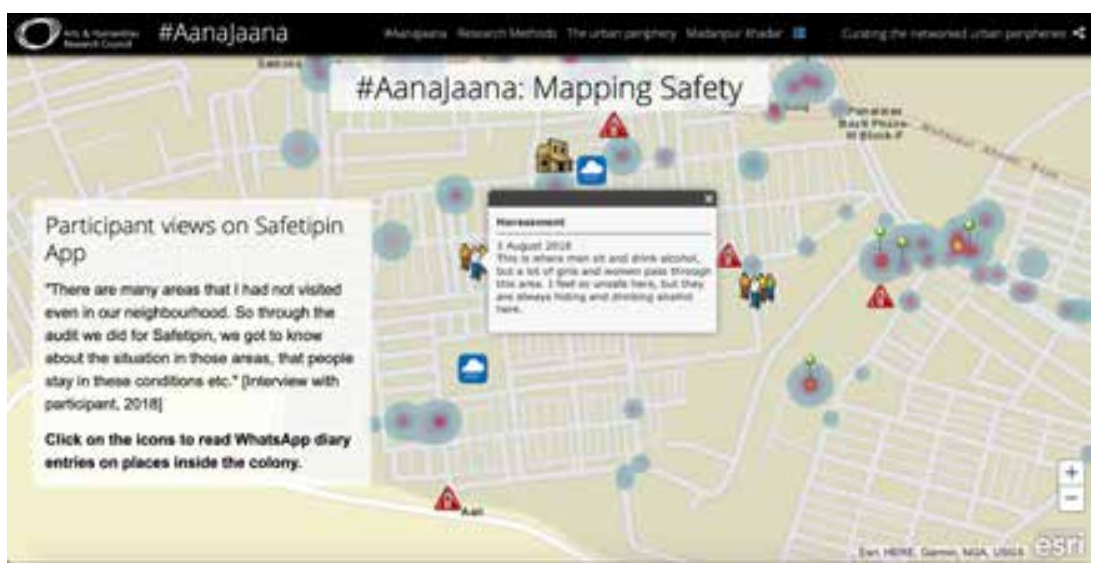

Figure 13.4: Screenshot of participant safety audit of the neighbourhood using Safetipin app.

Screenshot by the author.

in space and time. While safety apps focus instead on the cartographic particularity of violence, the time maps and WhatsApp diary entries represent the cyclical pattern of violence across day and night through a more subjective cartography. Significantly they also reflect how gender is produced as a binary category as male/female and by extension produce a binary perpetrator/female victim.

\section{Speed, Hoarding Time, and "Free" Time}

Adam notes, "rather than being elemental creatures attuned to natural rhythms, many women nowadays are, if anything, even more preoccupied with time measurement than men" (Adam 1995: 20). The women in our study too were if anything "clock watchers ... who view time as a precious commodity to hoard or to spend" (Adam 1995: 20) used to juggling between different timelines - family routines (particularly the imposition of curfew), work schedules, the challenges of public transport, and bodily routines of hunger, sleep, and exhaustion. Speed therefore was a normalized mode of urban aspiration, since without speed, one or more of their timelines would "fail." Those who struggled with the arrhythmic nature of these timelines would invariably either lose their jobs or face increased violence from families.

This was evident when our participants struggled to make it to our workshops on time or stay there for the duration of our sessions. Each of them had particular constraints of time, which led to delayed arrivals, early leaving, and continuous phone calls to rearrange existing commitments 
in order to stay for the workshop duration. Particular to this was also the hoarding of time. I would hear participants saying on the phone "I am leaving in 5 minutes" or "I am on my way" while they continued participating in the workshop. This was an attempt to hoard time by stretching it so that an employer or a family member would not reach out for punitive measures when they were late. But participants would call out on each other saying "I know you did not leave work in good time to be here." Or "you think your time is more important? And I have been waiting here to start our workshops for the last 30 minutes."

The mobile phone as a technology of time then provided them with a mechanization of speed to coordinate these very different timelines studying, working, cooking for family, attending workshops, and so on. The phone was an instrument of speed since it coordinated arrhythmic timelines into one rationalized system of measurement of clock time. Yet it was the ownership of this piece of technology that often presented the most challenging negotiations with family.

The first time I did a job, after my wedding, I told them, my family, that I want to buy a phone. They said, what would you do with a mobile, why do you want a mobile? Who do you want to talk to? There is a mobile at home, if you want to talk to someone, you can use this. What would you do with a personal mobile?

Shah has argued that young people see "the acquiring of the digital as a form of social and economic mobility and are catalyzed by its presence to bring about transformations in their lives" (Shah 2015: 10). Women participants noted that since their bodies and mobilities were often taken as proprietary property of their families, their need to personally own a mobile phone was seen as unnecessary or even threatening. Once they started earning, the first item bought by these women was a mobile phone. This was seen as a gift of personal space, mobility and speed.

It is that with smart phones, a lot of earlier things which were difficult has now become easier, like crowds, like if you go to the bank, you have to stand in queues, or pay the mobile bill or electricity bill, or water bill, you can just put an app and pay it here at home itself, you don't have to go anywhere.

Crucially, the phone enabled the women to smoothly navigate the city on their daily routes and routines as well as gathering more information 
about benefitting from different government schemes such as funds for economically weaker sections, funds for working women, and so on. The mobile phone was thus an infrastructure of knowledge and information that enabled these women to increase their mobility and crucially enhance their geographical awareness about places in the city. It was often discussed as transformative in their lives.

$\mathrm{Di}$, it is a very good thing, if we don't know something, sometimes they tell you, so here to this one's place in Badarpur, so how far is it from Khadar, where to go - we can check all that, and even on WhatsApp, there are groups and we can search and get help, it is very important to learn, Didi, there is so much in this.

Women's time was also time away from family rules and constraints around mobility, the time outside the limitations of their daily schedules and the time on their mobile phones, which enabled them to dwell in a parallel time of "leisure" in ways that had not be possible earlier. Thus the phone not only overlapped the time of production and social reproduction, but also enabled them to access information in their "free time." Free time was not "free" per se, but rather the time in between two different timelines - between commuting and working, between family routines of cooking and childcare, between communicating with social networks and studying for college. Because the phone enabled instantaneous access to other times and spaces of information, it was suited to lives that were made from struggles with time-poverty.

\section{Private and Public Time}

Precisely because it provided universal freedoms it also opened up intimate dangers of violation. Women thus felt they needed to be especially vigilant about protecting their privacy while using mobile phones. This was based on their experience of violence which first emerged in physical spaces of their neighbourhood or public transport, but would "bleed" into digital spaces through trolling, phone harassment, and occasionally hacking. In dealing with this challenge, women separated their times and spaces as public and private. While the bus was a public space of transport, travelling in the bus was also private time - women would wear headphones, look down into their phones, or pretend to be chatting in order to avoid being approached by men. Conversely, while their phones were private properties, women noted 
these as offering safer "public" time by connecting with trusted friends and networks via social media, text messaging, or WhatsApp.

Indeed, some women also explained how they made others aware of this notion of private time embodied by the mobile phone, and the dangers of allowing strangers to enter this private space and time of their digital identity. Thus especially while being present in crowded places such as public transport, women were vigilant about online privacy, making sure they did not reveal their phone numbers or social media identities to fellow passengers. This was in a context where their bodies, and the physical spaces they occupied and moved through, were continuously monitored by their families through strict curfews.

People, especially girls, are not allowed to simply move around. Even at my house this happens, so I can't imagine what it may be elsewhere. If it's around 7 o'clock [in the evening] and I need something from outside then Papa says, "Just get it tomorrow morning." At these times I have to send my younger brother [to get what I wanted].

Thus, while having the phone meant a continuous exchange across private and public time, no amount of phone time could bypass the clock time of the curfew imposed on women's bodies and spaces by families. The phone thus offered public time (i.e. chatting safely on WhatsApp from home) where public space was no longer possible to access, or provided private time when public space itself felt threatening.

\section{Living with Imminent Violence}

A major part of women's daily lives went in anticipating danger. Women commented that they were neither safe inside nor outside the house. Stories of rape, incest, and sexual harassment were common. Indeed each of the women interviewed had experienced sexual harassment in some form and they knew of someone in their family or neighbourhood who had been sexually assaulted. Hence, living with imminent danger was a reality and everyday aspect of their lives.

We were on the metro, this man kept staring at me for a long time, and my friend said, Didi, see how this man is looking at us - it feels like he is raping us with his eyes. Then I realized that he had taken our picture, and I asked him, "hey, you took a picture right," he said, "no I didn't take 
any," I said, "well, show me your phone" and I snatched his phone, asked him to open his phone and when he opened it, there were 6-7 photos. Then we caught hold of him and beat him up in the metro.

This vigilante "justice" of physical and collective violence against men who were perpetrators of sexual harassment was frequently used by the women to keep themselves safe in the absence of regular channels of justice. The time of procedural justice was often described as "slow," not least because many of them had experienced the police station as a threatening space, but also because complaints to the police or to the women's helpline were unfruitful. Each complaint required multiple follow-up calls to the helpline or personal visits to the police station, which was time-consuming when they were already struggling with time constraints.

Managing their time, therefore, to avoid this danger at all costs was one of their primary strategies of staying safe in the city and in the neighbourhood. This strategy was adopted differently by the women and by their families. For the former, living with imminent danger meant a continuous strategizing about when to go out, where to go and at which times of the day. For their families, danger was "avoided" by installing further controls over women's times, spaces and bodies. All the women in the study faced strict curfew hours and any violation of these hours would mean violence from within their own families. Indeed, a violation of the curfew hours was seen as a transgression into "immorality" - dangerous and illicit relations with men who were not approved by the family.

If you take an average girl who is going at 9 in the morning and returning at 6 ... if she is delayed and it is 6:30 instead of 6 , many times they are beaten up by their parents. "Where were they for half an hour! Who were you roaming around with!?," and would give really degrading verbal abuses. You are the parents! You have to consider the difference between the environment at your time and how it is now.

The women were clear that the curfew as a way of coping with imminent danger revealed the fault lines of generational time - its asynchronicity between them as "digital millennials" and the older generation who had grown up without mobile technologies and could not understand their importance for women's mobility. Instead they highlighted the contradictions between generational time and the time of imminent danger, because the curfew did not necessarily keep them safe from online abuse and sexual harassment. It was only in learning how to use the mobile phone safely that 
they could keep themselves safe when they went outside the home. The phone was a technology to occupy safe space and curate the co-presence of violence. Because violence against women was often connected to victim shaming, women used their phones to document how and when the violence occurred, as well as where it occurred.

And Didi, whatever happens, now I make video, take photos, in case one needs to place evidence, when people don't believe you, I just click these days.

\section{The Rubrics of Gentrification in India's Peripheries}

The geographic asynchronicity between the "incident" of violence in the smart safe city and the rhythms of violence in women's daily lives is produced from very different technologies of time. On the one hand, the technologies related to smart safe city focus on an instantaneous time of violence by seeking to reduce download speeds, eliminate crashes and bugs, and increase the speed of intervention. On the other hand, technologies related to use and access to urban infrastructures such as public toilets, transport, and public spaces seek to reduce travel times, increase physical and digital connectivity, and make work-life more efficient. Gentrification scholarship has not yet fully dealt with these temporal asynchronicities across digital and analogue spaces, nor with the paradoxical nature of inequalities that are produced in this digital urban age.

As safety gets incorporated within the rubrics of gentrification approaches in the global south, the smart safe city becomes its technological solution in the digital age. Yet, despite claims to speed, efficiency, and rationality, the smart safe city is marked by the disjunctures/flows between clock time and social time, between incident response time and spatio-temporalities of violence, between a technocratic "fix" and everyday uses of technology. This temporality of violence exists not in opposition, but in parallel with the cartographic representation of violence in the smart safe city. For the urban poor, contrary to the promise of an accelerated urban modernity, the smart safe city creates new struggles with time. It transforms their historical and subjective relationships with mobility, transport, urban public services, family norms, as well as with sexual and physical assault.

Thus it is that speed, an a priori condition of urban modernity, has become an authoritative force and a driver of new forms of networked marginality. Time has become the space of contestation, where its restraints, constraints, 
and slowness determine low-income women's everyday struggles to claim their space in the city. This is a process that cannot be captured by current rubrics or theories of gentrification alone. Rather this needs to be put in the context of an expanded sense of violence beyond the workings of state violence seen in the revanchist city - a central premise of gentrification theories. The processes of marginalization seen in this chapter go beyond theories of "accumulation by dispossession" (Harvey 2004). Rather these processes of networked marginality in urban peripheries need to be seen as a paradoxical form of inequality generated across time, space, geographies, and generations that traverses both digital and analogue spaces of being and belonging.

\section{Acknowledgements}

A longer version of this chapter was published in the Annals of the AAG, titled "The Smart Safe City: Gendered Time, Speed and Violence in the Margins of India's Urban Age," DOI: 10.108o/24694452.2019.1687279. This publication has been made possible through an AHRC funded research network (PI ref: AH/Roo3866/1 from 2018-2020). It would not have been possible without the participation and enthusiasm of the young women in the low-income settlements in Delhi who were part of this research. I am also grateful to Arya Thomas, our local research assistant for her hard work and support in interviews and organizing community workshops. I am also grateful to Jagori and Safetipin for partnering on this project, and providing support and access to the community, recruiting participants, organizing the workshops, and feedback on this research.

\section{Works Cited}

Adam, Barbara (1995) Timewatch: The Social Analysis of Time. Cambridge UK: Polity Press.

Adam, Barbara (2004) Time. London: Polity Press.

Adam, Barbara (2008) "Future Matters. Futures Known, Created and Minded." 21st Century Society: Journal of the Academy of Social Sciences 3.2:109-224.

Amin, Ash (2013) "Surviving the Turbulent Future." Environment and Planning D: Society and Space 31.1:140-156.

Anderson, Ben (2010) "Preemption, Precaution, Preparedness: Anticipatory Action and Future Geographies." Progress in Human Geography 34.6: 777-798. 
Bhan, Gautam and Kalyani Menon-Sen (2008) Swept Off the Map: Surviving Eviction and Resettlement in Delhi. New Delhi: Yoda Press.

Chakrabarty, Dipesh (2000) Provincializing Europe: Postcolonial Thought and Historical Difference. Princeton, NJ: Princeton University Press.

Chant, Sylvia (2013) “Cities through a 'Gender Lens': A Golden 'Urban Age' for Women in the Global South?” Environment and Urbanization 25.1: 9-29. https:// doi.org/10.1177/0956247813477809.

Chien, Shiuh-shen and Max D. Woodworth (2018) "China's Urban Speed Machine: The Politics of Speed and Time in a Period of Rapid Urban Growth." International Journal of Urban and Regional Research 42.4: 723-737. https://doi. org/10.1111/1468-2427.12610.

Datta, Ayona (2012) The Illegal City: Space, Law and Gender in a Delhi Squatter Settlement. London: Ashgate Publishing, Ltd.

Datta, Ayona (2016) "The Intimate City: Violence, Gender and Ordinary Life in Delhi Slums." Urban Geography 37.3: 323-342. https://doi.org/10.1080/0272363 8.2015.1096073.

Datta, Ayona (2017) "Introduction: Fast Cities in an Urban Age." In Abdul Shaban and Ayona Datta (eds) Mega-Urbanization in the Global South: Fast Cities and New Urban Utopias of the Global South. London: Routledge, 1-27.

Datta, Ayona and Nabeela Ahmed (2020) "Intimate Infrastructures: The Rubrics of Gendered Safety and Urban Violence in Kerala, India." Geoforum 110 (March): 67-76. https://doi.org/10.1016/j.geoforum.2020.01.016.

Elliott-Cooper, Adam, Phil Hubbard and Loretta Lees (2020) "Moving Beyond Marcuse: Gentrification, Displacement and the Violence of Un-Homing." Progress in Human Geography 44.3: 492-509.

Ghertner, D. Asher (2014) “India's Urban Revolution: Geographies of Displacement beyond Gentrification." Environment and Planning A 46.7: 1554-1571. https://doi. org/10.1068/a46288.

Graham, Stephen and Simon Marvin (2001) Splintering Urbanism: Networked Infrastructures, Technological Mobilities. London: Routledge.

Harvey, David (2004) “The 'New Imperialism': Accumulation by Dispossession.” Socialist Register 40: 63-87.

Hoelscher, Kristian (2016) "The Evolution of the Smart Cities Agenda in India." International Area Studies Review 19.1: 28-44.

Kitchin, Rob (2019) "The Timescape of Smart Cities." Annals of the American Association of Geographers 109 (3). https://doi.org/10.108o/24694452.2018.1497475.

Lees, Loretta, Hyun Shin and Ernesto Lopez Morales (2016) Planetary Gentrification. Polity Press.

Leszczynski, Agnieska (2016) "Speculative Futures: Cities, Data, and Governance beyond Smart Urbanism." Environment and Planning A 48.9: 1691-1708. 
Milojević, Ivana (2008) “Timing Feminism, Feminising Time.” Futures 40: 329-345. Ministry of Urban Development, GoI (2017) "What Is Smart City: SMART CITIES MISSION, Government of India.” Retrieved from: http://smartcities.gov.in/ content/innerpage/what-is-smart-city.php (accessed 7 July 2020).

Sardar, Ziauddin (1993) "Colonizing the Future: The 'Other' Dimension of Futures Studies.” Futures 25.2: 179-187. https://doi.org/10.1016/o016-3287(93)90163-N.

Shah, Nishant (2015) "Networked Margins: Revisiting Inequality and Intersection." In Sandra Cortesi and Urs Gasser (eds) Digitally Connected: Global Perspectives on Youth and Digital Media. Cambridge, MA: Harvard, 9-11. https://papers.ssrn. com/sol3/papers.cfm?abstract_id=2585686.

The Hindu (2004) "Madanpur Khadar Residents to Get Power Connections." Retrieved from: https://www.thehindu.com/2004/07/13/stories/2004071317280300. htm (accessed 7 July 2020).

Thomas, Pradip Ninan (2018) Digital India: Understanding Information, Communication and Social Change. New Delhi: SAGE Publications India.

Virilio, Paul (2006) Speed and Politics. Pasadena, CA: Semiotext(e).

\section{About the Author}

Ayona Datta is Professor of Human Geography at University College London. Her research interests are in postcolonial urbanism, smart cities, gender citizenship, and urban futures. 


\section{Index}

$1 \%$, the 171

100 Smart Cities $\quad 269,276$

432 Park Avenue $\quad 257-8$

absentee landowners $\quad 140$

activism 18, 21, 104, 138-9, 141-2, 145, 147-9, 200, 215-6, 363

Adam, Barbara $\quad 272-3,280$

adaptive reuse $\quad 160-1$

Adobe $5^{0}$

Adorno, Theodor 141

aerial-urban mobility $\quad 12$

aesthetic displacement $\quad 188$

aesthetic geography 128

aestheticization $116,225,235,240$

aestheticized $14,65,68,116,118,121-2,126,226$

aesthetics of belonging 146

aesthetics of diversity 121,123

aesthetics of engagement $\quad 17,138-9$

aesthetics of placemaking 15

aesthetics-as-politics 193

aesthetics, arts-based 17

aesthetics, engaged $138,140,142-5,147,151$

aesthetics, hipster $17-9,119,207,216$

aesthetics, industrial $\quad 92,107$

affordable housing $33,39,43,132,210,216-7$, $251,254,262$

affordable rent $\quad 156$

affordable space $\quad 156$

African American, communities $\quad 64-5,38,117$, 158,163

African American, neighbourhoods 33

ageing (communities) $\quad 189$

agency $15,18,20,134,152,188,210,230$

agonism 224

agonistic urbanism 225, 242

Ahmanson Pavilion, theatre 159

Airbnb 51,63-4

Al's Bar (Los Angeles) $\quad 162$

Allport, Gordan $35^{-6}$

Allshouse, Scott 115

alternative capitalist economy $\quad 77$

alternative tourism $\quad 225,235$

Amaral Gurgel Terminal 107

Amsterdam 177-6, 193

Amsterdam Court of Appeal $\quad 183$

Anderson, Elijah 40, 131

anti-displacement 257

anti-gentrification $\quad 20,145^{-6}$

anti-gentrification activism 200

anti-immigrant sentiment $\quad 228$

anti-Japanese American policy 158

Apollo Theatre (H Street) $\quad 120-1,123,127,132$

Apple 50,61

Apple Park 51, 59-61
Arantes, Otília $\quad$ 96-7, 103-4

archival practices $\quad 150$

Army Corps of Engineers 144

Arroyo Arts Collective 202

Arroyo Seco 201

art and politics 142,148

art colony 201

art historians 53

art-based activism $\quad 148$

art-led urban regeneration 186

ART@341 150-1

Article 10 of the European Convention on

Human Rights 182

artist-activists 148

artist-renters $\quad 165$

artistic capitalism 77

artistic practice $\quad 15,142,15^{2}, 224-6$

artists $19,5^{0}, 66,105,155^{-72}, 187-90,188,227$, 235

Arts Action Committee $\quad 150,153$

Arts District (Los Angeles) 155, 158-9, 161, 164, 169-70, 203

arts organizing 153

Asian American, community $\quad 138,147-8$

Ateliers Médicis 233-4

Atkinson, Rowland 186

Atomic Cafe 149-50

Australian cities 186

authentic urbanism 200, 205

authenticity $16-7,64,74,79-80-3,86-7,118-29$, $188,204,208,222-3,226$

avant la lettre 223

Avenue 5o Studio 214, 216, 202

Baca, Judy $\quad 143-5$

"back-to-the-city" movement $\quad 28,105,201,251$

banlieues 19, 21, 184, 222, 224, 227, 230-1, 238, 241

Bardeen, Jon 68

Battery Park City (New York City) 249

Baudelaire, Charles 209

beautification 201, 272

Becker, Howard 138,140

Bedoya, Roberto 146

Bell Telephone Laboratories (Bell Labs) 68

belonging $17,19,119,122,126,138-9,143,151-3$, 156, 162, 272, 286

Benjamin, Walter $\quad 51,141,209$

Berman, Marshall 35,211

big data 271

biopolitical capitalism 234

black aesthetic emplacement $\quad 119,121,123-4$

Black communities $\quad 118$

Black cultural space 17,119

Black Lives Matter 20 
Black neighbourhoods 121

Black space 117,130

Black Washingtonians 120

Black-owned (businesses) 121, 127-8

blackness $20,117-9,121,122-5,128,130,133$, 136,207

blight $37,95,100,252,255^{-6}$

block-busting (as illegal real estate practice) $\quad 25^{1}$

Boerum Hill 253-4

Bogotá, Colombia 202

Bos en Lommer (Amsterdam) 18, 180, 182, 185, 189-91

Bourdieu, Pierre $\quad 129,187,225$

Boutique 16, 21, 74, 78-87, 119, 124, 126-7, 129, 208-9

Boyle Heights $\quad 17-8,21,43,137-53,155,158$, 163-4, 169-70, 202-6, 213, 215-7

Boyle Heights Alliance Against Artwashing and Displacement (BHAAAD) $\quad 215$

Brattain, Walter 68

Brazil/Brasilia 20-1, 94, 98, 106-8, $25^{0}$

broedplaats 178

Brooklyn 105, 253, 255

Brooklyn Heights 254

brownstoners 30, 253

Bunker Hill (Los Angeles) 159

burnt cement $92,103,107$

Canberra $25^{\circ}$

Castle Clinton 249

CCTV 269-71

Centro de Arte Publico (Los Angeles) 202

Chapple, Karen $\quad 256-7$

CHARAS/El Bohio $\quad 258-60,262$

Chêne Pointu 222, 233-4

Chicano Moratorium 143

Chocolate City $\quad 120-2$

CicLAvia 202-3

Cisco 50

City of Montreal's Design Office 73,76

Clichy-sous-Bois $\quad 222-7,231-5,240-1$

Collaboration (as working method) 16, 51, 57, $65,67,69$

collective experience $\quad 17,145^{-7}$

collective interaction $17,140,142-4,151-2$

collective resilience $\quad 259$

Collins, Mary Evan 36

colonialism 11, 167, 190, 200, 210, $25^{0}$

colonization of time 272

colour (of material) $\quad 120,178,183,185,189,192-3$

colourfulness 178,192

commercial gentrification 34,127

Communist 66, 263

community activists $\quad 137,201-2$

community control $150,153,261$

community garden $19,204,260,262$

community land trusts $\quad 258$

community organizing $142,145,149,15^{2}$ community redevelopment agency 159

community self-reliance $\quad 258-9$

complexity $16,41-2,46,236$

Consolação 93

consumption of security 270

contract workers $\quad 59,63-4,69$

cool capitalism 77

cool 126-7, 133, 226

Cooperatives 19, 54, 248, 258-9, 263

Copan 99-100

corporate design $\quad 5^{2-3}$

cosmetic grit 123

craft culture $82-3,87$

creative cities $140,221,223-4$

creative class 128,207

Creative DC Action Agenda $\quad 128$

creative economy $75,128,207,226$

creative incubator $18,178-80,185,186,188$, 190-3

creative workforce $\quad 128$

creativity 128,226

Crenshaw (Los Angeles) 147, 202

Cruz, Sophie 66-7

cultural appropriation $\quad 122,216$

cultural erasure 173

cultural gentrification $\quad 137-53$

Culture Montréal $74-5$

Cupertino 50, 54, 59-61

Currid, Elizabeth 208

Dávila, Arlene 129

de Niro, Robert $\quad 235$

decline of manufacturing $79,162,207$

decolonization 228

Delacroix, Eugène $\quad 238-9$

Deleuze, Giles 230

Delhi 19, 269-70, 273, 275

delocalization movements 79

density 19, 29-30, 212, 255

design-driven neighbourhood 10

designers (independent) $\quad 77,81-3,85,87$

Destination DC 127

Deutsch, Morton 36

difference (as aesthetic or social concept) 116, $118,130,132,188-9$

Digital India $\quad 276$

digital infrastructures $\quad 270,276$

digital millennials $\quad 284$

Diller Scofidio + Renfro 10

disinvested 201, 209-10, 217, 248

disinvestment $\quad 30,33,117,129,201,247-8,257$

Disney Concert Hall $\quad 159$

disneyfication 13

displaced $13,41,118,123,187,201,232,271,276$

displacement of aesthetics 180

distribution of the sensible $\quad 184-5$

diversification $\quad 30-1$

diversity of use $29-30$

diversity, self-destruction of $16,29-31,33,41-4$ 
diversity $17,116,119,128$

dormitory law 262

Downtown L.A. $\quad 156,164,199$

Eagle Rock Association 202

Eagle Rock Center for the Arts 202

Eagle Rock (Los Angeles) 200, 204, 206, 208

East Coast (USA) $\quad 5^{0}, 57^{-} 5^{8}$

Echo Park (Los Angeles) 204, 207

economic inequality $16,51,122$

edginess 18, 20-1, 193

Eggers, David 61

El Mac 66

Ellis Island 249

Emirates Air Line $\quad$ 12-3

empty lots 39

empty spaces $\quad 19,248,257-9$

enclaved 222

energy shortages $\quad 271$

Engel, Frederick 211

enslavement of peoples $\quad 166$

environmental justice 46

erosion of public space $\quad 61$

ethical mode of consumption $\quad 119,129$

ethics $17,33,139,142,152,164$

European Council $\quad 272$

everyday entrepreneurship 43

Eviction Defense Network 214

evictions $33,149,210,213-4,216,272,277$

exclusion $9,14-5,20,22,28,40,44,121,169$, $271,276,279$

exclusionary practices $\quad 118$

"eyes on the street" 28

Facebook $\quad 52,62$

Fairchild Semiconductor $\quad 69$

fashion $18,73,76$

fast urbanism 271

Federal Housing Administration $\quad 271$

Felipe Morozini 105

feminist methods 273

feminist theory 53,71

filtering $96,250-1,254-5$

flâneur 209

Florida, Richard $\quad 75,128,139-40,207,225$

Folha de São Paulo 102,107

Frankfurt School 141

Friends of Highland Park 211-3

\section{G8 $\quad 272$}

garment industry 79

Gehry, Frank 159, 166

gender gap 53

gendered time $\quad 271-2,277-8$

generational time $\quad 284$

gentrification in Latin America 91-109

geography of buzz $\quad 200,208$

Ghertner, D. Asher 275

GIS $\quad 257-8$
Glass, Ruth $\quad 29,225,252$

global gentrification aesthetic $\quad 180,187-8,192$

global inequality 22,166

global neoliberal consumerism $\quad 18$

Global North $95-6,106,108$

global south $19,271,275^{-6}, 285$

"golden age of gentrification" 24, 33

Google 16, 50-1, 54, 61-2

Gorky's Café (Los Angeles) $\quad 162$

government-led gentrification 179,186

graffiti 19, 202, 227, 232

Grand Avenue Project 159

Grand Paris 222-5, 231-4, 241

Grand Paris Express $\quad 231,234,240$

"Great Streets" programme 202

Green Guerillas 260-1

greenwashing 11, 13

Greenwich Peninsula 9-14, 20

Greenwich Village (Manhattan) 28, 32, 39, 41

Greif, Mark 206-7

Guattari, Félix 230

H Street (Washington D.C.) $\quad$ 115-33

Harvey, David 201, 210-1

Hatherly, Owen 28

Heineken 105-6

Hertz, Daniel Kay 254

Hewlett-Packard 50,55

Heying, Charles 87

High Line effect 11

high-tech culture 49

Highland Park (Los Angeles) 200, 204, 206, 208, 213-4, 217

hipster economics $\quad 126$

hipsters 126, 191, 193, 200, 206-7, 215

historical analysis $\quad 16$

Hoefler, Dan 54

Hollande, Francois 240

Holmdel Township 68

Holocaust 35

homeless, tent encampments $\quad 5 \mathbf{1}, 54,68$

homelessness $39,108,156,213,215$

homogenization $\quad 30-1,33,86$

Hopper, Grace 53

horizontality $53-5$

Horkheimer 141

hospitality $16,74,80,85,87,127,153$

housing crisis 64

housing insecurity 157

housing segregation 45

Hudson Street 27,41

Hudson Yards $\quad 159,251,263$

ibasho 138,151

immigrant communities $\quad 62$

immigrant life 142

immigrant urbanism $\quad 152$

India $269,275^{-6}$

industrialization $76,81,98$ 
inner city $\quad 201,251,253-5,275$

Insight Property Group 127

Instant Messaging $\quad 5^{2}, 55$

institutional racism 37

Integrated Command and Control Centres

(ICCC) 270-1

integration $38,69,181-2,190,223,240$

Intel 50,69

Inter-American Development Bank 106

interior design 53

Internet, the $52,54,58,183$

Jackson, John $\quad 126$

Jacobs, Jane $\quad 15-6,20,27,29,33-4,42,45,201,256$

Japanese American community $138,147,149$

Japanese American Cultural Community

Center 149

Japanese American National Museum 149

Jewish communities 79, 143, 237

Jobs, Steve $\quad 51-2,55^{-6}, 59$

Jones, Kellie $\quad 158$

JR 223, 226-9, 235, 237-8, 240

Kant, Immanuel 141-2

Kay, Alan $\quad 55^{-7}$

Kendzior, Sarah $\quad$ 126-7

Kester, Grant $\quad$ 139, 141-2

Klein, Olivier $\quad 231,234,240$

Koolhaas, Rem $\quad 5^{1}$

Kwon, Miwon $\quad 158,163$

LA Metropolitan Transportation

Authority 202

LA Metro's Regional Connector station 149

LA River Redevelopment $\quad 166$

LACE, gallery 162

"Ladj Braquage" 227, 229-30, 235-6

land value $\quad 223,225,234,261$

"Large Lots" programme $\quad 255$

Latinx aesthetics 143

Latinx community $64,138,213,215^{-6}$

Lees, Loretta 14

Lefebvre, Henri $\quad 126$

Lemoine, Xavier $\quad 235,240$

Ley, David 225

Lincoln Park 253-4

Lindner, Christoph $\quad 186$

Lipovetsky, Gilles 77

Little Tokyo $\quad$ 138-40, 142, 147-53

Little Tokyo Service Center (LTSC) $\quad$ 148-9

Lloyd, Richard 204, 207

local activists $\quad 20,259$

local design $\quad 74,76,78,80-1$

loft living $\quad 92,98$

London 9-13, 105, 199, $25^{2}$

López-Morales, Ernesto 14

Lopez, Gil 260-2

Los Angeles $\quad 17-8,53,63,120,137,243,145$, $155^{-6}, 199-217$
Los Angeles Police Department (LAPD) $\quad 216$

Los Angeles Tenants Union 214

"Love Lots" programme 255

Lovelace, Ada 53

low-income populations $\quad 15,20$

Lummis Festival 202

Mackey, John 116, 122

MACLA (Movimiento de Arte y Cultura Latino Americano) 65

Macron, Emmanuel 235

maker culture 87

Manhattan 249, 256

mapping $78,150,273-4,277-9$

marginality $162,222,226,232,271,277$, $285^{-6}$

marginalized (peoples) 18, 20, 43, 53, 119, 210, 222-3, 226

margins 19, 222, 269-77

Marotta, Steve 87

Marx, Karl 211

Marxist 141, 201

Massachusetts Institute of Technology (MIT) 55

materiality $16,74,80,83,87,101,145,182$

Mechicano Art Center 202

Meissner, Miriam 186

mental mapping $\quad 273,275$

Messiaen, Olivier 164

Metropolitan Transit Authority 260

middle class $28,35,41,62,65,99-100,127,206$, $215,225,254-5,270$

migration $30,38,47,66,157-8,162-3,173,190$, 228

mild gentrification $\quad 32$

Mile End (Montreal) $\quad 16,74,78-9,86-7$

Mission District (San Francisco) $\quad 62,64$

mixed use 28,127

mixité (French policy) 234

mobile phone $275^{-8}, 281-4$

mobility, economic 16

mobility, social $\quad 31-2$

mobility, women's 284

modernist aesthetics $141-3,145^{-6}, 15^{2}$

modules (architecture) $\quad 56$

Molotch, Harvey 248

mom-and-pop (businesses) 202, 205, 210, 256

Montfermeil 223-4, 226, 228, 231-41

Montreal 73-88

Moore, Gordon 69

Morris, William $\quad 76$

Morse, Richard 99

Moses, Robert 211, 250

Mountain View $\quad 52,61-2,68$

Mozingo, Louise $5^{0}$

multiculturality 53-4

Museum of Contemporary Art (Los Angeles) 159,161

musicians 79,207 
neighbourhood activism 200

neighbourhood networks 31,41

NELA Second Saturdays Art Night 202

neo-bohemia $\quad 200,204,207$

neoliberal capitalism 87,211

neoliberal consumption $\quad 15-6$

neoliberal urban redevelopment $14,18,21$

New Delhi 250

New Jersey 68,249

New Left Urbanism $\quad 36-7$

New Urban Agenda $\quad 272$

New York City $17,19,39,139,211,248,250-1$, $255,258,263$

New York City Real Estate Investment

Cooperative $\quad 25^{8}$

Niebuhr, Reinhold $\quad 166-8$

Nochlin, Linda 53

NoMA (North of Massachusetts

Avenue) 124-5

non-profit $\quad 62,64,69,79,130,150,161,252,257$

North East Los Angeles (NELA) Alliance 2104, 216-7

Not in My Backyard (NIMBY) $\quad 45,140$

Noyce, Robert 69

O'Mara, Margaret $\quad 5^{2}$

obsolescence 95

Occupy Wall Street $\quad 261$

Ocejo, Richard 87

OECD 272

Old Philadelphia Development Corporation (OPDC) 252

Olympic Games 12, 231

Operações Urbanas (Urban Operations) 97

organized complexity 16,29

othering 17,21

otherness $18,40,178-80,182,184-5,192-3$

outorga onerosa 101-2

Padeken, Rory $\quad 65^{-6}$

Palais de Tokyo 235, 240

Palo Alto (California) $\quad 50,52,54,56,68$

participatory community development $\quad 17,149$

participatory maps $\quad 278$

pastoral capitalism $\quad 5^{0}$

performance-based art $173,143,162$

peripheries $19,99,229,241,271-3,275-7,279$, $285^{-6}$

Philadelphia Redevelopment Authority $\quad 25^{2}$

placelessness 11, 16, 22

placemakers 10,107

placemaking $15,138,223$

planetary gentrification $14,17,271,275$

planetary urbanization $\quad 271$

Plateau-Mont-Royal $\quad 78$

playfulness $\quad 53-4$

political aesthetic $180,184-5,191-3$

politico-aesthetics 242

Pope Francis 67 post-war (WWII) 35, 36, 38, 147, 159, 199, 201, 204

postcolonial urbanism 19

postindustrial $10-1,13,16,124,231$

postracial 133

precarity, or precariousness $19,28,43,106$, 108,165

private investments $97,109,159,225,231-3,251$

private offices $56,58,60$

privatization of public space $\quad 126$

prostitution 99, 101

pseudo-public space 11

public art 11, 19, 187, 202

public housing $35-6,39,45,65,210,254,263$

public infrastructure 18

public investment 94

public safety $\quad 31,269$

public spaces $11,116,125-6,130,133,183,185$, $188,209,282-3$

public toilets $271,277,285$

public transit 212,217

public transport $\quad 50,100,191,271,275,280-3$

Puerto Rican population $\quad 37-8,254,259$

pure aesthetics 142

queer artists, or art $\quad 71,162$

queer body 171

quitinetes $16,92,99-100,103$

racial liberal $\quad 36-8$

racial segregation $\quad 34-5$

racialization 20

racialized dispossession $\quad 28$

racialized gentrification $\quad 17$

racialized inequality 46

Rancière, Jacques $15,141,143,180,184,188,224$

real estate development $17,102,156$

real estate, market $\quad 21,64,170,263,276$

real-estate speculation 146,156

Redbull Station $\quad 104-5$

redlining $30,33,45,143,158,201,25^{1}$

rehabbers $253-5$

rehabilitation 201,222

reinvestment $30,33-4,201,254$

rent gap $30,34,95,201,25^{1}$

rent regulation 263

reparative witnessing (as practice) 17, 164, 172

Republic (France) 222, 228, 235, 239-41

República (São Paulo) 16, 91-3, 95, 97, 99-102, 104-9

resettlement $159,273,277$

resident-driven neighbourhood change $33-4$

resilience 31, 259

restricted mobility 11,20

reuse (as marker of urban redevelopment) $\quad 180$

revitalization, neighbourhood 38,217

revitalization, urban 13, 95-6, 209

Row, Jess 157, 172

Royal Docks (London) 12-3 


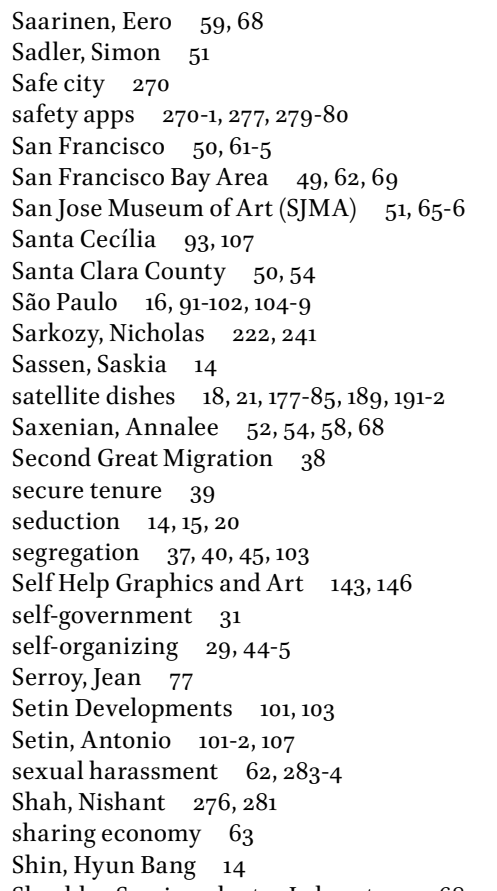

Shockley Semiconductor Laboratory $\quad 68-9$

Shockley, William 52,68-9

shopping 11, 76, 79, 84-5, 129, 206

"sidewalk ballet" $39-40$

Silicon Valley $\quad 5^{0-6}, 58,61-3,67-9$

Silton, Susan $\quad$ 156-8, 161-6, 169-73

simulacra 65,121

site-specific (art) $56,158,163,224$

Sixth Street Bridge $163-4,166,170$

Skid Row 155

slum $32,38,255,272,275^{-7}$

slum clearance $30-1,34,41,201,210$

smart city 269-70

Smiling Hogshead Ranch $\quad 258,261-2$

Smith, Neil 201, 251-2, 262

Snapper, Juliana $\quad 165$

social capital $31-2,41-2,15^{2}$

social housing $18,177^{-8}, 180-1,185^{-6}, 190,192$, 222

social justice $116,119,131,155,166,202-3$

social media $\quad 19,121,189,283$

social practice $139-40,152,200$

social praxis 157

Society Hill (Philadelphia) $\quad 252-3$

SoHo (New York City) 17, 92, 98, 103, 106-9, 253,256

SoMa (South of Market) 63

Soto, Laura 145

space of consumption $\quad 129$

SPARC 143

spatial asynchronicity $\quad 276$ spatial politics $\quad 15,19,224$

spatio-temporalities $270,272-3,285$

speculation $33,146,156,171-2,223-4,226$, 231-4, 242

speed $19,41,271-3,276-7,280-1,285$

Spotify 170

stage model of gentrification $\quad 200-1$

Stanford University $\quad 54-5$

state interventions 107

stoops $28,40-1$

storefronts $41,126,256$

street art 19, 103, 202, 223-4, 226-7, 230, 235, 242

striking workers $5^{1}$

studio (apartment) 16, 92, 101-3, 132

subjective cartography 280

Sunnyside Yards 262

sustainability $78,87,225$

sustainable construction 19

Sustainable Little Tokyo (SLT) $149-50$

Swampoodle 124-5

tabula rasa 106

Takachizu 149

Take Back the Boulevard 202, 208

Tate Modern 227, 235

Teaford, Jon $\quad 252$

technocratic gentrification 19,270

TED 227

tenant organizing $\quad 259,263$

Thatcher, Margaret $\quad 263$

Tide, the 9-11

time poverty $271,273,275,282$

time-maps $\quad 273-4,279$

time-space $\quad 278-9$

transient population $\quad 31$

transit oriented development (TOD) 210, 212-3, 217

transit village $211-3,217$

transnational gentrification 20

transnational social movements 20-1

Travers, Eric 229

Troy Cafe 149

Ubisoft 79

UCLA 147

ugly $179,181-5,191$

UN Smart Economics $\quad 272$

UN Special Rapporteurs $\quad 272$

UN Sustainable Development Goals

(SDG) 272

UNESCO City of Design 73

Union Center for the Arts 149

unions 60,259

unslumming $\quad 32-5,38,41,43-4$

upper-income whites 17

urban activism $\quad 104$

urban blight 30

urban branding $\quad 118$

urban crisis 28 
urban development $38,45,75,118,128,138-9$, 210, 269

Urban Displacement Project $\quad 256$

urban economies $38,42,44$

urban futures 271

urban margins $19,273,277$

urban planning $15,33,96-7,103,128,140,203$, 209, 217

urban power 15

urban redevelopment $14-5,17-9,21,30,158$, $172,186-8$

urban regeneration $\quad 140,186$

urban renewal $10,17,30,32-5,39,42-3,92,98$, $117,122,129,159,201,254-5$

urban whitewashing $\quad 156$

urban-cultural interventions 93, 96, 106

Utrillo Tower (Montfermeil) 233

vacancy $29,131,255^{-8}, 262$

Varda, Agnes 235

Varian Medical Systems 55

Veterans Administration 44

Vietnamese Americans 66

Vietnamese-American Community Center 66

visual culture $15-6,51-4,246$

visual methods 74

vitality $37-8,200,259,263$

Wainwright, Oliver 12

walkability 40,100
Washington, D.C. $\quad 115,118,120,124$

WhatsApp $274-5,279-80,282-3$

white art 137, 216

white flight $62,117,201,210,215,217$

white spatial imaginary $35,15^{2}$

whiteness 119, 124-5

Whole Foods $115^{-6}, 119-23,129$

Widener, Daniel $\quad 15^{8}$

Winchester Mystery House (San Jose) $\quad 5^{2}$

Winner, Langdon $\quad 5^{2}$

Winnubst, Shannon 116

work/play environments $5^{1}$

World Trade Centre 249

WOW Amsterdam $\quad$ 178, 185-6, 189-9o

xenophobia $\quad 17-8,179,185$

Xerox PARC (Palo Alto Research Center) 50, $5^{2}, 54-9,61,68$

Yes in my Backyard (YIMBY)

45

Young, Iris Marion 40

YouTube 275

Žižek, Slavoj 230

Zombie Homes Initiative 255

zoning $39,45,262$

Zuk, Miriam 256, 257

Zukin, Sharon $76,86,92,97-8,126,139-40$, 186, 225 

Gentrification is reshaping cities worldwide, resulting in seductive spaces and exclusive communities that aspire to innovation, creativity, sustainability, and technological sophistication. Gentrification is also contributing to growing social-spatial division and urban inequality and precarity. In a time of escalating housing crisis, unaffordable cities, and racial tension, scholars speak of eco-gentrification, techno-gentrification, super-gentrification, and planetary gentrification to describe the different forms and scales of involuntary displacement occurring in vulnerable communities in response to current patterns of development and the hype-driven discourses of the creative city, smart city, millennial city, and sustainable city.

In this context, how do contemporary creative practices in art, architecture, and related fields help to produce or resist gentrification? What does gentrification look and feel like in specific sites and communities around the globe, and how is that appearance or feeling implicated in promoting stylized renewal to a privileged public? In what ways do the aesthetics of gentrification express contested conditions of migration and mobility? Addressing these questions, this book examines the relationship between aesthetics and gentrification in contemporary cities from multiple, comparative, global, and transnational perspectives.

Christoph Lindner is Professor of Urban Studies and Dean of The Bartlett Faculty of the Built Environment at University College London.

Gerard F. Sandoval is an Associate Professor in the School of Planning, Public Policy and Management at the University of Oregon.

"The book brilliantly demonstrates that a focus on aesthetics should be at the core of our understanding of gentrification and displacement forces."

- Anastasia Loukaitou-Sideris, Distinguished Professor of Urban Planning, UCLA

"In this powerful collection of essays, editors Christoph Lindner and Gerard Sandoval identify the seduction of gentrification's aesthetics, its power to exclude, and the activism that can change its course."

- Karen Chapple, Professor of City and Regional Planning, University of California, Berkeley 